\title{
Untersuchung sub-mitochondrialer Proteinverteilungen in unbehandelten und apoptotischen humanen Zellen mittels STED-Mikroskopie
}

\author{
Dissertation \\ zur Erlangung des mathematisch-naturwissenschaftlichen Doktorgrades \\ "Doctor rerum naturalium" \\ der Georg-August-Universität Göttingen
}

angefertigt am

Max-Planck-Institut für biophysikalische Chemie

in Göttingen

vorgelegt von

Daniel Neumann

aus Essen

Göttingen 2010 

Referent: PD Dr. Thomas Teichmann

Korreferent: PD Dr. Stefan Jakobs

Tag der mündlichen Prüfung: 12.08.2010 

für Klarita 



\section{Inhaltsverzeichnis}

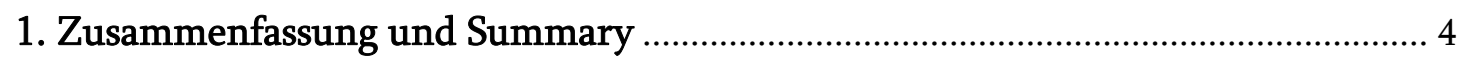

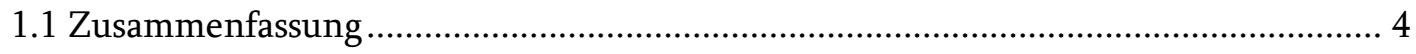

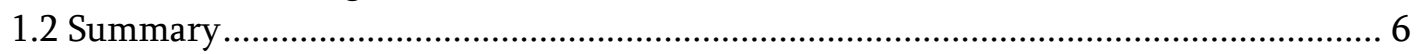

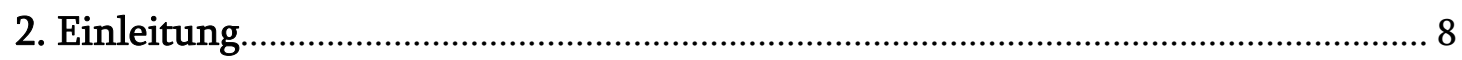

2.1 Mitochondrien: Struktur, Dynamik und Funktion ................................................... 8

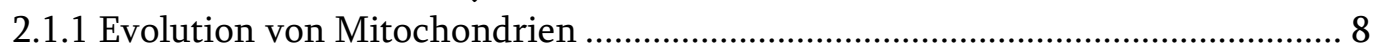

2.1.2 Struktur von Mitochondrien........................................................................... 9

2.1.3 Morphologie und Dynamik von Mitochondrien ............................................... 11

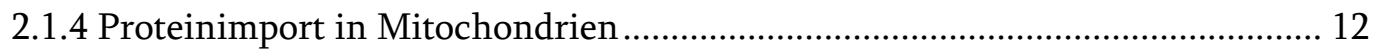

2.1.5 Beteiligung von Mitochondrien am zellulären Metabolismus ........................... 14

2.1.6 Interaktionen zwischen Hexokinase und VDAC..................................................... 16

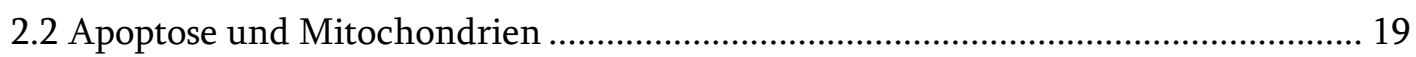

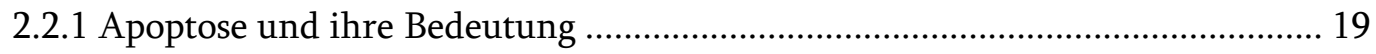

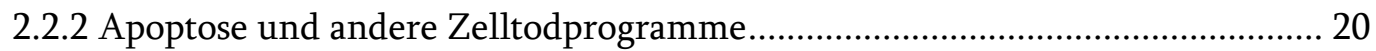

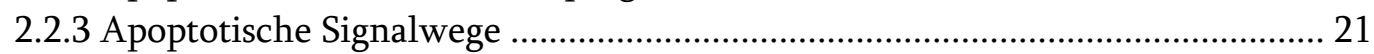

2.2.4 Mechanismus der Cytochrom $c$-Freisetzung ................................................. 24

2.2.5 Fragmentierung von Mitochondrien während der Apoptose ............................ 27

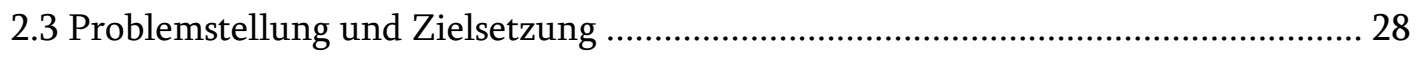

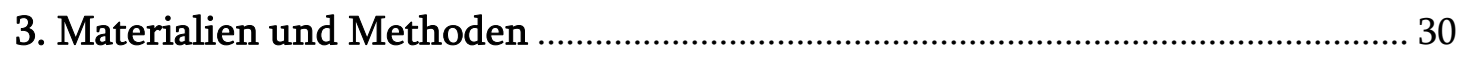

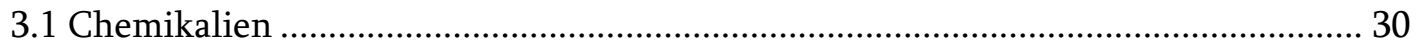

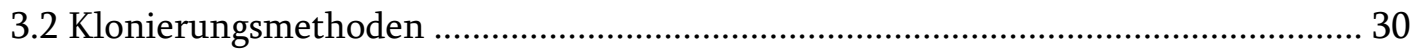

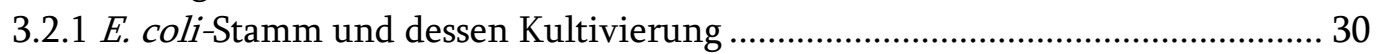

3.2.2 Agarose-Gelelektrophorese und Visualisierung von DNA-Fragmenten ........... 30

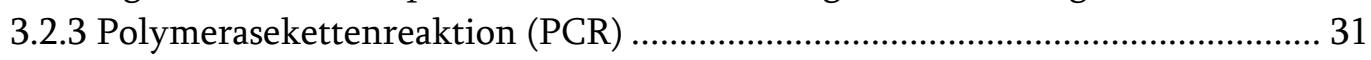

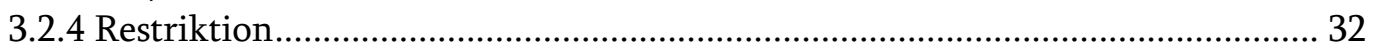

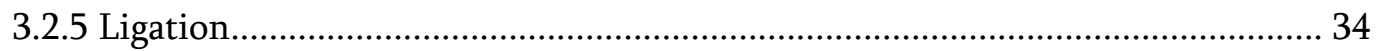

3.2.6 Herstellung elektrokompetenter $E$. coli-Zellen .................................................. 34

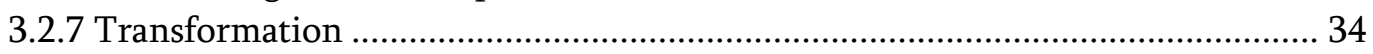

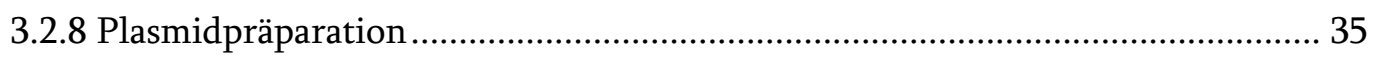

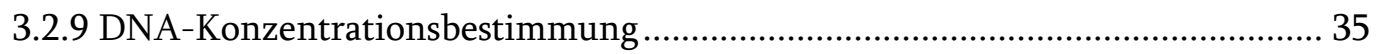

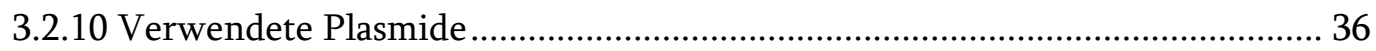

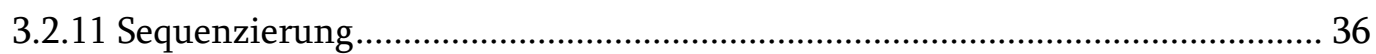

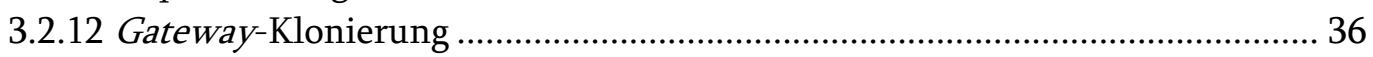

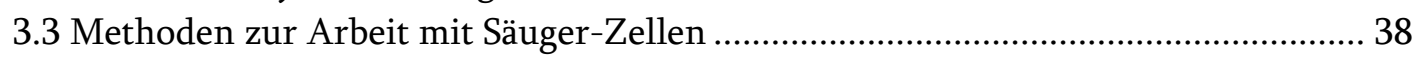

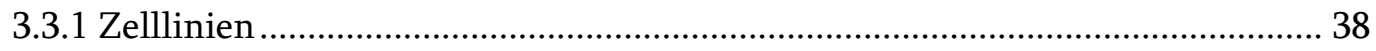

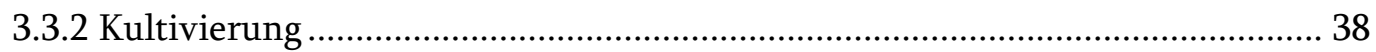

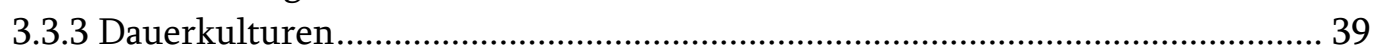

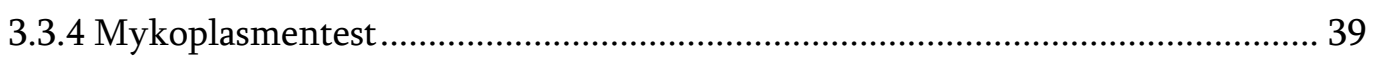




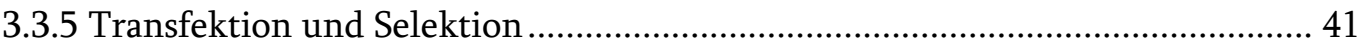

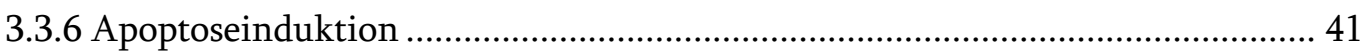

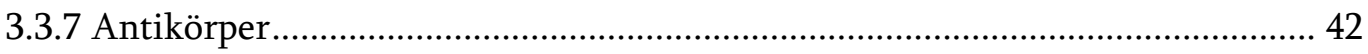

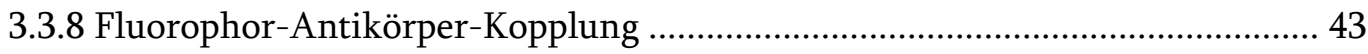

3.3.9 Indirekte Immunofluoreszenz-Markierung ….................................................. 45

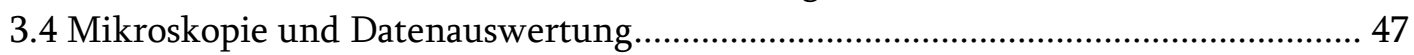

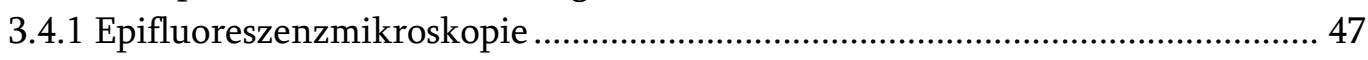

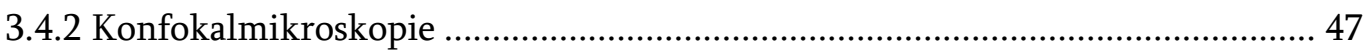

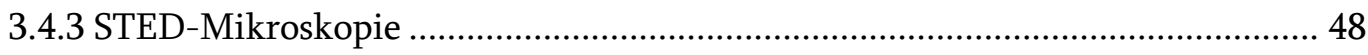

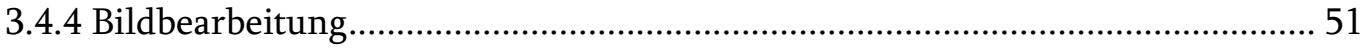

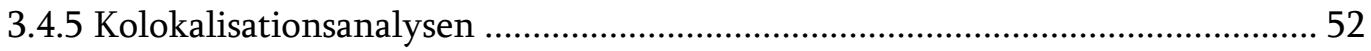

3.4.6 Analyse sub-mitochondrialer Proteinverteilungen ........................................ 54

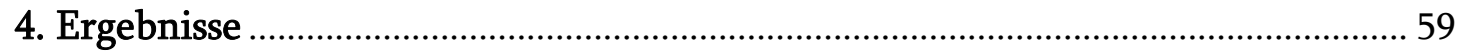

4.1 Sub-mitochondriale (Ko)Lokalisationsstudien zu den hVDAC-Isoformen .............. 59

4.1.1 Sub-mitochondriale Lokalisation der hVDAC-Isoformen ............................... 59

4.1.2 Einfluss der Aminosäuresequenz auf die sub-mitochondriale Lokalisation von

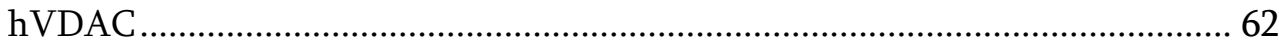

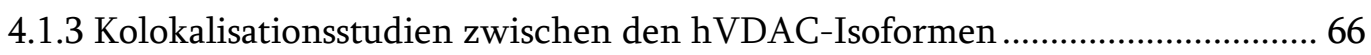

4.1.4 Kolokalisationsstudien zwischen den hVDAC-Isoformen und der Hexokinase-I

4.2 Untersuchung von sub-mitochondrialen Proteinverteilungen in unbehandelten und

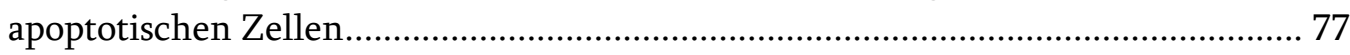

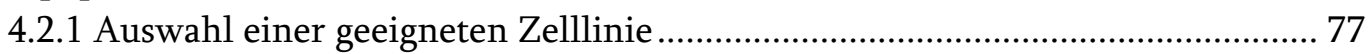

4.2.2 Auswahl eines geeigneten Apoptoseinduktors ............................................... 81

4.2.3 Hemmung der mitochondrialen Fragmentierung durch Herunterregulierung

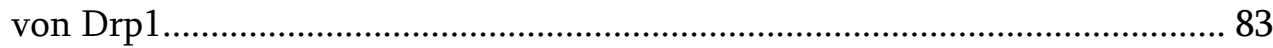

4.2.4 Charakterisierung des apoptotischen Signalweges in Wildtyp-Zellen und Drp1-

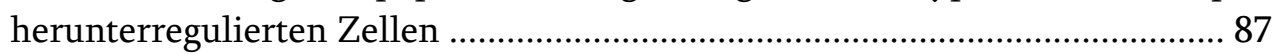

4.2.5 qualitative Untersuchung von sub-mitochondrialen Proteinverteilungen in

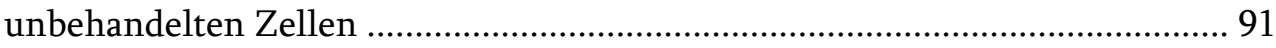

4.2.6 qualitative Untersuchung von sub-mitochondrialen Proteinverteilungen in

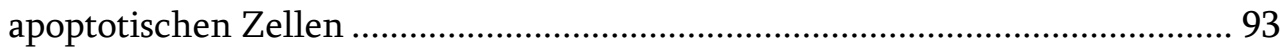

4.2.7 Aufnahme von STED-Daten zur anschließenden Quantifizierung................... 95

4.2.8 quantitative Untersuchung von sub-mitochondrialen Proteinverteilungen in unbehandelten und apoptotischen Zellen....................................................... 98

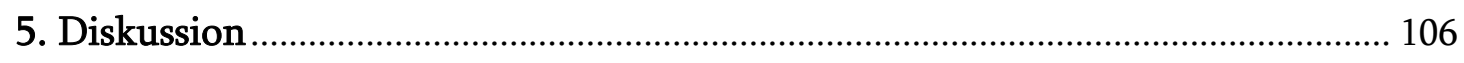

5.1 Sub-mitochondriale (Ko)Lokalisationsstudien zu den hVDAC-Isoformen ............. 106

5.1.1 Unterschiedliche sub-mitochondriale Lokalisation der hVDAC-Isoformen .. 106

5.1.2 Einfluss der Aminosäuresequenz auf die sub-mitochondriale Lokalisation von

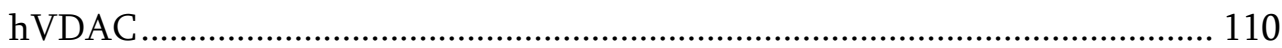

5.1.3 hVDAC-Homo- und Heterooligomere ........................................................ 111

5.1.5 Kolokalisationsstudien zwischen den hVDAC-Isoformen und der Hexokinase-I 
5.1.6 Ausblick: Studien zur Lokalisation und Funktion von VDAC. 118

5.2 Sub-mitochondrialen Proteinverteilungen in unbehandelten und apoptotischen

Zellen 121

5.2.1 Sub-mitochondriale Proteinverteilungen in unbehandelten Zellen 121

5.2.2 Drp1-Herunterregulierung und deren Einfluss auf die Apoptose 123

5.2.3 Sub-mitochondriale Proteinverteilungen in apoptotischen Zellen 128

5.2.4 Ausblick: Untersuchung von Bax-Komplexen 136

6. Abkürzungsverzeichnis. 140

7. Literatur 143

8. Anhang 159

8.1 STED-Mikroskopie und ihre Eignung zur Untersuchung sub-mitochondrialer Proteinverteilungen 159

8.2 Wahl des STED-Mikroskops zur quantitativen Datenanalyse sub-mitochondrialer

Proteinverteilungen 163

8.3 Ergänzende Abbildungen und Tabellen .... 165

9. Veröffentlichungen und Konferenzbeiträge. 184

9.1 Veröffentlichungen 184

9.2 Konferenzbeiträge 184

10. Danksagung 185

11. Lebenslauf. 186 


\section{Zusammenfassung und Summary}

\subsection{Zusammenfassung}

Mitochondrien sind ein essentieller Bestandteil eukaryotischer Zellen. Sie besitzen eine komplexe interne Struktur und erfüllen eine Vielzahl verschiedener Aufgaben. Aufgrund ihrer herausragenden Funktion in der Bereitstellung des universellen biologischen Energieäquivalents ATP werden Mitochondrien auch als Kraftwerke der Zelle bezeichnet.

Obwohl Mitochondrien zu den am besten untersuchten Organellen gehören, ist bisher wenig über die Verteilung von Proteinen innerhalb von Mitochondrien bekannt.

Die lichtmikroskopische Untersuchung sub-mitochondrialer Proteinverteilungen war lange Zeit nicht möglich, da der Durchmesser von Mitochondrien mit 200-400 nm im Bereich der Auflösungsgrenze konventioneller Lichtmikroskope liegt.

Die Entwicklung hochauflösender lichtmikroskopischer Techniken wie der STEDMikroskopie erlaubt es seit kurzer Zeit sub-mitochondriale Proteinverteilungen zu untersuchen, wobei bislang ausschließlich qualitative Studien durchgeführt wurden. In dieser Arbeit wurde die STED-Mikroskopie mit mathematischen Algorithmen kombiniert, um erstmalig quantitative Daten über submitochondriale Proteinverteilungen zu erhalten.

Durch die qualitative und quantitative Analyse fluoreszenz-mikroskopischer Daten konnten zwei verschiedene Fragestellungen adressiert werden:

(1) Der voltage-dependent anion-selective channel (VDAC) ist ein Protein der äußeren mitochondrialen Membran, welches für den Transport von Metaboliten wie ATP verantwortlich ist. Im Menschen sind drei verschiedene Isoformen beschrieben. Bis jetzt ist wenig über Unterschiede zwischen den einzelnen hVDAC-Isoformen bekannt. 
In dieser Arbeit wurde nachgewiesen, dass die drei hVDAC-Isoformen eine unterschiedliche sub-mitochondriale Lokalisation aufweisen und es konnte eine Aminosäure identifziert werden, die einen Einfluss auf diese Lokalisation hat. Ergebnisse quantitativer Kolokalisationsstudien mit den VDAC-Isoformen untereinander liefern Hinweise auf VDAC-Heterooligomere. Weiterhin konnte durch quantitative STED-Mikroskopie gezeigt werden, dass der Grad der Kolokalisation zwischen hVDAC und seinem putativen Interaktionspartner Hexokinase-I isoform-spezifisch ist. Da zudem ein Anteil der Hexokinase-I mit keiner der drei hVDAC-Isoformen kolokalisiert, deutet dies auf ein komplexeres Zusammenspiel dieser Proteine hin als zuvor angenommen.

(2) Apoptose, eine Form des programmierten Zelltods, ist ein zentraler Mechanismus für das Leben aller multizellulären Organismen. Trotz dieser wichtigen Bedeutung ist bis jetzt weder geklärt wie genau Cytochrom $c$ aus den Mitochondrien freigesetzt wird noch ist viel über sub-mitochondriale Proteinverteilungen und mögliche Änderungen während der Apoptose bekannt.

Durch quantitative STED-Mikroskopie konnte gezeigt werden, dass keine massiven Änderungen in den Verteilungen von sechs verschiedenen Proteinen während früherer Phasen der Apoptose stattfinden. Vielmehr konnten subtile Änderungen, hin zu homogeneren Proteinverteilungen nachgewiesen werden, die vor der Cytochrom $c$-Freisetzung stattfinden.

Diese Ergebnisse erweitern die Sichtweise auf den apoptotischen Signalweg: Es finden nicht nur, wie zuvor durch andere Studien nachgewiesen, subtile strukturelle Änderungen in den Mitochondrien während der Apoptose statt, sondern vielmehr auch subtile Änderungen in den Verteilungen von mitochondrialen Proteinen, die mit einer Tendenz zur Auflösung von Proteinclustern erklärt werden können.

Somit konnten durch die STED-Mikroskopie feine Änderungen in submitochondrialen Proteinverteilungen nachgewiesen werden, die mittels konventioneller Mikroskopie unentdeckt geblieben wären. 


\subsection{Summary}

Mitochondria are essential for eukaryotic cells. These organelles exhibit a complex internal structure and fulfil a variety of different tasks. They are known as the powerhouses of the cell because of their important role in the supply of the universal biological energy equivalent ATP.

Although mitochondria belong to the best characterized organelles, only little is known about protein distributions within mitochondria.

The light microscopic analysis of sub-mitochondrial protein distributions was neglected for a long time, because mitochondria have a diameter of 200-400 nm, which is in the range of the resolution limit of conventional light microscopes.

However, recent developments of high resolution light microscopic techniques like STED-microscopy allow the investigation of sub-mitochondrial protein distributions. Up to now, only qualitative analysis of mitochondrial proteins and their distributions were performed. In this work STED-microscopy was combined with mathematical algorithms to obtain for the first time quantitative data on submitocondrial protein distributions.

By qualitative and quantitative analysis of fluorescence-microscopy based data, two different issues could be addressed:

(1) The voltage-dependent anion-selective channel (VDAC) is a protein of the mitochondrial outer membrane mediating the transport of metabolites, including ATP. In humans, three different isoforms exist. Until now little is known about the differences between the three hVDAC isoforms.

In this work it was shown that the three hVDAC isoforms have a different submitochondrial localization. Further an amino acid residue was identified, which has an influence on the sub-mitochondrial localization of hVDAC. The results of quantitative colocalization analysis between the different hVDAC isoforms suggest the existence of VDAC-heterooligomers. Using quantitative STED-microscopy, it could be shown that the degree of colocalization between hVDAC and their possible interaction partner hexokinase-I is isoform specific. In addition, the data 
reveal that a substantial fraction of hexokinase-I does not colocalize with any of the hVDAC isoforms, suggesting a more complex interplay of these proteins than previously anticipated.

(2) Apoptosis, one form of programmed cell death, is a fundamental process for the life of multicellular organisms. Despite this very important fact, little is known about how exactly cytochrome $c$ is released from mitochondria, as well as the submitochondrial protein distributions and possible changes during apoptosis.

By using quantitative STED-microscopy, it could be shown that no massive changes in the protein distributions of six different mitochondrial proteins take place during early stages of apoptosis. Rather, subtle changes to more homogenous protein distributions were obeserved, which occur before the cytochrome $c$ release.

These results broaden the view on the apoptotic pathway: Not only subtle structural changes take place within mitochondria during apoptosis (as proven by other studies), but also subtle changes in the sub-mitochondrial protein distributions, which can be explained by the tendency of disintegration of protein clusters.

With STED-microscopy it was hence possible to detect subtle changes in submitochondrial protein distributions, which would otherwise remain undiscovered in conventional light microscopy. 


\section{Einleitung}

Mitochondrien sind ein essentieller Bestandteil eukaryotischer Zellen (Frederick und Shaw, 2007; Westermann, 2007). Die als Kraftwerke der Zelle bekannten Organellen besitzen eine komplexe interne Struktur und erfüllen eine Vielfalt verschiedener Aufgaben (Logan, 2006; McBride et al., 2006). Aufgrund ihrer Multifunktionalität sind dysfunktionale Mitochondrien an einer Vielzahl verschiedener Krankheiten beteiligt (Scheffler, 2001; Liesa et al., 2009). Ein genaueres Verständnis von Struktur und Funktion dieser dynamischen Organellen ist somit nicht zuletzt auch für therapeutische Fragestellungen von Bedeutung (Galluzzi et al., 2006; Gogvadze et al., 2009).

\subsection{Mitochondrien: Struktur, Dynamik und Funktion}

\subsubsection{Evolution von Mitochondrien}

Der Erwerb der Mitochondrien war möglicherweise das bedeutendste Ereignis in der Evolution eukaryotischer Zellen (Westermann, 2007). Nach der Endosymbiontentheorie sind vor ungefähr zwei Milliarden Jahren $\alpha$-Proteobakterien von anderen Zellen aufgenommen worden. Ob die Ektosymbionten frühe Eukaryoten oder, wie aktuellere Daten andeuten, Archaebakterien waren, kann bis jetzt nicht abschließend beantwortet werden (Taylor, 1974; Gray et al., 1999; Lang et al., 1999; Dyall et al., 2004). Fest steht aber, dass sich im Verlauf der Evolution die $\alpha$-Proteobakterien endosymbiontisch zu Mitochondrien entwickelt haben (Sagan, 1967; Margulis, 1970).

Dieses zentrale Ereignis hatte zwei wichtige Konsequenzen: (1) Durch die Endosymbiose sind die $\alpha$-Proteobakterien und somit die späteren Mitochondrien von zwei Membranen umgeben. (2) Im Verlauf der Evolution wurde ein Großteil der mitochondrialen DNA in den Kern der eukaryotischen Zelle transferiert. Von den ungefähr 1500 mitochondrialen Proteinen sind im Menschen nur noch 
13 mitochondrial kodiert (Meisinger et al., 2008). Um das mitochondriale Proteom aufrechtzuerhalten, ist somit ein kontinuierlicher Import kernkodierter Proteine in das Mitochondrium nötig.

\subsubsection{Struktur von Mitochondrien}

Mitochondrien weisen eine komplexe interne Architektur auf (Abbildung 2.1), die in vier strukturelle Einheiten unterteilt werden kann: Auf der einen Seite bestehen die Mitochondrien mit der äußeren und inneren mitochondrialen Membran aus zwei Membransystemen und auf der anderen Seite besitzen sie mit dem Intermembranraum und der mitochondrialen Matrix zwei wasserhaltige Kompartimente (Rehling et al., 2004).

Die beiden Membranen unterscheiden sich in ihrer Protein- und Lipidzusammensetzung. Die äußere Membran ähnelt in ihrer Protein- und Lipidzusammensetzung der Plasmamembran und ist für die meisten Ionen und

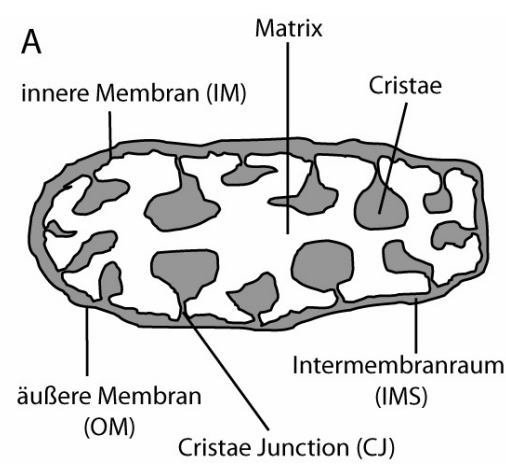
Abbildung 2.1: Schematische elektronenmikroskopische Aufnahme Rekonstruktion (C) eines Mitochondriums

Mitochondrien weisen eine komplexe interne Architektur auf, bestehend aus einer glatten äußeren und einer stark aufgefalteten inneren Membran, deren Einstülpungen als Cristae bezeichnet werden (A). Sowohl auf der transmissions-elektronenmikroskopischen Aufnahme eines Mitochondriums (B, aus Alberts et al, 2004) als auch auf der elektronentomographischen Rekonstruktion eines isolierten Mitochondriums aus der Rattenleber (C, aus Mannella, 2006) sind äußere und innere Membran sowie Cristae zu erkennen. Für (C): äußere Membran (rot), innere Grenzflächenmembran (gelb), Cristaemembran (grün), Mitochondrien-Durchmesser $1,5 \mu \mathrm{m}$. 
Makromoleküle durchlässig. Hingegen ist die innere mitochondriale Membran für die meisten Ionen und Makromoleküle nicht frei durchlässig und weist im Gegensatz zu vielen anderen Membranen, bei denen fast eine Gleichverteilung von Lipiden und Proteinen vorherrscht, einen sehr hohen Proteingehalt auf (Ardail et al., 1990).

Die innere Membran kann weiter in die innere Grenzflächenmembran (IBM) und die Cristae-Membran unterteilt werden. Die innere Grenzflächenmembran liegt der äußeren Membran an, wohingegen die in den Matrixraum hineinreichenden Membranabschnitte als Cristae-Membran bezeichnet werden. Diese strukturelle Subkompartimentierung hat auch funktionelle Relevanz. Es konnte gezeigt werden, dass Bestandteile der Atmungskette vorwiegend in der Cristae-Membran lokalisieren, wohingegen Komponenten der Protein-Import-Maschinerie vorwiegend in der inneren Grenzflächenmembran zu finden sind (Vogel et al., 2006; Wurm und Jakobs, 2006).

Aufgrund von unterschiedlichen Abständen zwischen innerer und äußerer Membran bzw. verschiedenen Durchmessern der Cristae können weitere strukturelle Unterscheidungen getroffen werden (Perkins et al., 1997): Der Durchmesser der Cristae ist nicht an allen Stellen gleich. Vielmehr sind die Cristae an dem Übergang zur inneren Grenzflächenmembran zu schmalen, tubulären Strukturen verengt, die als Cristae Junctions (CJ) bezeichnet werden (Perkins et al., 1997; Mannella, 2006). Die Funktion von Cristae Junctions ist bis jetzt nicht geklärt. Es wird spekuliert, dass sie eine Barriere zwischen Cristaeraum und dem übrigen Intermembranraum darstellen, welche die Bewegung von Proteinen und Metaboliten einschränkt (Rabl et al., 2009).

Die äußere und die innere Grenzflächenmembran weisen ebenfalls nicht immer den gleichen Abstand zueinander auf. Vielmehr gibt es Bereiche, in denen sich beide Membranen sehr nahe kommen (Perkins et al., 1997). Diese Regionen werden als Kontaktstellen bezeichnet. Vermutlich findet an diesen Orten der 
Proteinimport und Metabolittransport über beide mitochondriale Membranen statt (Reichert und Neupert, 2002).

\subsubsection{Morphologie und Dynamik von Mitochondrien}

Die Morphologie und die Verteilung von Mitochondrien innerhalb einer Zelle unterscheiden sich in verschiedenen Organismen. Mitochondrien von Organismen aus den Reichen der Pilze, Pflanzen und Tiere sind in Abbildung 2.2 dargestellt. Hier können die eher runden Mitochondrien in der Schließzelle einer Tabakpflanze (B) von den tubulären Mitochondrien in Hefe- (A) und Säugerzellen (C) unterschieden werden, wobei im Detail ein deutlich komplexeres mitochondriales Netzwerk in Säugerzellen im Vergleich zu Hefezellen auffällt.

Mitochondrien von Säugerzellen besitzen einen typischen Durchmesser von 200-400 nm und bilden ein weit verzweigtes, tubuläres Netzwerk (Griparic und van der Bliek, 2001; Frazier et al., 2006).

Dieses mitochondriale Netzwerk ist nicht starr, vielmehr unterliegt es fortwährenden Teilungs- und Fusionsprozessen und kann sich dynamisch an verschiedene physiologische Gegebenheiten anpassen (Egner et al., 2002; Cerveny et al., 2007; Westermann, 2008). Die dafür verantwortliche Teilungs- und
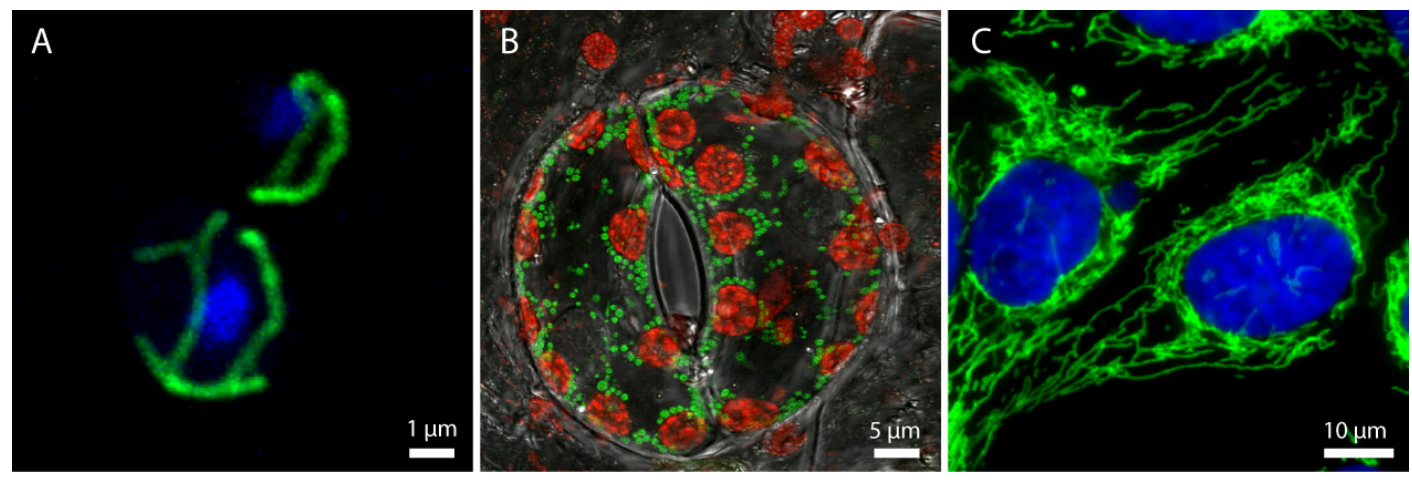

Abbildung 2.2: Morphologie von Mitochondrien verschiedener Organismen

Mitochondrien in Schließzellen von Tabakpflanzen (B, Nicotiana tabacum) unterscheiden sich durch ihre runde Form deutlich von den tubulären Mitochondrien in Hefe- (A, Saccharomyces cerevisiae) und Säuger-Zellen (C, U2OS-Zellen). Mitochondrien (grün), Zellkerne (blau), Chloroplasten (rot) 
Fusionsmaschinerie ist wichtig, da Mitochondrien nicht de novo entstehen können. Vielmehr bilden sie sich ausschließlich durch Abschnürung aus bereits existierenden Organellen.

\subsubsection{Proteinimport in Mitochondrien}

Da die große Anzahl aller mitochondrialen Proteine kernkodiert sind und an cytosolischen Ribosomen gebildet werden, ist der Import dieser Proteine in das Mitochondrium notwendig (Kutik et al., 2007). Zentraler Bestandteil dieses Prozesses sind die als Translokasen der mitochondrialen Membran bezeichneten Poren-bildende Multi-Protein-Komplexe (Rehling et al., 2004). Sie vermitteln den Transport von Vorläufer-Proteinen über die äußere und innere mitochondriale Membran. Diese Translokasen sind hochdynamische molekulare Maschinen, die sich in Abhängigkeit vom Importsignal des zu importierenden Proteins restrukturieren und transient mit anderen Bestandteilen der Import-Maschinerie interagieren (Rehling et al., 2004). Neben den eigentlichen Translokasen sind noch eine Vielzahl weiterer Proteine an den komplexen und hoch regulierten Importvorgängen beteiligt.

Die meisten Import-Komponenten und ihre Funktionen, die im Folgenden beschrieben werden, sind durch Studien an der Hefe Saccharomyces cerevisiae entdeckt worden (Baker et al., 2007), wobei viele homologe Proteine mittlerweile auch in Säugern nachgewiesen wurden (Hoogenraad et al., 2002).

Aktuell können vier verschiedene Importwege unterschieden werden (Bolender et al., 2008), wobei deren Beginn für alle gleich ist. Alle Vorläuferproteine werden über den TOM-Komplex (translocase of the outer mitochondrial membrane) durch die äußere mitochondriale Membran transportiert (Abbildung 2.3). Dieser Multiproteinkomplex besteht aus sieben verschiedenen Untereinheiten (Pfanner et al., 2004). Für die Erkennung der Vorläuferproteine sind die RezeptorUntereinheiten Tom20, Tom22 und Tom70 zuständig, wohingegegen die zentrale Importpore von dem $\$$-barrel Protein Tom 40 gebildet wird. Vervollständigt wird 


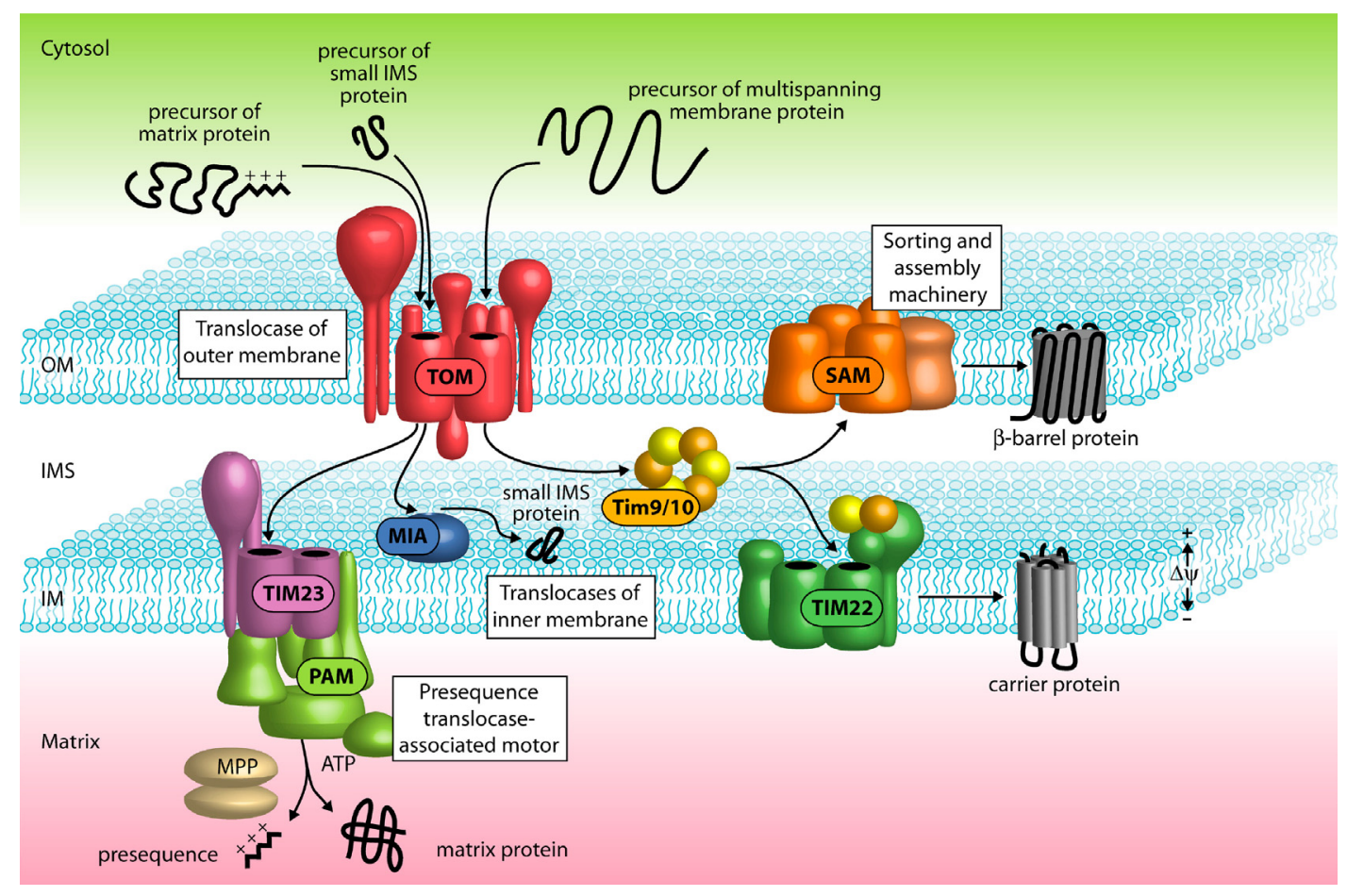

\section{Abbildung 2.3: Importwege von mitochondrialen Vorläuferproteinen}

Alle mitochondrial kodierten Vorläuferproteine werden zunächst über die äußere mitochondriale Membran durch den TOM-Komplex transportiert. Im Anschluss ergeben sich in Abhängigkeit von der Signalsequenz vier verschiedene Importwege: der Import in die mitochondriale Matrix über den TIM23-Komplex, der Import in die äußere mitochondriale Membran über den SAM-Komplex, der Import in die innere mitochondriale Membran über den TIM22-Komplex und der Import in den Intermembranbereich über den MIA-Komplex (aus Kutik et al., 2007)

der Multiproteinkomplex durch die drei kleineren Tom-Proteine, die für die Stabilität des Gesamtkomplexes bzw. für die korrekte Insertion des Vorläuferproteins in die Importpore wichtig sind (Dietmeier et al., 1997; Model et al., 2001).

Der weitere Importverlauf hängt ab hier von der Signalsequenz des zu importierenden Vorläuferproteins ab.

(1) Weist dieses eine N-terminale Importsequenz auf, so gelangt es über den TIM23-Komplex (translocase of the inner mitochondrial membrane) mit Unterstützung von anderen, teilweise als PAM-Komplex (presequence translocaseassociated motor) bezeichneten, Proteinen in die mitochondriale Matrix, in der seine Presequenz durch die Peptidase MMP (mitochondrial processing peptidase) 
entfernt wird (Herrmann und Neupert, 2000). Weist das Vorläuferprotein hinter der Importsequenz eine hydrophobe Region auf, so wird es nicht wie zuvor beschrieben in die Matrix importiert, sondern vielmehr über den TIM23-Komplex in die innere mitochondriale Membran integriert.

Für Proteine mit internen Signalsequenzen ergeben sich die folgenden Importwege:

(2) Vorläufer von $\beta$-barrel Proteinen der äußeren Membran werden im Intermembranraum zunächst von kleinen Tim-Proteinen gebunden (Tim9-Tim10 bzw. Tim8-Tim13) und zum SAM-Komplex (sorting and assembly machinery) geleitet, der möglicherweise mit Unterstützung des MDM-Komplexes (mitochondrial distribution and morphology) die Integration in die äußere Membran bewirkt (Vial et al., 2002; Wiedemann et al., 2004).

(3) Vorläufer von Multidomänen-Transmembranproteinen der inneren Membran werden ebenfalls von den kleinen Tim-Proteinen zum TIM22-Komplex transportiert, welcher für deren Insertion in die innere Membran verantwortlich ist (Rehling et al., 2003).

(4) Lösliche Vorläuferproteine des Intermembranraumes können nach Import über den TOM-Komplex durch Oxidierung von Cysteinen, vermittelt über den MIA-Komplex (mitochondrial intermembrane space assembly machinery), in ihre gefaltete Struktur überführt werden (Chacinska et al., 2004).

\subsubsection{Beteiligung von Mitochondrien am zellulären Metabolismus}

Mitochondrien sind an einer Vielzahl verschiedener Stoffwechselwege beteiligt. Hierzu gehört die ß-Oxidation von Fettsäuren, der Harnstoffzyklus, die Ketonund Häm-Biosynthese, die Bildung von Eisen-Schwefel-Zentren und der Aminosäure-Metabolismus (Kennedy und Lehninger, 1949; Craddock und Simpson, 1961; Maier et al., 1974; Scheffler, 1999; Bartlett und Eaton, 2004; Levi und Rovida, 2009; Lill, 2009). Ihre herausragende Rolle besteht aber in der Erzeugung des universellen biologischen Energieäquivalents ATP. Die Erzeugung 
von ATP geschieht im Rahmen der oxidativen Phosphorylierung, die im weiteren Verlauf genauer erläutert wird (Saraste, 1999).

Der Abbau von Glukose-Molekülen findet zunächst durch die Glykolyse im Cytosol statt. In diesem zehnstufigen Prozess wird jeweils ein Molekül Glukose zu zwei Molekülen Pyruvat abgebaut. Hierbei werden zwei Moleküle ATP gewonnen. Pyruvat wird dann, nach Transport in die Mitochondrien, zu Acetyl-CoA umgewandelt, welches das Ausgangssubstrat für den Krebs-Zyklus (Zitronensäurezyklus) darstellt. Im Krebs-Zyklus werden die Acetyl-Gruppen des Coenzyms $\mathrm{A}$ zu CO 2 oxidiert, welches von der Zelle ausgeschieden wird. Während des Krebs-Zyklus werden Elektronen auf die Trägermoleküle $\mathrm{NAD}^{+}$und FAD übertragen. Diese Elektronen werden über nacheinander geschaltete Redoxkomplexe transportiert und abschließend auf molekularen Sauerstoff übertragen, der zu Wasser reduziert wird. Dieser Elektronentransport wird zum Aufbau eines Protonengradienten genutzt, der schließlich die Synthese des universellen biologischen Energieträgers ATP ermöglicht.

Der für den Elektronen- und Protonentransport sowie für die ATP-Synthese verantwortliche Stoffwechselweg wird als Atmungskette bezeichnet und besteht aus fünf Komplexen (Abbildung 2.4): Auf Komplex I werden die Elektronen von $\mathrm{NADH}$ übertragen, dieser reduziert Ubichinon, welches die Elektronen auf den Komplex III überträgt. Komplex II ist Bestandteil des Krebs-Zyklus und überträgt von $\mathrm{FADH}_{2}$ Elektronen ebenfalls auf Ubichinol. Komplex III wiederum leitet die Elektronen auf das lösliche Intermembranprotein Cytochrom $c$ weiter, welches seinerseits die Elektronen auf Komplex IV überträgt. Hier findet die abschließende Reduktion von Sauerstoff zu Wasser statt. Zusätzlich zu diesem Elektronentransport findet der Transport von Protonen in den Intermembranraum statt. Dies geschieht an den Komplexen I, III und IV und führt zum Aufbau eines elektrochemischen Protonengradienten. Dieser Gradient wird von der F1FoATP-Synthase (Komplex V) genutzt, um unter Rückfluss von 


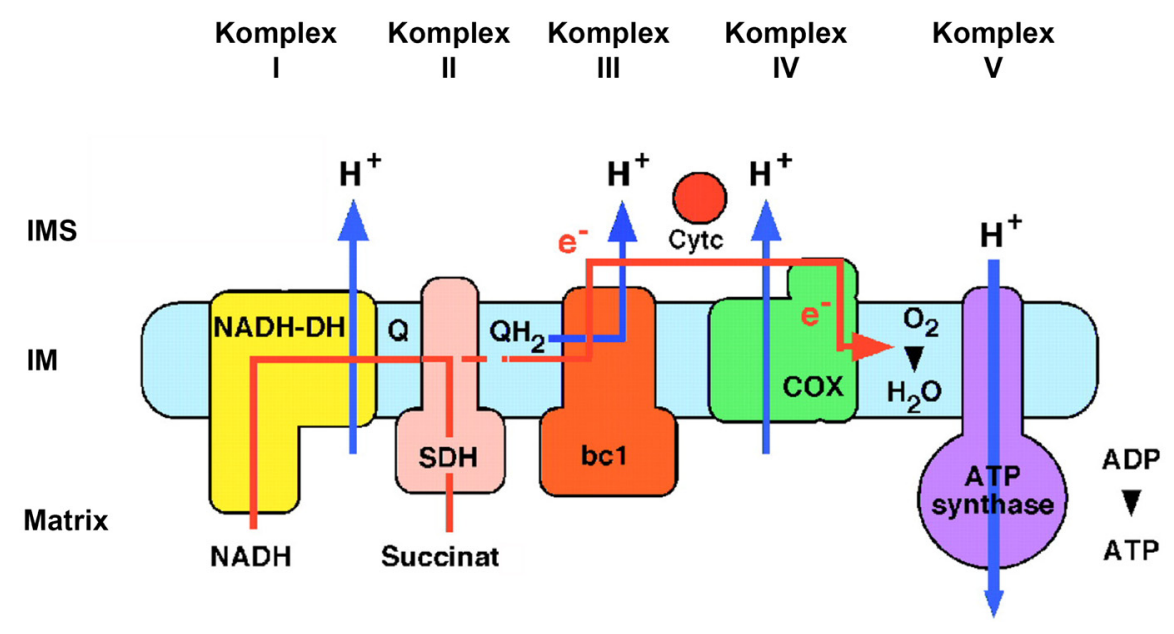

\section{Abbildung 2.4: Mitochondriale Atmungskette}

Vier Enzymkomplexe sind für den Transport von Elektronen aus dem Krebs-Zyklus verantwortlich: NADH-Deyhdrogenase-Komplex (I, NADH-DH), Succinat-DehydrogenaseKomplex (II, SDH), Cytochrom- $c$-Reduktase-Komplex (III, bc1), Cytochrom- $c$-OxidaseKomplex (IV, COX). Zwischen den Komplexen vermitteln Ubichinon (Q) und Cytochrom $c$ (Cytc) den Elektronentransport. Der Elektronentransport wird gleichzeitig genutzt, um einen elektrochemischen Protonengradienten aufzubauen. Die FiFoATP-Synthase (Komplex V) wiederum nutzt diesen, um aus ADP und anorganischem Phosphat ATP zu synthetisieren. Der gesamte Prozess wird als oxidative Phosphorylierung bezeichnet und findet an der inneren mitochondrialen Membran statt. (verändert nach Saraste et al., 1999)

Elektronen in den Matrixraum aus ADP und anorganischem Phosphat ATP zu synthetisieren.

In diesem hocheffizienten Stoffwechselweg werden pro Ausgangsmolekül Glukose 30 Moleküle ATP gewonnen, welche die Grundlage für die meisten Stoffwechselwege in Eukaryoten darstellen. Man geht sogar davon aus, dass die Entstehung mehrzelliger Organismen erst durch die oxidative Phosphorylierung möglich wurde, da durch die Glykolyse alleine der Energiebedarf komplexer, multizellulärer Organismen nicht gedeckt werden kann (Semenza, 2007).

\subsubsection{Interaktionen zwischen Hexokinase und VDAC}

Der Abbau von Glykose zu Pyruvat findet während der zuvor bereits erwähnten Glykolyse statt, in deren ersten Schritt Glukose zu Glukose-6-Phosphat umgesetzt wird. Dieser ATP-abhängige Schritt wird durch die 50-100 kDa großen 
Hexokinasen katalysiert. Es sind vier Hexokinase-Isoformen beschrieben, wobei nur Hexokinase-I und II mit den Mitochondrien assoziiert sind (Gelb et al., 1992).

Durch Interaktion mit VDAC, einem Protein der äußeren mitochondrialen Membran, bekommt die Hexokinase direkten Zugang zu dem durch die F1FoATP-Synthase hergestellten ATP. Dieses gelangt über ANT (AdenosinNukleotid-Translokase) und VDAC in das Cytosol (Abbildung 2.5).

VDACs (voltage-dependent anion-selective channel) sind die häufigsten Proteine in der äußeren mitochondrialen Membran (Colombini, 1979; Mayer et al., 1993). Es handelt sich $30-35 \mathrm{kDa}$ große Proteine, die in allen Eukaryoten vorkommen (Young et al., 2007). Sie sind für den Transport von Ionen und kleinen Molekülen wie ATP über die äußere mitochondriale Membran verantwortlich (BlachlyDyson und Forte, 2001; Rostovtseva et al., 2005). Im Menschen sind drei

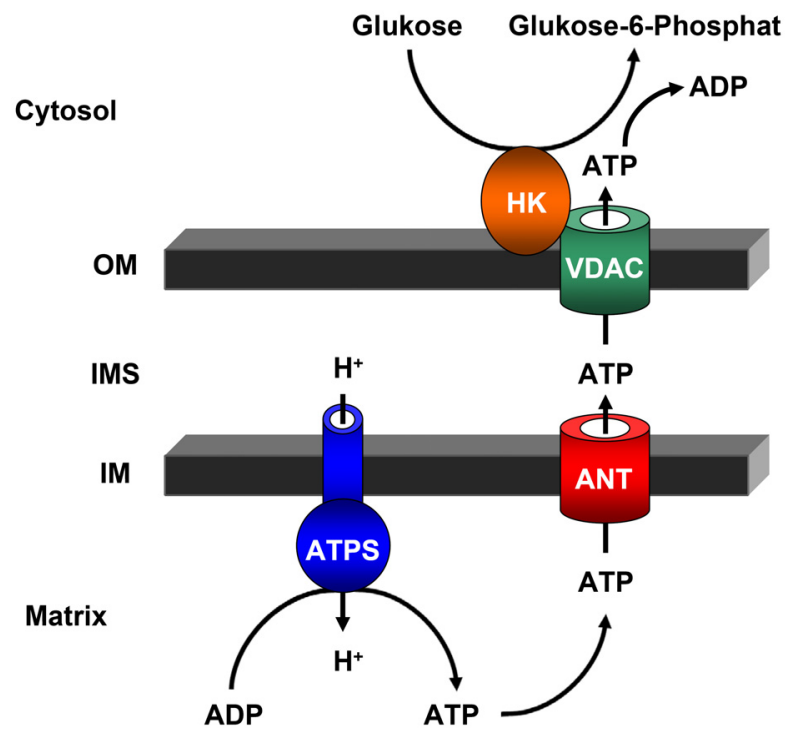

Abbildung 2.5: Zusammenhang zwischen ATP-Synthese und Glykolyse über die Interaktion zwischen VDAC und Hexokinase.

Im ersten Schritt der Glykolyse wird Glukose zu Glukose-6-Phosphat umgesetzt. Dieser ATP verbrauchende Schritt wird durch die Hexokinase katalysiert. Im Rahmen der oxidativen Phosporylierung wird unter Ausnutzung eines elektrochemischen Protonengradienten ATP synthetisiert, welches über ANT und VDAC in das Cytosol gelangt. Die Interaktion der Hexokinase mit VDAC ermöglicht der Hexokinase direkten Zugang zum neu synthetisierten ATP. ATPS: F1FoATP-Synthase, ANT: Adenosin-Nukleotid-Translokase, VDAC: voltagedependent anion-selective channel, HK: Hexokinase 
verschiedene Isoformen bekannt (hVDAC1, hVDAC2, hVDAC3), die in unterschiedlichen Expressionshöhen in den meisten Geweben vorkommen (Sampson et al., 1996; Huizing et al., 1998; Shinohara et al., 2000; Cesar Mde und Wilson, 2004). Für VDACs sind eine Vielzahl an Interaktionen beschrieben, unter anderem eben mit dem Protein Hexokinase (Wilson, 1995; Pastorino und Hoek, 2008). Hierbei ist zu beachten, dass in frühen Studien VDAC zwar als HexokinaseBindungsfaktor beschrieben wurde (Linden et al., 1982), diese Interaktion aber nicht essentiell für die Bindung der Hexokinase-I an die äußere mitochondriale Membran ist. Notwendig und hinreichend ist vielmehr eine 15 Aminosäure lange N-terminale Domäne, über die Hexokinase-I in die Membran inseriert (Gelb et al., 1992).

Bezüglich der genauen Interaktion einzelner VDAC Isoformen mit der Hexokinase gibt es nur wenige und sich teilweise widersprechende Daten: Für Hexokinase-I aus Rattenhirn ist eine Interaktion mit VDAC1 und VDAC2 gezeigt worden (Azoulay-Zohar und Aflalo, 1999), wobei die Interaktion mit VDAC2 durch eine andere Studie in Frage gestellt worden ist (Blachly-Dyson et al., 1993). Für VDAC3 ist bis jetzt meines Wissens nach keine Interaktion mit der Hexokinase beschrieben worden. Es existieren wenig quantitative Daten über das Ausmaß von Interaktionen zwischen VDAC und Hexokinase, noch ist viel über die genaue sub-mitochondriale Lokalisation der Proteine bekannt (Yu et al., 1995). Einige Daten deuten darauf hin, dass die Hexokinase in fast allen Tumoren überexprimiert wird und es zu einer verstärkten Interaktion mit VDAC kommt (Pedersen, 2007). Diese Überexpression soll eine massive Erhöhung der Glykolyse und eine Reduzierung der oxidativen Phosphorylierung bewirken (Gogvadze et al.). Dieser Zusammenhang wurde bereits 1926 postuliert und ist unter dem Namen Warburg-Effekt bekannt (Warburg, 1926). Zusammengenommen nimmt die Hexokinase somit eine zentrale Stellung in der Tumorzellprogression ein und macht sie zu einem möglichen pharmazeutischen Ziel für Tumortherapien (Galluzzi et al., 2008). 
Zusammenfassend kann festgehalten werden, dass wenig über die submitochondriale Lokalisation der VDAC-Isoformen bekannt ist und es kaum und teils widersprüchliche Daten bezüglich der Interaktion zwischen den VDACIsoformen und der Hexokinase existieren.

\subsection{Apoptose und Mitochondrien}

\subsubsection{Apoptose und ihre Bedeutung}

Neben der immensen Bedeutung von Mitochondrien für den gesunden Organismus kommt ihnen auch eine zentrale Stellung während der Apoptose zu. Apoptose ist eine Form des programmierten Zelltods (Kroemer et al., 2009). Hierbei handelt es sich um ein natürlich vorkommendes, aktiv reguliertes Selbstmordprogramm der Zelle.

Apoptose gewährleistet die Beseitigung von nicht mehr benötigten Zellen während der Entwicklung eines Organismus, stellt die Gewebehomöostase sicher und ist für die Entfernung von kranken und alten Zellen verantwortlich (Hengartner, 2000; Bleackley und Heibein, 2001; Lucken-Ardjomande und Martinou, 2005).

Beispiele hierfür sind Entfernung des Schwanzes einer Kaulquappe bei der Metamorphose zum Frosch (Abbildung 2.6A) oder die Entfernung von Milchdrüsengewebe bei weiblichen Säugetieren nach der Stillzeit (Kiess und Gallaher, 1998; Meier et al., 2000; Alberts, 2004).

Bei der Aufrechterhaltung von Geweben stellt die Apoptose das Gegenstück zur Zellproliferation dar (Abbildung 2.6B). Im menschlichen Organismus werden in jeder Sekunde 100.000 Zellen durch Proliferationsprozesse gebildet und eine vergleichbare Anzahl stirbt jede Sekunde durch Apoptose (Vaux und Korsmeyer, 1999). 
A

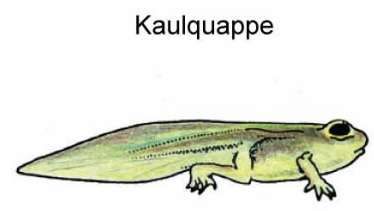

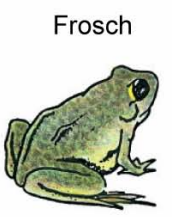

B

Zellproliferation

Apoptose

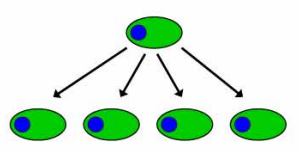

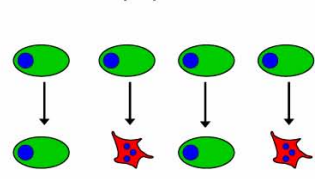

Abbildung 2.6: Bedeutung der Apoptose für mehrzellige Organismen

Für die Entfernung von nicht mehr benötigtem Gewebe während der Entwicklung von mehrzelligen Organismen ist die Apoptose verantwortlich. Ein Beispiel hierfür ist die Entfernung des Schwanzes einer Kaulquappe bei der Metamorphose zum Frosch (A) Zur Aufrechterhaltung von Geweben stellt die Apoptose das Gegenstück zur Zellproliferation dar (B). Alte, kranke und nicht mehr benötigte Zellen werden gezielt durch das Selbstmordprogramm entfernt. (A aus Alberts et al., 2004)

Die Lebensdauer der meisten menschlichen Zellen liegt im Bereich von Tagen bis Monaten. Für Dünndarmzellen wurde z.B. eine durchschnittliche Lebensdauer von 1,4 Tagen und für Leberzellen von 222 Tagen ermittelt (Kunsch, 2006). Somit unterliegt der gesamte Organismus ständigen Erneuerungsprozessen, gesteuert durch Zellproliferation und Apoptose.

Eine entscheidende Bedeutung kommt der Apoptose bei der Eliminierung von kranken oder für den Organismus gefährlich gewordenen Zellen zu. Ist dieser Prozess gestört, kommt es zu pathophysiologischen Zuständen: Bei neurodegenerativen Erkrankungen wie Parkinson und Alzheimer findet zu viel Apoptose statt, was zu einem massiven Verlust an neuronalem Gewebe führt, wohingegen die Entstehung von Tumoren bis hin zu Krebs durch einen Mangel an Apoptose erklärt werden kann (Green und Kroemer, 2004).

\subsubsection{Apoptose und andere Zelltodprogramme}

Der Ausdruck Apoptose wurde ursprünglich von J. F. Kerr eingeführt, um bestimmte morphologische Charakteristika zu beschreiben (Kerr et al., 1972): Hierzu gehört das Abrunden der Zelle, Reduktion des zellulären Volumens, die Kondensation des Chromatins, Fragmentierung des Kerns, die Bildung von apoptotischen Körperchen und schließlich die Phagozytose durch Makrophagen. 
Mittlerweile konnten diese morphologischen Beschreibungen durch biochemische ergänzt werden: Beteiligung von Proteinen der Bcl-2-Familie, Freisetzung von Proteinen aus dem Intermembranraum des Mitochondriums, Aktivierung von Proteasen (Caspasen), Fragmentierung der DNA (sog. DNA Leitern) und Umlagerung von Phosphatidylserin von der Membraninnen- zur Membranaußenseite der Plasmamembran (Galluzzi et al., 2007; Kroemer et al., 2009).

Neben der Apoptose gibt es noch eine Reihe anderer regulierter Programme, die zum Zelltod führen können (PCD: programmed cell death). Hier ist die Nekrose zu nennen, bei der es es zum Schwellen des Cytoplasmas und Aufreißen der Plasmamembran kommt, wie auch der Zelltod durch Autophagie. Die Autophagie ist durch eine massive Vakuolenbildung im Cytosol gekennzeichnet. Es findet keine Chromatinkondensation statt und Phagocyten sind nicht an der Beseitigung der Zelle beteiligt (Galluzzi et al., 2007; Kroemer et al., 2009). Neben weiteren, weniger klar abgrenzbaren Programmen wie mitotischer Katastrophe und Anoikis ist der Caspase-unabhängige Zelltod zu nennen (Broker et al., 2005). Beim Caspase-unabhängigen Zelltod finden zwar alle Prozesse oberhalb der CaspaseAktivierung statt, diese selbst bleibt aber aus (Tait und Green, 2008). Genaue Mechanismen sind bis jetzt nicht abschließend geklärt. Momentan wird davon ausgegangen, dass es durch die Permeabilisierung der mitochondrialen Membran und die Freisetzung von Intermembranproteinen zum Funktionsverlust der Mitochondrien kommt, was schließlich den Tod der Zelle zur Folge hat (Tait und Green, 2008).

\subsubsection{Apoptotische Signalwege}

Apoptose wird vorwiegend über zwei verschiedene Signalwege ausgelöst, wobei in beiden Fällen das Ziel in der Aktivierung der Proteine besteht, die für die Vollstreckung des Zelltods verantwortlich sind, den Caspasen (cysteine-dependent aspartate-specific proteases). Bei diesen Schlüsselenzymen handelt es sich um 
Proteasen, die in ihrem aktiven Zentrum ein Cystein besitzen und ihre Substrate nach einem Aspartat spalten. Die Caspasen werden als inaktive Vorläufer (Procaspasen) gebildet und durch andere Enzyme oder durch Autokatalyse aktiviert. Man kann zwischen Initiator- (Caspase-8 und -9) und ExekutorCaspasen unterscheiden (Taylor et al., 2008). Sie werden entweder über einen intrinsischen oder über einen extrinsischen Signalweg aktiviert (Abbildung 2.7) (Galluzzi et al., 2009).

Beim extrinsischen Signalweg (Abbildung 2.7A) werden extrazelluläre Signale von sogenannten Todesrezeptoren (z.B. Fas) in der Plasmamembran erkannt. Die Todesrezeptoren trimerisieren und rekrutieren Adaptorproteine (FADD), sowie Pro-Caspase-8 Moleküle. Diese als DISC (death inducing signaling complex) bezeichnete Multiproteinplattform bietet die Grundlage für die autokatalytische Prozessierung von Pro-Caspase-8-Molekülen (Zimmermann et al., 2001). Erst die räumliche Nähe der Pro-Caspase-8-Moleküle im DISC führt zur Aktivierung der Caspasen. Die aktiven Caspase-8-Moleküle prozessieren im Folgenden EffektorCaspasen, die schließlich eine große Anzahl verschiedener Substrate proteolytisch spalten.

Der intrinsische Signalweg (Abbildung 2.7B) kann durch eine Vielzahl verschiedener Faktoren ausgelöst werden, wie z.B. oxidativer Stress oder DNASchäden. Die zentrale Stellung innerhalb des intrinsischen Signalwegs wird von den Mitochondrien eingenommen (Spierings et al., 2005). Sie enthalten verschiedene pro-apoptotische Proteine im Intermembranraum, die während der Apoptose freigesetzt werden.

Hierfür verantwortlich sind die als Regulatoren der Apoptose bekannten Mitglieder der Bcl-2-Proteinfamilie, die in drei verschiedene Gruppen eingeteilt werden können (Youle und Strasser, 2008; Chipuk et al., 2010): anti-apoptotische Bcl-2-Proteine (z.B. Bcl-2, Bcl-XL), pro-apoptotische multidomänen Bcl-2Proteine (z.B. Bax, Bak) und pro-apoptotische Bcl-2-Proteine (z.B. Bad, Noxa), die nur die BH3-Domäne besitzen. Das fein austarierte Verhältnis zwischen den 


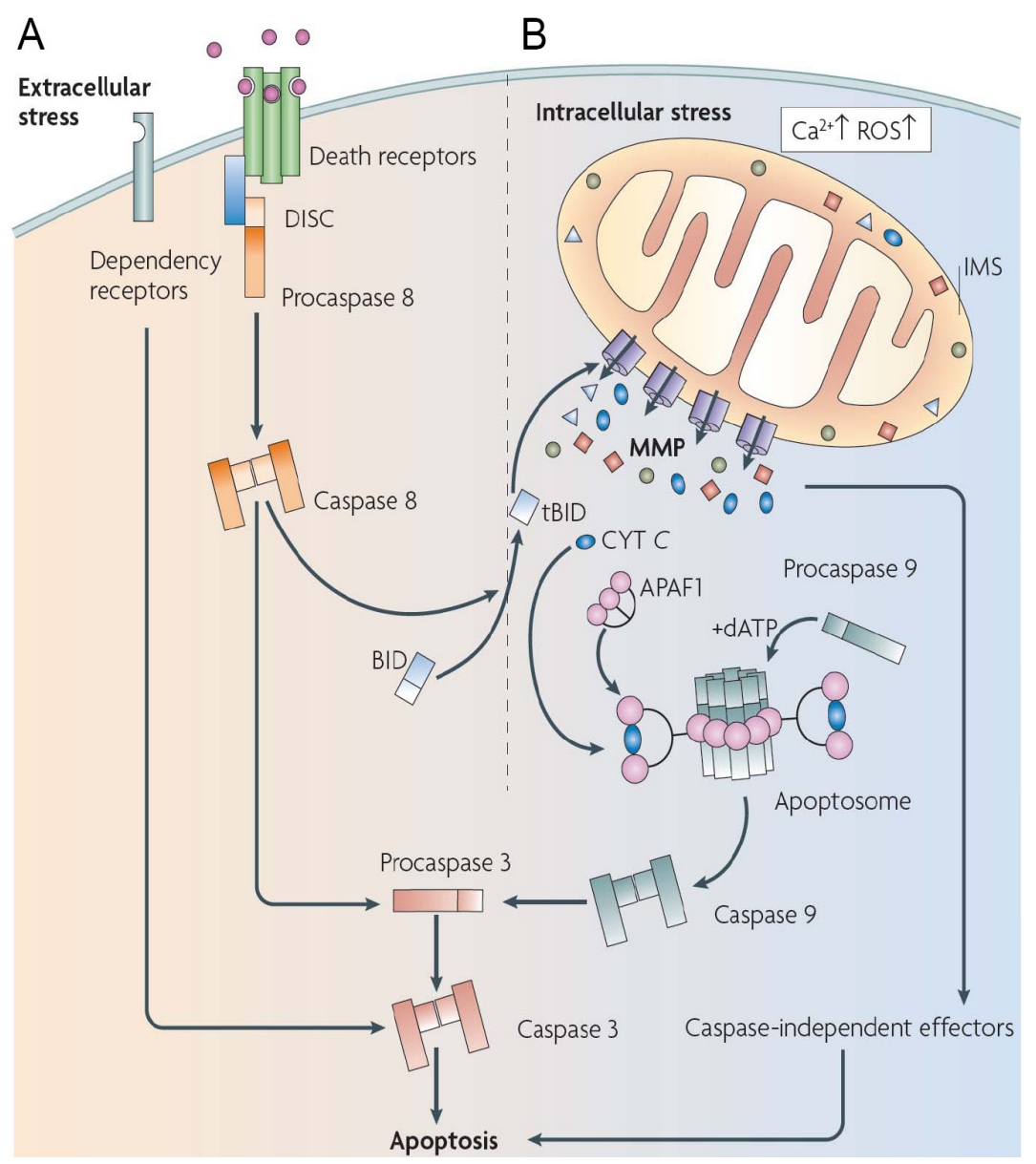

\section{Abbildung 2.7: Extrinsischer (A) und intrinsischer (B) Apoptose-Signalweg}

Apoptose kann entweder über extra- oder intrazelluläre Signale ausgelöst werden. In beiden Fällen kommt es zur Bildung einer Multienzymplattform (DISC, Apotosom), die zur Aktivierung von Initiator-Caspasen $(8,9)$ führt, welche ihrerseits Exekutor-Caspasen aktivieren. Als zentrales Organell des intrinsischen Signalwegs ist das Mitochondrium zu nennen. (aus Galluzzi et al., 2009)

Konzentrationen der einzelnen Bcl-2-Proteine bestimmt darüber, ob ein apoptotisches Signal an das Mitochondrium weitergeleitet wird oder nicht (Wong und Puthalakath, 2008).

Dies geschieht möglicherweise dadurch, dass Bax und/oder Bak direkt von Mitgliedern der proapoptotischen BH3-Sub-Familie aktiviert werden, welche zuvor durch die Bindung an anti-apoptotischen Bcl-2-Proteine in einem inaktiven Zustand vorlagen (Kim et al., 2006). Ein alternatives Model geht davon aus, dass Bax und/oder Bak zunächst inaktiv an anti-apoptotische Bcl-2-Proteine gebunden vorliegen. Durch die Bindung von pro-apoptotischen BH3-Proteinen an anti- 
apoptotische Bcl-2-Proteine werden Bax und/oder Bak freigesetzt und somit indirekt aktiviert (Willis et al., 2007).

Die Aktivierung von Bax bewirkt eine Konformationsänderung, eine Translokation an das Mitochondrium und eine Oligomerisierung zu großen Komplexen (Nechushtan et al., 2001) (bis auf die Translokation gilt dasselbe auch für das membranständige Protein Bak). Kurz darauf kommt es zur Freisetzung von verschiedenen Intermembranproteinen, wobei Cytochrom $c$ eine besondere Rolle zukommt (Ow et al., 2008). Cytchrom $c$ ist nämlich Bestandteil eines sich bildenden Multienzymkomplexes, der als Apoptosom bezeichnet wird. Das Apoptosom besteht aus Apaf-1, dATP, der Pro-Caspase-9 und eben Cytochrom $c$ und ist analog zum DISC-Komplex des extrinsischen Signalweges für die Aktivierung von Initiator-Caspasen verantwortlich, in diesem Fall von Pro-

Caspase-9. Diese aktiviert im Folgenden wiederrum Exekutor-Caspasen (Riedl und Salvesen, 2007).

Der extrinsische und der intrinsische Signalweg sind über ein pro-apoptotisches BH3-Protein namens Bid verbunden (Abbildung 2.7). Dieses kann, von der Caspase-8 verkürzt und somit aktiviert, Bax und Bak direkt oder indirekt aktivieren und somit ausgehend vom extrinsischen den intrinsischen ApoptoseSignalweg stimulieren (Li et al., 1998; Luo et al., 1998).

\subsubsection{Mechanismus der Cytochrom $c$-Freisetzung}

Trotz intensiver Forschung ist der detaillierte Mechanismus, der zur Freisetzung von Cytochrom $c$ führt, weiterhin umstritten (Wang und Youle, 2009). Fest steht, dass kurz nach der Oligomerisierung von Bax und Bak an der äußeren mitochondrialen Membran Cytochrom $c$ freigesetzt wird (Abbildung 2.8) und, dass ohne das Vorhandensein von Bax und Bak Cytchrom $c$ im Mitochondrium verbleibt (Lindsten et al., 2000; Wei et al., 2001). Somit sind Bax und Bak notwendig für dessen Freisetzung. 


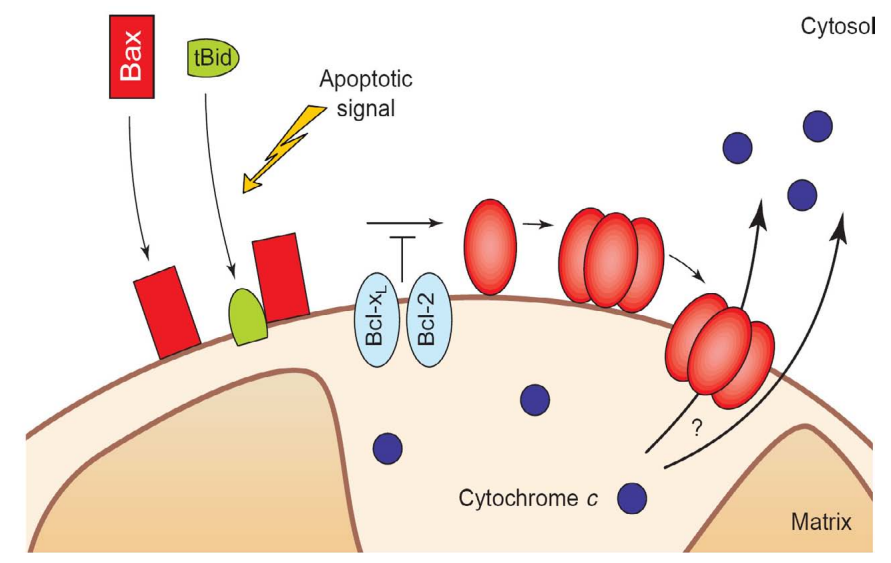

\section{Abbildung 2.8: Mechanismus der Cytochrom $c$-Freisetzung}

Die Aktivierung von Bax bewirkt eine Konformationsänderung, eine Translokation zum Mitochondrium und eine Oligomerisierung an der äußeren mitochondrialen Membran, ggf. stimuliert durch t-Bid. Kurz danach wird Cytochrom $c$ freigesetzt, möglicherweise durch Bax/Bak Poren. (aus Desagher et al, 2000)

Die meisten Modelle gehen davon aus, dass eine Pore gebildet wird, über die Proteine des Intermembranraums in das Cytosol gelangen. Dieser zentrale Prozess wird als mitochondrial outer membrane permeabilisation (MOMP) bezeichnet (Spierings et al., 2005; Chipuk et al., 2006). Möglicherweise wird diese Pore in der äußeren Membran ausschließlich durch Bax und/oder Bak gebildet, wobei die Größe, Anzahl und Struktur dieser Bax/Bak-Pore unklar ist (Youle und Strasser, 2008; Dewson und Kluck, 2009). In einem alternativen Modell wird davon ausgegangen, dass durch die Insertion von oligomerem Bax/Bak eine Krümmung in der äußeren mitochondrialen Membran erzeugt wird. Dies führt entweder zur Bildung einer aus Bax, Bak und Lipiden bestehenden Pore oder aber zum Aufreißen der äußeren mitochondrialen Membran und somit zur Cytochrom $c^{-}$ Freisetzung (Kuwana et al., 2002; Terrones et al., 2004; Lucken-Ardjomande et al., 2008; Zhou und Chang, 2008).

In einem anderen Modell wird davon ausgegangen, dass VDAC eine Pore bildet und so entweder durch deren Öffnung Cytochrom $c$ direkt freisetzt oder aber, dass durch den Verschluss der Pore ein osmotisches Ungleichgewicht herbeigeführt wird, welches zum Aufreißen der äußeren Membran führt und so letztendlich zur Cytochrom c-Freisetzung (Shimizu et al., 1999; Ow et al., 2008). In einem 


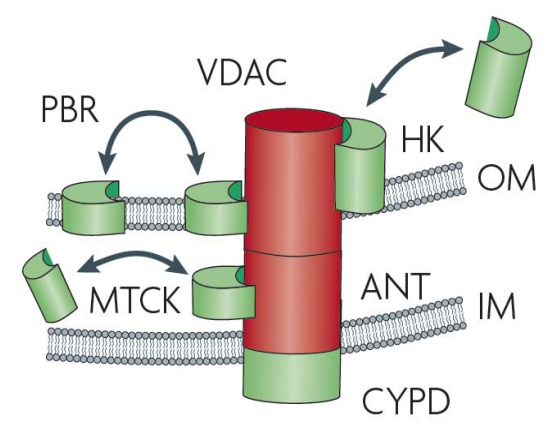

Abbildung 2.9: Komponenten der Permeability Transition Pore (PTP)

Die Permeability Transition Pore (PTP) stellt einen Multiproteinkomplex dar, bestehend aus VDAC (voltage dependent selective anion channel), PBR (Pheripherer Benzodiazipinrezeptor), HK (Hexokinase), der mitochondrialen Kreatinkinase (MTCK), der Adenin-NukleotidTranslokase (ANT) und Cyclophilin D (CYPD). Es wird postuliert, dass die PTP durch Öffnung während der Apoptose für den Einstrom von Wasser und Ionen in die Matrix verantwortlich ist. Durch das Anschwellen des Matrixraumes wird die äußere Membran zerstört und Cytochrom $c$ freigesetzt. (aus Galluzzi et al., 2009)

weiteren Modell wird ein über beide mitochondriale Membranen reichender, als permeability transition pore (PTP) bezeichneter, Multiproteinkomplex postuliert, durch dessen Öffnung das Schwellen der mitochondrialen Matrix verursacht wird (Abbildung 2.9). Als Konsequenz zerreißt die äußere Membran und die Intermembranproteine werden freigesetzt. Bestandteile dieser Pore sollen VDAC, Hexokinase, PBR (peripherer Benzodiazipinrezeptor), Kreatinkinase, ANT (Adenin-Nukleotid-Translokase) und Cyclophilin D sein (Desagher und Martinou, 2000; Kroemer et al., 2007; Galluzzi et al., 2009).

Sowohl die Zusammensetzung als auch die Funktion dieser PTP wird kontrovers diskutiert. Es konnte u.a. gezeigt werden, dass sich der Apoptoseverlauf in VDAC1/VDAC2/VDAC3 knockout-Mäusen nicht von dem in Wildtyp-Mäusen unterscheidet (Baines et al., 2007). Vergleichbares wurde für ANT nachgewiesen (Kokoszka et al., 2004). Cyclophilin D-defiziente Zellen sterben normal nach Apoptose-Behandlung, zeigen jedoch eine erhöhte Resistenz gegenüber der Auslösung des nekrotischen Zelltods (Baines et al., 2005; Nakagawa et al., 2005). Somit sind VDAC, ANT, Cylophilin D und andere Proteine möglicherweise zwar nicht essentiell für die Apoptose, eine regulatorische Funktion kann aber nicht 
ausgeschlossen werden (Galluzzi und Kroemer, 2007). Denkbar ist ebenfalls, dass in Abhängigkeit vom apoptotischen Signalweg unterschiedliche Poren gebildet werden (Gogvadze et al., 2006). Zudem wird vermutet, das die Öffnung der PTP möglicherweise nach der Cytochrom $c$-Freisetzung stattfindet und somit eine Konsequenz und nicht der Auslöser von MOMP ist (Ow et al., 2008; Wang und Youle, 2009).

Zusammengenommen steht zwar die zentrale Bedeutung von Bax und Bak für MOMP fest, der detaillierte Mechanismus der Cytochrom $c$-Freisetzung ist aber weiterhin umstritten. Da MOMP in den meisten Zellen der Punkt im apoptotischen Signalweg ist, von dem an es kein Zurück mehr gibt, ist das genaue Verständnis des molekularen Mechanismus von zentraler Bedeutung für die Apoptoseforschung (Kroemer et al., 1995; Perfettini et al., 2005; Jourdain und Martinou, 2009).

\subsubsection{Fragmentierung von Mitochondrien während der Apoptose}

Das mitochondriale Netzwerk zerfällt während der Apoptose um den Zeitpunkt herum, an dem Cytochrom $c$ freigesetzt wird (Dimmer und Scorrano, 2006; Suen et al., 2008). Dieser Zerfall führt zu vielen kleinen, fragmentierten Organellen. Es ist nicht klar, ob die Cytochrom $c$ Freisetzung vor oder nach der Fragmentierung stattfindet (Martinou und Youle, 2006). Genauso wenig steht fest, ob mitochondriale Teilungsprozesse aktiv zur MOMP beitragen oder ob die mitochondriale Fragmentierung nur ein Nebenprodukt von MOMP ist, möglicherweise hervorgerufen durch eine zweite, unabhängige Funktion der Bcl-2 Proteine bei der Aufrechterhaltung der mitochondrialen Morphologie (Frank et al., 2001; Perfettini et al., 2005; Youle und Karbowski, 2005; Cereghetti und Scorrano, 2006; Brooks et al., 2007; Sheridan et al., 2008; Autret und Martin, 2009).

In mehreren Publikationen wurde gezeigt, dass die Hemmung der an der Teilung der mitochondrialen Außenmembran beteiligten GTPase Drp1 (dynamin related 
protein 1) die mitochondriale Fragmentierung hemmt und zu einer Verzögerung der Cytochrom $c$ Freisetzung während der Apoptose führt (Frank et al., 2001; Parone et al., 2006; Estaquier und Arnoult, 2007; Cassidy-Stone et al., 2008). Dieser Effekt deutet auf eine aktive Rolle von Drp1 bei MOMP hin, wurde aber von einer anderen Studie in Frage gestellt (Sheridan et al., 2008). Möglicherweise hat die Fragmentierung an sich keinen Einfluss auf MOMP, wohl aber einzelne an der Teilungs-Maschinerie beteiligte Proteine wie Drp1, denen während der Apoptose eine zweite Rolle zukommt (James und Martinou, 2008; Ow et al., 2008).

\subsection{Problemstellung und Zielsetzung}

Obwohl Mitochondrien zu den am besten untersuchten Organellen gehören (Scheffler, 1999), ist bisher wenig über die Verteilung von Proteinen innerhalb von Mitochondrien bekannt.

Da der Durchmesser von Mitochondrien mit 200-400 nm im Bereich der Auflösungsgrenze konventioneller Lichtmikroskope liegen, scheidet diese Methode zur Untersuchung sub-mitochondrialer Proteinverteilungen aus.

Die Immunogold-Elekronenmikroskopie eignet sich mit ihrer hohen Auflösung zwar sehr gut, um sub-mitochondriale Lokalisationen von Proteinen in fixierten Zellen zu untersuchen, ist aber aufgrund ihrer geringen Markierungsdichte schlecht geeignet um Proteinverteilungen zu analysieren.

Die Entwicklung hochauflösender lichtmikroskopischer Techniken wie der STEDMikroskopie (Hell und Wichmann, 1994) eröffnet seit kurzem die Möglichkeit, Proteinverteilungen innerhalb von Mitochondrien zu untersuchen (Donnert et al., 2007; Schmidt et al., 2008; Schmidt et al., 2009).

Durch die qualitative und quantitative Analyse fluoreszenz-mikroskopischer Daten sollten zwei verschiedene Fragestellungen untersucht werden: 
(1) Der voltage-dependent anion-selective channel (VDAC) ist ein Kanalprotein der äußeren mitochondrialen Membran, der für den Transport von Metaboliten (z.B. ATP) verantwortlich ist. Für den Menschen sind drei verschiedene Isoformen beschrieben. Es ist wenig über die sub-mitochondriale Verteilung der verschiedenen hVDAC-Isoformen und deren Interaktion mit dem Protein Hexokinase bekannt.

Ein Ziel dieser Arbeit bestand darin, die sub-mitochondriale Verteilung der verschiedenen hVDAC Isoformen $\mathrm{zu}$ untersuchen und den Kolokalisationsgrad zwischen den hVDAC-Isoformen untereinander als auch mit der Hexokinase zu bestimmen, um so mögliche Unterschiede zwischen den verschiedenen Isoformen nachzuweisen.

(2) Apoptose, eine Form des programmierten Zelltods, ist ein zentraler Prozess für alle multizellulären Organismen (Spierings et al., 2005). Es ist zwar bekannt, dass ein entscheidender Vorgang während der Apoptose in der Freisetzung von Cytochrom $c$ aus den Mitochondrien besteht. Trotzdem ist bis jetzt umstritten, wie es zu dieser Freisetzung kommt. Zudem ist wenig über sub-mitochondriale Proteinverteilungen und deren Änderungen während der Apoptose bekannt.

Ein weiteres Ziel dieser Arbeit bestand darin, mitochondriale Proteinverteilungen in unbehandelten Zellen $\mathrm{zu}$ analysieren und diese mit denen in apoptotischen Zellen zu vergleichen. Durch den Einsatz quantitativer STED-Mikroskopie sollten mögliche Änderungen in Proteinverteilungen auf der Nanoskala nachgewiesen werden, die mittels konventioneller Lichtmikroskopie nicht aufgelöst werden können. 


\section{Materialien und Methoden}

\subsection{Chemikalien}

Soweit nicht anders angegeben, wurden sämtliche Chemikalien mit dem Reinheitsgrad "zur Analyse" von den Firmen Sigma-Aldrich (München), Roth (Karlsruhe), Merck (Darmstadt), Applichem (Darmstadt) und Serva (Heidelberg) bezogen.

Alle Puffer und Lösungen wurden mit Wasser aus der Reinstwasseraufbereitungsanlage ELGA (LabWater, Celle, Deutschland) angesetzt.

\subsection{Klonierungsmethoden}

\subsubsection{E. coli-Stamm und dessen Kultivierung}

Im Rahmen dieser Arbeit wurde der E. coli-Stamm DH5 $\alpha$ mit folgendem Genotyp verwendet: $\mathrm{F}^{\prime} \varphi 80$ lacZ $\Delta \mathrm{M} 15 \Delta\left(\right.$ lacZYA-argF)U169 deoR recA1 endA1 hsdR17 ( $\mathrm{rK}^{-}$

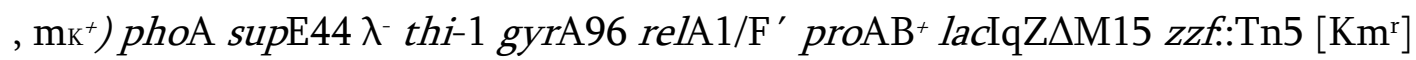

E. coli-Zellen wurden bei $37^{\circ} \mathrm{C}$ entweder in flüssigem LB-Medium $(0,5 \%(\mathrm{w} / \mathrm{v})$ Hefe-Extrakt; $1 \%$ (w/v) Pepton; 5 mM NaOH; 0,5 \% (w/v) NaCl) kultiviert oder auf LB-Platten aufgebracht. Hierzu wurde das LB-Medium mit 2 \% Agar versetzt. Zur Selektion von Plasmiden wurde das Antibiotikum Ampicillin (Sigma-Aldrich Chemie GmbH, München, Deutschland) in einer Endkonzentration von $50 \mu \mathrm{g} / \mathrm{ml}$ dem Kulturmedium zugesetzt.

\subsubsection{Agarose-Gelelektrophorese und Visualisierung von DNA-Fragmenten}

Die Gelelektrophorese ist eine Methode zur Auftrennung von doppelsträngigen Nukleinsäuren unterschiedlicher Länge. Sie beruht auf der Tatsache, dass DNA aufgrund der Phosphatgruppen gleichmäßig negativ geladen ist und daher in 
einem elektrischen Feld in Richtung der Anode wandert. Die Wanderungsgeschwindigkeit ist dabei umgekehrt proportional zur Größe des DNA-Moleküls. Zur Analyse von DNA-Fragmentgrößen wurden DNA-Proben mit Probenpuffer (Endkonzentration:1,7 mM Tris/HCl; 0,005 \% (w/v) Bromphenolblau; 0,005 \% (w/v) Xylencyanol; $10 \%$ (w/v) Glyzerin; 10 mM EDTA; pH 7,6) versetzt und im Anschluss in horizontalen TAE-Agarose-Gelen (1-1,2 \% (w/v) Agarose in $40 \mathrm{mM}$ Tris/Acetat; 1 mM EDTA; pH 7,2-7,5) ihrer Größe nach bei einer Spannung von $80 \mathrm{~V}$ aufgetrennt (Sambrook, 2001). Im Anschluss erfolgte ein 5 min Inkubation in einem Ethidiumbromid-Färbebad (3 mg EtBr/1 $\left.1 \mathrm{H}_{2} \mathrm{O}\right)$. Nach kurzer Entfärbung im Wasserbad wurden zur Sichtbarmachung der DNA-Fragmente die Agarose-Gele in einer Gel-Dokumentationsanlage (Intas, Göttingen, Deutschland) mit UV-Licht bestrahlt und dokumentiert. Als DNA-Standard wurde die $1 \mathrm{~kb}$ Leiter (Gene Ruler) von Fermentas verwendet.

\subsubsection{Polymerasekettenreaktion (PCR)}

Zur selektiven Vervielfältigung von DNA-Abschnitten bzw. zur Einführung von Mutationen wurde die Polymerase-Ketten-Reaktion eingesetzt (Mullis und Faloona, 1987). Dieses in vitro Verfahren ermöglicht die selektive Anreicherung von Nukleinsäureabschnitten definierter Sequenz aus einem Nukleinsäuregemisch.

Einen Überblick über die in dieser Arbeit verwendeten Oligonukleotide gibt die Tabelle 3.1. PCR-Ansätze und Programme hängen von der genauen Fragestellung $\mathrm{ab}$ und unterscheiden sich entsprechend. Die für Klonierungen in dieser Arbeit verwendeten Programme sind im Folgenden aufgeführt. Alle Amplifizierungen wurden in einem Tpersonal Thermocycler (Biometra, Göttingen, Deutschland) durchgeführt. 
VDAC-Klonierung

Programm: $1 \min 95^{\circ} \mathrm{C},\left[1 \min 95^{\circ} \mathrm{C}, 30 \sec 55^{\circ} \mathrm{C}, 4 \min 72{ }^{\circ} \mathrm{C}\right] \mathrm{x} 35,10 \min 72{ }^{\circ} \mathrm{C}, 4^{\circ} \mathrm{C}$

Ansatz (50 $\mu \mathrm{l}): 0,1 \mu \mathrm{g}$ DNA, 0,3 $\mu \mathrm{M}$ von jedem Oligonukleotid, 0,2 mM dNTPs, 2,5 Einheiten PfuPolymerase (Fermentas, St. Leon-Rot, Deutschland) in $10 \mathrm{mM}$ Tris/HCl; $50 \mathrm{mM} \mathrm{KCl;} \mathrm{2,5} \mathrm{mM}$ $\mathrm{MgCl}_{2} ; \mathrm{pH} 8,3$

VDAC-Punktmutationen

Programm: $30 \sec 95^{\circ} \mathrm{C},\left[1 \min 95^{\circ} \mathrm{C}, 1 \min 55^{\circ} \mathrm{C}, 11 \min 68^{\circ} \mathrm{C}\right] \mathrm{x} 16,10 \min 68^{\circ} \mathrm{C}, 4{ }^{\circ} \mathrm{C}$

Ansatz $(50 \mu \mathrm{l}): 0,1 \mu \mathrm{g}$ DNA, 0,2 $\mu \mathrm{M}$ von jedem Oligonukleotid, 0,2 mM dNTPs, 2,5 Einheiten PfuPolymerase (Fermentas, St. Leon-Rot, Deutschland) in $10 \mathrm{mM}$ Tris/HCl; $50 \mathrm{mM} \mathrm{KCl;} \mathrm{2,5} \mathrm{mM}$ $\mathrm{MgCl}_{2} ; \mathrm{pH} 8,3$

\subsubsection{Restriktion}

Zum Schneiden von DNA (Meselson et al., 1972) wurden in dieser Arbeit verschiedene Restriktionsendonukleasen des Typs II eingesetzt. Diese schneiden DNA ausschließlich innerhalb oder in der Nähe einer kurzen palindromischen Nukleotidsequenz, wobei entweder glatte oder überhängende Enden entstehen können.

Um nach einer PCR sicherzustellen, dass weitere Schritte ausschließlich mit der amplifizierten DNA stattfinden und nicht mit der (methylierten) Matrizen-DNA, wurde ein Verdau mit DpnI (NEB) durchgeführt. Dieses Enzym schneidet ausschließlich methylierte DNA. Hierzu wurde ein $50 \mu \mathrm{l}$ PCR-Ansatz mit 10 Einheiten $D p n I$ versetzt und über Nacht bei $37^{\circ} \mathrm{C}$ inkubiert.

Um ein DNA-Fragment in einem Plasmid zu integrieren, ist eine Restriktion beider DNA-Moleküle mit denselben Enzymen (oder Isoschitzomeren) Voraussetzung. Hierzu wurden im Rahmen dieser Arbeit die Restriktionsendonukleasen BamHI und KpnI (NEB, Ipswich, MA, USA) verwendet. Für einen $20 \mu$ l Reaktionsansatz wurden 2 Einheiten von jedem Enzym und $1 \mu \mathrm{g}$ DNA in Reaktionspuffer $(10 \mathrm{mM} \mathrm{NaCl}, 5 \mathrm{mM}$ Tris/HCl, $1 \mathrm{mM}$ 
$\mathrm{MgCl}_{2}$, 0,1 mM Dithiothreitol (DTT), $\mathrm{pH}$ 7,9, NEB-Puffer 3 von NEB) für $2 \mathrm{~h}$

(Plasmid) bzw. über Nacht (PCR-Produkt) bei $37^{\circ} \mathrm{C}$ inkubiert.

Um die geschnittene DNA von den Restriktionsenzymen zu trennen, wurde eine Reinigung mit dem Qiagen PCR-Purification Kit (Qiagen, Hilden, Deutschland) nach Angaben des Herstellers durchgeführt.

\section{Tabelle 3.1: verwendete Oligonukleotide}

$\mathrm{F}$ : forward $\mathrm{R}$ : reverse

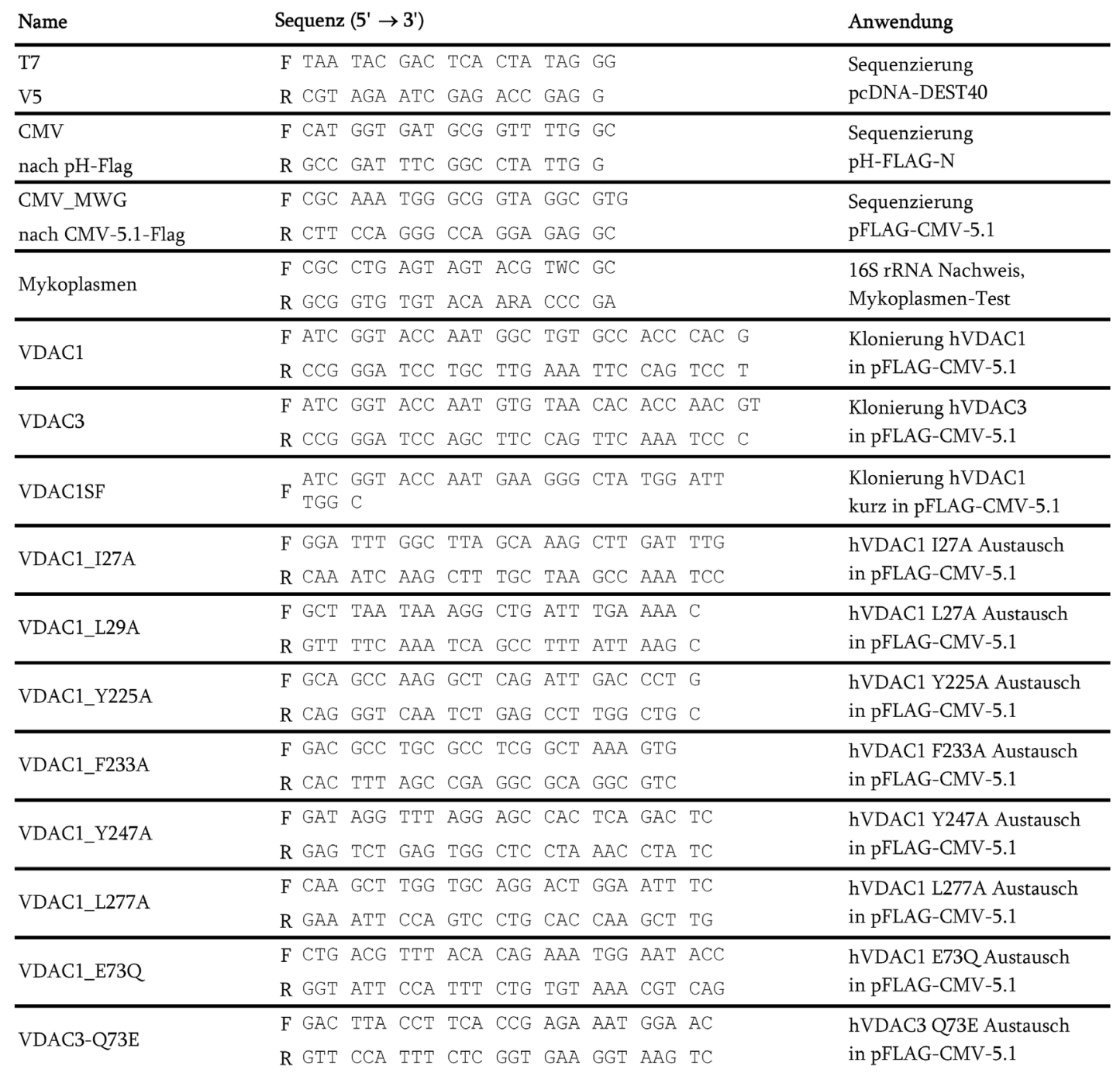




\subsubsection{Ligation}

Die Verknüpfung von linearisierten DNA-Fragmenten wurde mit der T4-DNA Ligase durchgeführt (Lehman, 1974). Hierzu wurden 0,1 $\mu \mathrm{g}$ Plasmid-DNA, $1 \mu \mathrm{g}$ des $\mathrm{zu}$ intregrierenden DNA-Fragments, 2,5 Einheiten T4-DNA Ligase (Fermentas) in 6,6 mM Tris/HCl, 0,5 mM MgCl2, 0,1 mM ATP, 0,5 mM DTT und 0,25\% (w/v) PEG 8000 bei pH 7,5 in einem Gesamtvolumen von $20 \mu \mathrm{l}$ für $1 \mathrm{~h}$ bei RT inkubiert. Im Anschluss wurde eine Enzymdeaktivierung durch eine 10 minütige Inkubation bei $65^{\circ} \mathrm{C}$ durchgeführt.

\subsubsection{Herstellung elektrokompetenter $E$. coli-Zellen}

Zur Herstellung von elektrokompetenten E. coli-Zellen wurden $500 \mathrm{ml}$ LB-Medium mit $5 \mathrm{ml}$ einer DH5 $\alpha$ Übernachtkultur (ÜK) versetzt und bis zu einer OD 600 von $0,6-1$ bei $37^{\circ} \mathrm{C}$ schüttelnd inkubiert. Nach einer 30 minütige Inkubation auf Eis wurden die Zellen bei 4000 x g (Sorvall RC-5B, DuPont Instruments, Wilmington, DE, USA) für $15 \mathrm{~min}$ und $4{ }^{\circ} \mathrm{C}$ zentrifugiert. Das Pellet wurde nacheinander mit $500 \mathrm{ml} \mathrm{H} \mathrm{H}_{2} \mathrm{O}$ (eiskalt), $250 \mathrm{ml} \mathrm{H} \mathrm{H}_{2} \mathrm{O}$ (eiskalt) und $10 \mathrm{ml} 10 \%$ (w/v) Glyzerin (eiskalt) gewaschen, dann in $1 \mathrm{ml} 10 \%(\mathrm{w} / \mathrm{v})$ Glyzerin (eiskalt) resuspendiert und anschließend in Aliquots von je $40 \mu \mathrm{l}$ in flüssigem Stickstoff schockgefroren. Die Lagerung erfolgte bei $-80{ }^{\circ} \mathrm{C}$.

\subsubsection{Transformation}

Zur Transformation von DNA wurden $40 \mu \mathrm{l}$ elektrokompetente $E$. coli-Zellen auf Eis aufgetaut, mit der zu transformierenden DNA vermischt (3 $\mu$ l Ligationsansatz bzw. 20 ng Plasmid-DNA) und in eine vorgekühlte Elektroporationsküvette überführt. Die Transformation erfolgte durch Elektroporation bei 2,5 kV, $25 \mu \mathrm{F}$ und $200 \Omega$ (GenePulser, BioRad). Sofort nach der Transformation wurden die Zellen mit $1 \mathrm{ml}$ LB-Medium versetzt und für $1 \mathrm{~h}$ bei $37^{\circ} \mathrm{C}$ schüttelnd inkubiert. 
Verschiedene Verdünnungen wurden auf LB-Platten mit dem Antibiotikum Ampicilin aufgetragen und über Nacht bei $37^{\circ} \mathrm{C}$ inkubiert.

\subsubsection{Plasmidpräparation}

Die Isolation von Plasmid-DNA zu analytischen Zwecken wurde nach folgendem Protokoll durchgeführt: $5 \mathrm{ml}$ einer ÜK wurden bei 1000 x g für 20 min pelletiert, in 0,3 ml P1-Puffer (Qiagen, 50 mM Tris/HCl; 10 mM EDTA; $100 \mu \mathrm{g} / \mathrm{ml}$ RNase A; $\mathrm{pH}$ 8.0) resuspendiert, für $5 \mathrm{~min}$ mit 0,3 ml P2-Puffer (Qiagen, $200 \mathrm{mM} \mathrm{NaOH}$; $1 \%(w / v)$ SDS) inkubiert und nach Zugabe von 0,3 ml P3-Puffer (Qiagen, $3 \mathrm{M}$ Kalium-Acetat; $\mathrm{pH}$ 5,5) für $15 \mathrm{~min}$ bei $15700 \mathrm{x}$ g zentrifugiert. Nach Wiederholung dieses Zentrifugationsschrittes wurde der Überstand abgenommen und die DNA durch Zugabe von 0,5 Volumen Isopropanol für 5 min bei RT gefällt. Nach 30 min Zentrifugation bei 15700 x g und $4{ }^{\circ} \mathrm{C}$ wurde das Pellet $2 \times$ mit $70 \%$ (v/v) Ethanol gewaschen (5 min, $15700 \mathrm{~g}$ ), getrocknet und in $100 \mu \mathrm{l} \mathrm{H}_{2} \mathrm{O}$ resuspendiert.

Die Isolation von Plasmid-DNA zu präparativen Zwecken wurde mit dem QIAGEN Plasmid Midi Kit (Qiagen, Hilden) nach Angaben des Herstellers durchgeführt.

\subsubsection{DNA-Konzentrationsbestimmung}

Zur Bestimmung der DNA-Konzentration in einer Probe wurde ein BioPhotometer (Eppendorf, Hamburg) verwendet. Die Proben wurden mit $\mathrm{H}_{2} \mathrm{O}$ verdünnt und die Absorption bei $260 \mathrm{~nm}$ bestimmt. Aufgrund des linearen Zusammenhangs zwischen Absorption und Konzentration doppelsträngiger Nukleinsäuren (1 Absorptions-Einheit entspricht $50 \mu \mathrm{g} / \mathrm{ml}$ Nukleinsäure), konnte direkt auf die Nukleinsäure-Menge in einer Probe geschlossen werden. Die Qualität der Nukleinsäure-Probe wurde über den Quotienten der Absorption bei 
260 und $280 \mathrm{~nm}$ bestimmt, wobei ein Wert von 1,8 einer hohen Reinheit entspricht.

\subsubsection{Verwendete Plasmide}

Eine Übersicht über die in dieser Arbeit verwendeten und erstellten Plasmide gibt die Tabelle 3.2.

\subsubsection{Sequenzierung}

Zur Verifikation der erzeugten Plasmide wurden Sequenzierungen mit spezifischen Oligonukleotiden durchgeführt (Tabelle 3.1). Alle Sequenzierungen wurden von der Firma MWG Biotech (Ebersberg, Deutschland) ausgeführt.

\subsubsection{Gateway-Klonierung}

Neben der konventionellen Klonierung wurde ein Teil der in dieser Arbeit verwendeten Konstrukte über eine Gateway-Klonierung erzeugt.

Die Gateway-Klonierungen basieren auf den Rekombinationsenzymen des Bakteriophagen Lambda (Landy, 1989). Die beiden wesentlichen Komponenten des Klonierungssystems sind die DNA-Rekombinations-Sequenzen (att sites) und die Enzyme (BP-Clonase, LR-Clonase), die die Rekombination katalysieren. Restriktions- und Ligationsschritte werden dadurch überflüssig.

Für die Gateway-Klonierung konnte auf eine Genbank (Lamesch et al., 2007), bestehend aus über 12000 verschiedenen humanen Genen, zurückgegriffen werden.

Expressionsklone (expression clone) wurden durch die Rekombination eines Ausgangsklons (entry-clone) mit einem Zielvektor (destination vector), welcher z.B. die Sequenzen für einen FLAG- oder V5-Tag trug, erzeugt. Die einzelnen Gateway-Reaktionen wurden nach Angaben des Herstellers durchgeführt. 


\section{Tabelle 3.2: Verwendete Plasmide}

\begin{tabular}{|c|c|c|c|c|}
\hline Insert & Plasmid-Stamm & Selektion & Quelle & Tag \\
\hline 16S rDNA & pGEM & Amp & Upphoff et al. (2002) & - \\
\hline shRNA Drp1 & pREP4 & Amp, Hyg & Lee et al. (2004) & - \\
\hline- & pcDNA-DEST40 & Amp, Neo & Invitrogen & V5 \\
\hline- & pFLAG-CMV-5.1 & Amp & Invitrogen & Flag \\
\hline- & pH-FLAG-N & Amp, Neo & Christian Wurm & Flag \\
\hline hVDAC1 & pDONR223 & Spec & $\begin{array}{l}\text { HumanORFeome } \\
\text { Clone collection }\end{array}$ & - \\
\hline hVDAC2 & pDONR223 & Spec & $\begin{array}{l}\text { HumanORFeome } \\
\text { Clone collection }\end{array}$ & - \\
\hline hVDAC3 & pDONR223 & Spec & $\begin{array}{l}\text { HumanORFeome } \\
\text { Clonc collection }\end{array}$ & - \\
\hline hVDAC1 & pcDNA-DEST40 & Amp, Neo & diese Arbeit & V5 \\
\hline hVDAC2 & pcDNA-DEST40 & Amp, Nco & diesc Arbcit & V5 \\
\hline hVDAC3 & pcDNA-DEST40 & Amp, Neo & diese Arbeit & v5 \\
\hline hVDAC2 & pH-FLAG-N & Amp, Neo & diese Arbeit & Flag \\
\hline hVDAC1 & pFLAG-CMV-5.1 & Amp & diese Arbeit & Flag \\
\hline hVDAC3 & pFLAG-CMV-5.1 & Amp & diese Arbeit & Flag \\
\hline $\begin{array}{l}\text { hVDAC1, } \\
\text { DN-Terminus }\end{array}$ & pFLAG-CMV-5.1 & Amp & diese Arbeit & Flag \\
\hline hVDAC1, I27A & pFLAG-CMV-5.1 & Amp & diese Arbeit & Flag \\
\hline hVDAC1, L29A & pFLAG-CMV-5.1 & Amp & diese Arbeit & Flag \\
\hline hVDAC1, Y225A & pFLAG-CMV-5.1 & Amp & diese Arbeit & Flag \\
\hline hVDAC1, Y247A & pГLAG-CMV-5.1 & Amp & diese Arbeit & Flag \\
\hline hVDAC1, L277A & pFLAG-CMV-5.1 & Amp & diese Arbeit & Flag \\
\hline hVDAC1, F233A & pFLAG-CMV-5.1 & Amp & diese Arbeit & Flag \\
\hline hVDAC1, E73Q & pFLAG-CMV-5.1 & Amp & diese Arbeit & Flag \\
\hline hVDAC3, Q73E & pFLAG-CMV-5.1 & Amp & diese Arbeit & Flag \\
\hline
\end{tabular}




\subsection{Methoden zur Arbeit mit Säuger-Zellen}

\subsubsection{Zelllinien}

Einen Überblick über die in dieser Arbeit verwendeten Säugerzelllinien gibt die Tabelle 3.3. Es handelt sich hierbei ausschließlich um adhärent wachsende Zelllinien (Bratthauer, 1999). Besonders hervorzuheben ist die U2OS Zelllinie, da diese hauptsächlich in der Arbeit verwendet worden ist. Diese Zelllinie stammt aus dem Sarkom des Schienbeinknochens (Tibia) eines 15 Jahre alten Mädchens.

\section{Tabelle 3.3: Übersicht über die verwendeten Säugerzellen}

${ }^{1}$ Deutsche Sammlung von Mikroorganismen und Zellkulturen (Braunschweig, Deutschland), ${ }^{2}$ American Type Culture Collection (Manassas, USA), ${ }^{3}$ European Collection of Cell Cultures (Salisbury, UK)

\begin{tabular}{|c|c|c|c|}
\hline Name & Organismus & Gewebe & Quelle \\
\hline A172 & Mensch (IIomo sapiens) & Glioblastom & F. Eßmann, Uni. Düsseldorf \\
\hline BLM & Mensch (Homo sapiens) & Melanom & F. Eßmann, Uni. Düsseldorf \\
\hline HCT116 & Mensch (Homo sapiens) & Darmkarzinom & F. Eßmann, Uni. Düsseldorf \\
\hline HEK293 & Mensch (Homo sapiens) & embryonale Niere & F. Eßmann, Uni. Düsseldorf \\
\hline $\mathrm{HeLa}$ & Mensch (Homo sapiens) & Gebärmutterhalskrebs & $\mathrm{DSMZ}^{1}, \mathrm{ACC} 57$ \\
\hline HT1080 & Mensch (Homo sapiens) & Bindegewebssarkom & F. Ełṡmann, Uni. Düsseldorf \\
\hline LN18 & Mensch (Homo sapiens) & Glioblastom & F. Eßmann, Uni. Düsseldorf \\
\hline MCF-7 & Mensch (Homo sapiens) & Brustadenokarzinom & F. Eßmann, Uni. Düsseldorf \\
\hline $\operatorname{RCC}(\mathrm{A}, \mathrm{B}, \mathrm{D}, \mathrm{MF})$ & Mensch (Homo sapiens) & Nierenkarzinom & F. Eßmann, Uni. Düsseldorf \\
\hline RKO & Mensch (Homo sapiens) & Darmkarzinom & F. Eßmann, Uni. Düsseldorf \\
\hline SHEP & Mensch (Homo sapiens) & Neuroblastom & F. Eßmann, Uni. Düsseldorf \\
\hline SH-SY5Y & Mensch (Homo sapiens) & Neuroblastom & F. Eßßmann, Uni. Düsseldorf \\
\hline U2OS & Mensch (Homo sapicns) & Knockensarkom & $\mathrm{ECACC}^{3}, 92022711$ \\
\hline $\mathrm{MEF}$ & Maus (Mus musculus) & embryonales Bindegewebe & F. Eßmann, Uni. Düsseldorf \\
\hline PtK2 & Beutelratte (Potorous tridactylus) & Niere & ATCC $^{2}$, CCL-56 \\
\hline Vero & grüne Meerkatze (Cercopithecus aethiops) & Niere & $\mathrm{ATCC}^{2}, \mathrm{CCL}-81$ \\
\hline
\end{tabular}

\subsubsection{Kultivierung}

HeLa-, Vero-, Ptk2- und U2OS-Zellen wurden in DMEM (Dulbecco's Modified Eagle Medium) mit Glutamax und 4,5 \% (w/v) Glukose (Invitrogen, Carlsbad, USA) kultiviert, welches mit $10 \%$ (v/v) fötalem Rinderserum (FBS, Invitrogen), $1 \mathrm{mM}$ Natrium-Pyruvat (Sigma-Aldrich, München, Deutschland), 50 Einheiten Penicillin/ml und $50 \mu \mathrm{g} / \mathrm{ml}$ Streptomycin (BIOCHROM KG, Berlin, Deutschland) 
supplementiert wurde. Die Zellen wurden in Petrischalen $(10 \mathrm{~cm}$, Sarstedt, Nümbrecht, Deutschland) bei $7 \% \mathrm{CO}_{2}$, einer Temperatur von $37{ }^{\circ} \mathrm{C}$ und bei wassergesättigter Atmosphäre in einem Zellkulturinkubator (Heracell 240, Heraeus, Hanau, Deutschland) kultiviert.

Die Zellen wurden 2-3 mal die Woche passagiert. Hierzu wurde das alte Medium entfernt, die Zellen wurden mit PBS (phosphate buffered saline, $137 \mathrm{mM} \mathrm{NaCl}$, $3 \mathrm{mM} \mathrm{KCl}, 8 \mathrm{mM} \mathrm{Na2HPO} 4$ und 1,5 mM KH2PO4, $\mathrm{pH} \mathrm{7,5)} \mathrm{gewaschen,} \mathrm{für}$ 3-5 min mit 0,05 \% (w/v) Trypsin und 0,02 \% (w/v) EDTA in PBS (BIOCHROM KG) bei $37{ }^{\circ} \mathrm{C}$ inkubiert und anschließend nach 1-2 $\mathrm{ml}$ Mediumzugabe in der gewünschten Verdünnung in eine neue Petrischale mit oder ohne Deckgläschen ausgesät.

Alle anderen Zelllinien sind von Dr. Frank Eßmann (Institut für molekulare Medizin, Universität Düsseldorf) kultiviert worden und auf Deckgläschen ausgesät, zur Fixierung zu Verfügung gestellt worden.

\subsubsection{Dauerkulturen}

Zur Herstellung von Dauerkulturen wurden die Zellen wie unter Abschnitt 3.3.2 beschrieben trypsiniert und für 5 min bei 100 x g zentrifugiert. Das entstandene Pellet wurde pro konfluente Petrischale mit 6 ml Einfriermedium (50 \% (v/v) Zellkulturmedium, $10 \%$ (v/v) Dimetylsulfoxid (DMSO), $40 \%$ (v/v) FBS) resuspendiert und in 1,8 $\mathrm{ml}$ Kryoröhrchen (Nunc, Wiesbaden, Deutschland) überführt. Anschließend wurden die Zellen mit Hilfe eines mit Isopropanol gefüllten Gefäßes bei einer Einfrier-Rate von $-1^{\circ} \mathrm{C} / \mathrm{min}$ eingefroren. Die Lagerung der Zellen erfolgte in flüssigem Stickstoff.

\subsubsection{Mykoplasmentest}

Mykoplasmen sind extrem kleine, spezialisierte Bakterien, die keine Zellwand besitzen und deren Vorkommen eng mit dem anderer Lebewesen verknüpft ist. 
Sie leben kommensalisch oder parasitisch in Tieren und Pflanzen (Lang, 1985). Diese Eigenschaften machen sie zu einer nicht zu unterschätzenden Gefahr für die Kultivierung von Säuger-Zellen. Um Mykoplasmen-Kontaminationen frühzeitig zu erkennen, wurden in regelmäßigen Abständen zwei verschiedene Tests durchgeführt:

Zum einen wurde durch eine DAPI-Färbung (4',6-Diamidino-2-phenyindole) die komplette DNA einer Zellkultur sichtbar gemacht und mikroskopisch analysiert.

Zum anderen wurde ein PCR basierter Mykoplasmentest durchgeführt. Hierbei wurden Oligonukleotide verwendet, die die prokaryotische $16 \mathrm{~S}$ rDNA als Zielsequenz erkennen. Vor der eigentlichen PCR musste zunächst die DNA aus der Zellkultur isoliert werden. Hierfür wurden $10 \mathrm{ml}$ des Überstandes einer Zellkultur für 5 min bei 15700 x g zentrifugiert, das Pellet zweimal mit PBS gewaschen (jeweils 5 min, 15700 x g), um im Anschluss das Pellet in $200 \mu \mathrm{l}$ PBS zu resuspendieren und für $15 \mathrm{~min}$ bei $95^{\circ} \mathrm{C} \mathrm{zu}$ inkubieren. Die eigentliche DNAIsolierung wurde dann mit dem Genomic DNA Purification Kit (Fermentas, St. Leon-Rot, Deutschland) nach Angaben des Herstellers durchgeführt.

Eine PCR (Abschnitt 3.2.3, Details siehe unten), gefolgt von einer analytischen Agarose-Gelelektrophorese und Visualisierung der DNA (Abschnitt 3.2.2), gab Auskunft über mögliche Kontaminationen. Es wurden drei Kontrollen zur Verifizierung des Ergebnisses durchgeführt: Eine Negativkontrolle, in der anstelle der DNA Wasser verwendet wurde, eine Positivkontrolle (500 bp Fragment) mit Mykoplasmen DNA und eine interne Kontrolle (1000 bp Fragment), in der ein Plasmid (pMycoIntCont) verwendet wurde, welches ein 16S rDNA PCR-Produkt von Acholeplasma laidlawii liefert.

PCR-Mykoplasmen-Nachweis

Programm: $5 \min 95^{\circ} \mathrm{C},\left[45 \sec 95^{\circ} \mathrm{C}, 45 \sec 55^{\circ} \mathrm{C}, 1 \min 72^{\circ} \mathrm{C}\right] \mathrm{x} 35,5 \min 72^{\circ} \mathrm{C}, 4^{\circ} \mathrm{C}$

Ansatz $(25 \mu \mathrm{l}): 4 \mu \mathrm{l}$ DNA, 0,2 mM dNTPs (Promega, Madison, USA), 0,2 $\mu \mathrm{M}$ von jedem Oligonukleotid (Mycopl1-5’, Mycopl5-3’), farbloser GoTaq Reaktionspuffer und 1 Einheit GoTaq DNA-Polymerase (Promega). 


\subsubsection{Transfektion und Selektion}

Zur Transfektion von U2OS-Zellen wurde das Optifect-Reagenz (Invitrogen) nach Angaben des Herstellers verwendet. Dieses Reagenz basiert auf dem Prinzip der Lipofektion. Hierbei bilden kationische Lipide Komplexe mit der negativ geladenen DNA. Diese Komplexe werden dann vermutlich durch Endozytose von den Zellen aufgenommen (Chalberg, 2005; Gopalakrishnan und Wolf, 2009). Transfektionen wurden typischerweise in 6 well Platten (Nunc) durchgeführt, wobei pro well $2 \mathrm{ml}$ Zellkulturmedium ohne Antibiotika verwendet worden sind. Pro well wurden $4 \mu \mathrm{g}$ DNA und $18 \mu \mathrm{l}$ Optifect jeweils in $250 \mu \mathrm{l}$ Opti-MEM reduced Serum Medium (Invitrogen) für 5 min inkubiert. Nach Mischung der beiden Ansätze und einer $20 \mathrm{~min}$ Inkubationsphase wurde das DNATransfektionsgemisch tropfenweise zu den auf Deckgläschen befindlichen Zellen eines 6 wells pipettiert und für $5 \mathrm{~h}$ inkubiert, bevor das Zellkulturmedium gewechselt wurde (Inkubation weiterhin ohne Antibiotika).

VDAC Proteine exprimierende Zellen wurden $24 \mathrm{~h}$ nach Transfektion analysiert. Im Gegensatz dazu wurde zur Herunterregulierung von Drp1 (pREP4 Plasmid) eine Selektion mit Hygromycin B (Roche, Mannheim, Deutschland) durchgeführt. $24 \mathrm{~h}$ nach Transfektion wurde für 2 Tage mit $200 \mu \mathrm{g} / \mathrm{ml}$ Hygromycin B und im Anschluss mit $50 \mu \mathrm{g} / \mathrm{ml}$ für 6 Tage selektiert.

\subsubsection{Apoptoseinduktion}

Es ist eine Vielzahl von Chemikalien beschrieben, die auf unterschiedliche Weise Apoptose auslösen können. Je nach Chemikalie werden z.B. Proteine der Transkriptions-, Translations- oder Replikationsmaschinerie, bestimmte carrier oder aber Proteinkinasen inhibiert. Eine Übersicht über die in dieser Arbeit verwendeten Apoptosestimulanzien gibt Tabelle 3.4. Hervorzuheben ist Actinomycin D, welches hauptsächlich in dieser Arbeit verwendet worden ist. Die Wirkungsweise von Actinomycin D besteht darin, dass es Komplexe mit GuaninNukleotiden der DNA bildet und dadurch die DNA-abhängige RNA-Polymerase 
Tabelle 3.4: Verwendete Apoptoseinduktoren

\begin{tabular}{|c|c|c|c|c|}
\hline Stimulanz & Wirkung & $\begin{array}{l}\text { Endkonzen- } \\
\text { tration }\end{array}$ & gelöst in & Quelle \\
\hline Actinomycin D & Transkriptionsinhibitor & $10 \mu \mathrm{M}$ & DMSO & Calbiochem \\
\hline Betulinsäure & Topoisomerase-I Inhibitor & $11 \mu \mathrm{M}$ & DMSO & Sigma-Aldrich \\
\hline Camptothecin & Topoisomerase-I Inhibitor & $10 \mu \mathrm{M}$ & DMSO & Sigma-Aldrich \\
\hline $\begin{array}{l}\text { Cycloheximid + } \\
\text { TRAIL }\end{array}$ & $\begin{array}{l}\text { Translationsinhibitor/ } \\
\text { Rezeptor vermittelte } \\
\text { Apoptose }\end{array}$ & $\begin{array}{l}1 \mathrm{ng} / \mu \mathrm{l} \\
0,1 \mathrm{ng} / \mu \mathrm{l}\end{array}$ & $\begin{array}{l}\text { DMSO/ } \\
20 \mathrm{mM} \text { HEPES (pH 7,4), } 300 \mathrm{mM} \\
\mathrm{NaCl}, 1 \%(\mathrm{w} / \mathrm{v}) \text { Sucrose, } \\
0,01 \%(\mathrm{v} / \mathrm{v}) \text { Tween 20, } 1 \mathrm{mM} \text { DTT }\end{array}$ & $\begin{array}{l}\text { Sigma-Aldrich/ } \\
\text { Alexis Biochemicals }\end{array}$ \\
\hline Ionomycin & Ca2+ Carrier Inhibitor & $10 \mu \mathrm{M}$ & DMSO & Sigma-Aldrich \\
\hline Mitomycin C & $\begin{array}{l}\text { Transkriptions- und } \\
\text { Replikationsinhibitor }\end{array}$ & $75 \mu \mathrm{M}$ & $\begin{array}{l}20 \%(\mathrm{v} / \mathrm{v}) \mathrm{MeOH}, \\
80 \%(\mathrm{v} / \mathrm{v}) \mathrm{H}_{2} \mathrm{O}\end{array}$ & Sigma-Aldrich \\
\hline Staurosporin & Protein-Kinase-Inhibitor & $1 \mu \mathrm{M}$ & DMSO & Sigma-Aldrich \\
\hline
\end{tabular}

blockiert (Meienhofer und Atherton, 1973; Yung et al., 1992; Kawanishi und Hiraku, 2004). Dies resultiert in Einzel- oder Doppelstrangbrüchen (Ross und Bradley, 1981), es kommt zur Aktivierung des DNA-Schaden-Signalwegs und letztendlich zur Induktion des intrinsischen Apoptosesignalweges (Rich et al., 2000; Ferri und Kroemer, 2001; Zhou und Bartek, 2004).

In allen Fällen wurden die Apotosestimulanzien dem Zellkulturmedium hinzugefügt und die Zellen für 12-16 h damit inkubiert. Diese wurden zuvor in einem Lösungsmittel, vorwiegend DMSO, gelöst. Die Lösungsmittelmenge wurde zur Vermeidung von toxischen Effekten so gewählt, dass Endkonzentration des Lösungsmittels im Medium maximal $1 \%$ betrug.

\subsubsection{Antikörper}

Antikörper finden aufgrund ihrer hohen Spezifität und Robustheit bei einer Vielzahl verschiedener Methoden zum Nachweis biologisch relevanter Makromoleküle Anwendung. Die IgG's sind die am Häufigsten in der Molekularbiolgoie verwendete Antikörperklasse. Sie weisen ein Molekulargewicht von $\sim 150 \mathrm{kDa}$ auf und da sie bei einer indirekten Immunofluoreszenz-Markierung 
zu einer Strukturvergrößerung um $\sim 36 \mathrm{~nm}$ führen, kann eine Antikörperlänge von $\sim 9$ nm abgeschätzt werden (Weber et al., 1978; Dyba et al., 2003). Im Rahmen dieser Arbeit wurden Antikörper für Immunofluoreszenz-Markierungen an Säuger-Zellen verwendet. Einen Überblick über die verwendeten Antikörper gibt Tabelle 3.5.

\subsubsection{Fluorophor-Antikörper-Kopplung}

Neben kommerziell erhältlichen Fluorophor-gekoppelten Sekundärantikörpern wurden für spezielle Fluorophore (z.B. Atto647N) in dieser Arbeit eine Kopplung an Antikörper durchgeführt. Eine Übersicht über die einzelnen Absorptions- und Emissionsspektren der in dieser Arbeit verwendeten Fluorophore ist der Abbildung $8.5 \mathrm{zu}$ entnehmen.

Zur Kopplung von Fluorophoren an Antikörper wurden N-hydroxy-succinimidylEster (NHS-Ester) der zu koppelnden Fluorophore mit den freien primären Aminogruppen von Antikörpern zur Reaktion gebracht (LaRochelle et al. 1986).

Hierfür wurden 0,2 mg eines Atto Fluorophors (Atto532, Atto590, Atto647N, ATTOTEC, Siegen, Deutschland) oder des KK114 Fluorophors (freundlicherweise zur Verfügung gestellt von Dr. K. Kolmakov und Dr. V. Belov, Max-PlanckInstitut für biophysikalische Chemie, Göttingen) in $20 \mu$ l Dimethylformamid (DMF) gelöst. Parallel dazu wurde $1 \mathrm{mg}$ des BSA-freien Antikörpers (gegen Kanninchen (aus Ziege, 111-005-003), gegen Maus (aus Schaf, 515-005-003) oder gegen Ziege (aus Esel, 705-005-003), Jackson Immuno Research, West Grove, USA) mit 1/10 Volumen $1 \mathrm{M} \mathrm{NaHCO}(\mathrm{pH} 8,3-9,0)$ versetzt. Unter ständigem Rühren wurde langsam der gelöste Fluorophor zum Antikörper gegeben und im Anschluss für $1 \mathrm{~h}$ unter Rühren bei RT inkubiert. Durch Zugabe von $20 \mu \mathrm{l} 1 \mathrm{M}$ Tris/HCl ( $\mathrm{pH}$ 8) wurde die Reaktion abgestoppt. Nach einstündiger Inkubation wurde das Gemisch auf eine mit $30 \mathrm{ml}$ PBS äquilibrierte Sephadex G-25-Säule (PD-10, GE Healthcare, Freiburg, Deutschland) gegeben. Nachdem das 


\section{Tabelle 3.5: Verwendete Antikörper}

\begin{tabular}{|c|c|c|c|c|}
\hline Antikörper gegen & aus & Fluorophor & Verdünnung & Quelle \\
\hline $\begin{array}{l}\text { ATP-Synthase } \\
\text { Untereinheit } B\end{array}$ & Maus & - & $1: 100$ & $\begin{array}{l}\text { Abcam } \\
\text { (ab5432) }\end{array}$ \\
\hline Bax & Maus & - & $1: 100$ & $\begin{array}{l}\text { Trevigen } \\
(2282)\end{array}$ \\
\hline $\operatorname{Bax}$ & Kaninchen & - & $1: 100$ & $\begin{array}{l}\text { Millipore } \\
(06-499)\end{array}$ \\
\hline Cyclophilin D & Maus & - & $1: 100$ & $\begin{array}{l}\text { Mitoscience } \\
\text { (MSA04) }\end{array}$ \\
\hline Cytochrome $c$ & Maus & - & $1: 100$ & $\begin{array}{l}\text { BD Bioscience } \\
(556432)\end{array}$ \\
\hline Cytochrome $c$-Cy 3 & Maus & Cy3 & $1: 25$ & diese Arbeit \\
\hline Drp1 & Maus & - & $1: 100$ & $\begin{array}{l}\text { BD Bioscience } \\
(611113)\end{array}$ \\
\hline Flag & Maus & - & $1: 400$ & $\begin{array}{l}\text { Sigma-Aldrich } \\
\text { (F3165) }\end{array}$ \\
\hline Hexokinase-I & Kaninchen & - & $1: 100$ & $\begin{array}{l}\text { Cell Signaling } \\
\text { Technology (C35C4) }\end{array}$ \\
\hline Tom20 & Kaninchen & - & $1: 100$ & $\begin{array}{l}\text { Santa Cruz } \\
\text { Biotechnology (sc-11415) }\end{array}$ \\
\hline Tom22 & Maus & - & $1: 100$ & $\begin{array}{l}\text { Sigma-Aldrich } \\
\text { (T6319) }\end{array}$ \\
\hline V5 & Kaninchen & - & $1: 400$ & $\begin{array}{l}\text { Sigma-Aldrich } \\
\text { (V8137) }\end{array}$ \\
\hline Huhn & Maus & - & $1: 50$ & $\begin{array}{l}\text { Biozol } \\
(8320-01)\end{array}$ \\
\hline Kaninchen & Ziege & Alexa488 & $1: 1000$ & $\begin{array}{l}\text { Invitrogen } \\
\text { (A11034) }\end{array}$ \\
\hline Kaninchen & Ziege & Atto532 & $1: 200$ & diese Arbeit \\
\hline Kaninchen & Ziege & Atto647N & $1: 200$ & diese Arbeit \\
\hline Kaninchen & Ziege & Cy3 & $1: 1000$ & $\begin{array}{l}\text { Dianova } \\
(111-165-003)\end{array}$ \\
\hline Kaninchen & Ziege & KK114 & $1: 50 / 1: 200$ & diese Arbeit \\
\hline Kaninchen & Ziege & $\begin{array}{l}\text { Oregon } \\
\text { Green } 488\end{array}$ & $1: 1000$ & $\begin{array}{l}\text { Invitrogen } \\
(\mathrm{O}-11038)\end{array}$ \\
\hline Maus & Schaf & Cy3 & $1: 1000$ & $\begin{array}{l}\text { Dianova } \\
(515-165-062)\end{array}$ \\
\hline Maus & Schaf & Atto532 & $1: 200$ & diese Arbeit \\
\hline Maus & Schaf & Atto590 & $1: 200$ & diese Arbeit \\
\hline Maus & Schaf & Atto647N & $1: 200$ & diese Arbeit \\
\hline Maus & Schaf & KK114 & $1: 50 / 1: 200$ & diese Arbeit \\
\hline Maus & Ziege & $\begin{array}{l}\text { Oregon } \\
\text { Green } 488\end{array}$ & $1: 1000$ & $\begin{array}{l}\text { Invitrogen } \\
(\mathrm{O}-6380)\end{array}$ \\
\hline
\end{tabular}


Antikörper-Fluorophor-Gemisch komplett in das Säulenmaterial eingedrungen ist, wurde mit PBS in $1 \mathrm{ml}$ Fraktionen eluiert. Zur Identifizierung der AntikörperFluorophor-Fraktionen wurde eine Proteinkonzentrationsbestimmung mit dem BioRad-Protein-Assay (BioRAD, Hercules, CA, USA) nach Angaben des Herstellers durchgeführt. Die so identifzierten Antikörper-enthaltenden Fraktionen wurden vereinigt, durch Zugabe von BSA (Endkonzentration $5 \mathrm{mg} / \mathrm{ml}$ ) stabilisiert, portioniert, schockgefroren und bis zur Verwendung bei $-80{ }^{\circ} \mathrm{C}$ gelagert.

\subsubsection{Indirekte Immunofluoreszenz-Markierung}

Die Immunofluoreszenz-Markierung ist eine sensitive Methode zur Visualisierung von Antigenen. Von einer indirekten Markierung spricht man dann, wenn der Erst-Antikörper, welcher spezifisch für das zu untersuchende Antigen ist, von einem Zweit-Antikörper, welcher fluorophor-gekoppelt ist, detektiert wird (Allan, 2000; Osborn, 2006; Malka et al., 2007). Die ImmunofluoreszenzMarkierung für Proben, die später mit einem STED-Mikroskop aufgenommen werden sollen, unterscheidet sich generell nicht von der für konventionelle Mikroskopie. Trotzdem sollte aufgrund der höheren Auflösung besonders auf die Strukturerhaltung der Probe geachtet werden (Wurm et al., 2010).

\subsubsection{Markierung mit zwei Antikörpern}

Die einen Tag zuvor auf Deckgläschen ausgesäten Zellen wurden mit 8 \% (w/v) frisch angesetztem Formaldehyd (8 g Paraformaldehyd in $100 \mathrm{ml}$ PBS lösen, hierfür Zugabe von einem $\mathrm{NaOH}$ Pellet, bei $60{ }^{\circ} \mathrm{C}$ rühren, bis die Lösung klar wird, $\mathrm{pH}$-Wert mit $\mathrm{HCl}$ auf 7,5 einstellen) für 5 min bei $37{ }^{\circ} \mathrm{C}$ fixiert. Im Anschluss wurden die Zellen für 5 min mit 0,5 \% (v/v) Triton-X-100 (in PBS) permeabilisiert, für 5 min mit 10 \% BSA (w/v) (in PBS) geblockt und im Anschluss für $1 \mathrm{~h}$ mit den primären Antikörpern (in $10 \% \mathrm{BSA}(\mathrm{w} / \mathrm{v})$ in PBS) inkubiert. Alle Inkubationen mit Antikörpern wurden in einer feuchten Kammer durchgeführt, 
um die Austrocknung der Probe zu verhindern. Nach einem kurzen Waschschritt in PBS, gefolgt von 5 min Permeabilisation mit 0,5 \% (v/v) Triton-X-100 (in PBS) und $5 \mathrm{~min}$ Blocken in $10 \% \mathrm{BSA}(\mathrm{w} / \mathrm{v}$ ) (in PBS), wurden die sekundären Antikörper (in 10 \% BSA (w/v) in PBS) für $1 \mathrm{~h}$ hinzugegeben. Nach einem $30 \mathrm{~min}$ Waschschritt in PBS wurden die Deckgläschen in Mowiol mit DABCO (25\% (w/v) Glyzerin, $9 \%$ (w/v) Mowiol 4-88, 0,1 M Tris/HCl, 0,1 \% (w/v) 1,4-Diazabicyclo[2.2.2]octane; $\mathrm{pH}$ 8,5), optional mit DAPI (Sigma-Aldrich) eingedeckelt.

\subsubsection{Markierung mit drei Antikörpern}

Die unter 3.3.9.1 beschriebenen Schritte wurden bis einschließlich der Inkubation mit den sekundären Antikörpern durchgeführt. Anschließend erfolgte ein kurzer Waschschritt in PBS, gefolgt von 5 min Permeabilisation mit 0,5 \% (v/v) Triton-X-100 (in PBS) und 5 min Blocken in $10 \%$ BSA (w/v) (in PBS). Danach wurden die Proben für $1 \mathrm{~h}$ mit Maus-Antikörpern (gegen Huhn, in 10 \% BSA (w/v in PBS) inkubiert, um die zuvor verwendeten, gegen Maus gerichteten Sekundärantikörper abzusättigen. Um die Antigen-Antikörper-Komplexe im Anschluss $\mathrm{zu}$ konservieren, wurde eine zweite Fixierung mit $8 \%$ (w/v) Formaldehyd (in PBS) für $5 \mathrm{~min}$ bei $37{ }^{\circ} \mathrm{C}$ durchgeführt, gefolgt von $5 \mathrm{~min}$ Detergenzbehandlung mit 0,5\% (v/v) Triton-X-100 (in PBS) und 5 min Blocken in $10 \%$ BSA (w/v) (in PBS). Im Anschluss wurde die Probe für $1 \mathrm{~h}$ mit einem an Cy3-gekoppelten Cytochrom c Antikörper (in 10 \% BSA (w/v) in PBS) inkubiert. Nach einem 30 minütigen Waschschritt in PBS wurden die Deckgläschen in Mowiol mit DABCO (25 \% (w/v) Glyzerin, 9 \% (w/v) Mowiol 4-88, 0,1 M Tris/HCl, 0,1 \% (w/v) 1,4-Diazabicyclo[2.2.2]octane; $\mathrm{pH} 8,5$ ), optional mit DAPI (Sigma-Aldrich) eingedeckelt. 


\subsubsection{Markierung mit dem Drp1-Antikörper}

Auf Deckgläser ausgesäte Zellen wurden mit $4 \%(\mathrm{w} / \mathrm{v})$ frisch angesetztem Formaldehyd (in PBS, Abschnitt 3.3.9.1) für $30 \mathrm{~min}$ bei $37^{\circ} \mathrm{C}$ fixiert, für $20 \mathrm{~min}$ mit $0,15 \%(\mathrm{v} / \mathrm{v})$ Triton-X-100 (in PBS) permeabilisiert und für 45 min mit $10 \%$ BSA (w/v) (in PBS) geblockt. Im Anschluss erfolgte eine Inkubation mit dem Drp1-Antikörper bei $4{ }^{\circ} \mathrm{C}$ über Nacht. Alle sich anschließenden Schritte sind identisch mit denen unter Abschnitt 3.3.9.1.

\subsection{Mikroskopie und Datenauswertung}

\subsubsection{Epifluoreszenzmikroskopie}

Für die Epifluoreszenzmikroskopie wurde das Leica Mikroskop DM6000B (Leica Microsystems, Wetzlar, Deutschland) verwendet, ausgestattet mit einem Öl-Immersionsobjektiv (PL APO, 100x/1.40-0.70 oil) und einer CCD-Kamera (DFC350FX). Die Beleuchtung erfolgte mittels einer Metallhalogenidlampe (EL6000, Leica Microsystems), in deren Strahlengang verschiedene Filter plaziert wurden. DAPI wurde mit einem A4-Filterwürfel (Anregung 360/40 nm, Emission 470/40 nm), Oregon Green488 und Alexa488 mit einem GFP-Filterwürfel (Anregung 470/40 nm, Emission 525/50 nm), Cy3 und Atto532 mit einem N3Filterwürfel (Anregung 546/12, Emission 600/40 nm), Atto590 mit einem BGRFilterwürfel (Anregung 570/20, Emission 640/40 nm) und Atto647N sowie KK114 wurden mit einem Spectrum FRED-Filterwürfel (Anregung 630/20, Emission $667 / 30 \mathrm{~nm}$ ) detektiert.

\subsubsection{Konfokalmikroskopie}

Für die Konfokalmikroskopie wurde das Laser Raster Mikroskop TCS SP5 (Leica Microsystems) verwendet, ausgestattet mit einem Öl-Immersionsobjektiv (PL APO 63x/1.40-0.60 oil). Die Anregung erfolgte mit 405 nm (für DAPI, 
Diodenlaser), 488 nm (für Oregon Green488, Argonlaser) und 561 nm (für Cy3, Diodenlaser). Die Breite der Detektionsfenster wurde für DAPI von 410-435 nm, für Oregon Green488/Alexa488 von 495-520 nm und für Cy3 von 570-650 nm gewählt. Die zur Detektion verwendeten Photomultiplier (PMT) wurden im dynamischen Bereich betrieben. Für Mehr-Farben-Aufnahmen wurde das Mikroskop im sequenziellen Modus benutzt und in Abhängigkeit von der Fragestellung wurden z-Stapel aufgenommen. Alle Voxel-Größen wurden gemäß des Nyquist-Kriteriums gewählt (Voxel-Größe $\sim 70$ nm x 70 nm x $\sim 200$ nm). Jede Aufnahme wurde zumindest zweifach aufgenommen und im Anschluss gemittelt.

\subsubsection{STED-Mikroskopie}

Bei der STED-Mikroskopie handelt es sich um eine lichtmikroskopische Technik, bei der die Auflösung im Vergleich zur konventionellen Mikroskop deutlich verbessert ist (Abschnitt 8.1). In dieser Arbeit wurden drei verschiedene STED-Mikroskope verwendet, deren Charakteristika in Tabelle 3.6 aufgeführt sind.

Beim kommerziellen STED-Mikroskop besteht die Möglichkeit neben einem STED-Kanal mehrere konfokale Kanäle zu verwenden. Somit können z.B. Proben, die mit drei verschiedenen Fluorophoren markiert wurden, untersucht werden. Ein weiterer Vorteil besteht in der Auswahl der Zellen. Im Gegensatz zu den nicht kommerziellen STED-Mikroskopen ist es mit dem Leica TCS STED möglich, aufgrund eines großen Gesichtsfeldes in Kombination mit einer Fluoreszenzlampe und einem schnell zu bedienenen $\mathrm{x}, \mathrm{y}$-Tisch, in kurzer Zeit große Probenbereiche $\mathrm{zu}$ analysieren und geeignete Zellen auszuwählen.

Ein wesentlicher Vorteil der nicht kommerziellen STED-Mikroskope besteht in der verbesserten Auflösung ( 40 nm) im Vergleich zu der des kommerziellen STED-Mikroskops ( 100 nm). Beim Vergleich der beiden nicht kommerziellen STED-Mikroskope untereinander ist festzuhalten, dass mit dem Ein-Farben-STEDMikroskop zwar nur ein Protein/Fluorophor im STED-Modus untersucht werden 


\section{Tabelle 3.6: Übersicht über die Charakteristika der verschiedenen STED-Mikroskope}

In dieser Arbeit wurden drei STED-Mikroskope verwendet, die verschiedene Vor- und Nachteile haben. Der Vorteile des kommerziellen STED-Mikroskops bestehen in Möglichkeit, neben dem STED-Kanal mehrere konfokale Kanäle zur Aufnahme von verschiedenen Proteinen/Fluorophoren zu verwenden, sowie in einer schnellen Auswahl der zu untersuchenden Zellen. Die nicht kommerziellen STED-Mikroskope weisen im Gegensatz zum kommerziellen STED-Mikroskop eine deutlich verbesserte Auflösung auf. Hier besteht die Möglichkeit, 1-2 verschiedene Proteine im STED-Modus zu analysieren. Bei der Analyse von nur einem Protein im STED-Modus (Ein-Farben-STED) besteht die zusätzliche Möglichkeit ein weiteres Protein konfokal zu untersuchen. Angegeben sind die in dieser Arbeit verwendeten Aufnahmeparameter

\begin{tabular}{|c|c|c|c|}
\hline & \multirow{2}{*}{$\begin{array}{l}\text { kommerzielles STED-Mikroskop } \\
\text { (TCS STED) }\end{array}$} & \multicolumn{2}{|c|}{ nicht kommerzielle STED-Mikroskope } \\
\hline & & Ein-Farben-STED & Zwei-Farben-STED \\
\hline Auflösung & $\sim 100 \mathrm{~nm}$ & $\sim 40 \mathrm{~nm}$ & $\sim 40 \mathrm{~nm}$ \\
\hline Objektiv & PL APO 100x, NA 1,40, ÖI & PL APO 100x, NA 1,40, Öl & PL APO 100x, NA 1,40, Öl \\
\hline Anregungslaser & $635 \mathrm{~nm}$ Diodenlaser & $635 \mathrm{~nm}$ Diodenlaser & $570 \mathrm{~nm}, 650 \mathrm{~nm}$ Weißlichtlaser \\
\hline \multicolumn{4}{|l|}{ STED-Laser } \\
\hline Bezeichnung & Mai-Tai (Spectra Physics, USA) & MIRA 900 (Coherent, USA) & Supercontinuum (Fianium, England) \\
\hline Wellenlänge & $750 \mathrm{~nm}$ & $760 \mathrm{~nm}$ & $710 / 20 \mathrm{~nm} ; 755 / 20 \mathrm{~nm}$ \\
\hline Leistung & $100 \mathrm{~mW}$ & $200 \mathrm{~mW}$ & $1,5 \mathrm{~mW}$ \\
\hline gepulst & ja & ja & ja \\
\hline Repititionsrate & $80 \mathrm{MHz}$ & $76 \mathrm{MHz}$ & $1 \mathrm{MHz}$ \\
\hline Pulsdauer & $300 \mathrm{ps}$ & $300 \mathrm{ps}$ & $80 \mathrm{ps}$ \\
\hline Doughnut & $\begin{array}{l}2 \text { reflektierende Phasenplatten } \\
\text { (1x } x \text {-Richtung, } 1 \times y \text {-Richtung) }\end{array}$ & $\begin{array}{l}\text { Phasenplatte mit } \\
\text { helikaler Phasenverschiebung }\end{array}$ & $\begin{array}{l}\text { Phasenplatte mit } \\
\text { helikaler Phasenverschiebung }\end{array}$ \\
\hline weitere Laser & Argon-Laser (488 nm, 514 nm) & Laserdiode $(532 \mathrm{~nm})$ & - \\
\hline Detektion & PMT & 4 APDs & 2 APDs \\
\hline Detektionsbereiche & $\begin{array}{l}500-540 \mathrm{~nm} \\
570-620 \mathrm{~nm} \\
655-720 \mathrm{~nm}\end{array}$ & $\begin{array}{l}560-620 \mathrm{~nm} \\
650-690 \mathrm{~nm}\end{array}$ & $\begin{array}{l}600-640 \mathrm{~nm} \\
660-690 \mathrm{~nm}\end{array}$ \\
\hline
\end{tabular}

konnte, dafür aber eine zweiter Fluorophor konfokal aufgenommen werden konnte. Hingegen bestand beim Zwei-Farben-STED-Mikroskop die Möglichkeit zwei verschiedene Proteine/Fluorophore im STED-Modus zu analysieren, dafür aber kein weiteres Protein/Fluorophor mehr im konfokalen Modus.

\subsubsection{Kommerzielles STED-Mikroskop}

Als kommerzielles System zur hochauflösenden Mikroskopie wurde das Laser

Raster Mikroskop TCS STED (Leica Microsystems, Tabelle 3.6) verwendet, ausgestattet mit einem Öl-Immersionsobjektiv (PL APO 100x/1.40 oil STED). Die 
Auflösung dieses Mikroskops im STED-Modus betrug 100 nm. Das Mikroskop wurde für Drei-Farben-Aufnahmen im sequenziellen Modus benutzt. Die Anregung erfolgte bei 488 nm (für Oregon Green488, Argonlaser), 514 nm (für Cy3, Argonlaser) und 635 nm (für Atto647N/KK114, gepulster Diodenlaser). Die Abregung der Fluorophore fand durch den gepulsten STED-Laser (Mai-Tai, Spectra Physics, USA) bei einer Wellenlänge von 750 nm statt. Die Leistung des STED-Lasers in der Rückappertur des Objektivs betrug $100 \mathrm{~mW}$ bei einer Repititionsrate von $80 \mathrm{MHz}$. Der für die STED-Mikroskopie essentielle doughnut wurde durch zwei reflektierende Phasenplatten erzeugt, wobei die Überlagerung der beiden STED-Strahlen in der Mitte eine leicht diamantenförmige Ausparung ergab. Die Detektionsfenster lagen für Oregon Green488 zwischen 500-540 nm, für Cy3 zwischen 570-620 nm und für Atto647N/KK1114 zwischen 655-720 nm.

Die zur Detektion verwendeten Photomultiplier (PMT) wurden im dynamischen Bereich betrieben. Alle Pixel-Größen wurden gemäß des Nyquist-Kriteriums unter der Voraussetzung einer Auflösung von 100 nm gewählt (Pixel-Größe $30 \mathrm{~nm}$ x $30 \mathrm{~nm}$ ). Es wurden ausschließlich Aufnahmen in einer optischen Ebene durchgeführt und somit keine Projektionen entlang der optischen Achse erzeugt. Konfokale Aufnahmen wurden mit einer Frequenz von $100 \mathrm{~Hz}$ aufgenommen, STED-Aufnahmen mit einer Frequenz von $10 \mathrm{~Hz}$. Jede Aufnahme wurde viermal aufgenommen und im Anschluss gemittelt.

\subsubsection{Nicht kommerzielle STED Mikroskope}

Ein Teil der STED-Messungen zur Untersuchung von Proteinverteilungen vor und während der Apoptose wurde in Zusammenarbeit mit Dr. B. Harke an einem von ihm erstellten mikroskopischen Aufbau (Ein-Farben-STED, Tabelle 3.6) durchgeführt (Harke et al., 2008a; Harke et al., 2008b). Die Auflösung dieses Mikroskops lag bei $\sim 40 \mathrm{~nm}$. Der Aufbau war mit einem Ölimmersionsobjektiv ausgestattet (NA 1.4 Oil immersion, 100x PL APO, Leica Microsystems). Bei diesem Aufbau wurden die Farbstoffe Atto532 und KK114 verwendet, wobei 
KK114 für die STED-Messungen genutzt wurde. Die Anregung erfolgte bei 532 nm (für Atto532, Laserdiode) und 635 nm (für KK114, gepulster Diodenlaser). Die Abregung durch den gepulsten STED-Laser (MIRA 900, Coherent, USA) fand bei $760 \mathrm{~nm}$ statt. Die Leistung des STED-Lasers in der Rückappertur des Objektives betrug $200 \mathrm{~mW}$ bei einer Repititionsrate von $76 \mathrm{MHz}$. Der für die STED-Mikroskopie essentielle doughnut wurde durch eine Phasenplatte mit helikaler Phasenverschiebung erzeugt. Die Detektion erfolgte mit vier Avalanche Photo Dioden (APD) bei 560-620 nm (Atto532) und 650-690 nm.

STED Aufnahmen im Rahmen der Kolokalisationsanalyse zwischen Hexokinase-I und hVDAC wurden in Zusammenarbeit mit Dipl.-Phys. J. Bückers an einem von ihr erstellten mikroskopischen Aufbau (Zwei-Farben-STED, Tabelle 3.6) durchgeführt (Wildanger et al., 2009; Neumann et al., 2010). Die Auflösung dieses Mikroskops lag bei $40 \mathrm{~nm}$. Der Aufbau war mit einem Ölimmersionsobjektiv ausgestattet (NA 1.4 Oil immersion, 100x PL APO, Leica Microsystems). Bei diesem Aufbau wurden die Farbstoffe Atto590 und KK114 eingesetzt. Die Anregung erfolgte bei $570 \mathrm{~nm}$ (für Atto590, Weißlichtlaser) und $650 \mathrm{~nm}$ (für KK114, Weißlichtlaser). Die Abregung durch den gepulsten STED-Laser (Supercontinuum, Fianium, England) fand zwischen 700-720 nm bzw. zwischen 745-765 nm statt. Die Leistung des STED-Lasers in der Rückappertur des Objektives betrug 1,5 $\mathrm{mW}$ bei einer Repititionsrate von $1 \mathrm{MHz}$. Der für die STED-Mikroskopie essentielle doughnut wurde durch eine Phasenplatte mit helikaler Phasenverschiebung erzeugt. Die Detektion erfolgte mit zwei Avalanche Photo Dioden (APD) bei 600-640 nm (Atto590) bzw. 660-690 nm (KK114).

\subsubsection{Bildbearbeitung}

Zur Auswertung und Bearbeitung der aufgenommenen Bilder wurden die Progamme Imspector (Schönle A., 2006. Imspector Image Acquisition \& Analysis Software, v0.1), Leica Confocal Software LAS AF (Leica Microsystems) und Adobe Photoshop CS3 (Adobe, San Jose, USA) verwendet. Neben Kontrastanpassungen 
wurden keine weiteren Änderungen an den Rohdaten durchgeführt. Zur Darstellung der aufgenommenen Strukturen wurden verschiedene Farbtabellen (Abbildung 8.6) verwendet.

\subsubsection{Kolokalisationsanalysen}

Die Analysen zur konfokalen VDAC-VDAC Kolokalisation wie auch zur ZweiFarben-STED Hexokinase-I VDAC Kolokalisation wurden in Zusammenarbeit mit Dr. L. Kastrup, basierend auf selbst geschriebenen Routinen in MATLAB (The Mathworks, Natick, USA), durchgeführt und unter Neumann et al. (2010) im Detail beschrieben.

Das prinzipielle Vorgehen zur Analyse der STED, wie auch der konfokalen 2D Daten war identisch, bis auf die Tatsache, dass für die 2D STED-Daten das spektrale Überlappen zwischen den beiden Kanälen korrigiert wurde (Abbildung 3.1). Dies war nötig, da die Absorptions- und Emissionsspektren von Atto590 und KK114 spektral überlappen (Abbildung 8.5). Hierzu wurde eine lineare Entmischung der Aufnahmen (Zimmermann, 2005), basierend auf Messungen mit einzeln gefärbten Referenzproben, durchgeführt (Abbildung 3.1). Ein crosstalk für die Kolokalisationsanalyse der konfokalen Daten konnte hingegen ausgeschlossen werden (Abbildung 8.12).

Vor der eigentlichen Kolokalisationsanalyse wurden die Mitochondrien durch Erzeugung von Masken vom nicht für die Analyse relevanten Hintergrund getrennt (Abbildung 3.1).

Für die eigentliche Kolokalisationsanalyse wurden drei verschiedene Koeffizienten mit unterschiedlichen Vor- und Nachteilen bestimmt, namentlich der Pearson's Korrelationskoeffizient $r_{\mathrm{p}}$, der Überlappungskoeffizient $r$ und die Kolokalizationskoeffizienten $M_{1}$ und $M_{2}$ (Manders, 1993; Zinchuk und Zinchuk, 2008): Der Pearson's Korrelationskoeffizient $r_{p}$ ermöglicht sowohl die Bestimmung von Korrelationen wie auch von Anti-Korrelationen und reicht von +1 (perfekte Korrelation) bis -1 (perfekte Anti-Korrelation). 


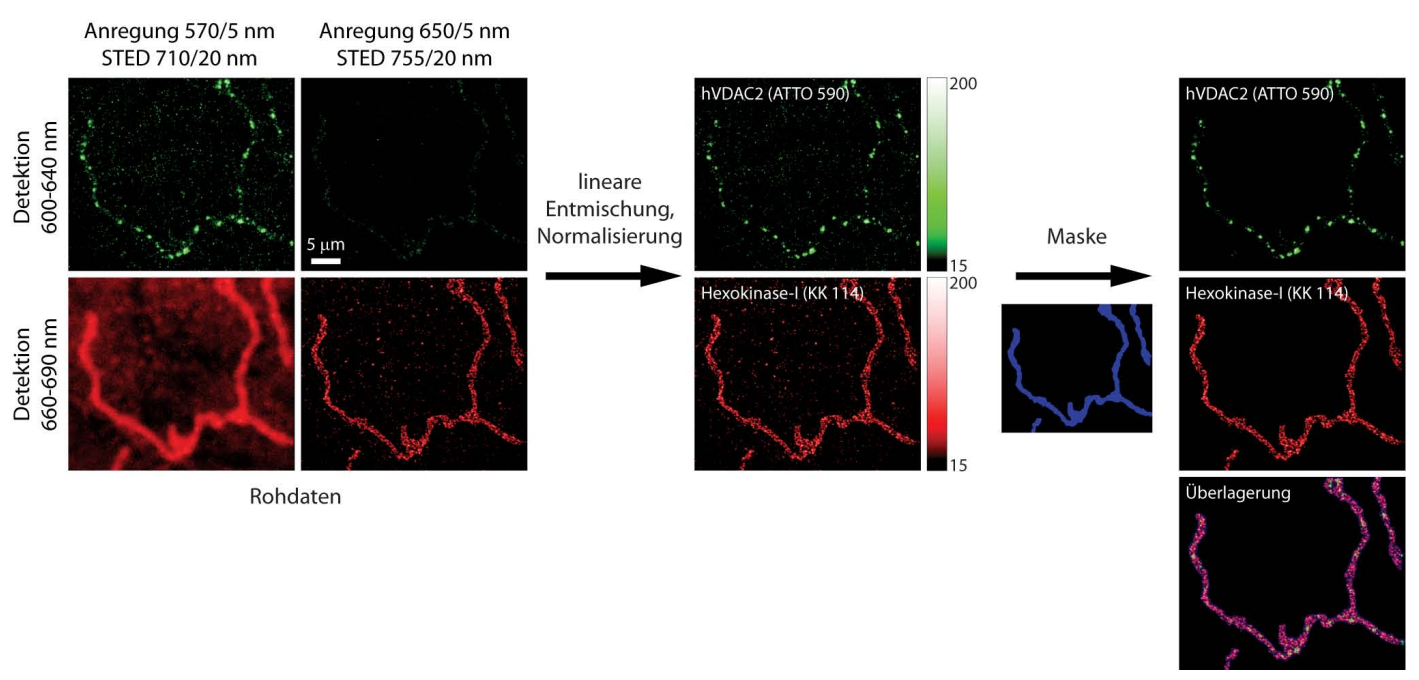

\begin{abstract}
Abbildung 3.1: Ablauf der Bildanalyse
Da die Absorptions- und Emissionsspektren von Atto590 und KK114 spektral überlappen, wurde eine lineare Entmischung durchgeführt. Dazu wurden jeweils vier Bilder generiert. Zunächst wurden Laserpulse mit Anregungs- und STED-Wellenlängen von $650 \mathrm{~nm}$ und 755 $\mathrm{nm}$ verwendet, danach Laserpulse von $570 \mathrm{~nm}$ und $710 \mathrm{~nm}$. In beiden Fällen wurden zwei Detektoren zur Signalaufnahme verwendet. Um den crosstalk zu eliminieren erfolgte dann die lineare Entmischung. Nach Normalisierung der Bilder wurde ein Algorithmus verwendet, der die Mitochondrien vom Bildhintergrund trennt. Nur diese Bildregionen wurden im Folgenden für die Bestimmung der Korrelationskoeffizienten verwendet.
\end{abstract}

Aussagen über Anti-Korrelationen können mit dem von 0 bis +1 reichenden Überlappungskoeffizient $r$ nicht getroffen werden. Dafür sind die Werte des Überlappungskoeffizienten einfacher $\mathrm{zu}$ interpretieren. Hier steht ein Wert von z.B. 0,6 exakt für eine 60 prozentige Kolokalisation der in den beiden Bildern befindlichen Objekte. Beide Koeffizienten berücksichtigen nicht eine asymmetrische Verteilung in den zwei verschiedenen Kanälen. Zum Beispiel würden 100 Punkte in dem ersten Bild und 10 Punkte in dem zweiten Bild, die sich an derselben Position befinden, einen Koffizienten von 0,1 ergeben. Dies berücksichtigt aber nicht den Unterschied, dass die 10 Punkt des zweiten Bildes zu $100 \%$ mit den Punkten im ersten Bild kolokalisieren, die 100 Punkte im ersten Bild aber nur zu $10 \%$.

Dieser Tatsache tragen die Kolokalizationskoeffizienten $M_{1}$ und $M_{2}$ Rechnung. $M_{1}$ gibt an, wie viele der Objekte des einen Bildes mit denen der anderen Bilder kolokalisieren und genau das Gegenteil trifft auf $M_{2}$ zu. Ein Nachteil der 
Kolokalisationkoeffizienten besteht darin, dass Grenzen gesetzt werden müssen, um Pixel als Signal oder Hintergrund zu klassifizieren.

\subsubsection{Analyse sub-mitochondrialer Proteinverteilungen}

Die Analyse sub-mitochondrialer Proteinverteilungen, basierend auf 2D STED-Aufnahmen (kommerzielles STED-Mikroskop, Leica Microsystems, Mannheim), wurden in Zusammenarbeit mit Dr. A. Egner und Dr. J. Keller durchgeführt. Sie bedient sich selbstgeschriebener Algorithmen und läuft unter MATLAB (The Mathworks, Natick, USA), einschließlich der DIPlib Bibliothek (Quantitative Imaging Group, Delft University of Technology, NL).

Die Datenanalyse erfolgte nicht auf der gesamten Fläche der Mitochondrien (Abbildung 3.2), sondern entlang ihrer Mittellinie. Dabei sollten optische Einflüsse (insbesondere Randeffekte), die durch die Geometrie der Mitochondrien entstehen können, ausgeschlossen werden. Zur Bestimmung der Mittellinie wurde jedes Bild zunächst geglättet (Abbildung 3.2B) und binärisiert (Abbildung 3.2C). Durch die Binärisierung wird eine Maske erzeugt mit deren Hilfe die Fläche der Mitochondrien vom Bildhintergrund getrennt werden konnte. Im Anschluss wurden die Mittellinien auf den Mitochondrien bestimmt (Abbildung 3.2D). Sehr kurze Mittellinien ( $\leq 1 \mu \mathrm{m}$ Länge) wurden von der Analyse ausgeschlossen, um die Häufigkeit von Übergängen bei einer späteren Aneinanderreihung der Daten zu reduzieren. Zusätzlich wurden Bereiche, an denen sich die Mittellinien verzweigten, von der Analyse ausgeschlossen (Abbildung 3.2E). Im Anschluss wurden die einzelnen Mittellinien numeriert (siehe Farbkodierung, Abbildung 3.2E).

Der Zweck in der Herunterregulierung von Drp1 (Abschnitt 3.3.5) bestand darin, die Analyse von runden (fragmentierten) Mitochondrien zu vermeiden. Teilweise wurden aber auch hier große Ballon-ähnliche, runde Strukturen beobachtet. Damit diese nicht die Analyse beeinflussen, wurden bei Drp1-herunterregulierten Zellen nur Mitochondrien mit einem maximalen Durchmesser von $<1 \mu \mathrm{m}$ 

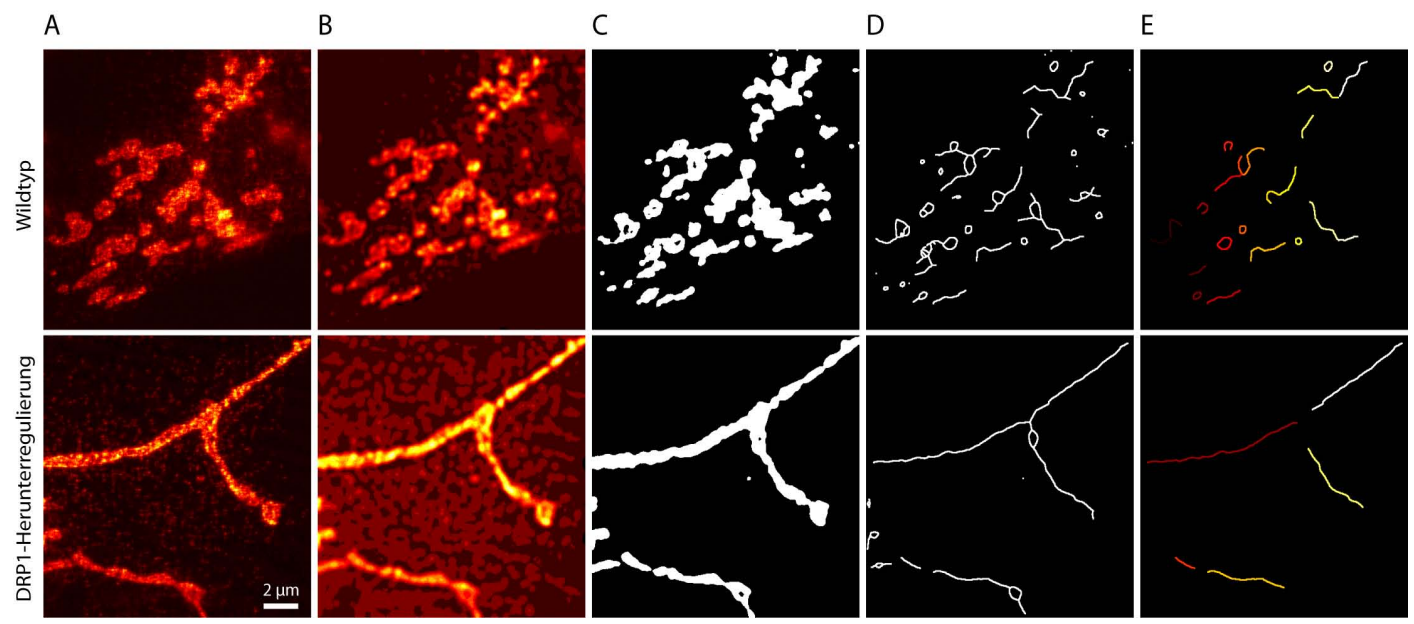

\section{Abbildung 3.2: Bestimmung von mitochondrialen Mittellinien}

Beispiele für die Bestimmung von Mittellinien in apoptotischen Wildtyp-Zellen (erste Reihe) und in apoptotischen Drp1-herunterregulierten Zellen (zweite Reihe). Zunächst wurden die aufgenommenen Rohdaten (A) geglättet (B) und binärisiert (C), damit die Mitochondrien exakt vom Bildhintergrund getrennt werden konnten. Im Anschluss wurden einzelne Mittellinien bestimmt (D). Für die spätere Analyse wurden nur die Daten der Mittellinien verwendet, deren Länge größer als $1 \mu \mathrm{m}$ war (E). Zudem wurden Verzweigungspunkte entfernt und die Mittellinien wurden numeriert (siehe Farbkodierung, E).

ausgewertet. Diese weisen mit einer sehr hohen Wahrscheinlichkeit eine tubuläre Morphologie auf.

Alle Mittellinien eines Bildes mit einer Einzellänge von mindestens $1 \mu$ m wurden nun aneinandergereiht und auf einen festgelegten Wert normiert (Abbildung 3.3B). Die Normierung war nötig, um den Einfluss einer unterschiedlichen Helligkeit zwischen verschiedenen Bildern auszugleichen. Im Anschluss wurden alle Mittellinien der verschiedenen Bilder eines Datensatzes aneinander gehängt. Aufgrund der großen Datenmenge ergaben sich für jede Bedingung recht große Gesamtlängen. Für das Protein Tom20 in unbehandelten Wildtyp-Zellen ergab sich z.B. für 63 aufgenommene Bilder $(15,5 \mu \mathrm{m} \quad \mathrm{x} 15,5 \mu \mathrm{m})$ eine Gesamtmittellinienlänge von über $4 \mathrm{~cm}$ bei über 1300 einzelnen Mittellinien.

Bei der Betrachtung der aneinandergereihten Mittellinien fiel auf, dass die durchschnittliche Fluoreszenzintensität beim Vergleich von verschiedenen Abschnitten $(>1 \mu \mathrm{m})$ recht inhomogen verteilt war. Damit die Variationen in den 
A

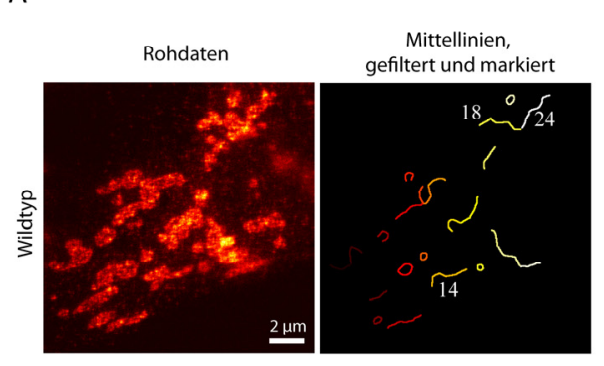

B
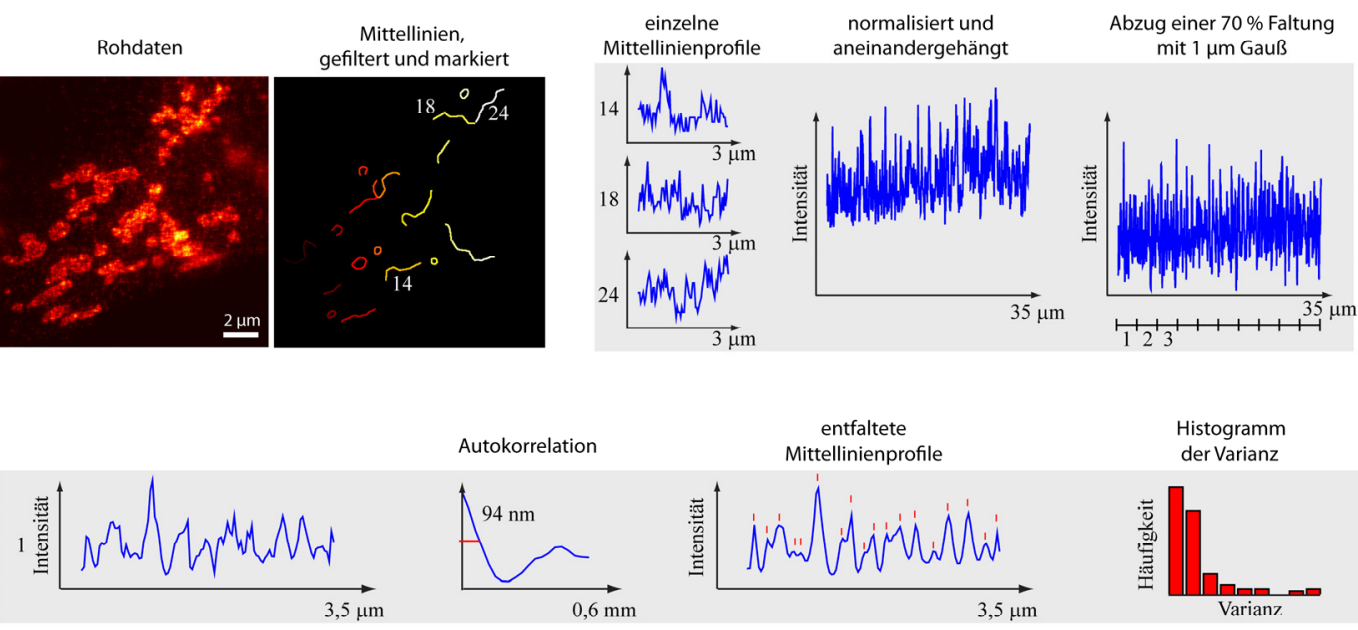

Autokorrelation
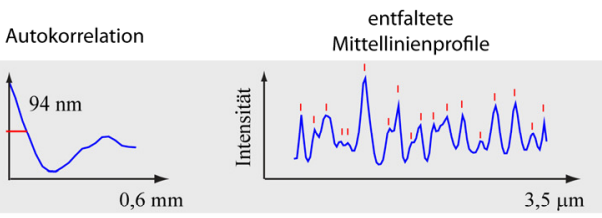

Histogramm der Varianz
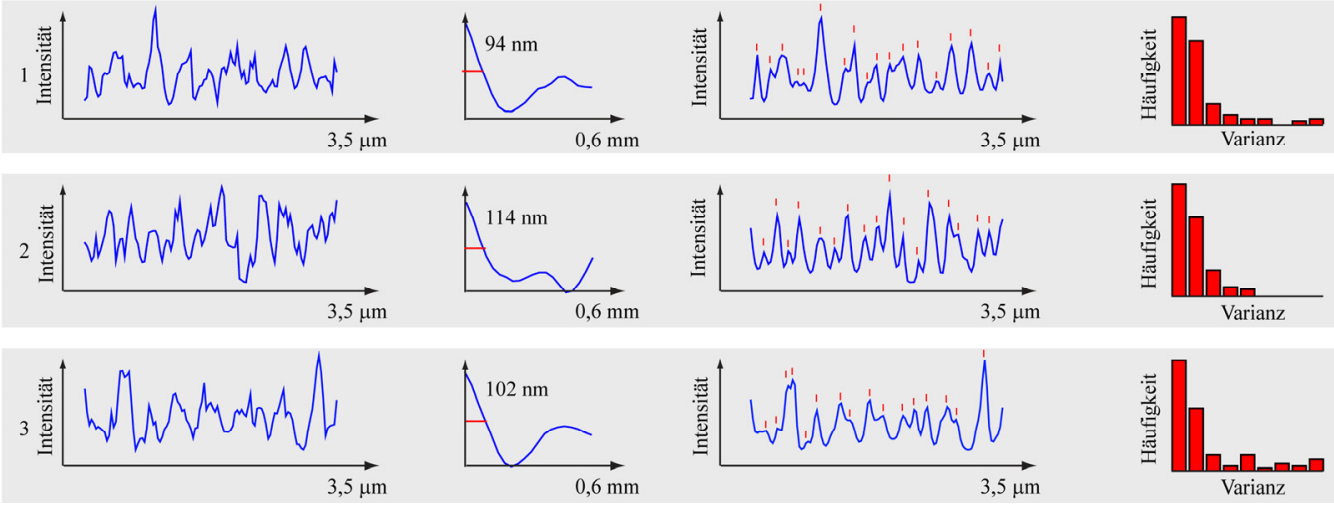

\section{Abbildung 3.3: Analyse der Daten mitochondrialer Mittellinien}

Die Analyse der Daten mitochondrialer Mittellinien ist hier zur Vereinfachung an einem einzelnen Bild (A) gezeigt. Da die Intensitätsprofile entlang einzelner Mittellinien variieren (B, hier exemplarisch 3 gezeigt), wurden alle Mittellinien eines Bildes auf einen festen Wert normiert und aneinandergehängt (B). Im Anschluss wurden die Mittellinien verschiedener Bilder ebenfalls aneinander gehängt (hier nicht dargestellt). Hierbei wurden ebenfalls Variationen (auf größeren Bereichen) in den Intensitäten beobachtet. Diese wurde mathematisch korrigiert, indem die Daten mit einer $1 \mu \mathrm{m}$ breiten Gauß-Verteilung gefaltet wurden und $70 \%$ dieser Faltung von den Rohdaten abgezogen wurde (B, aber hier nur für ein Bild gezeigt). Im Folgenden wurde die Gesamtmittellinie einer Bedingung in 10 gleich große Teile geteilt, um Mittelwerte und Standardfehler bestimmen zu können (hier mit 1,2,3 in B angedeutet). Auf jedem dieser 10 Teilabschnitte (C, hier 3 Teilabschnitte (1-3) dargestellt) wurde nun die Autokorrelation, das Verhältnis von Cluster- zur Hintergrundintensität und die Varianz der Fluoreszenzintensität bestimmt (C).

Helligkeiten verschiedener Mittellinien keinen Einfluss auf Analyse sub-mitochondrialer Proteinverteilungen haben, wurden diese rechnerisch entfernt. Hierzu wurden die Daten der Mittellinie mit einer $1 \mu \mathrm{m}$ breiten GaußVerteilung gefaltet (Abbildung 3.3B). Da eine solche Verteilung deutlich über der Größe der zu untersuchenden (mit Antikörpern dekorierten) Proteincluster liegt (100-200 nm), führt die Faltung zu einem recht homogenen Intensitätsprofil, in dem keine klaren Signale mehr unterschieden werden können. Ein Teil dieser so 
erzeugten Intensität (70 \%) wurde im Folgenden von den originalen Daten abgezogen, so dass von den Orginaldaten zwar möglichst alle charakteristischen Signalspitzen, aber nur wenige Helligkeitsvariationen über längere Mittelinienabschnitte übrig blieben (Abbildung 3.3B).

Da alle Daten einer experimentellen Bedingung zu einer einzigen Mittellinie vereinigt worden sind, konnte $\mathrm{zu}$ den interessanten Größen nicht direkt eine Standardabweichung bzw. Standardfehler berechnet werden. Aus diesem Grund wurden die Daten der Mittellinie in 10 gleich lange Teile unterteilt und die quantitative Analyse wurde auf jedem der 10 Teile einzeln durchgeführt (Abbildung 3.3B). Damit wird die Berechnung der Streuungen für einzelne Bedingungen möglich.

Bei der quantitativen Analyse wurden drei verschiedene Parameter bestimmt:

(1) Der mittlere Clusterdurchmesser wurde ermittelt, indem von den Daten der Mittellinie die Autokorrelation bestimmt wurde (Abbildung 3.3C). An die resultierende Kurve wurden die Autokorrelationen von Gauß-Verteilungen variabler Größe angepasst. Hierdurch können Aussagen über den mittleren Durchmesser von Proteinclustern und deren mögliche Änderungen während der Apoptose getroffen werden. Bei der Bestimmung von mittleren Clusterdurchmessern ist $\mathrm{zu}$ beachten, dass diese von der Auflösung des Mikroskops beeinflusst werden. Clusterdurchmesser unterhalb der Auflösungsgrenze können nicht fehlerfrei bestimmt werden. Bei mittleren Clusterdurchmessern in der Nähe der Mikroskopauflösung erhält man nur eine obere Grenze der Clusterdurchmesser.

(2) Die Varianz der Fluoreszenzintensität wurde für jeweils $200 \mathrm{~nm}$ lange Abschnitte bestimmt (Abbildung 3.3C). Es wurden $200 \mathrm{~nm}$ lange Abschnitte gewählt, da diese einerseits über der Auflösung des verwendeten Mikroskops liegen $(\sim 100 \mathrm{~nm})$ und andererseits den Bereich abdecken, der den erwarteten mittleren Durchmesser von (mit Antikörpern dekorierten) Proteinclustern (100-200 nm) entspricht. Im Anschluss wurde die mittlere Varianz über alle 
Einzelvarianzen bestimmt. Da die Varianz ein Streumaß ist, können Aussagen über die Homogenität von Proteinverteilungen getroffen werden. Ein geringer Varianzwert der Fluoreszenzintensität entspricht einer eher homogenen Proteinverteilung, wohingegen ein hoher Varianzwert einer eher inhomogenen Verteilung entspricht.

(3) Unter der Annahme, dass zumindest einige einzelne Cluster in den Daten der Mittellinie enthalten sind, wurde nach Glättung der Daten die Position der lokalen Maxima bestimmt. Die mittlere Intensität an den Stellen der lokalen Maxima (rote Striche in Abbildung 3.3C) wurde dann durch die mittlere Intensität an den Stellen zwischen den lokalen Maxima geteilt. Dieser Wert wurde als Verhältnis von Cluster- zu Hintergrundintensität (im Mitochondrium) definiert (Abbildung 3.3C). Durch diesen Paramter können z.B. Aussagen darüber getroffen werden, in wie weit sich Proteincluster gegebenenfalls auflösen. 


\section{Ergebnisse}

\subsection{Sub-mitochondriale (Ko)Lokalisationsstudien zu den hVDAC- Isoformen}

Bis jetzt ist wenig über die sub-mitochondriale Lokalisation der drei humanen VDAC (voltage-dependent anion-selective channel) -Isoformen bekannt. Außerdem existieren wenige und zum Teil widersprüchliche Daten bezügl. Interaktionen mit dem Protein Hexokinase. Um die exakte Lokalisation der einzelnen hVDAC-Isoformen in humanen Zellen zu bestimmen und um Hinweise auf mögliche Interaktionen zwischen den hVDAC-Isoformen untereinander als auch mit deren putativen Interaktionsparter Hexokinase zu erhalten, wurden sowohl konventionelle wie auch auf dem STED-Prinzip basierende lichtmikroskopische Studien durchgeführt.

\subsubsection{Sub-mitochondriale Lokalisation der hVDAC-Isoformen}

Im Menschen sind drei VDAC-Isoformen bekannt, deren Aminosäuresequenz zu 67-72\% identisch ist (Abbildung 4.1). Da die meisten der nicht identischen Aminosäuren konservierte oder semi-konservierte Aminosäuren sind, führt dies zu einer sehr hohen Homologie (Ähnlichkeit > 90 \%) zwischen den drei hVDACIsoformen. Da bis jetzt wenig über die sub-mitochondriale Lokalisation der, auf Aminosäureebene sehr ähnlichen, hVDAC-Isoformen bekannt ist (Yu et al., 1995), wurde diese im Folgenden in humanen Zellen mittels konfokaler Mikroskopie untersucht.

Da verfügbare Antikörper gegen VDAC für die Fluoreszenzmikroksopie ungeeignet sind und die Unterscheidung der einzelnen VDAC-Isoformen damit nicht möglich ist, wurde die mitochondriale Verteilung der drei hVDACIsoformen analysiert, indem genetisch die für hVDAC kodierenden Sequenzen am 


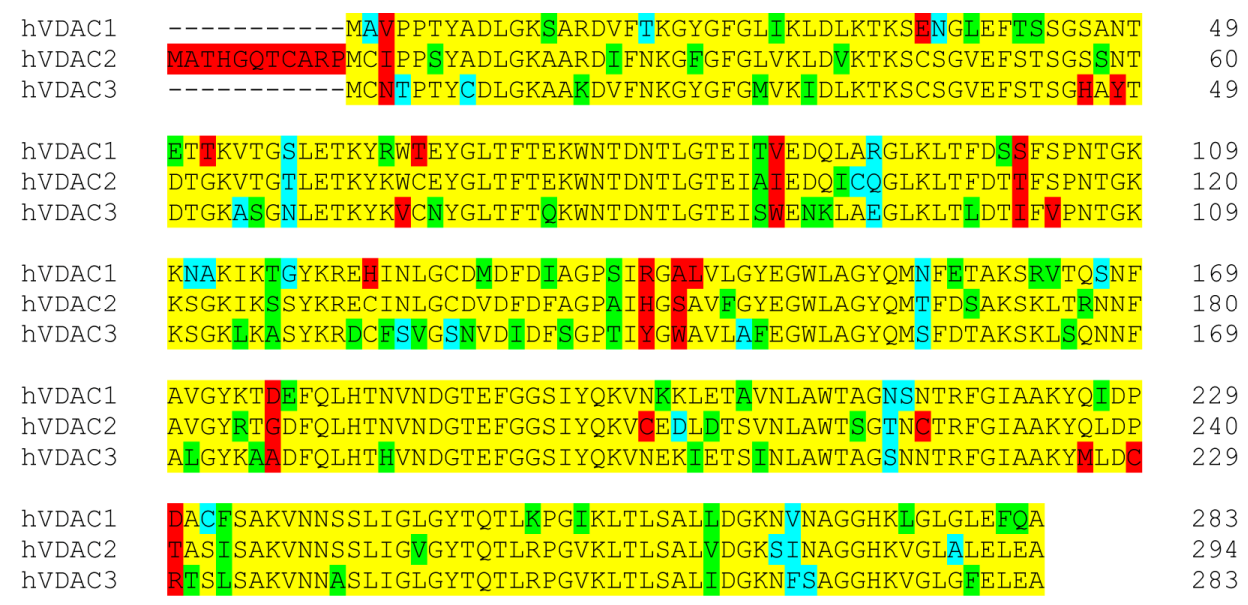

Abbildung 4.1: Aminosäure-Sequenz-Vergleich der hVDAC-Isoformen

Identische Aminosäuren sind in gelb, konservierte Austausche in grün, semi-konservierte Austausche in türkis und nicht konservierte Austausche in rot dargestellt. hVDAC1 und hVDAC2 sind auf Aminosäureebene zu $72 \%$ identisch und zu $91 \%$ ähnlich, hVDAC2 und hVDAC3 sind zu $71 \%$ identisch und zu $91 \%$ ähnlich und hVDAC1 und hVDAC3 weisen zu $67 \%$ identische und zu $94 \%$ ähnliche Aminosäuren auf.

C-Terminus mit einer für einen Flag-Tag kodierenden Sequenz fusioniert wurden. Die so erstellen Plasmide wurde in U2OS-Zellen transfiziert und die Expression wurde nach 24 Stunden durch Immuno-Markierung unter Verwendungen von Antikörpern, die spezifischen den acht Aminosäure langen Flag-Tag erkennen, konfokal-mikroskopisch analysiert. Mit diesem Ansatz konnte zum ersten Mal die sub-mitochondriale Lokalisation aller drei hVDAC-Isoformen untersucht werden.

Die drei Flag-markierten hVDAC-Isoformen sind ausschließlich an Mitochondrien lokalisiert, was durch den Vergleich mit dem mitochondrialen Marker Tom20 deutlich wird (Abbildung 4.2). Des Weiteren ist die Lokalisation der drei hVDAC-Isoformen nicht identisch. hVDAC1 und hVDAC2 lokalisieren in den meisten Zellen in relativ großen Domänen, wohingegen hVDAC3 weitgehend homogen über die komplette Länge der mitochondrialen Membran verteilt ist. Bis jetzt ist meines Wissens nach von keinem weiteren Protein der äußeren mitochondrialen Membran bekannt, dass es in vergleichbar großen Domänen lokalisiert. 


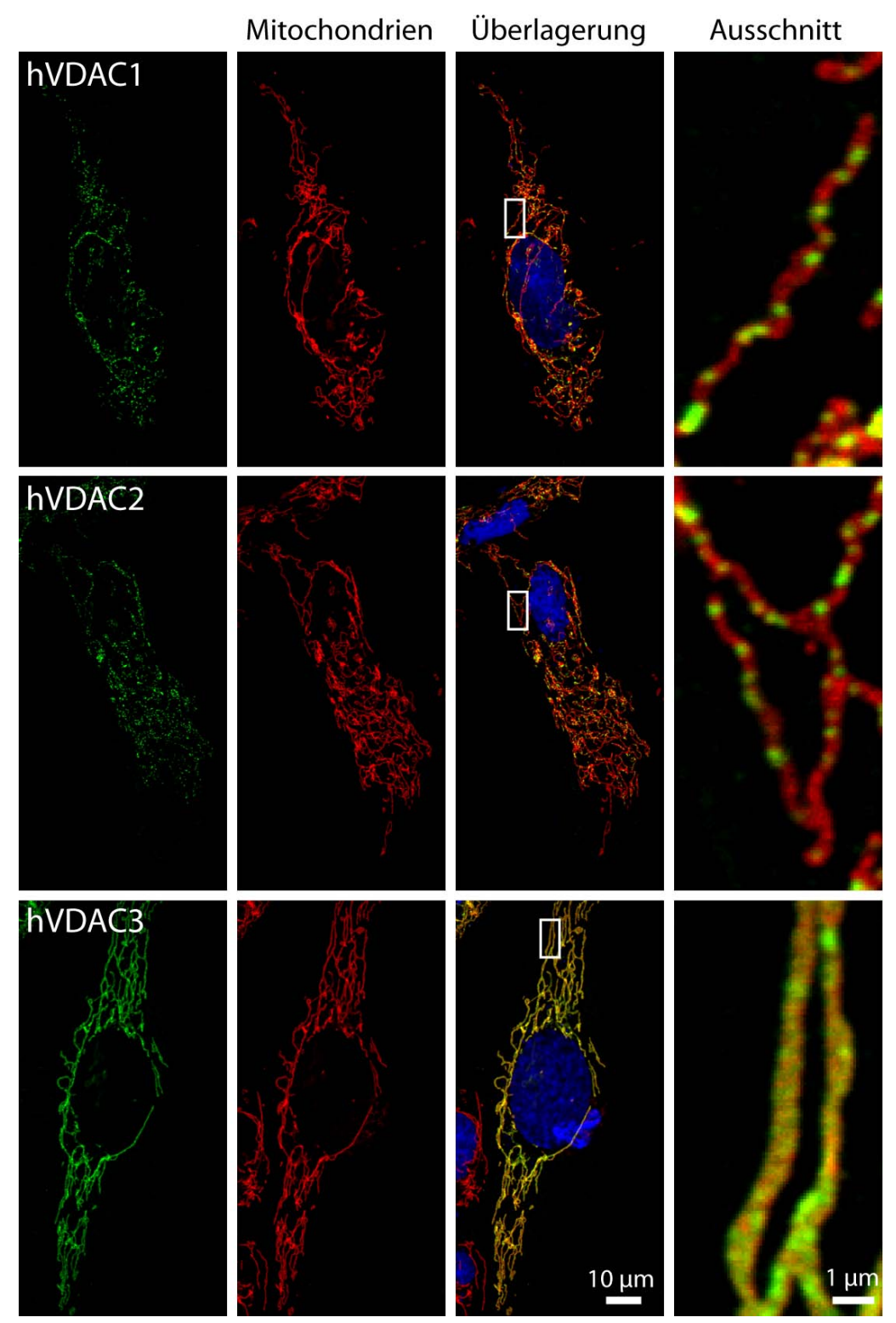

\section{Abbildung 4.2: Sub-mitochondriale Lokalisation der hVDAC-Isoformen}

Konfokal-mikroskopische Aufnahmen von immunofluoreszenz-markierten U2OS-Zellen. Zur Visualisierung der VDAC-Isoformen wurden die entsprechenden Flag-Fusionsproteine mit Antikörpern gegen den Flag-Tag detektiert (grün). Als mitochondrialer Marker wurde Tom20 verwendet (rot). Der Zellkern wurde mit DAPI gefärbt (blau). hVDAC1 und hVDAC2 sind in distinkten Domänen in der mitochondrialen Membran lokalisiert, wohingegen hVDAC3 gleichförmig verteilt erscheint.

Der exakte Domänendurchmesser für hVDAC1 und hVDAC2 wurde anhand verschiedener konfokal-mikroskopischer Aufnahmen bestimmt (Tabelle 8.1). Für hVDAC1 variierte der Domänendurchmesser zwischen 319-741 nm, bei einem Mittelwert von $452 \pm 132$ nm. Für hVDAC2 wurden Domänendurchmessern von 276-887 $\mathrm{nm}$ ermittelt, bei einem Mittelwert von $459 \mathrm{~nm} \pm 162 \mathrm{~nm}$. Somit ist kein 
signifikanter Unterschied zwischen den mittleren Domänendurchmesser von hVDAC1 und hVDAC2 zu erkennen. Vielmehr lokalisieren beide Proteine in vergleichbar großen Domänen mit ungefähren Durchmessern von 300-900 nm.

Die Unterschiede in der sub-mitochondrialen Lokalisation von hVDAC1 und hVDAC2 im Vergleich zu hVDAC3 wurden durch die Expression von Plasmiden, in denen die hVDAC kodierenden Sequenzen genetisch mit der kodierenden Sequenz für einen V5-Tag fusioniert worden sind, bestätigt. Nach Transfektion und Antikörperdetektion des 14 Aminosäure langen V5-Tags konnte mikroskopisch nachgewiesen werden, dass hVDAC1-V5 und hVDAC2-V5 in relativ großen Domänen lokalisieren, wohingegen hVDAC3-V5 eine homogene Verteilung aufweist (Abbildung 8.7).

Somit zeigen alle Daten, dass sich die drei hVDAC-Isoformen, trotz ihrer hohen Sequenzähnlichkeit auf Aminosäureebene, in ihrer sub-mitochondrialen Lokalisation deutlich unterscheiden.

\subsubsection{Einfluss der Aminosäuresequenz auf die sub-mitochondriale Lokalisation von hVDAC}

Um spezifische Aminosäuren oder Aminosäureregionen zu identifizieren, die für die Domänen-Lokalisation von hVDAC1 und hVDAC2 im Vergleich zu hVDAC3 verantwortlich sind, wurden verschiedene Mutationen in die DNA-Sequenz von VDAC eingeführt, die entsprechenden Plasmide in Zellen transfiziert und im Anschluss die Lokalisation der veränderten Proteine fluoreszenzmikroskopisch untersucht.

Diese Experimente wurden vorwiegend mit der Isoform 1 von hVDAC durchgeführt, da deren Struktur, im Gegensatz zu der von hVDAC2 und hVDAC3, bekannt ist (Bayrhuber et al., 2008; Hiller et al., 2008; Ujwal et al., 2008). hVDAC1 bildet ein $\beta$-barrel, welches aus 19 $\$$-Faltblättern aufgebaut ist, in dessen Mitte sich eine horizontal angeordnete $\alpha$-Helix befindet (Abbildung 8.8). 
Die 2D-Topologie von hVDAC1 ist der Abbildung $4.3 \mathrm{zu}$ entnehmen, wobei die in dieser Arbeit ausgetauschten Aminosäuren (rote Kreise) bzw. AminosäureRegionen (roter Strich) gekennzeichnet sind (siehe auch Abbildung 8.9). Da bis jetzt kaum funktionale Unterschiede zwischen den einzelnen VDAC-Isoformen bekannt sind, wurden Aminosäuren und Aminosäureregionen für den Austausch ausgewählt, für die es Hinweise gibt, dass sie eine allgemeine funktionale Relevanz für VDAC besitzen (auch wenn diese bis jetzt nicht als isoform-spezifisch nachgewiesen worden ist). Die Auswahl der einzelnen Aminosäuren bzw. Aminosäure-Regionen wird im Folgenden beschrieben.

Abu-Hamad und Kollegen haben gezeigt, dass die N-terminale $\alpha$-Helix von hVDAC1 eine zentrale Rolle bei der Apoptose spielt und dass deren Deletion zur Apoptoseresistenz führt (Abu-Hamad et al., 2009). Um zu untersuchen, ob der N-Terminus von hVDAC1 auch einen Einfluss auf die sub-mitochondriale Lokalisation hat, wurden die ersten 19 N-terminalen Aminosäuren von hVDAC1 deletiert.

Des Weiteren wurden insgesamt sechs verschiedene Aminosäuren einzeln gegen

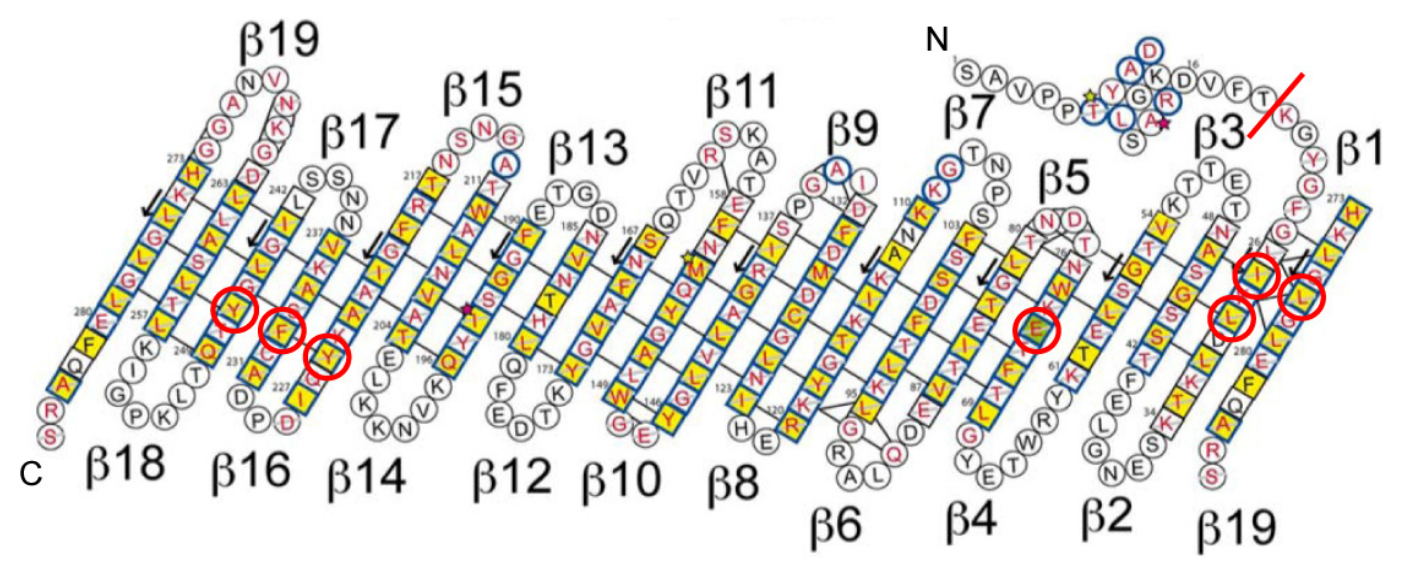

\section{Abbildung 4.3: 2D-Topologie von hVDAC1}

Darstellung der 2D-Topologie von hVDAC1, bestehend aus 19 ß-Faltblättern und einer $\mathrm{N}$-terminalen $\alpha$-Helix. Das $ß$-Faltblatt 19 ist zweimal eingetragen um die Dimerisierung mit dem $ß$-Faltblatt $1 \mathrm{zu}$ verdeutlichen. In rot sind die einzelnen Aminosäuren markiert, die ausgetauscht wurden. Die Deletion des N-Terminus ist durch einen Strich angedeutet (verändert aus Bayrhuber et al., 2008). 
Alanin ausgetauscht. Um die Bedeutung von einzelnen Aminosäuren für die Gesamtfunktion eines Proteins zu untersuchen, wird häufig die kleine und unpolare Aminosäure Alanin als Austauschaminosäure verwendet (Perez et al., 1994).

NMR-spektroskopische, sowie röntgenkristallographische Daten deuten darauf hin, dass VDAC1 als Dimer oder höheres Oligomer vorliegt (Bayrhuber et al., 2008; Ujwal et al., 2009). Um zu überprüfen, inwieweit die Oligomerisierung Einfluss auf die Domänenlokalisation von hVDAC1 hat, wurden drei Aminosäuren (I27, L29, L277) aus dem Bereich des Dimerisierungsinterface ausgewählt und gegen Alanin ausgetauscht.

Da Interaktionen zwischen VDAC und Bid (Rostovtseva et al., 2004) bzw. VDAC und Hexokinase (Blachly-Dyson et al., 1993; Azoulay-Zohar und Aflalo, 1999; Shoshan-Barmatz et al., 2009) beschrieben worden sind, wurden die putativ an diesen Interaktionen beteiligten Aminosäuren Y225, F233 und Y247 (persönliche Mitteilung Prof. Dr. M. Zweckstetter, Max-Planck-Institut für biophysikalische Chemie, Göttingen) gegen Alanin ausgetauscht, um deren Bedeutung für die submitochondriale Lokalisation von hVDAC1 zu studieren.

Die Aminosäure Glutaminsäure an der Position 73 scheint für die strukturelle Instabilität des $\mathrm{N}$-terminalen Teils des $\beta$-barrel von hVDAC1 wichtig zu sein (Bayrhuber et al., 2008) und der Austausch zu Glutamin (E73Q) verhindert eine Interaktion mit Hexokinase-I (Abu-Hamad et al., 2008; Shoshan-Barmatz et al., 2009). Bei hVDAC3 befindet sich an der Position 73 in der Sequenz ein Glutamin. Um zu überprüfen, ob die Aminosäure Glutaminsäure bzw. Gluatmin an der Position 73 einen Einfluss auf die sub-mitochondriale Lokalisation von hVDAC hat, wurde der Aminosäureaustausch E73Q für hVDAC1 und Q73E für hVDAC3 durchgeführt.

Alle gerade beschriebenen Mutationen wurden auf den, in vorangegangenen Experimenten verwendeten, hVDAC-Flag Plasmiden durchgeführt. 
Bei der mikroskopischen Analyse der mit hVDAC-Flag Plasmiden transfizierten Zellen wurde sowohl für die Deletion des $\mathrm{N}$-Terminus als auch für die Aminosäureaustausche I27A, L29A, L277A, Y225A, F233A, Y247 und E73Q für hVDAC1 keine veränderte sub-mitochondriale Lokalisation beobachtet (Abbildung 8.10). Gleiches gilt für den Austausch von Q73E bei hVDAC3 (Abbildung 8.10).

Hingegen wurde für den Aminosäureaustausch L29A eine teilweise veränderte sub-mitochondriale Lokalisation festgestellt. Es wurden sowohl Zellen gefunden, in denen hVDAC1-L29A eine homogene Verteilung über das komplette Mitochondrium aufwies, wie auch Zellen, in denen hVDAC1-L29A in klar erkennbaren Domänen lokalisiert war (Abbildung 4.4). Das Verhältnis von homogener zur Domänen-Lokalisation hat von Experiment zu Experiment
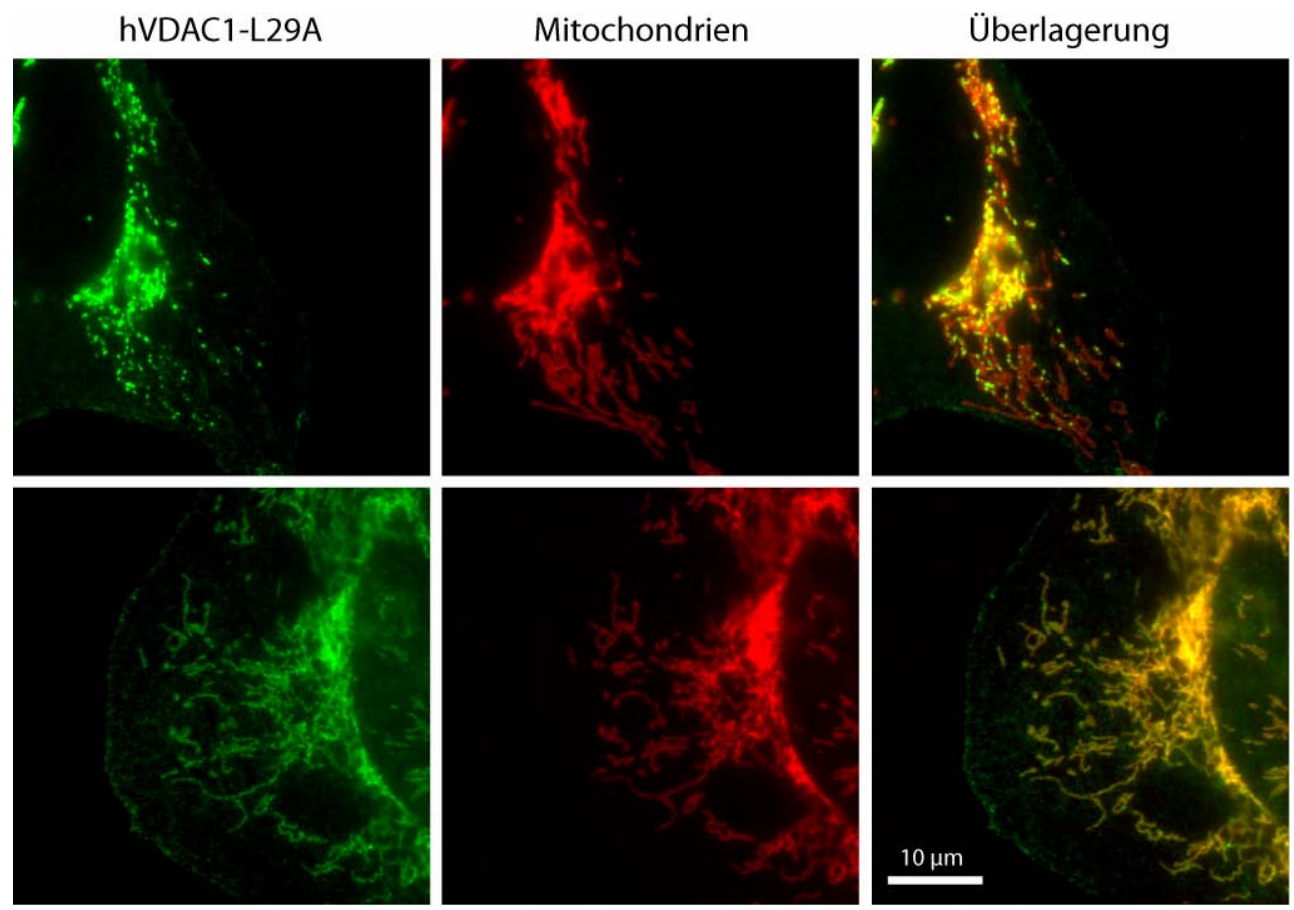

\section{Abbildung 4.4: Lokalisationen von hVDAC1-L29A}

U2OS-Zellen wurden mit einem hVDAC1-Flag Plasmid transfiziert, in dem die Aminosäure Leucin gegen Alanin (L29A) ausgetauscht war. Nach einer Immunofluoreszenz-Markierung unter Verwendung von Antikörpern gegen den Flag-Tag wurde sowohl eine Lokalisation in distinkten Domänen (erste Reihe) wie auch eine homogene Verteilung (zweite Reihe) von hVDAC1-L29A im Verhältnis 1:1 beobachtet. 
variiert. Die Bestimmung des Mittelwerts über alle Experimente ergab eine $45 \%$ Lokalisation in klar erkennbaren Domänen, wohingegen $55 \%$ der Zellen Mitochondrien aufwiesen, in denen hVDAC1-L29A homogen verteilt vorlag.

Somit lässt sich zusammenfassend festhalten, dass die Deletion des N-Terminus, die Aminosäureaustausche I27A, L29A, L277A, Y225A, F233A, Y247 und E73Q für hVDAC1 als auch Q73E für hVDAC3 keinen Einfluss auf die submitochondriale Lokalisation von hVDAC haben. Hingegen wurde für den Austausch L27A bei hVDAC1 eine teilweise veränderte sub-mitochondriale Lokalisation nachgewiesen. Da aber diese veränderte sub-mitochondriale Lokalisation innerhalb eines Experiments wie auch zwischen verschiedenen Experimenten nicht eindeutig war, wurden zunächst keine weiteren Studien hierzu durchgeführt.

\subsubsection{Kolokalisationsstudien zwischen den hVDAC-Isoformen}

Ein zentrales Ergebnis der vorangegangenen Experimente besteht darin, dass hVDAC1 und hVDAC2 in klar erkennbaren Domänen lokalisieren, wohingegen hVDAC3 vorwiegend homogen über das komplette Mitochondrium verteilt ist (Abschnitt 4.1.1). Unklar ist bis jetzt allerdings, ob hVDAC1 und hVDAC2 in denselben oder aber verschiedenen Domänen lokalisieren. Genausowenig können exakte Aussagen über die genaue Kolokalisation von hVDAC1 bzw. hVDAC2 mit hVDAC3 getroffen werden. Aus diesen Gründen wurden Kotransfektionen mit hVDAC-Flag und hVDAC-V5 Plasmiden durchgeführt und die transfizierten Zellen im Anschluss konfokal-mikroskopisch untersucht.

Es ist klar zu erkennen, dass die Fluoreszenzsignale von hVDAC1 und hVDAC2 fast vollständig überlappen, was auf eine hohe Kolokalisation der beiden Proteine schließen lässt (Abbildung 4.5). Zur Kontrolle wurden Plasmide bestehend aus hVDAC1-Flag und hVDAC1-V5 koexprimiert (Abbildung 8.11). Hier konnte, wie für hVDAC1 und hVDAC2, ebenfalls eine fast vollständige Überlappung der Fluoreszenzsignale beobachtet werden. Im Gegensatz dazu unterscheidet sich die 

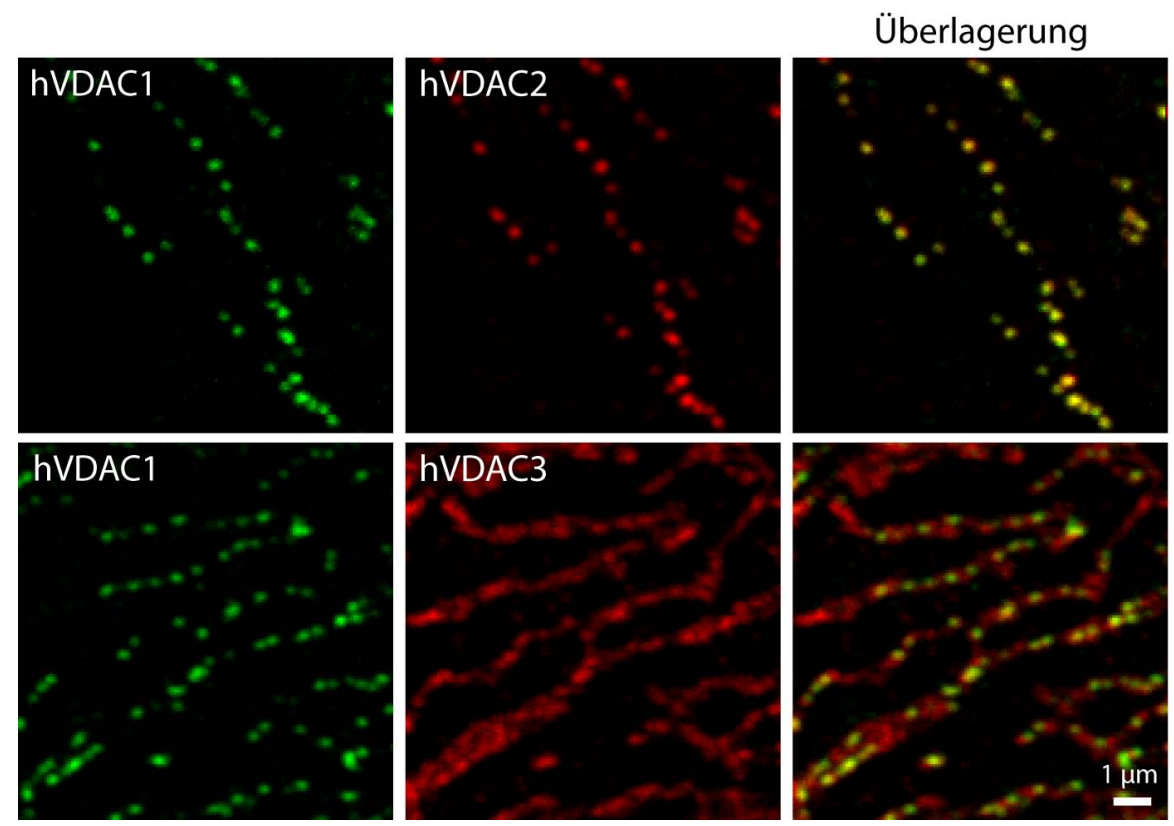

\section{Abbildung 4.5: Kolokalisationsstudien zwischen den hVDAC-Isoformen}

U2OS-Zellen, die zwei hVDAC-Isoformen exprimierten, wurden mit Antikörpern gegen den Flag-Tag und den V5-Tag inkubiert und im Anschluss mit einem konfokalen Mikroskop analysiert. Die Fluoreszenzsignale von hVDAC1-V5 und hVDAC2-Flag überlappen fast vollständig, wohingegen hVDAC3-Flag einen geringeren Kolokalisationsgrad mit hVDAC1-V5 aufweist.

Lokalisation von hVDAC3, dessen Fluoreszenzsignal nur teilweise mit dem von hVDAC1 (Abbildung 4.5) oder hVDAC2 (Abbildung 8.11) übereinstimmt.

Jedoch wurde bei der Koexpression von hVDAC3 mit hVDAC1 oder mit hVDAC2 eine gewisse Heterogenität in der Verteilung von hVDAC3 induziert, die bei der Expression von hVDAC3 alleine nicht zu beobachten war (Abbildung 4.6). Diese schwach ausgeprägten hVDAC3 Domänen kolokalisieren mit den Domänen von hVDAC1 bzw. hVDAC2. Um auszuschließen, dass es sich bei den schwach erkennbaren hVDAC3 Domänen um das "Durchbluten" eines hVDAC1 bzw. hVDAC2 Signal handelt, wurden Aufnahmen von einzeln gefärbten Proben unter identischen Bedingungen gemacht (Abbildung 8.12). Da hierbei ein crosstalk zwischen den einzelnen Signalen ausgeschlossen werden konnte, deutet die Beobachtung darauf hin, dass eine Interaktion zwischen hVDAC3 und hVDAC1 bzw. hVDAC2 stattfindet, die eine leichte Änderung in der Proteinverteilung von hVDAC3 bewirkt. Nichtsdestotrotz wurde hVDAC3 bei Koexpression vorwiegend 


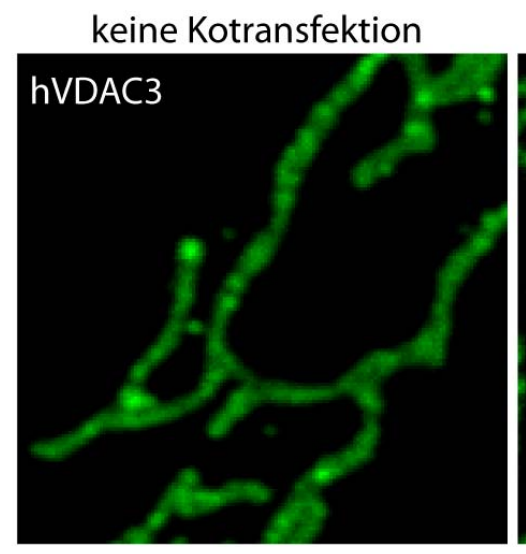

Kotransfektion hVDAC1

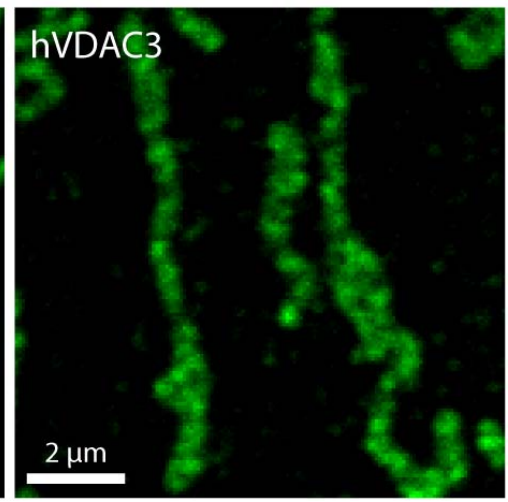

Abbildung 4.6: Heterogenität in der Verteilung von hVDAC3, induziert durch Koexpression mit hVDAC1

Konfokal-mikroskopische Aufnahmen von U2OS-Zellen, transfiziert mit hVDAC3-Flag alleine (linkes Bild) oder zusammen mit hVDAC1-V5 (rechtes Bild). Zur Visualisierung von hVDAC3 wurde eine Immuno-Markierung mit Antikörpern gegen den Flag-Tag durchgeführt. Beim Vergleich fällt auf, dass die Koexpression von hVDAC1-V5 eine schwache Heterogenität in der Verteilung von hVDAC3 induziert.

entlang des gesamten Mitochondriums nachgewiesen und unterschied sich somit weiterhin eindeutig von der hVDAC1 bzw. hVDAC2 Lokalisation.

Durch die qualitative Untersuchung der Kolokalisation der hVDAC-Isoformen konnte zwar gezeigt werden, dass hVDAC1 und hVDAC2 vorwiegend in denselben Domänen lokalisieren, wohingegen hVDAC1 bzw. hVDAC2 nur eine partielle Kolokalisation mit hVDAC3 aufweisen. Hingegen können aufgrund dieser qualitativen Untersuchung keine exakten Aussagen über den Grad der Kolokalisation zwischen den verschiedenen Isoformen getroffen werden. Hierfür ist die quantitative Analyse der konfokal-mikroskopischen Daten nötig (Abschnitt 3.4.5). Dazu wurden die Mitochondrien zunächst vom Hintergrund getrennt und im Anschluss wurden drei Parameter als Maß für die Kolokalisation bestimmt (Manders, 1993). Namentlich handelt es sich um den Pearson's Korrelationskoeffizienten $r_{\mathrm{p}}$, den Überlappungskoeffizienten $r$ und die Kolokalisationskoeffizienten $M_{1}$ und $M_{2}$.

Als Kontrolle wurden Experimente durchgeführt, bei denen hVDAC1-Flag mit hVDAC1-V5 koexprimiert worden sind (Abbildung 4.7). Des Weiteren wurden 
Daten quantifiziert, die auf der Koexpression von hVDAC1 mit hVDAC2 und auf der Koexpression von hVDAC1 mit hVDAC3 basieren (Abbildung 4.7). Die Werte (Tabelle 8.2) für den Pearson's Korrelationskoeffizienten sind fast identisch mit denen des Überlappungskoeffizienten. Für hVDAC1 mit hVDAC1 wie auch für hVDAC1 mit hVDAC2 wurden Koeffizienten von $\sim 0,9$ ermittelt, wobei rechnerisch ein Wert von 1 einer 100 \% Kolokalisation entsprechen würde. Dieser Unterschied kann experimentell durch unvollständige Antikörpermarkierungen bzw. Variationen im Expressionslevel erklärt werden. Da es aber bei dem Wert von hVDAC1 mit hVDAC2 keinen signifikanten Unterschied zur Kontrolle (hVDAC1/hVDAC1) gibt, ist von einer vollständigen Kolokalisation auszugehen. Der Koeffezient für hVDAC1/hVDAC3 liegt mit 0,77-0,78 signifikant niedriger als die Werte für hVDAC1/hVDAC2, was einem geringeren Grad an Kolokalisation entspricht.
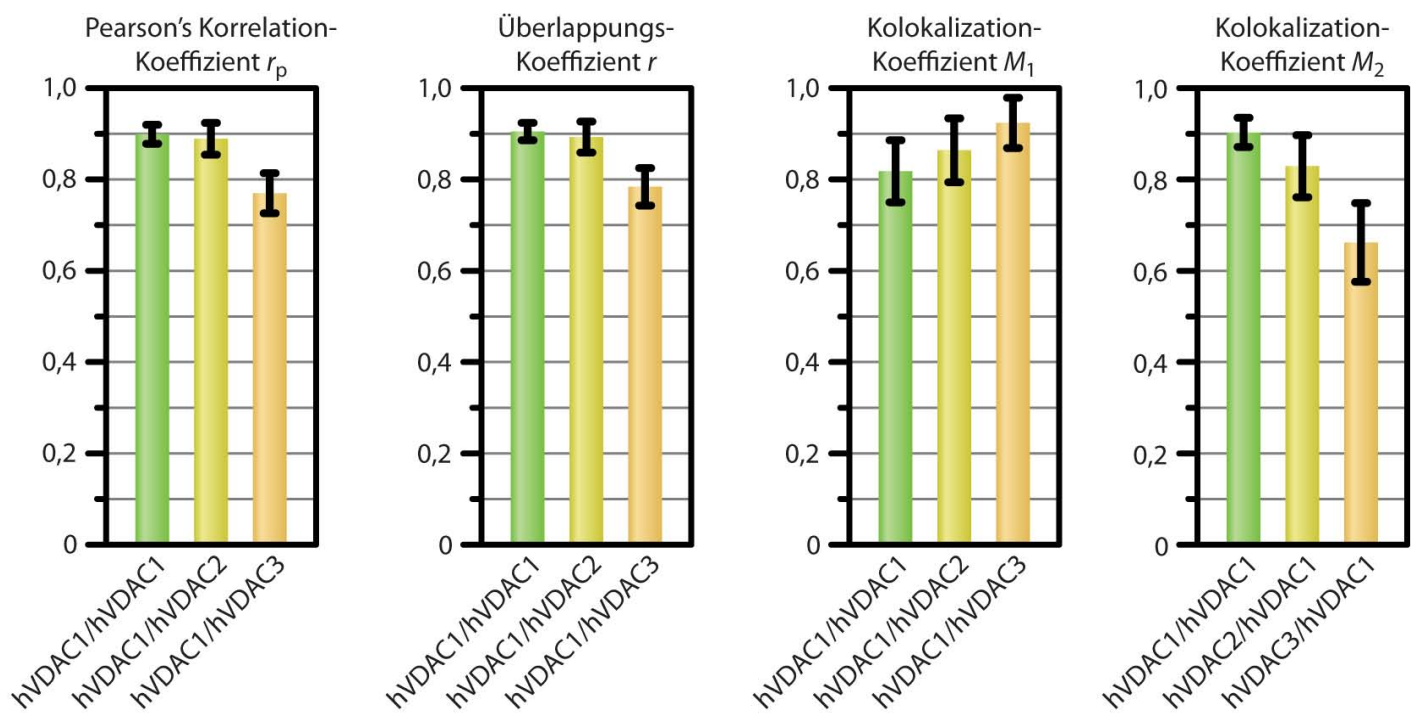

\section{Abbildung 4.7: Kolokalisationsanalyse zwischen den hVDAC-Isoformen}

Analysiert worden ist die Kolokalisation von hVDAC1-V5 mit hVDAC2-Flag bzw. mit hVDAC3-Flag basierend auf konfokal-mikroskopischen Aufnahmen. Als Positivkontrolle diente die Kolokalisation von hVDAC1-V5 mit hVDAC1-Flag. Dargestellt sind der Pearson's Korrelationskoeffizient $r_{\mathrm{p}}$, der Überlappungskoeffizient $r$ und die Kolokalisationskoeffizienten $M_{1}$ und $M_{2}$. Die Fehlerbalken stellen die Standardabweichung von zehn Aufnahmen dar. Die einzelnen Werte sind der Tabelle $8.2 \mathrm{zu}$ entnehmen. 
Sowohl der Pearson's Korrelationskoeffizient wie auch der Überlappungskoeffizient hängen von der relativen Anzahl an Strukturen in den beiden Detektionskanälen $\mathrm{ab}$ und berücksichtigen keine asymmetrischen Verteilungen (Abschnitt 3.4.5). Aus diesem Grund wurden zusätzlich die Kolokalisationskoeffizienten $M_{1}$ und $M_{2}$ bestimmt. Für hVDAC1/hVDAC1 wie auch für hVDAC1/hVDAC2 wurden keine signifikanten Unterschiede zwischen $M_{1}$ und $M_{2}$ gefunden. Es liegt keine asymmetrische Verteilung zwischen hVDAC1 sowohl mit sich selbst als auch mit hVDAC2 vor. Im Gegensatz dazu unterscheidet sich für hVDAC1/hVDAC3 $M_{1}$ mit $0,92 \pm 0,06$ von $M_{2}$ mit $0,66 \pm 0,09$ deutlich. Erklärbar werden diese Werte dadurch, dass es kaum Regionen gibt, in denen zwar ein Signal von hVDAC1, nicht aber ein Signal von hVDAC3 vorliegt. Im Gegensatz dazu gibt es sehr wohl deutlich erkennbare Stellen, in denen Signale von hVDAC3 vorliegen, nicht aber von hVDAC1. Somit reflektieren die unterschiedlichen Werte der Kolokalisationskoeffizienten $M_{1}$ und $M_{2}$ die asymmetrische Verteilung von hVDAC1 und hVDAC3.

Zusammenfassend konnte durch qualitative und quantitative Kolokalisationsstudien gezeigt werden, dass hVDAC1 und hVDAC2 nahezu vollständig in denselben Domänen lokalisieren, wohingegen hVDAC3 zu einem signifikant geringeren Grad mit hVDAC1 (und somit auch mit hVDAC2) kolokalisiert.

\subsubsection{Kolokalisationsstudien zwischen den hVDAC-Isoformen und der}

\section{Hexokinase-I}

Sowohl in gesunden wie auch in apoptotischen Zellen scheint die Interaktion von VDAC und Hexokinase eine wichtige Rolle zu spielen (Linden et al., 1982; Wilson, 1995; Pastorino und Hoek, 2003; Abu-Hamad et al., 2008; Pastorino und Hoek, 2008). Wenige und teilweise widersprüchliche Daten sind über die genaue Interaktion einzelner VDAC-Isoformen mit Hexokinase-I bekannt (Abschnitt 2.1.6). Um Hinweise auf Interaktionen zwischen den hVDAC-Isoformen und der 
Hexokinase zu bekommen, wurden mit diesen Proteinen Kolokalisationsstudien durchgeführt.

Zur Detektion der Hexokinase-I wurde ein Hexokinase-I-spezifischer Antikörper verwendet. Die drei Flag-markierten hVDAC-Isoformen wurden nach Transfektion über Flag spezifische Antikörper nachgewiesen.

Beim konfokal-mikroskopischen Vergleich der Färbungen von hVDAC3 und Hexokinase-I (Abbildung 4.8, links) fällt es schwer visuell deutliche Unterschiede in der Lokalisation der beiden Proteine auszumachen. Beide Proteine sind über die komplette Länge des Mitochondriums verteilt, wobei sich bei genauer Betrachtung der konfokalen Aufnahmen höchstens schwache Unterschiede in der submitochondrialen Lokalisation erahnen lassen. Aufgrund dieser dichten Verteilung von Hexokinase-I und hVDAC3 ist eine Kolokalisationsanalyse basierend auf
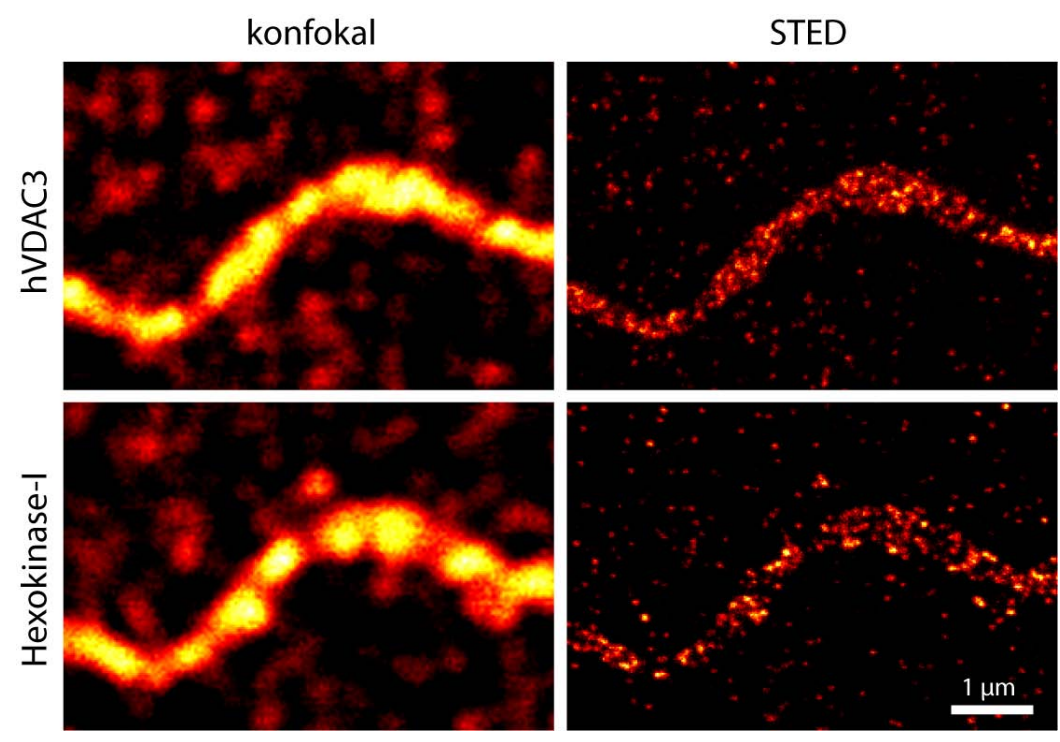

Abbildung 4.8: Sub-mitochondriale Lokalisation von hVDAC3 und Hexokinase-I, analysiert mit einem konfokalen und einem STED-Mikroskop

U2OS-Zellen wurden mit einem hVDAC3-Flag Plasmid transfiziert. Zur Visualisierung wurden Antikörper gegen den Flag-Tag und gegen Hexokinase-I verwendet. In den STED-Aufnahmen ist zu erkennen, dass sowohl die Hexokinase-I als auch hVDAC3 in vielen kleinen Clustern entlang des Mitochondriums lokalisiert sind. Hingegen können im konfokalen Mikroskop keine sub-Strukturen nachgewiesen werden und die Proteinverteilungen erscheinen weitgehend homogen. Deshalb ist eine Kolokalisationsanalyse, basierend auf konfokalmikroskopischen Daten, nicht möglich. Die STED-Aufnahmen wurden an einem nicht kommerziell erhältlichen Aufbau durchgeführt. 
konfokal-mikroskopischen Daten nicht möglich. Hingegen bietet sich die STED (stimulated emission depletion)-Mikroskopie (Abschnitt 8.1) (Hell und Wichmann, 1994; Hell, 2009b) mit ihrer deutlich verbesserten Auflösung zur Untersuchung sub-mitochondrialer Proteinverteilungen an. Um genauere Einblicke in die sub-mitochondriale Lokalisation von hVDAC und Hexokinase-I zu erhalten wurde ein Zwei-Farben STED-Mikroskop verwendet.

In den STED-Aufnahmen (Abbildung 4.8, rechts) ist deutlich zu erkennen, dass sowohl die Hexokinase-I wie auch hVDAC3 in vielen kleinen Clustern lokalisieren, die über das komplette Mitochondrium verteilt sind. Die Clusterdurchmessern (inklusive verwendeter Antikörper) variieren zwischen 40-100 nm (Tabelle 8.3), wobei $40 \mathrm{~nm}$ der Auflösung des Mikroskops entspricht. Darüberhinaus entsteht der visuelle Eindruck, dass beide Proteine zumindest nicht komplett kolokalisieren.

Nicht nur für hVDAC3 und die Hexokinase-I, sondern auch für hVDAC1 und hVDAC2 konnten durch die Zwei-Farben-STED-Mikroskopie mehr Details in der sub-mitochondrialen Lokalisation beobachtet werden. Bei der Untersuchung der hVDAC1 und hVDAC2 Domänen mittels STED-Mikroskopie fiel auf, dass diese

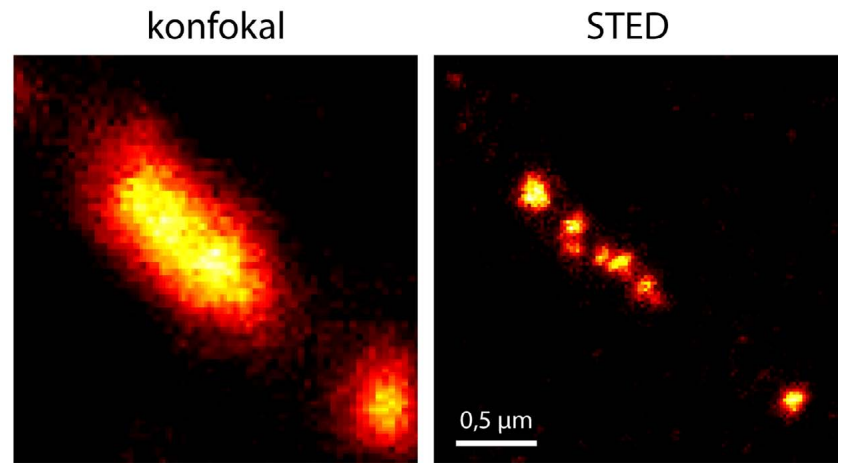

Abbildung 4.9: Konfokale und korrespondierende STED-Aufnahme von hVDAC1-Domänen

U2OS-Zellen wurden mit einem hVDAC1-Flag Plasmid transfiziert, im Anschluss mit Antikörpern gegen den Flag-Tag inkubiert und im konfokalen- und STED-Modus eines nicht kommerziellen Mikroskops analysiert. Hierbei wurde festgestellt, dass die im konfokalen Mikroskop beobachteten VDAC-Domänen häufig aus mehreren kleineren Sub-Domänen bestehen. 
zwar weiterhin in klar abgrenzbaren Bereichen im Mitochondrium lokalisieren.

Die, basierend auf konfokalen Daten, beschriebenen hVDAC1 und hVDAC2

Domänen bestehen aber häufig aus kleineren Sub-Domänen (Abbildung 4.9) mit

Durchessern (inklusive verwendeter Antiköper) von 70-340 nm (Tabelle 8.3).

Die qualitative Beurteilung der STED-Aufnahmen aller drei Isoformen und deren

Kolokalisation mit Hexokinase-I führt zu einem komplexen Bild (Abbildung 4.10).

Die Hexokinase-I kolokalisiert bis zu einem gewissen Maß zwar mit allen drei hVDAC-Isoformen. Über den Grad an Kolokalisation kann aber, basierend auf diesen qualitativen Daten, keine Aussage getroffen werden.

Um den Grad der Kolokalisation zwischen Hexokinase-I und den drei hVDAC-
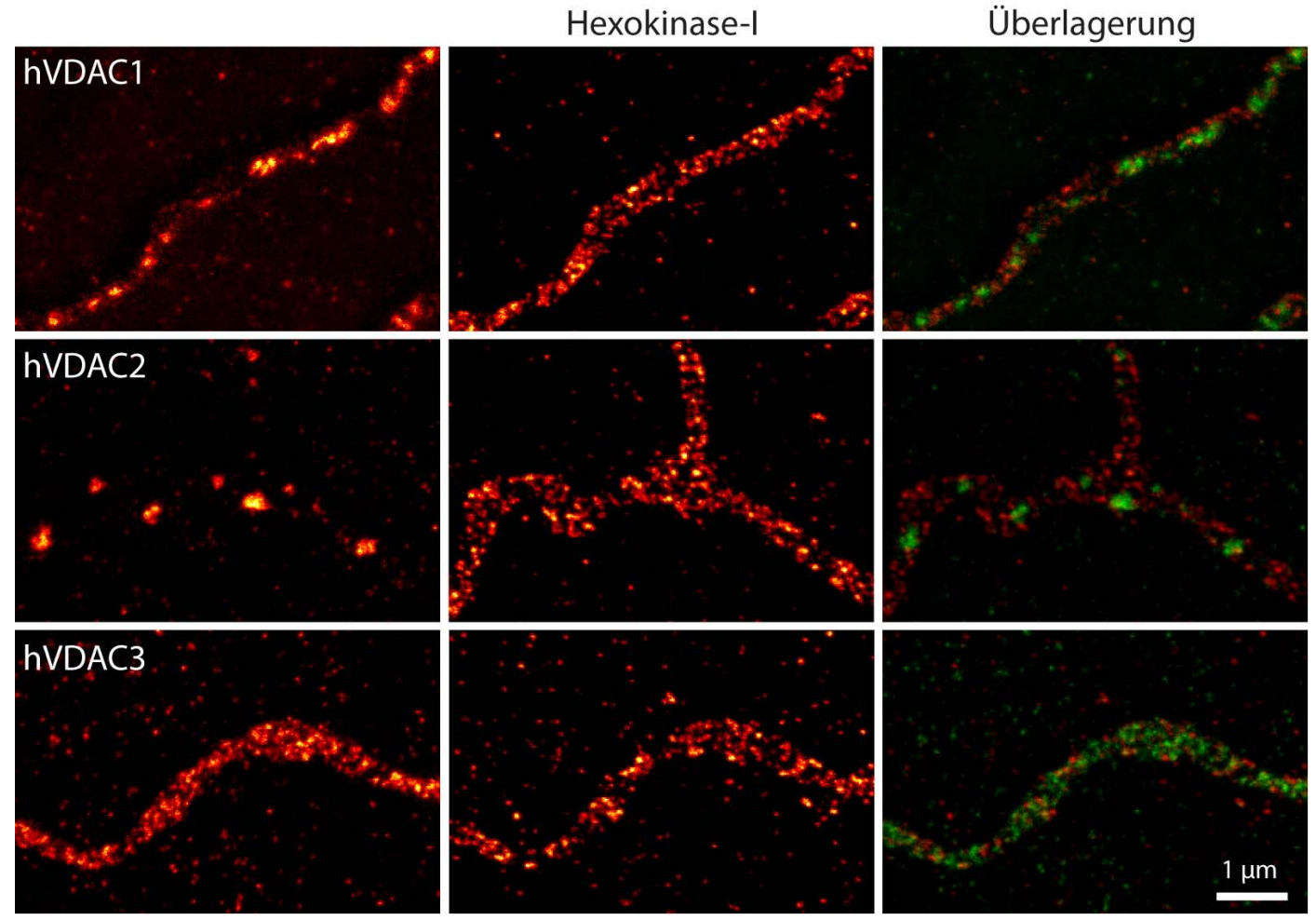

\section{Abbildung 4.10: Zwei-Farben-STED-Mikroskopie von den drei hVDAC- Isoformen und Hexokinase-I}

U2OS-Zellen, die eine der Flag-markierten hVDAC-Isoformen exprimierten, wurden mit Antikörpern gegen den Flag-Tag und Hexokinase-I inkubiert. Unter Verwendung der STEDMikroskopie war es möglich, sowohl einzelne hVDAC3 und Hexokinase-I-Cluster aufzulösen, als auch zu zeigen, dass die hVDAC1- und hVDAC2-Domänen aus kleineren Sub-Domänen bestehen (siehe auch Abbildung 4.9). Die Daten deuten darauf hin, dass die Hexokinase-I mit den drei hVDAC-Isoformen nur teilweise kolokalisiert. In der Überlagerung ist das VDACSignal in grün, das Hexokinase-I-Signal in rot dargestellt. 
Isoformen $\mathrm{zu}$ bestimmen, wurde eine Kolokalisationsanalyse durchgeführt (Abschnitt 3.4.5). Wie zuvor für die konfokalen Daten (Abschnitt 4.1.3) wurden drei verschiedene Korrelationskoeffizienten bestimmt (Abbildung 4.11).

Es wurden zwei Kontrollen durchgeführt. Für die eine Kontrolle wurde eine Doppeltransfektion mit zwei hVDAC1 kodierenden Plasmiden durchgeführt, die sich in der Sequenz des kodierenden Protein-Tags (Flag/V5) unterschieden. Für die andere Kontrolle wurden Hexokinase-I-Antikörper verwendet, die mit fluorophor-gekoppelten (KK114) sekundären Antikörpern detektiert wurden. Zusätzlich wurden tertiäre Antikörper, markiert mit einem anderen Fluorophor (Atto590), eingesetzt, welche gegen die sekundären Antikörper gerichtet waren. Sowohl der Pearson's Korrelationskoeffizient wie auch der Überlappungskoeffizient lagen für beide Kontrollen bei 0,83, was unter diesen experimentellen Bedingungen einer 100\% igen Kolokalisation entspricht.

Für die quantitative Kolokalisationsanalyse zwischen der Hexokinase-I und den drei hVDAC-Isoformen konnten kaum Unterschiede zwischen dem Pearson's Korrelationskoeffizienten und dem Überlappungskoeffizienten festegestellt werden. Sowohl für hVDAC1/Hexokinase-I als auch für hVDAC2/Hexokinase-I wurden Werte von $r_{\mathrm{p}}=0,45$ und $r=0,49$ ermittelt. Im Gegensatz dazu war der Grad an Kolokalisation zwischen hVDAC3 und Hexokinase-I mit Werten von $r_{\mathrm{p}}=$ 0,66 und $r=0,71$ signifikant höher, aber weiterhin unterhalb der Positivkontrollen.

Die Werte für den Kolokalisationkoeffizient $M_{1}$ liegen in allen Fällen (hVDAC13/Hexokinase-I) mit 0,76 bis 0,80 im Bereich der Positivkontrollen (0,80 und 0,84). Unterschiede in der Kolokalisation der einzelnen hVDAC-Isoformen mit Hexokinase-I sind für den Kolokalisationskoeffizient $M_{1}$ nicht zu erkennen. Ein vergleichbar hoher $M_{2}$ Koeffizient wurde für die Hexokinase-I/hVDAC3 bestimmt $(0,81)$, wohingegen für Hexokinase-I/hVDAC1 und Hexokinase-I/hVDAC2 der $M_{2}$ Koeffizient mit 0,52 signifikant geringer war. Hiernach kolokalisiert eine größere Fraktion der Hexokinase-I mit hVDAC3 als mit hVDAC1 oder hVDAC2. 
A

B

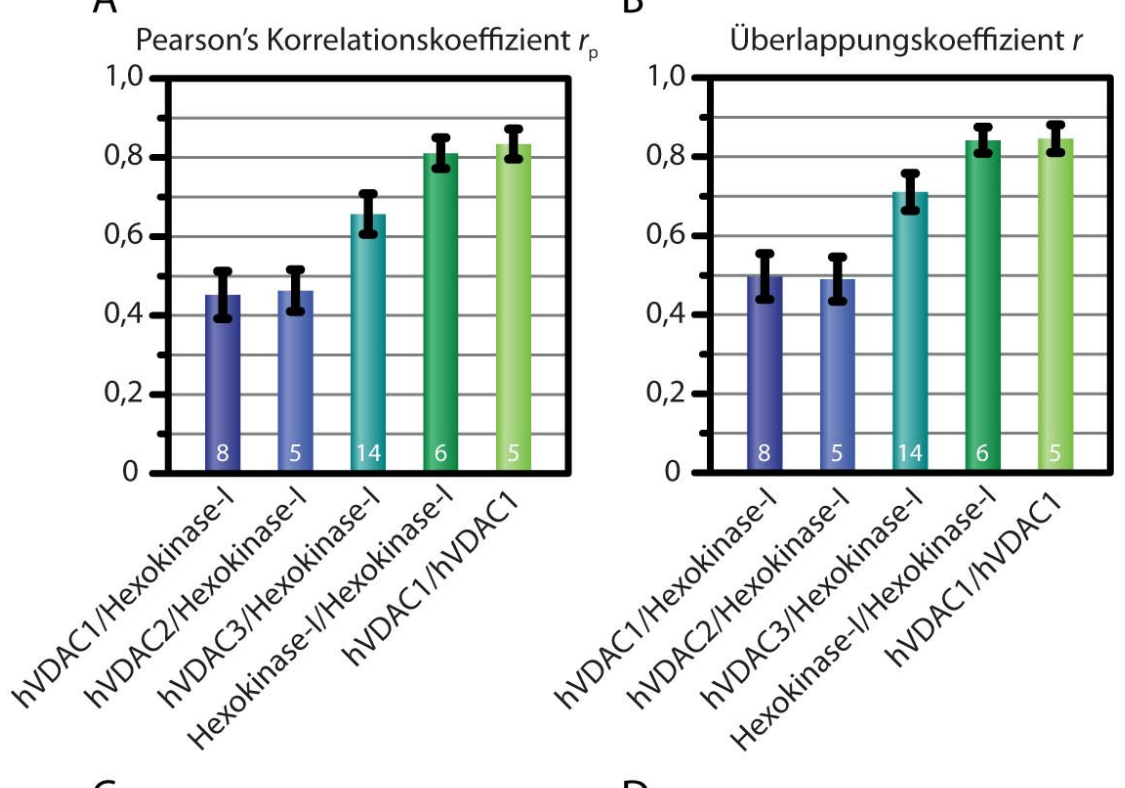

C

D

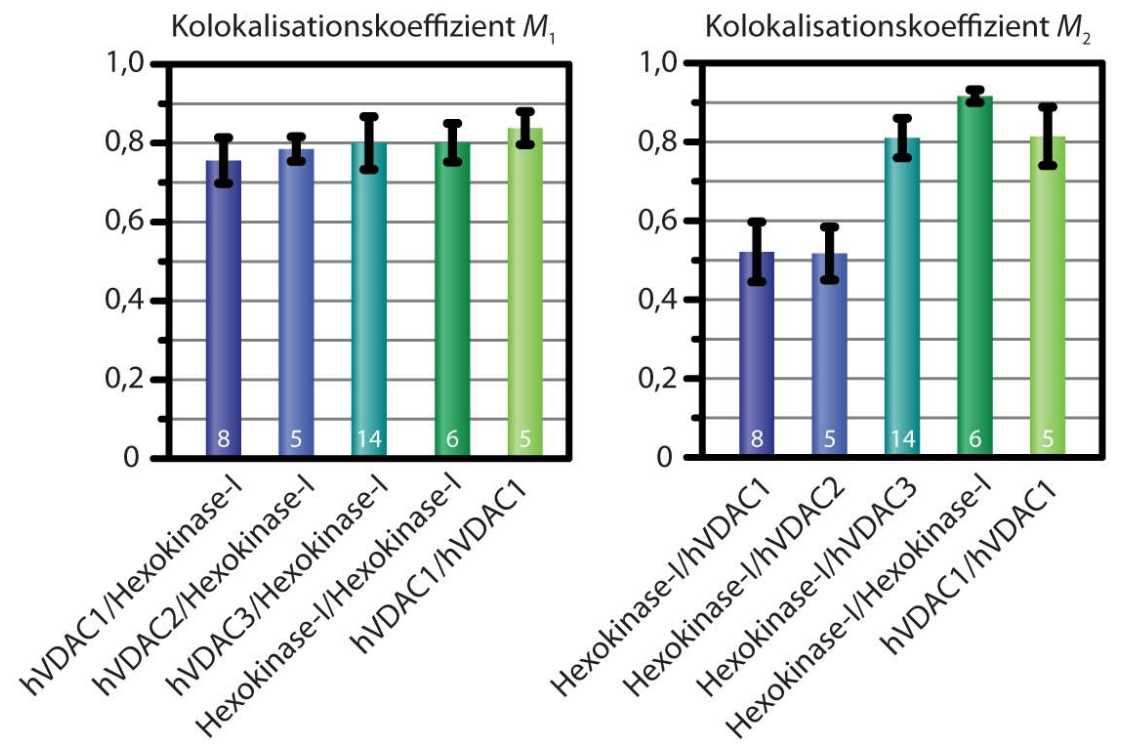

\section{Abbildung 4.11: Kolokalisationsanalyse zwischen den hVDAC-Isoformen und der Hexokinase-I}

Analyse der Kolokalisation von Hexokinase-I mit hVDAC1-Flag, hVDAC2-Flag und hVDAC3-Flag. Als Positivkontrolle wurden einerseits Zellen verwendet, die mit hVDAC1-V5 und hVDAC1-Flag Plasmiden transfiziert worden sind. Andererseits wurde eine Hexokinase-IAntikörper-Markierung auf untransfizierten Zellen durchgeführt, in der sekundäre und tertiäre Antikörper verwendet wurden, an die zwei unterschiedliche Flurophore (KK114, Atto590) gekoppelt waren. Dargestellt sind der Pearson's Korrelationskoeffizient $r_{\mathrm{p}}$, der Überlappungskoeffizient $r$ und die Kolokalisationskoeffizienten $M_{1}$ und $M_{2}$. Die Fehlerbalken stellen die Standardabweichung dar. Die Zahlen an den einzelnen Säulen geben die Anzahl der analysierten Zellen wieder. Die einzelnen Werte sind der Tabelle 8.4 zu entnehmen. 
Zusammenfassend ist festzuhalten, dass alle drei hVDAC-Isoformen $\mathrm{zu}$ einem gewissen Teil mit Hexokinase-I kolokalisieren. Der Grad der Kolokalisation zwischen hVDAC und Hexokinase-I ist hingegen isoform-spezifisch. Während das Vorhandensein von hVDAC3 und der Hexokinase-I stark korreliert, kolokalisiert die Hexokinase-I mit hVDAC1 bzw. hVDAC2 hingegen zu einem signifikant geringeren Teil. Darüberhinaus kolokalisiert ein beträchtlicher Teil von hVDAC1 und hVDAC2, und ein geringerer Teil von hVDAC3, überhaupt nicht mit der Hexokinase-I. 


\subsection{Untersuchung von sub-mitochondrialen Proteinverteilungen in}

\section{unbehandelten und apoptotischen Zellen}

Apoptose ist als antagonistischer Vorgang zur Zellproliferation ein zentraler Prozess für alle multizellulären Organismen. Sie spielt bei der Entfernung von überflüssigen Zellen während der Entwicklung von Organismen, bei der kontinuierlichen Erneuerung von Geweben, wie auch für die Entfernung von mutierten Zellen eine nicht zu unterschätzende Rolle. Trotz dieser wichtigen Bedeutung sind bis jetzt viele mechanistische Details des apoptotischen Signalwegs weitgehend unklar (z.B. bei der Cytochrom $c$-Freisetzung). Genauso ist wenig über die sub-mitochondriale Verteilung von Proteinen und deren mögliche Änderungen während der Apoptose bekannt.

Aus diesen Gründen wurde die Verteilung von verschiedenen mitochondrialen Proteinen in unbehandelten und apoptotischen Zellen mittels STED-Mikroskopie und sich anschließender quantitativer Analyse untersucht.

\subsubsection{Auswahl einer geeigneten Zelllinie}

Die meisten mitochondrialen Proteine sind zu dicht gepackt, um deren Verteilung mittels konventioneller Lichtmikroskopie untersucht zu können. Durch die verbesserte Auflösung der STED-Mikroskopie ist zwar die Analyse sub-mitochondrialer Proteinverteilungen möglich (Abschnitt 8.1), in Abhängigkeit von der Dichte der Proteine kann die Unterscheidung von einzelnen Proteinclustern aber weiterhin schwierig sein. Da durch eine andere Arbeit bekannt ist (Wurm, 2008), dass die Dichte mitochondrialer Proteinverteilungen zwischen Zelllinien variiert, wurde zunächst eine geeignete Zelllinie für die Untersuchung sub-mitochondrialer Proteinverteilungen in unbehandelten und apoptotischen Zellen ausgewählt. Es wurde eine Zelllinie gesucht, in der einzelne Proteincluster deutlich unterschieden werden konnten. Des Weiteren ist für die mikroskopische Analyse eine Zelllinie von Vorteil, die ausgestreckt ist und deren 
Mitochondrien in einzelnen, klar unterscheidbaren Tubuli im Cytosol angeordnet sind.

Aus diesen Gründen wurde sowohl die mitochondriale Morphologie, als auch die sub-mitochondriale Proteinverteilung von 16 verschiedenen Säuger-Zelllinien (Abschnitt 3.3.1) untersucht. Als Marker-Protein wurde Tom20 verwendet, von dem bekannt ist, dass es in Proteinclustern lokalisiert (Donnert et al., 2007; Schmidt et al., 2008; Wurm, 2008).

Die mitochondrialen Netzwerke der verschiedenen Zelllinien wurden mittels Epifluoreszenz-Mikroskopie visualisiert (Abbildung 4.12). Sie unterscheiden sich deutlich. Grob können zwei verschiedene Netzwerk-Typen unterschieden werden: Mitochondrien des einen Netzwerk-Typs sind sehr dicht zusammengelagert und konzentrieren sich um den Kern. Es können kaum einzelne Tubuli unterschieden werden. Dieser Typus wurde in den Zelllinien A172, BLM, HeLa, HT1080 MCF-7, RCC-A, SHEP und SH-SY5Y gefunden. Mitochondrien des anderen Netzwerk-Types sind hingegen nicht so dicht zusammengelagert. Einzelne Tubuli können klar unterschieden werden. Dieser Netzwerk-Typ wurde in den Zelllinien LN18, MEV, PtK2, RCC-B, RCC-D, RCC-MF, U2OS und Vero beobachtet. Aufgrund der einzeln, voneinander abgrenzbaren Tubuli ist der zweite Netzwerk-Typ gut für mikroskopische Studien geeignet.

Bei der Untersuchung des Markerproteins Tom20 mittels STED-Mikroskopie wurden Unterschiede in der Dichte der Proteinverteilung festgestellt. In den Zelllinien HT1080, PtK2, RCC-B, RCC-C und U2OS sind einzelne Proteincluster deutlich zu erkennen, wohingegen dies in den übrigen Zelllinien schwerer fällt. Da vier der fünf Zelllinien (HT1080 ausgenommen) zu der zweiten Gruppe des Netzwerk-Types gehören, also klar erkennbare, isolierte mitochondriale Tubuli und zusätzlich einzelne Tom20 Proteincluster aufweisen, sind sie potentiell gut für die Untersuchung sub-mitochondrialer Proteinverteilungen geeignet. 
In dieser Arbeit sollten mitochondriale Proteine vorwiegend über Antikörpermarkierungen analysiert werden. Deshalb ist die Verfügbarkeit von spezifischen Antikörpern von nicht zu unterschätzender Bedeutung. Eine große Zahl von kommerziell erhältlichen Antikörpern ist gegen humane Proteine gerichtet. Das spricht für die Verwendung von humanen Zellen. Ein weiterer Vorteil bei der Verwendung von humanen Zellen ist das Vorhandensein von
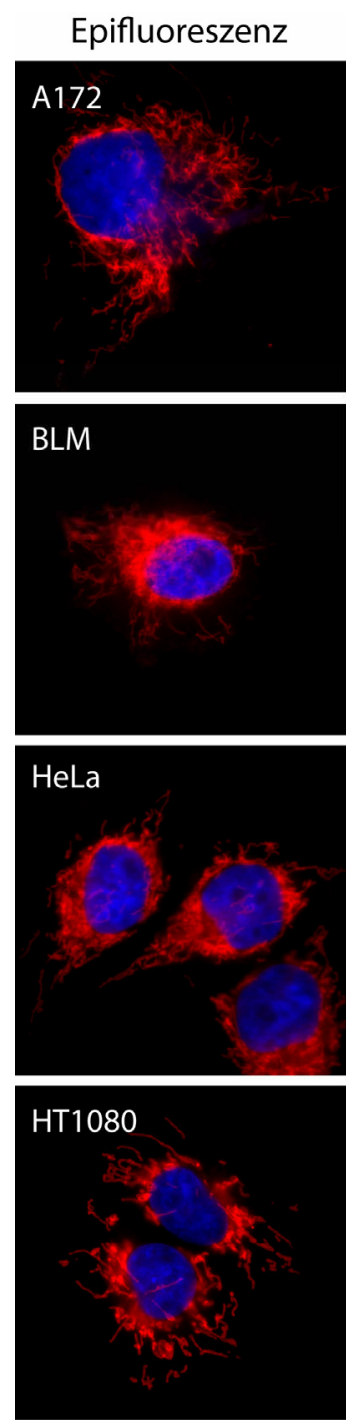
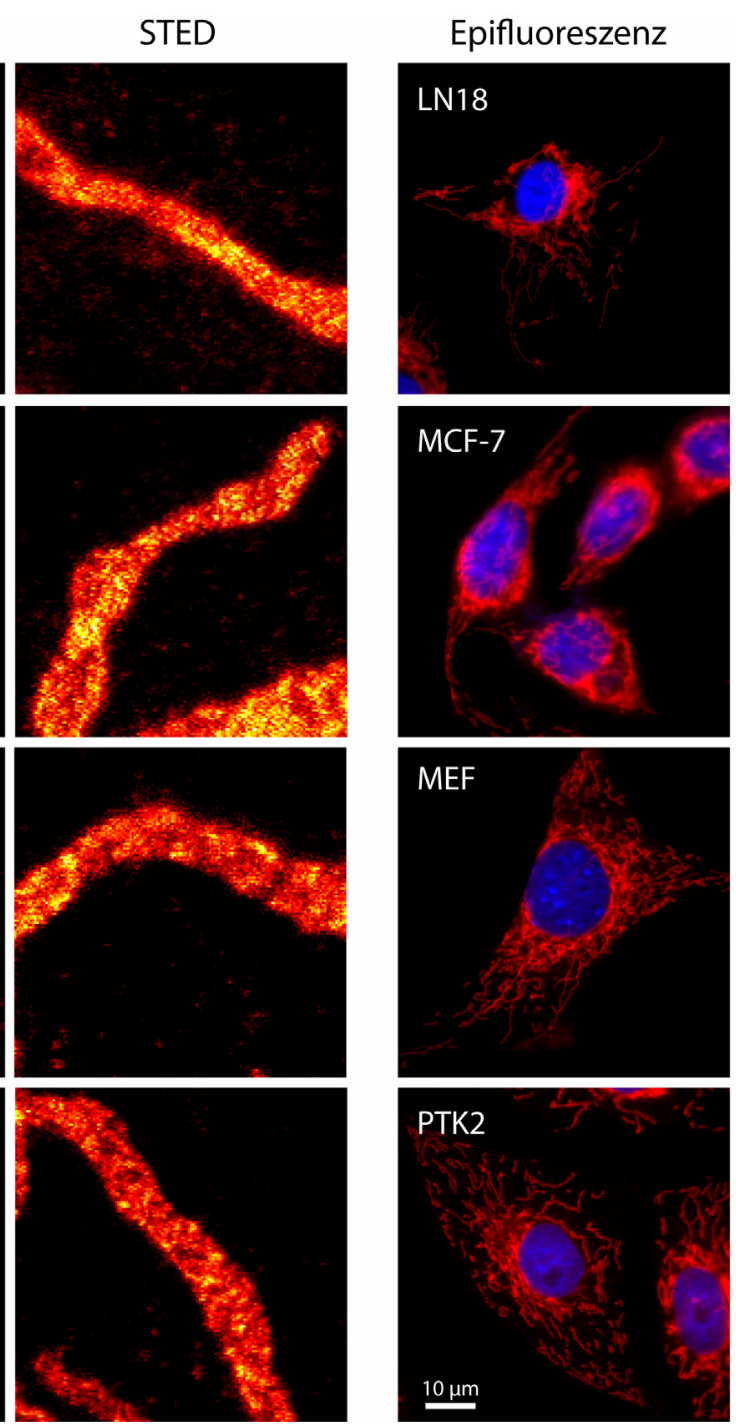
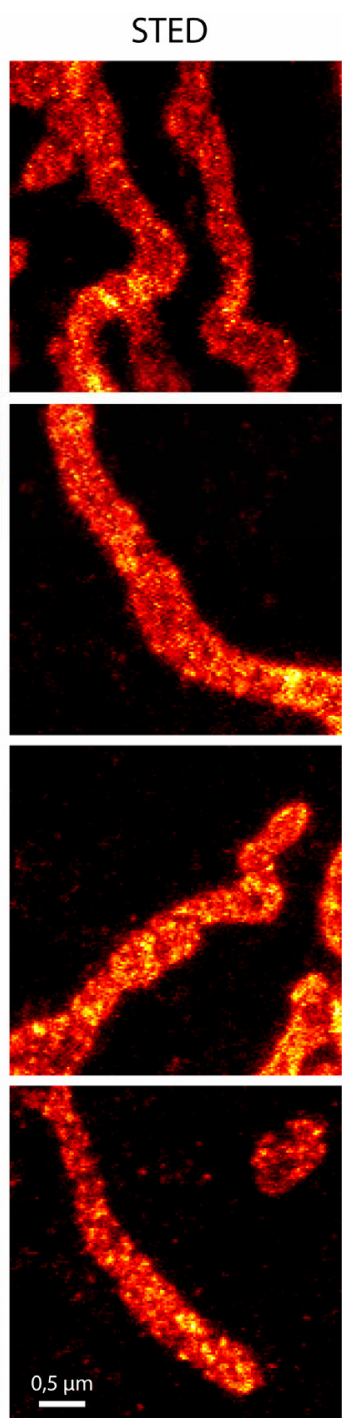

Abbildung 4.12: Mitochondriale Morphologie und sub-mitochondriale Verteilung des Proteins Tom20

Fortsetzung und Abbildungsbeschreibung siehe nächste Seite. 

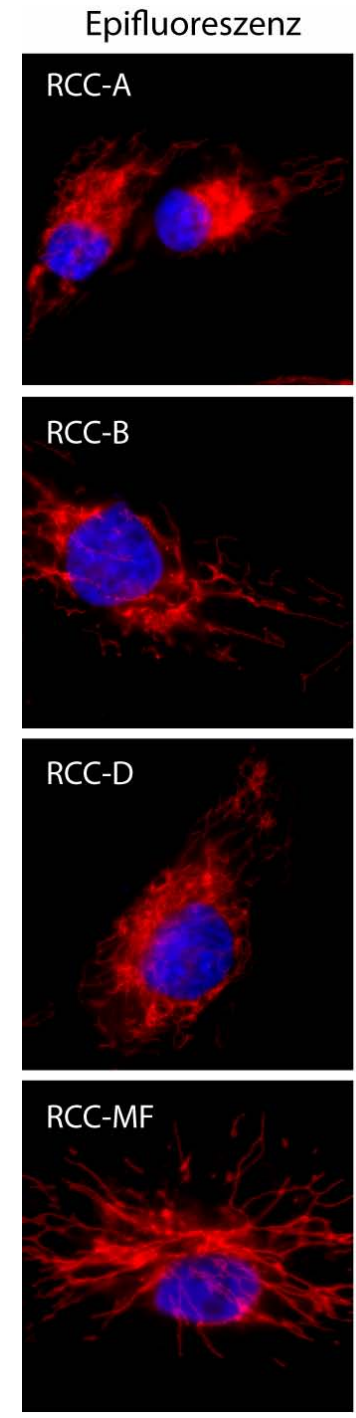
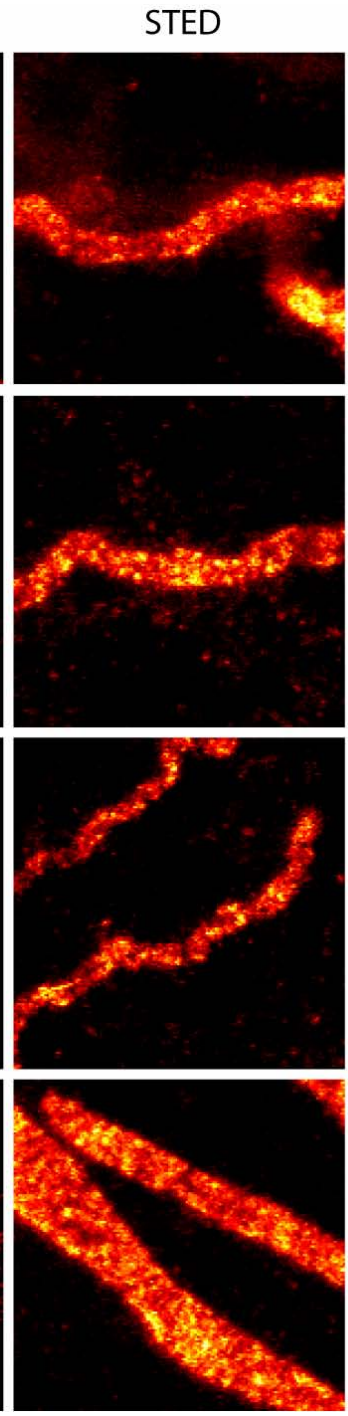

Epifluoreszenz
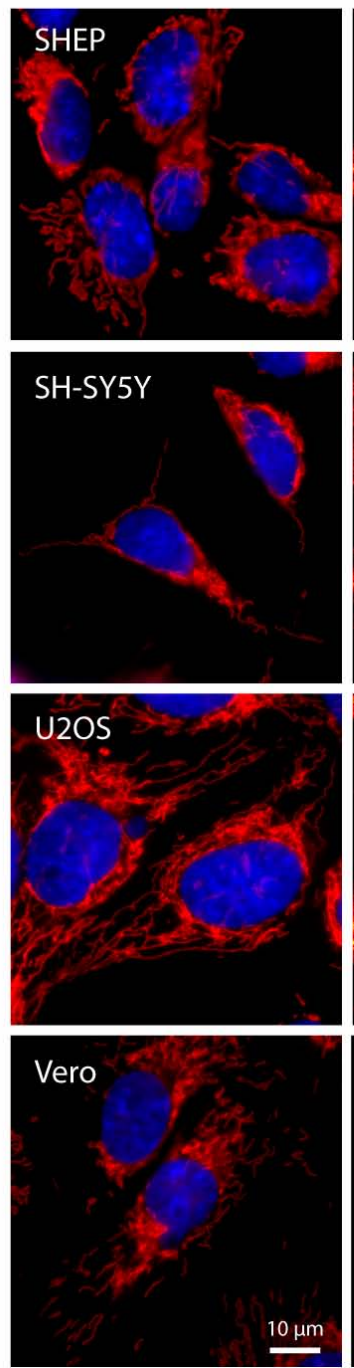

STED
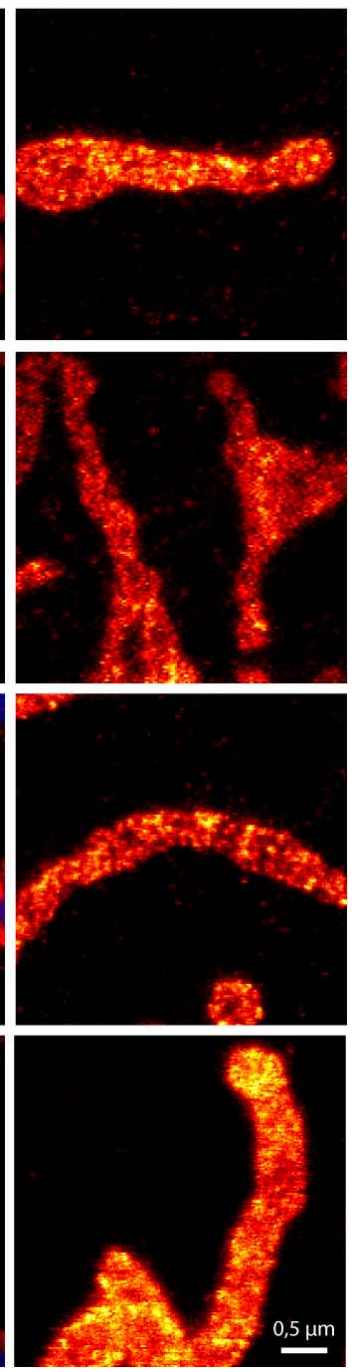

\section{Abbildung 4.12: Mitochondriale Morphologie und sub-mitochondriale} Verteilung des Proteins Tom20

Zellen der verschiedenen Zelllinien (Abschnitt 3.3.1) wurden fixiert, gefolgt von einer Immunfluoreszenz-Markierung mit Antikörpern gegen das Protein Tom20. In den Epifluoreszenz-Bildern ist das mitochondriale Netzwerk (rot) und der Zellkern (blau) zu erkennen. Das mitochondriale Netzwerk variiert in den verschiedenen Zelllinien von sehr dichten Anordnungen, konzentriert um den Zellkern (z.B. in HeLa-Zellen) bis hin zu weit verzweigten, einzeln erkennbaren Tubuli (z.B. in PtK2-Zellen). Die sub-mitochondriale Proteinverteilung von Tom20 (fire Farbtabelle) variiert ebenfalls zwischen den verschiedenen Zelllinien (STED-Bilder). Basierend auf diesen Daten erscheinen die Zelllinien PtK2, RCC-B, RCC-D und U2OS als am Besten zur Analyse sub-mitochondrialer Proteinverteilungen geeignet.

Sequenzinformationen, da das menschliche Genom (z.B. im Gegensatz zu dem der

Beutelratte) komplett sequenziert ist. Nicht zuletzt für die Apoptoseforschung und die damit verbundenen Krankheiten ist die Arbeit mit humanen Zellen nahe 
liegend. Aus diesen Gründen bietet sich die Verwendung einer humanen Zelllinie an. Da die Tom20 Proteincluster in den Zellen der Beutelratte (PtK2) nicht deutlich besser zu unterscheiden sind als in den humanen RCC-B-, RCC-C- und U2OS-Zellen, wurde die Verwendung der PtK2-Zellen für nachfolgende Studien verworfen. Des Weiteren weisen die U2OS-Zellen deutlich kürzere Verdopplungszeiten auf als die RCC-B- und RCC-C-Zellen. Da kurze Verdopplungszeiten für viele Experimente von Vorteil sind und die U2OS-Zellen, im Gegensatz zu den RCC-Zellen eine etablierte Zelllinie sind, wurden für alle folgenden Experimente U2OS-Zellen verwendet.

\subsubsection{Auswahl eines geeigneten Apoptoseinduktors}

Neben der Auswahl einer geeigneten Zelllinie wurde im nächsten Schritt ein geeignetes Apoptosestimulanz gesucht. Es ist eine Vielzahl von verschiedenen Chemikalien beschrieben, die auf unterschiedliche Weise Apoptose auslösen. Im Rahmen dieser Arbeit wurden sieben verschiedene Stimulanzien (Actinomycin D, Betulinsäure, Camptothecin, Ionomycin, Mitomycin C, Staurosporin, TRAIL/Cyclohexemid, Abschnitt 3.3.6) getestet. Es wurde ein Reagenz gesucht, welches über den intrinsischen Signalweg (Abschnitt 2.2.3) Apoptose auslöst und von dessen Wirkung möglichst viele Zellen zum gleichen Zeitpunkt betroffen sind. Darüber hinaus wäre es für mikroskopische Aufnahmen von Vorteil, wenn die Zellen zum Zeitpunkt der Cytochrom $c$-Freisetzung noch ausgestreckt sind.

Hierzu wurden U2OS-Zellen ausgesät, zwölf Stunden mit dem entsprechenden Reagenz behandelt, fixiert und im Anschluss eine Immuno-Markierung durchgeführt. Um den Apoptose-Status in den Zellen zu charakterisieren, wurde ein Cytochrom $c$-Antikörper verwendet. Zur Beurteilung der mitochondrialen Morphologie wurde ein Tom20-Antikörper eingesetzt.

Bei mikroskopischer Betrachtung (Abbildung 4.13) fiel auf, dass ein Teil der Zellen, die mit Actinomycin D, Camptothecin, Mitomycin C, Staurosporin und TRAIL/Cyclohexemid behandelt worden sind, eine Cytochrom $c$-Freisetzung 

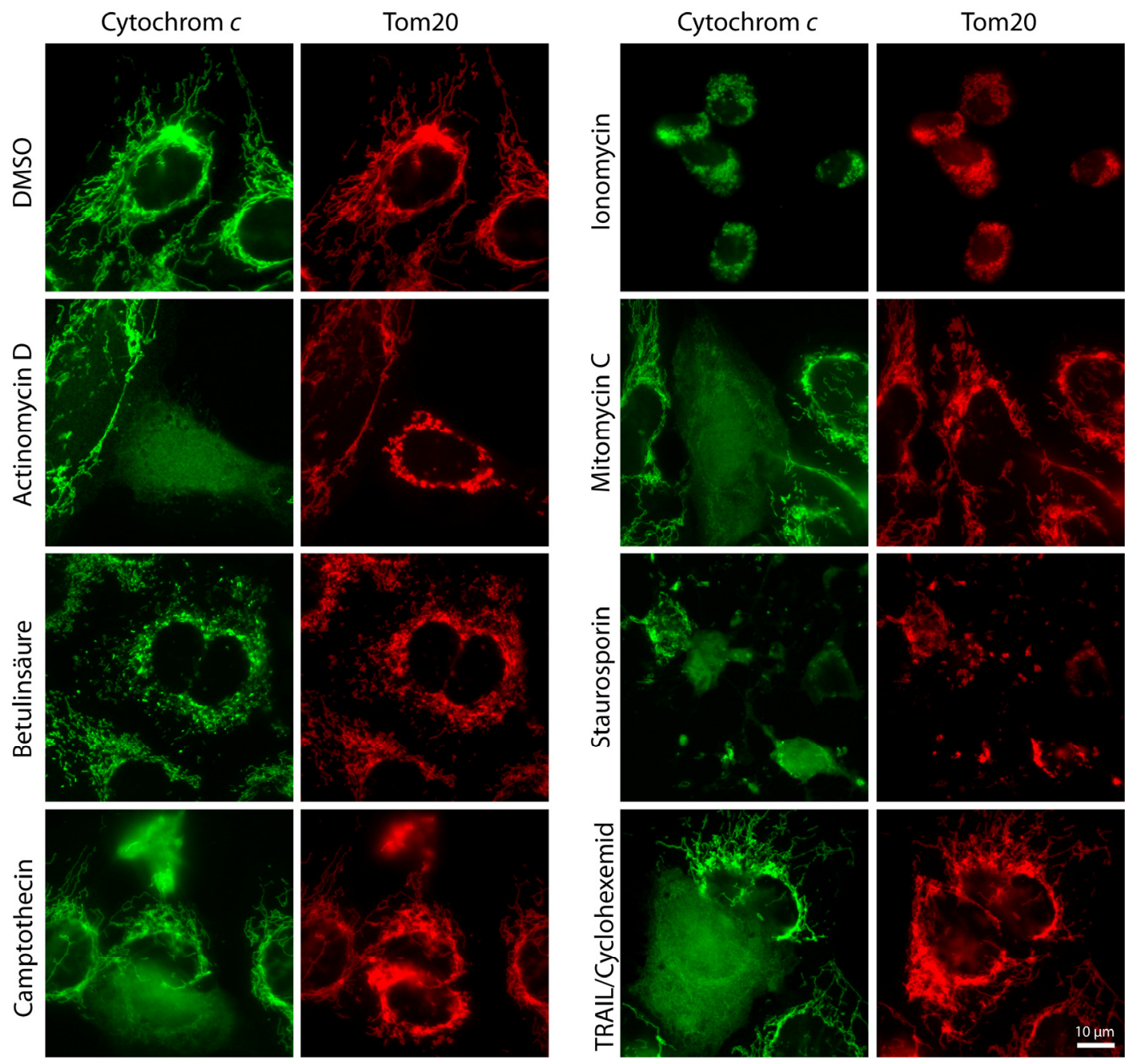

Abbildung 4.13: Wirkung verschiedener Apoptosestimulanzien

U2OS-Zellen wurden für zwölf Stunden mit den Apoptosestinduktoren Actinomycin D $(10 \mu \mathrm{M})$, Betulinsäure $(11 \mu \mathrm{M})$, Camptothecin $(10 \mu \mathrm{M})$, Ionomycin $(10 \mu \mathrm{M})$, Mitomycin $\mathrm{C}$ $(75 \mu \mathrm{M})$, Staurosoporin $(1 \mu \mathrm{M})$ und TRAIL $(0,1 \mathrm{ng} / \mu \mathrm{l}) /$ Cyclohexemid $(1 \mathrm{ng} / \mu \mathrm{l})$ inkubiert (Abschnitt 3.3.6). Um die Wirkung der verschiedenen Reagenzien zu beurteilen, wurde eine Antikörpermarkierung mit Cytochrom $c$ (grün) durchgeführt, da dieses während der Apoptose aus den Mitochondrien freigesetzt wird. Zur Beurteilung der mitochondrialen Morphologie wurde ein Tom20 Antikörper (rot) eingesetzt. Da die meisten Apoptosestimulanzien in DMSO gelöst worden sind, wurde eine 1 \%ige DMSO-Lösung als Negativkontrolle verwendet.

zeigten. Bei der Negativkontrolle (DMSO), wie auch bei Zellen, die mit Betulinsäure und Ionomycin behandelten worden sind, wurde hingegen keine Cytochrom $c$-Freisetzung beobachtet. In den beiden letzten Fällen waren die Mitochondrien zudem noch fragmentiert und bei Ionomycin die Zellen sogar zusammengeschrumpft. Aus diesen Gründen schieden Betulinsäure und 
Ionomycin für weitere Apoptoseexperimente aus. Mit Staurosporin behandelte Zellen zeigen zwar eine klare Cytochrom $c$-Freisetzung, darüber hinaus bewirkte Staurosporin aber das Zusammenschrumpfen von Zellen (vor der Cytochrom $c^{-}$ Freisetzung), was eine mikroskopische Analyse erschwert (Arnoult et al., 2002). Für die Kombination TRAIL/Cyclohexemid ist festzuhalten, dass die Zellen zwar Cytochrom $c$ freisetzen und $\mathrm{zu}$ diesem Zeitpunkt noch ausgestreckt sind, die Mitochondrien aber dünner und verlängert erscheinen. Hierbei scheint es sich um einen durch Cyclohexemid hervorgerufenen Effekt zu handeln, der unabhängig von der Apoptose ist. Deshalb wurde die Verwendung von TRAIL/Cyclohexemid ausgeschlossen. Zwischen den drei verbleibenden Stimulanzien (Actinomycin D, Campthotecin, Mitomycin C) sind keine wesentlichen Unterschiede zu erkennen. Da der Anteil der Zellen, die Cytochrom $c$ freigesetzt hatten, bei der Verwendung von Camptothecin deutlich niedriger war als bei den anderen beiden Stimulanzien, wurde Campthotecin ausgeschlossen. Schließlich wurde der, den intrinsischen Apoptose-Signalweg auslösende, Transkriptionsinhibitor Actinomycin D ausgewählt, da dessen Wirkung detaillierter beschrieben ist und häufiger Verwendung findet als Mitomycin C.

\subsubsection{Hemmung der mitochondrialen Fragmentierung durch Herunterregulierung von Drp1}

Ziel dieser Arbeit war es die Verteilung von verschiedenen mitochondrialen Proteinen in unbehandelten und apoptotischen Zellen vergleichend $\mathrm{zu}$ untersuchen. Da die Mitochondrien aber während der Apoptose ihre Gesamtform ändern und fragmentieren (Abbildung 4.14) (Desagher und Martinou, 2000; Youle und Karbowski, 2005; Dimmer und Scorrano, 2006), könnte diese Fragmentierung die Ergebnisse einer lichtmikroskopischen Untersuchung der Proteinverteilung beeinflussen. Möglicherweise würde sich zwar die Verteilung eines Proteins während der Apoptose ändern. Dies würde aber unentdeckt bleiben, da durch die 


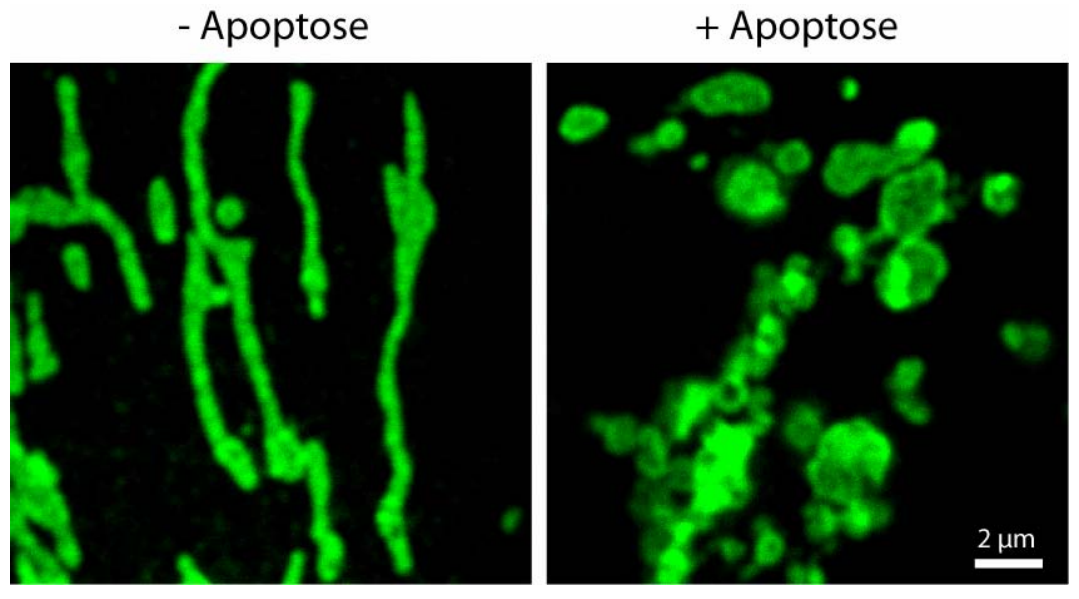

\begin{abstract}
Abbildung 4.14: Formänderungen der Mitochondrien während der Apoptose
U2OS-Zellen wurden zur Apoptoseinduktion für 14 Stunden mit Actinomycin D inkubiert und im Anschluss mit Tom20-Antikörpern zur Visualisierung des mitochondrialen Netzwerks inkubiert. Die Mitochondrien verändern während der Apoptose ihre Form von tubulären zu runden Organellen. Diese mitochondriale Fragmentierung als auch die Cytochrom $c^{-}$ Freisetzung findet im selben Zeitraum statt.
\end{abstract}

mitochondriale Fragmentierung der fälschliche Eindruck einer gleich bleibenden Verteilung entsteht.

Um die Mitochondrien auch während der Apoptose in ihrer ursprünglichen, tubulären Form zu halten, wurde in dieser Arbeit ein Protein (Drp1), welches für die mitochondriale Teilung verantwortlich ist, mittels RNAi herunterreguliert. Es wurde beschrieben, dass die Hemmung bzw. Entfernung von Drp1 (dynamin related protein 1) die mitochondriale Fragmentierung reduziert und die Cytochrom c-Freisetzung während der Apoptose verzögert (Abschnitt 2.2.5) (Frank et al., 2001; Lee et al., 2004; Parone et al., 2006; Estaquier und Arnoult, 2007). Für die Herunterregulierung von Drp1 wurde ein shRNA Plasmid verwendet (Abschnitt 3.3.5) (Lee et al., 2004).

In Abbildung 4.15 ist die mitochondriale Morphologie von Wildtyp-Zellen im Vergleich zu Zellen dargestellt, in denen Drp1 herunterreguliert worden ist. Es ist klar erkennbar, dass die Mitochondrien in den Drp1-herunterregulierten Zellen deutlich verlängert sind. Es sind so gut wie keine mitochondrialen Tubuli mit freien Enden zu erkennen. Vielmehr scheint das Netzwerk einer Zelle aus einem 

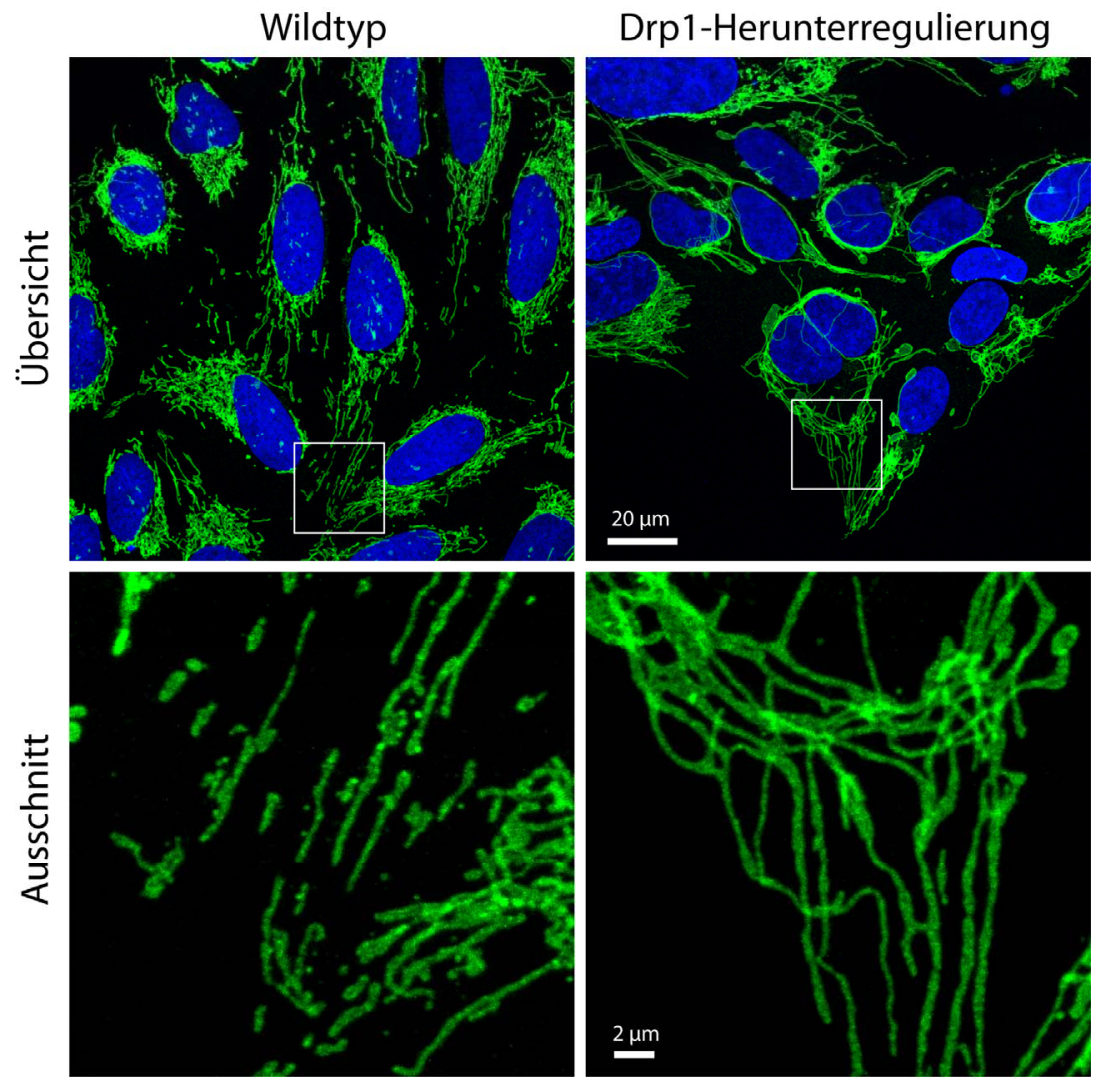

\section{Abbildung 4.15: Mitochondriale Morphologie in Wildtyp und Drp1- herunterregulierten Zellen}

Die Herunterregulierung von Drp1 wurde durch Transfektion und anschließende Selektion eines Drp1 shRNA kodierenden Plasmids erreicht (Abschnitt 3.3.5). Die Mitochondrien sind durch eine Antikörpermarkierung mit Tom20 (grün) und Zellkerne durch eine DAPI-Färbung (blau) visualisiert worden. Klar unterscheidbar sind die stark verlängerten Mitochondrien in den Drp1-herunterregulierten Zellen, von den deutlich kürzeren und nicht so stark vernetzten Mitochondrien in Wildtyp-Zellen.

einzigen, weit verzweigten Tubulus zu bestehen. Im Gegensatz dazu sind die einzelnen Mitochondrien in Wildtyp-Zellen deutlich kürzer und bei Weitem nicht so stark miteinander verbunden.

Zur Überprüfung der Herunterregulierung von Drp1 wurde eine Antikörpermarkierung mit einem Drp1-spezifischen Antikörper durchgeführt. Um Wildtyp-Zellen und Zellen, in denen Drp1 herunterreguliert worden ist, miteinander vergleichen zu können, wurden für den Drp1 Kanal alle Aufnahmen unter identischen Bedingungen durchgeführt (Abbildung 4.16). In Wildtyp-Zellen ist eine klare Drp1-Markierung zu erkennen, wobei Drp1 sowohl im Cytosol wie 
auch an den Mitochondrien lokalisiert ist. In den Drp1-herunterregulierten Zellen ist die Drp1-Färbung deutlich schwächer. Es konnten nur einige, wenige Drp1Moleküle durch den Drp1-spezifische Antikörper nachgewiesen werden.

Zusammenfassend kann festgehalten werden, dass die Herunterregulierung von Drp1 mittels RNAi erfolgreich war und zur Hemmung der mitochondrialen Teilungsmaschinerie führt. Im Folgenden wurde nun überprüft, ob die tubuläre mitochondriale Morphologie auch während der Apoptose erhalten bleibt.
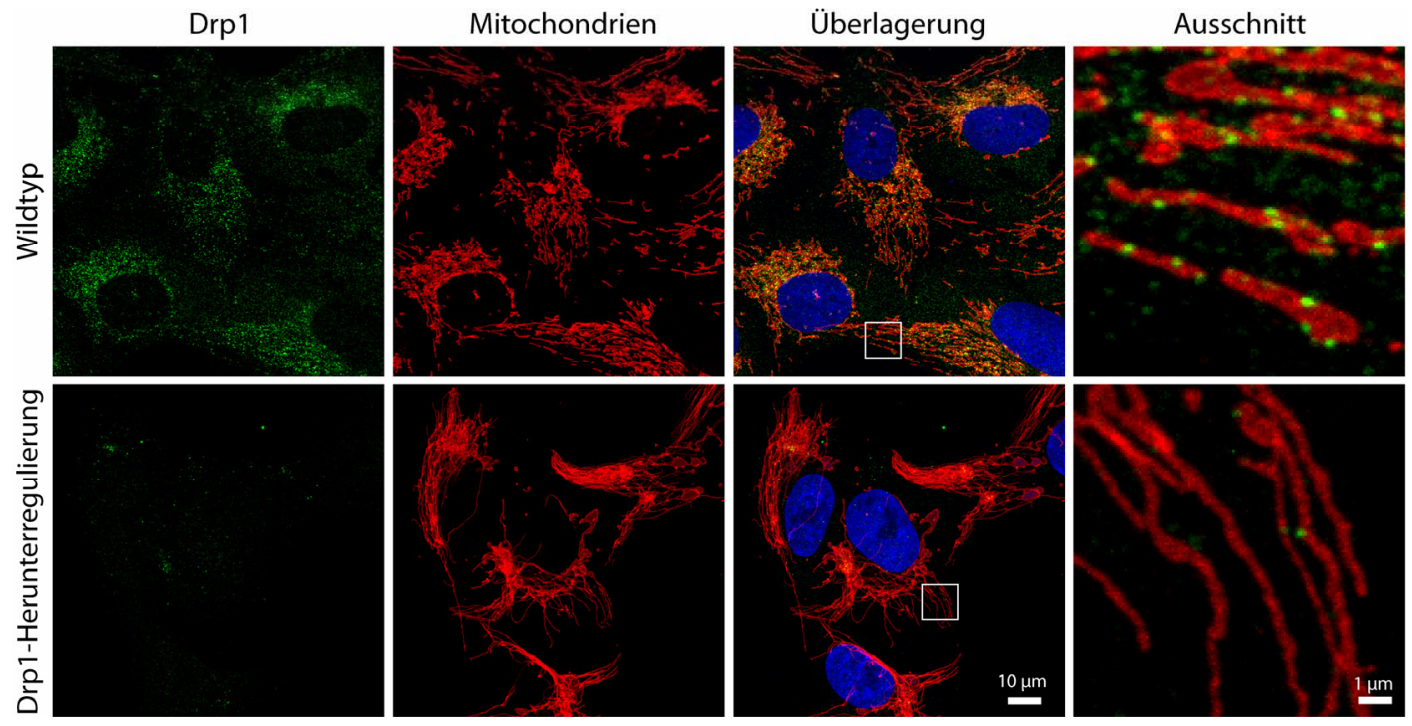

\section{Abbildung 4.16: Visualisierung des Drp1-Proteins in Wildtyp und Drp1- herunterregulierten Zellen.}

Die Herunterregulierung von Drp1 wurde durch Transfektion und anschließende Selektion eines Drp1 shRNA kodierenden Plasmids erreicht (Abschnitt 3.3.5). Im Anschluss wurden die U2OS-Zellen mit spezifischen Antikörpern gegen Drp1 (grün) und Tom20 (rot) inkubiert. Zellkerne wurden mit DAPI gefärbt (blau). Um einen genauen Vergleich der Drp1-Expression in Wildtyp und Drp1-herunterregulierten Zellen zu ermöglichen, wurden beide Proben unter identischen Bedingungen (Drp1-Kanal) aufgenommen. In den Drp1-herunterregulierten Zellen sind nur vereinzelt schwache Drp1-Signale zu erkennen, wohingegen in Wildtyp-Zellen sowohl im Cytosol als auch an den Mitochondrien sehr deutlich Drp1-Moleküle nachgewiesen werden konnten. 


\subsubsection{Charakterisierung des apoptotischen Signalweges in Wildtyp-Zellen und}

\section{Drp1-herunterregulierten Zellen}

Das Ziel in der Herunterregulierung von Drp1 bestand darin, die Mitochondrien während der Apoptose in ihrer ursprünglichen, tubulären Form zu halten. Um dies zu testen, wurde sowohl in Wildtyp-Zellen, als auch in Drp1herunterregulierten Zellen, Apoptose induziert. Um den Verlauf der Apoptose beurteilen und vergleichen $\mathrm{zu}$ können, wurde neben dem zuvor schon verwendeten Cytochrom $c$-spezifischen Antikörper ein Bax-Antikörper verwendet, der ausschließlich aktives Bax erkennt. Die Aktivierung und Oligomerisierung von Bax findet zeitlich vor der Cytochrom $c$-Freisetzung statt (Eskes et al., 1998; Jurgensmeier et al., 1998; Pastorino et al., 1998).

In Abbildung 4.17 ist eine Bax-aktivierte Wildtyp-Zelle (zweite Reihe) zu erkennen, die Cytochrom $c$ (grün) freigesetzt hat und deren Mitochondrien (rot) fragmentiert sind. Im Gegensatz dazu weisen die tubulären Mitochondrien der Nachbarzelle weder eine Bax-Aktivierung, noch eine Cytochrom $c$-Freisetzung auf und verhalten sich somit genauso wie die Mitochondrien der Kontroll-Zellen (erste Reihe). Hingegen zeigt die Zelle, in der Drp1 herunterreguliert worden ist, zwar eine Bax-Aktivierung, aber keine Cytochrom $c$-Freisetzung. Darüber hinaus weist sie neben aufgeblähten, ballon-ähnlichen Mitochondrien klar erkennbare tubuläre Mitochondrien auf.

Diese qualitativen Beobachtungen wurden durch die quantitative Auswertung eines größeren Datensatzes ergänzt. Dies war nötig, da sich einzelne Zellen bezüglich der mitochondrialen Morphologie und der Cytochrom $c$-Freisetzung durchaus unterschieden.

Es wurden ausschließlich Zellen analysiert, die ausgestreckt waren und eine BaxAktivierung aufwiesen. Beurteilt wurde die Cytochrom $c$-Freisetzung und die mitochondriale Morphologie. Wies eine Zelle sowohl tubuläre wie auch fragmentierte Mitochondrien auf, so wurden die tubulären Mitochondrien beurteilt. Wichtig ist an dieser Stelle $\mathrm{zu}$ erwähnen, dass bezogen auf die 


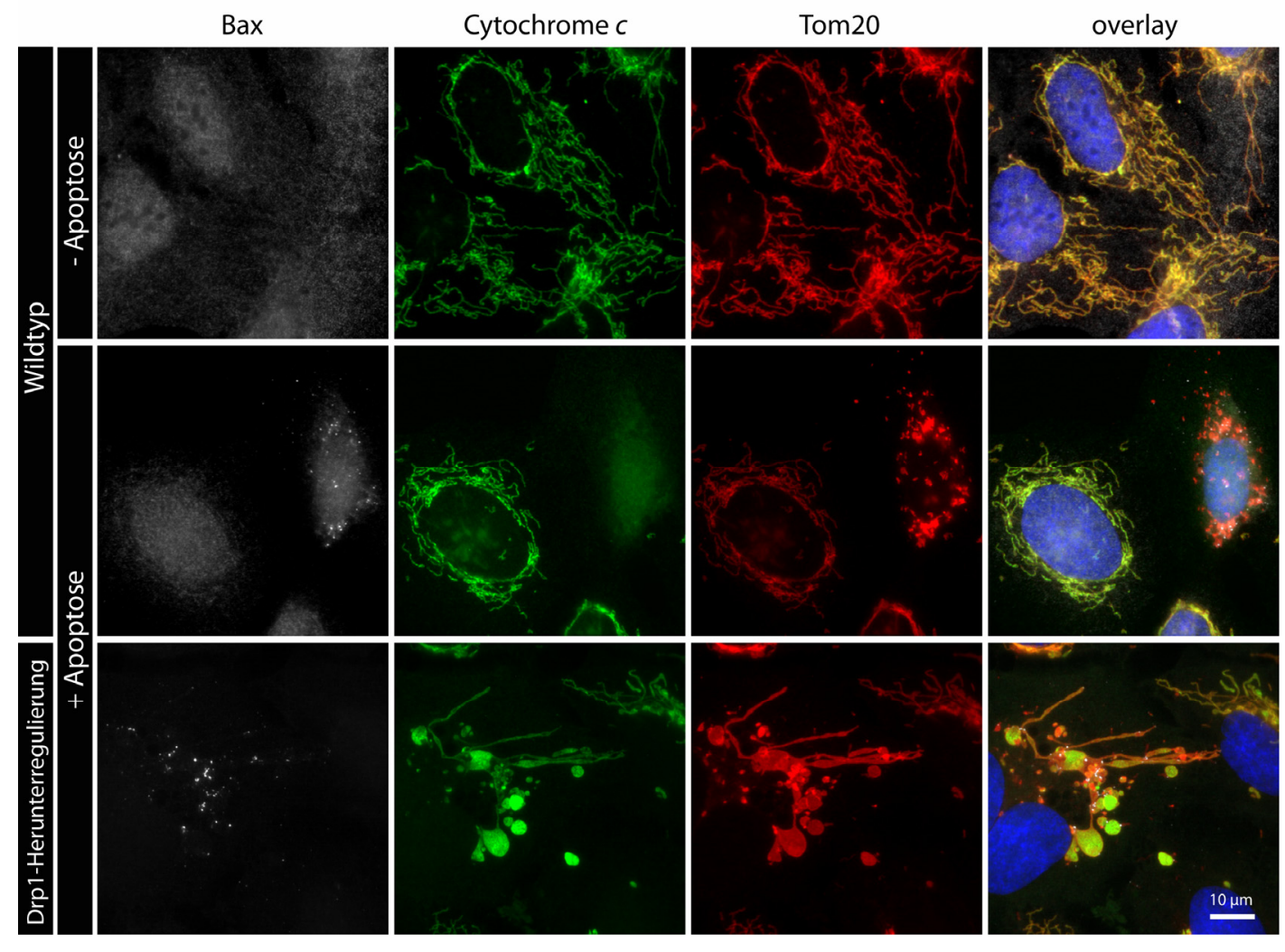

\section{Abbildung 4.17: Qualitative Charakterisierung des Apoptoseverlaufs in Wildtyp und Drp1-herunterregulierten Zellen}

Die Herunterregulierung von Drp1 wurde durch Transfektion und anschließende Selektion eines Drp1 shRNA kodierenden Plasmids erreicht (Abschnitt 3.3.5). In Wildtyp (zweite Reihe) wie auch in Drp1-herunterregulierten Zellen (dritte Reihe) wurde mittels Actinomycin D Apoptose induziert. Als Kontrolle dienten unbehandelte Wildtyp-Zellen (erste Reihe). Zur Charakterisierung des Apoptoseverlaufs wurden U2OS-Zellen mit Antikörpern gegen aktiviertes Bax (weiß), Cytochrom $c$ (grün) und Tom20 (rot) inkubiert. Zellkerne wurden mit DAPI angefärbt (blau). Es ist zu erkennen, dass die Bax aktivierte Wildtyp-Zelle (zweite Reihe), Cytochrom $c$ freigesetzt hat und fragmentierte Mitochondrien aufweist. Im Gegensatz dazu besitzt die Bax-aktivierte Drp1-herunterregulierte Zelle (dritte Reihe) weiterhin tubuläre (neben ballon-förmigen) Mitochondrien, die keine Cytochrom $c$ Freisetzung zeigen.

Cytochrom $c$-Freisetzung in Drp1-herunterregulierten Zellen regelmäßig Sub-

Populationen von Mitochondrien innerhalb einer Zelle beobachtet wurden. Zum Beispiel wurden einige Zellen beobachtet, in denen einzelne mitochondriale Tubuli Cytochrom $c$ freigesetzt hatten, wohingegen andere mitochondriale Tubuli der gleichen Zelle keine Cytchrom $c$-Freisetzung aufwiesen (Abbildung 4.18). Diese Beobachtungen stehen im Gegensatz zu der Situation in Wildtyp-Zellen, in 


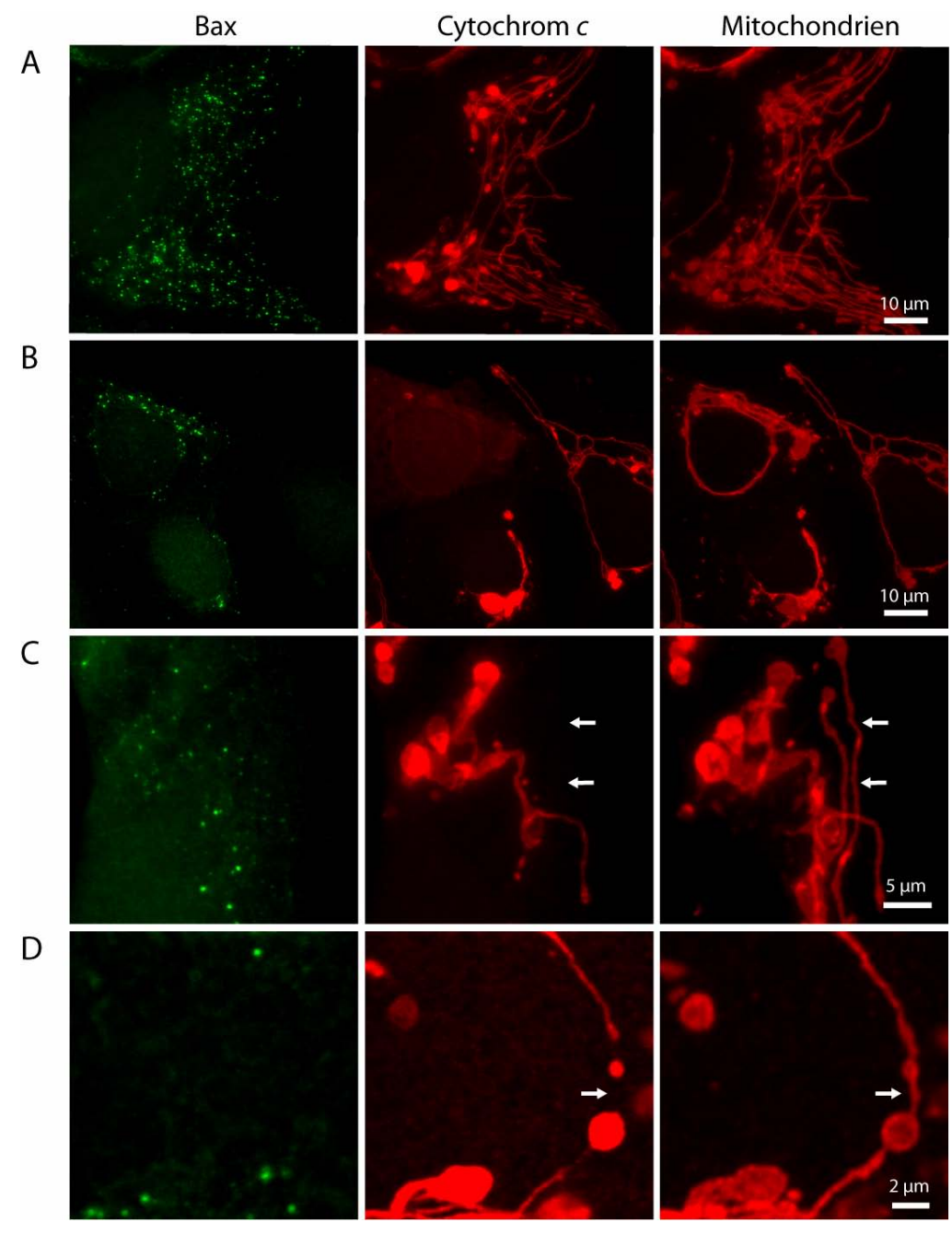

\section{Abbildung 4.18: Verschiedene Stadien der Cytochrom $c$-Freisetzung in Drp1- herunterregulierten Zellen}

Drp1-herunterregulierte U2OS-Zellen wurden mit Actinomycin D behandelt und 14 Stunden später mit Antikörpern gegen aktiviertes Bax, Cytochrom $c$ und Tom20 (A-C Reihe)/Hexokinase-I (D Reihe) inkubiert. In (A) ist eine für die Drp1 Herunterregulierung typische Zelle dargestellt. Diese weist zwar eine Bax-Aktivierung auf, die Mitochondrien sind aber weiterhin tubulär und Cytchrom $c$ ist nicht freigesetzt. In (B) sind zwei Bax-aktivierte Zellen (links) zu erkennen, wobei die obere Cytochrom $c$ freigesetzt hat, die untere hingegen nicht. Beide Zellen besitzen teilweise tubuläre Mitochondrien. In (C) ist der Ausschnitt einer Zelle dargestellt, in dem ein Teil der mitochondrialen Tubuli Cytochrom $c$ freigesetzt haben, ein anderer Teil hingegen nicht. In (D) ist ein mitochondrialer Tubulus dargestellt, der an einer Stelle Cytochrom $c$ freigesetzt hat, in anderen Bereichen hingegen nicht.

denen entweder alle Mitochondrien einer Zelle Cytochrom $c$ komplett (oder teilweise) freigesetzt haben oder eben kein einziges Mitochondrium.

Betrachtet man die Ergebnisse der statistischen Auswertung (Abbildung 4.19), so ist festzuhalten, dass $\sim 90 \%$ der Bax-aktivierten Wildtyp-Zellen fragmentierte 
Mitochondrien besitzen und $\sim 70 \%$ der Bax-aktivierten Wildtyp-Zellen Cytochrom $c$ freigesetzt haben. Im Gegensatz dazu weisen nur 55\% der Baxaktivierten, Drp1-herunterregulierten Zellen fragmentierte Mitochondrien auf und nur $\sim 20 \%$ der Bax-aktivierten Drp1-herunterregulierten Zellen haben Cytochrom $c$ freigesetzt.

Aus diesen und anderen Daten (Frank et al., 2001; Lee et al., 2004; Parone et al., 2006; Cassidy-Stone et al., 2008) lässt sich schließen, dass die Herunterregulierung von Drp1 die mitochondriale Fragmentierung während der Apoptose reduziert und die Cytochrom $c$-Freisetzung verzögert. Diese Verzögerung führt zu einer Vergrößerung des Zeitfensters zwischen der Bax-Aktivierung und der Cytochrom

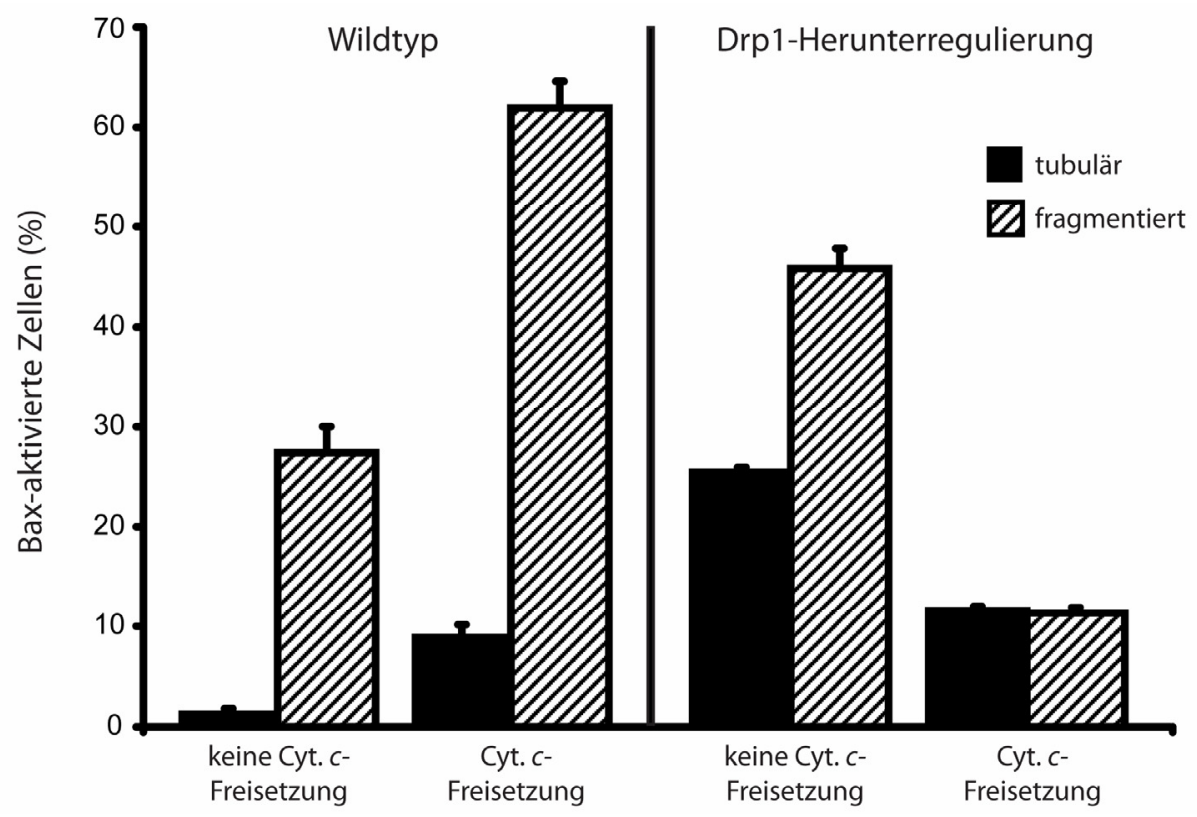

Abbildung 4.19: Quantitative Charakterisierung des Apoptoseverlaufs in Wildtyp und Drp1-herunterregulierten Zellen

Um die qualitative Beurteilung des Apoptoseverlaufs (Abbildung 4.17) genauer zu analysieren, wurden in drei unabhängigen Experimenten Bax-aktivierte Wildtyp $(\mathrm{n}=200)$ und Drp1herunterregulierte Zellen $(\mathrm{n}=400)$ aufgrund der mitochondrialen Morphologie und der Cytochrom $c$-Freisetzung beurteilt. Es ist klar erkennbar, dass $\sim 90 \%$ der bax-aktivierten Wildtyp-Zellen fragmentierte Mitochondrien besitzen, aber nur 55 \% der Drp1herunterregulierten Mitochondrien fragmentiert sind. $70 \%$ der bax-aktivierten WildtypZellen haben Cytochrom $c$ freigesetzt, wohingegen dass nur auf $\sim 20 \%$ der Drp1herunterregulierten Zellen zutrifft. Somit für die Herunterregulierung von Drp1 zu einer Reduzierung der mitochondrialen Fragmentierung und zu einer Verzögerung der Cytochrom $c$-Freisetzung während der Apoptose. 
$c$-Freisetzung. Die Herunterregulierung von Drp1 kann somit verwendet werden, um die Mitochondrien während der Apoptose in tubulärer Form zu halten und wurde in den folgenden Experimenten neben Mitochondrien aus Wildtyp-Zellen zur Untersuchung sub-mitochondrialer Proteinverteilungen eingesetzt. Zudem ermöglicht die Drp1-Herunterregulierung Vorgänge, die zwischen BaxAktivierung und Cytochrom $c$-Freisetzung stattfinden, genauer zu untersuchen.

\subsection{5 qualitative Untersuchung von sub-mitochondrialen Proteinverteilungen in} unbehandelten Zellen

Die Verteilung von sechs verschiedenen Proteinen (Abbildung 4.20) wurde in unbehandelten und apoptotischen Zellen untersucht und miteinander verglichen. Hierfür wurden gezielt Proteine ausgewählt, die aus verschiedenen mitochondrialen Sub-Kompartimenten stammen. Es wurden Hexokinase-I, Tom20 und Tom22 als Proteine der äußeren mitochondrialen Membran, Cytochrom $c$ als Intermembranprotein, die $\mathrm{F}_{1} \mathrm{FoATP}_{\mathrm{O}} \mathrm{Synthase}$ als Protein der inneren

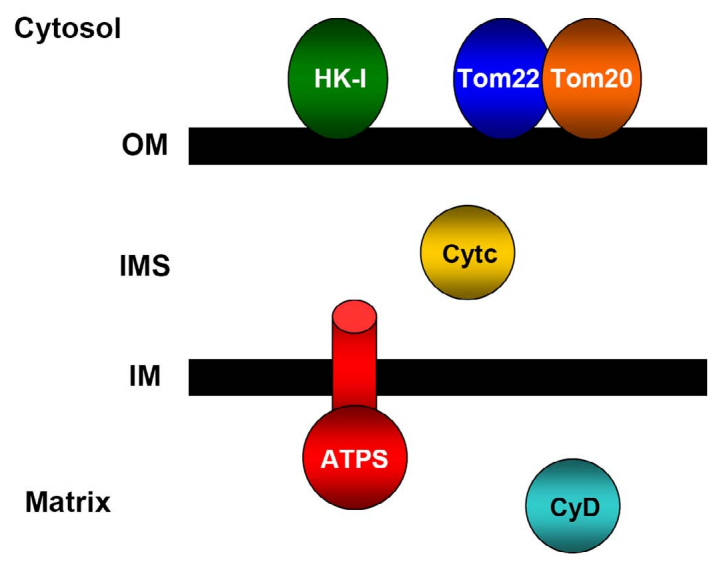

\footnotetext{
Abbildung 4.20: Vereinfachte Darstellung der sub-mitochondriale Lokalisation von den sechs Proteinen, deren Verteilungen in dieser Arbeit untersucht wurde

Die sub-mitochondriale Verteilung von sechs verschiedenen Proteinen wurde in unbehandelten und apoptotischen Zellen untersucht und miteinander verglichen. Als Proteine der äußeren Membran wurden Hexokinase-I (HK), Tom20 und Tom22, als Intermembranraum-Protein Cytochrom $c$ (Cyt. c), als Protein der inneren Membran die F1FoATP-Synthase (ATPS) und als Matrixprotein Cyclophilin D (CyD) ausgewählt.
} 
mitochondrialen Membran und Cyclophilin D als Matrixprotein (möglicherweise an die innere Membran assoziiert) ausgewählt. Darüber hinaus wird einem Teil der Proteine Funktionen im apoptotischen Signalweg zugeschrieben (Abschnitt 2.2.4) (Desagher und Martinou, 2000; Bellot et al., 2007; Ott et al., 2007; Ow et al., 2008).

Wie zuvor beschrieben (Abschnitt 4.1.4, Abschnitt 8.1) ist eine Untersuchung submitochondrialer Proteinverteilungen mittels konventioneller Mikroskopie nicht möglich, da die Proteine zu dicht gepackt sind, um aufgelöst zu werden. Aus diesem Grund wurde die STED-Mikroskopie zur Untersuchung submitochondrialer Proteinverteilungen verwendet (Abschnitt 8.1).

Die Verteilung von den sechs zuvor genannten Proteinen in unbehandelten Wildtyp-Zellen ist der Abbildung $4.21 \mathrm{zu}$ entnehmen. Zwischen den einzelnen Proteinen sind Unterschiede in der Verteilung zu erkennen: Die spärlichste Verteilung weist das Protein Hexokinase-I auf. Hier sind deutlich einzelne Proteincluster $\mathrm{zu}$ erkennen. Dichter und untereinander sehr ähnlich ist die Verteilung von Tom20 und Tom22, die ebenfalls in Proteinclustern lokalisiert sind. Noch etwas dichter erscheint die Verteilung von Cytochrom $c$. Bei den Proteinen der inneren Membran und der Matrix sind so gut wie keine Proteincluster mehr zu erkennen. Die $F_{1} F_{0} A T P-S y n t h a s e$ scheint vorwiegend homogen verteilt $\mathrm{zu}$ sein, unterbrochen von vielen, einzelnen Aussparungen. Cyclophilin D weist eine sehr homogene Verteilung auf, unterbrochen nur von wenigen, vereinzelten Aussparungen.

Zusammenfassend kann festgehalten werden, dass sich die verschiedenen Proteine in ihrer Verteilung durchaus unterscheiden, wobei eine Tendenz zu erkennen ist: Proteine der äußeren Membran erscheinen weniger dicht gepackt als Proteine der inneren Membran und der Marix. 

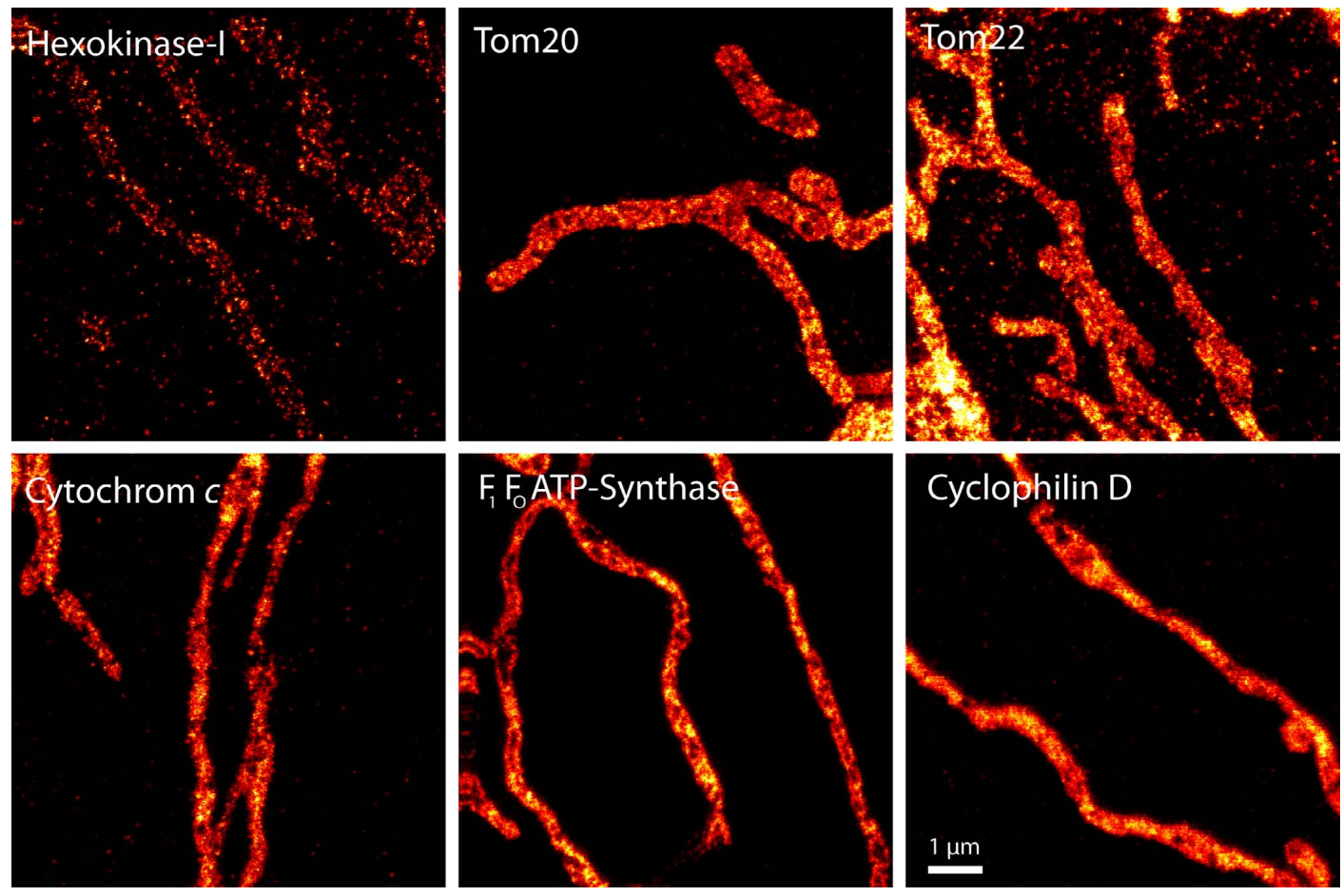

\section{Abbildung 4.21: STED-Aufnahmen von sub-mitochondrialen Proteinverteilungen der sechs verschiedenen Proteine}

U2OS-Zellen wurden mit Antikörpern gegen die Hexokinase-I, Tom20, Tom22, Cytochrom $c$, die $F_{1}$ FoATP-Sythase oder Cyclophilin D inkubiert und im Anschluss mit einem nicht kommerziellen STED Mikroskop untersucht. Proteine der äußeren Membran (Hexokinase-I, Tom20, Tom22) sind in Clustern lokalisiert und nicht so homogen verteilt, wie die Proteine der inneren Membran/Matrix ( $F_{1} F_{0} A T P-S y n t h a s e$, Cyclophilin D). Bei diesen fallen mehr oder weniger häufig Aussparungen auf. Am Spärlichsten verteilt und in klar erkennbaren Proteinclustern lokalisiert ist die Hexokinase-I, wohingegen die homogeneste Verteilung das Protein Cyclophilin D aufweist. Hier sind keine einzelnen Proteincluster mehr zu erkennen.

\subsection{6 qualitative Untersuchung von sub-mitochondrialen Proteinverteilungen in} apoptotischen Zellen

Um mögliche Änderungen in Proteinverteilungen nachzuweisen, wurden STEDAufnahmen von Mitochondrien unbehandelter Drp1-herunterregulierter Zellen mit Mitochondrien Drp1-herunterregulierter Zellen verglichen, die eine BaxAktivierung aufwiesen (Abbildung 4.22) (korrespondierende konfokalmikroskopische Aufnahmen sowie Aufnahmen zur Bax-Aktivierung siehe Abbildungen 8.13-8.15). Als Kontrolle wurden ebenfalls unbehandelte und Baxaktivierte Mitochondrien von Wildtyp-Zellen untersucht. 
A

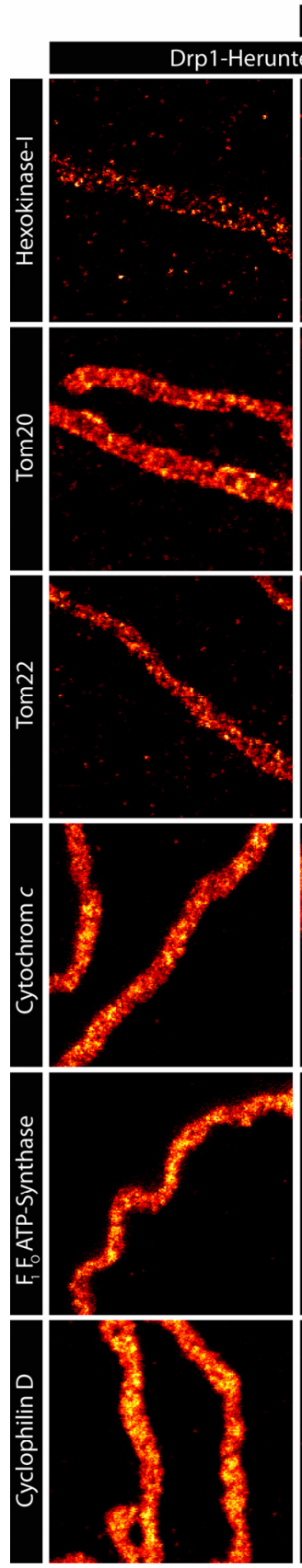

4.22:
B
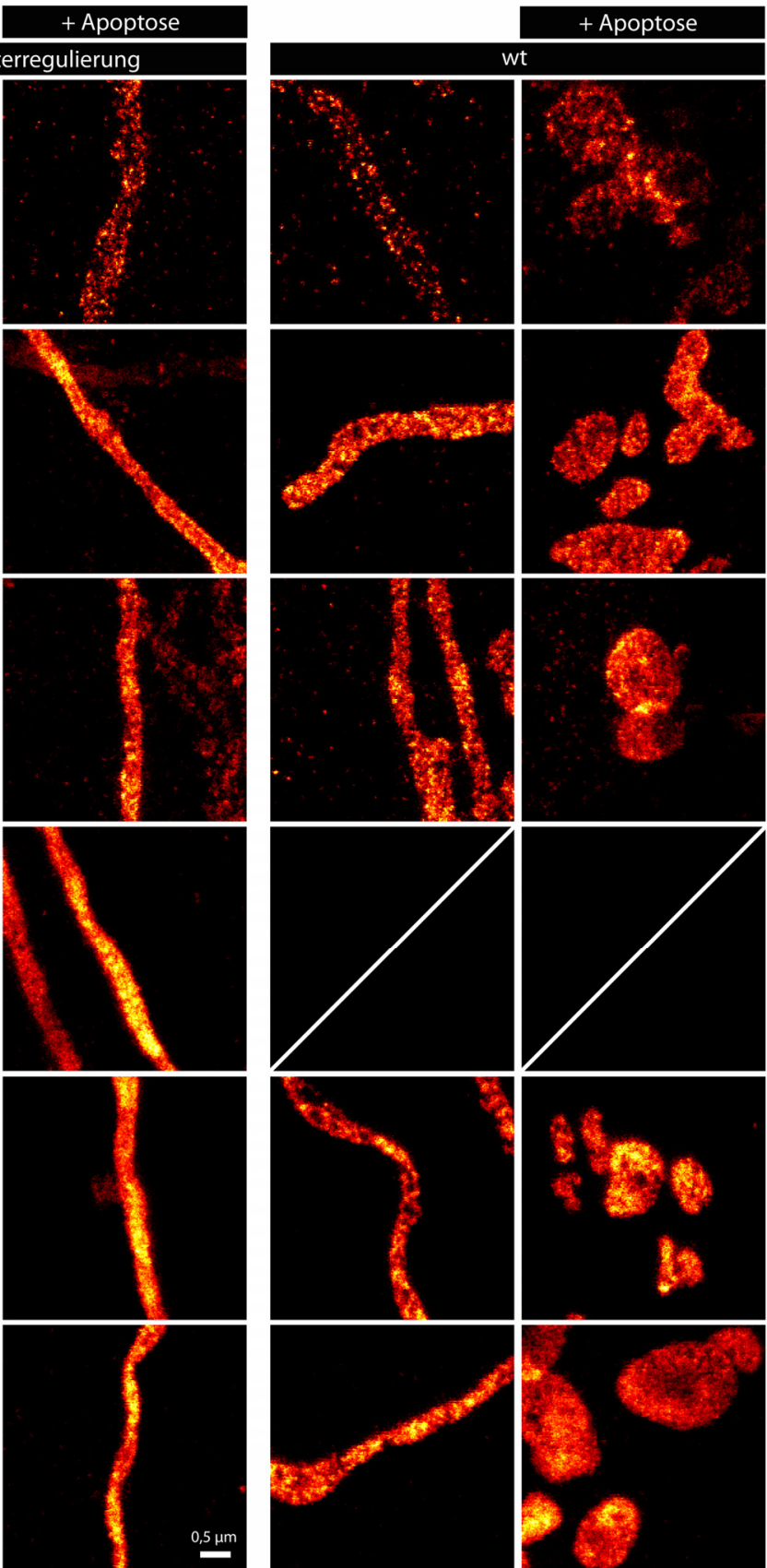

$0,5 \mu \mathrm{m}$

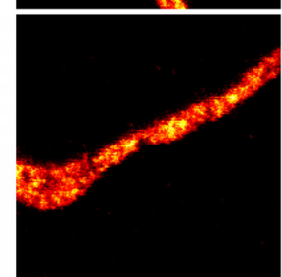

von

STED-Aufnahmen

sub-mitochondrialen

Abbildung

in unbehandelten und

\section{apoptotischen Zellen}

Unbehandelte oder mit Actinomycin D behandelte Drp1-herunterregulierte (A) oder Wildtyp (B) U2OS-Zellen wurden mit Antikörpern gegen Bax und gegen eines der folgenden Proteine inkubiert: Hexokinase-I, Tom20, Tom22, Cytochrom $c$, F1FoATP-Synthase, Cyclophilin D. Für Cytochrom $c$ in Wildtyp-Zellen gibt es keine Daten, da Cytochrom $c$ unter apoptotischen Bedingungen aus den Mitochondrien freigesetzt wird. Die korrespondierenden konfokalmikroskopischen Bilder zu den einzelnen Proteinen und die entsprechenden Bax-Aufnahmen sind den Abbildungen 8.13-8.15 zu entnehmen. Die Bilder wurden an einem nicht kommerziellen STED-Aufbau aufgenommen. Es sind keine sichtbaren Änderungen in submitochondrialen Proteinverteilungen zwischen unbehandelten und apoptotischen Zellen zu erkennen. 
Bei der Beurteilung der STED-Aufnahmen (Abbildung 4.22) wurden keine erkennbaren Änderungen in sub-mitochondrialen Proteinverteilungen zwischen unbehandelten und apopotischen Zellen festgestellt. Dies trifft sowohl auf Drp1herunterregulierte Zellen wie auch auf Wildtyp-Zellen zu. Genauso wird aber klar, dass zum Nachweis von möglichen subtileren Änderungen in submitochondrialen Proteinverteilungen die qualitative Beurteilung der STEDAufnahmen alleine nicht ausreichend ist. Das hängt damit zusammen, dass einzelne Aufnahmen innerhalb jeder Bedingung eine nicht zu vernachlässigende Streuung zeigen. Zum Beispiel erscheint die Verteilung der Hexokinase-I in unbehandelten Wildtyp-Zellen in einer Aufnahme deutlich dichter als in der nächsten (Abbildung 8.16). Des Weiteren werden leichte Änderungen in submitochondrialen Proteinverteilungen möglicherweise visuell nicht wahrgenommen. Um Aussagen über subtilere Änderungen in submitochondrialen Proteinverteilungen zu treffen, ist somit die Quantifizierung von STED-Daten unumgänglich.

\subsubsection{Aufnahme von STED-Daten zur anschließenden Quantifizierung}

Für die Quantifizierung von Proteinverteilungen wurde eine weitere Differenzierung bezüglich der Beurteilung des apoptotischen Signalweges vorgenommen. Die Zellen wurden nicht nur danach beurteilt, ob sie eine BaxAktivierung zeigten oder nicht, sondern zusätzlich auch, ob Cytochrom $c$ freigesetzt worden ist oder nicht. Dies führte letztlich $\mathrm{zu}$ fünf verschiedenen Bedingungen (Abbildung 4.23): Es wurden unbehandelte Drp1-herunterregulierte Zellen (1) mit Drp1-herunterregulierten Zellen verglichen, die tubuläre, Bax-

aktivierte Mitochondrien aufwiesen, welche entweder kein Cytochrom $c$ freigesetzt hatten (2) oder aber Cytochrom $c$ freigesetzt hatten (3). Als Vergleich zur Kontrolle wurden unbehandelte Wildtyp-Zellen (4) mit Wildtyp-Zellen verglichen, die eine Bax-Aktivierung und eine Cytochrom $c$-Freisetzung (zumindest teilweise) zeigten (5). Für Wildtyp-Zellen wurden keine 


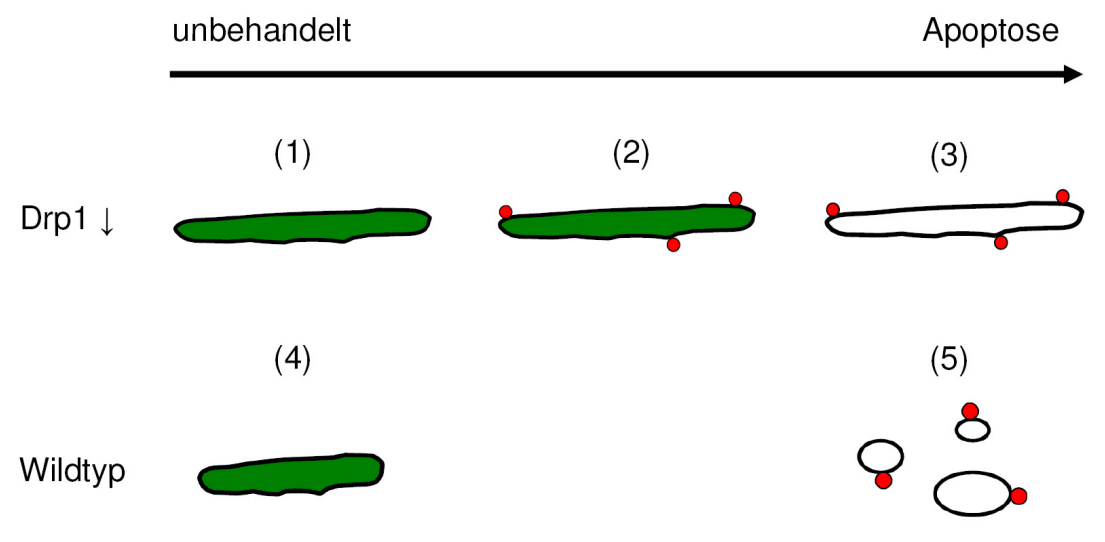

\begin{abstract}
Abbildung 4.23: Schematische Übersicht über die fünf verschiedenen Bedingungen, unter denen sub-mitochondriale Proteinverteilungen untersucht wurden

Unbehandelte Drp1-herunterregulierte Zellen (1) wurden mit Drp1-herunterregulierten Zellen verglichen, die tubuläre, bax-aktivierte Mitochondrien aufwiesen, die entweder kein Cytochrom $c$ freigesetzt hatten (2) oder aber Cytochrom c freigesetzt hatten (3). Zur Kontrolle wurden unbehandelte Wildtyp-Zellen (4) mit Wildtyp-Zellen verglichen, die Bax akiviert (rot) waren und Cytochrom $c$ (grün) freigesetzt hatten (5).
\end{abstract}

Mitochondrien mit Bax-Aktivierung ohne Cytochrom $c$-Freisetzung aufgenommen, da beide Prozesse innerhalb von wenigen Minuten stattfinden (Eskes et al., 2000; Karbowski et al., 2004). Somit ist der Prozentsatz von Zellen mit diesen Eigenschaften innerhalb einer fixierten Probe zu gering, um sinnvolle Auswertungen durchzuführen.

Die Herunterregulierung von Drp1 und die damit verbundene Vergrößerung des Zeitfensters zwischen Bax-Aktivierung und Cytochrom $c$-Freisetzung ermöglicht eine weitreichende Differenzierung: Es konnte festgestellt werden, ob mögliche Änderungen der Proteinverteilungen schon zum Zeitpunkt der Bax-Aktivierung oder erst später nach der Cytochrom $c$-Freisetzung stattfinden.

Die für die quantitative Analyse verwendeten STED-Daten wurden an einem kommerziellen STED-Mikroskop aufgenommen, da durch dessen Ausstattung die zusätzliche Analyse von zwei weiteren Proteinen (Bax, Cytochrom $c$ ) im konfokalen Modus möglich war (Abschnitt 8.2). Für jedes Protein wurden fünf verschiedene Bedingungen (Abbildung 4.23) aufgenommen. Pro Bedingung 
wurden mindestens 30 Bilder in drei unabhängigen Experimenten aufgenommen (Ausnahme Bedingung 3). Dies führt insgesamt zu mehr als 1000 STEDAufnahmen. $\mathrm{Zu}$ jeder STED-Aufnahme existiert ein korrespondierendes, konfokales Bild sowie eine Aufnahme von Bax und Cytochrom c. Exemplarisch ist dies für die Hexokinase-I in Abbildung 4.24 gezeigt (für die anderen Proteine siehe Abbildungen 8.17-8.21). In den drei Auschnitten (2., 4. und 5. Reihe)

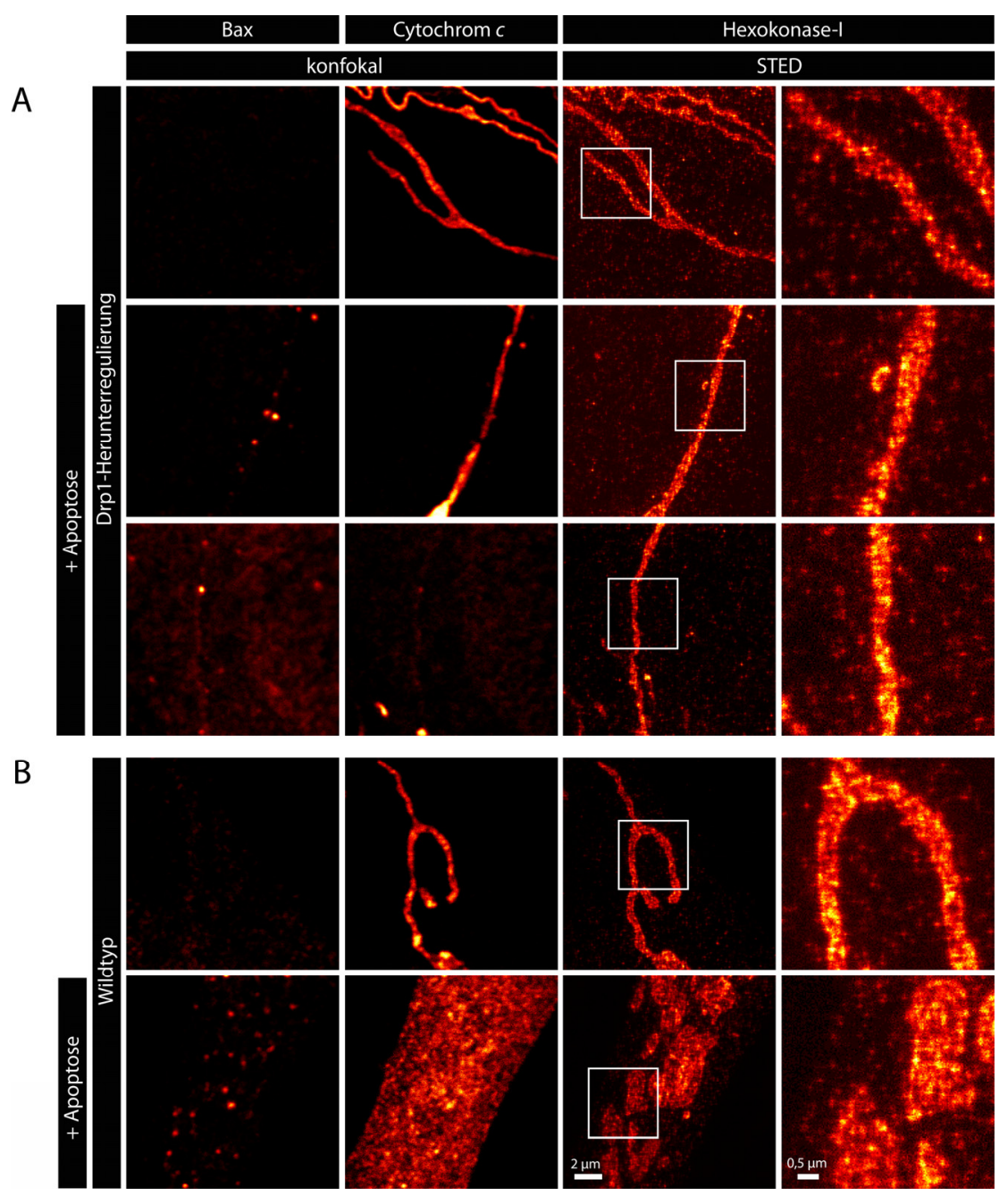

\section{Abbildung 4.24: STED-Aufnahmen von sub-mitochondrialen Proteinverteilungen der Hexokinase-I in unbehandelten und apoptotischen Zellen}

Unbehandelte oder mit Actinomycin D behandelte Drp1-herunterregulierte (A) und WildtypZellen (B) wurden mit Antikörpern gegen Bax, Cytochrom $c$ und Hexokinase-I inkubiert. Die repräsentativen Bilder wurden an einem kommerziellen STED Aufbau aufgenommen und zusammen mit vielen Anderen für die quantitative Analyse sub-mitochondrialer Proteinverteilungen verwendet. 
apoptotischer Zellen ist jeweils eine Bax-Aktivierung $\mathrm{zu}$ erkennen, wobei für Drp1-herunterregulierte Zellen sowohl tubuläre Mitochondrien ohne Cytochrom $c$-Freisetzung (2. Reihe) als auch mit Cytochrom $c$-Freisetzung (3. Reihe) zu erkennen sind. Hingegen sind die Mitochondrien der apoptotischen WildtypZellen (5. Reihe) fragmentiert und haben Cytochrom $c$ freigesetzt.

\subsection{8 quantitative Untersuchung von sub-mitochondrialen Proteinverteilungen in unbehandelten und apoptotischen Zellen}

Zur Quantifizierung der zuvor beschriebenen STED-Daten wurden drei verschiedene Parameter bestimmt (Abschnitt 3.4.6): (1) Der Durchmesser der (mit Antikörper dekorierten) Proteincluster wurde ermittelt, um Aussagen über mögliche Änderungen auf der Ebene von einzelnen Proteinclustern zu machen. (2) Die Varianz der Fluoreszenzintensität wurde als ein Maß für die Homogenität der Proteinverteilung als Ganzes bestimmt und (3) das Verhältnis der Clusterintensität zur Hintergrundintensität (im Mitochondrium) wurde ermittelt, um z.B. genauere Informationen darüber zu bekommen, inwieweit sich Cluster auflösen.

Generell ist bei der Quantifizierung und insbesondere bei der Angabe von Durchmessern von Proteinclustern zu beachten, dass diese auf indirekten Immunofluoreszenz-Markierungen basieren. Somit geht die Länge der zur Detektion verwendeten Antikörper mit in den Clusterdurchmesser ein und führt zu einer Strukturvergrößerung. Somit sind absolute Werte von Clusterdurchmessern mit Vorsicht zu behandeln, wohingegen das Verhältnis von zwei Clusterdurchmessern (z.B. unbehandelt, apoptotisch) ein robustes Maß ist, um mögliche Änderungen zu quantifizieren.

Die drei berechneten Parameter sind für unbehandelte und apoptotische Drp1herunterregulierte Zellen (ohne Cytochrom $c$-Freisetzung) in der Abbildung 4.25 dargestellt. 

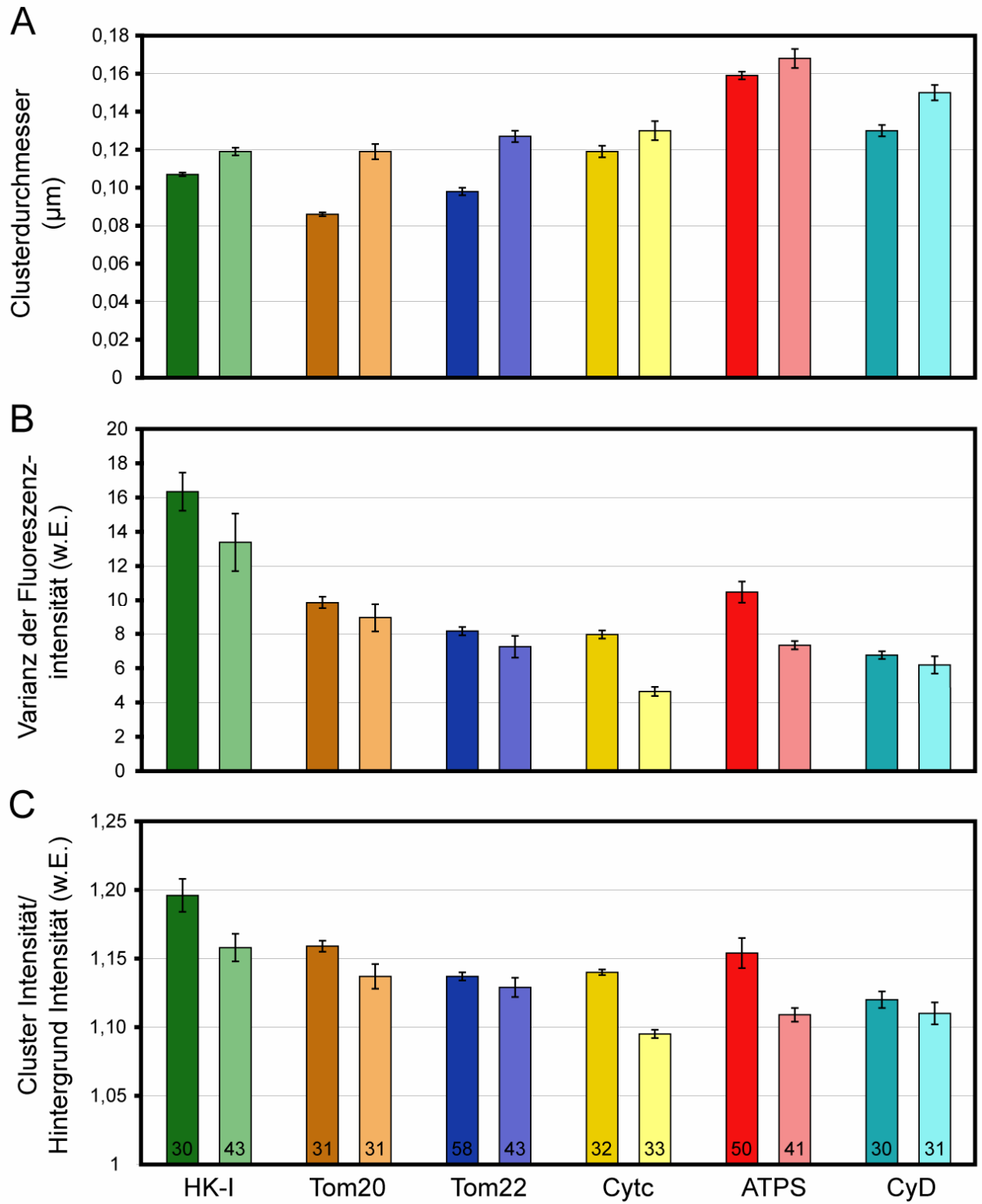

\section{Abbildung 4.25: Ergebnisse der quantitativen Analyse sub-mitochondrialer Proteinverteilungen in unbehandelten und apoptotischen Drp1- herunterregulierten Zellen}

Für die Proteine Hexokinase-I (HK-I), Tom20, Tom22, Cytochrom $c$ (Cytc), F1FoATPSynthase (ATPS) und Cyclophilin D (CyD) wurde der Clusterdurchmesser (A), die Varianz der Fluoreszenzintensität (B) und das Verhältnis von Cluster- zu Hintergrundintensität (C) (in den Mitochondrien) bestimmt. Die Fehlerbalken entsprechen dem Standardfehler. Die Zahlen am unteren Ende der Balken in (C) geben die Anzahl der analysierten Zellen wieder. In der jeweils dunkleren Farbe (links) sind die unbehandelten Zellen, in der helleren Farbe (rechts) die Bax aktivierten Zellen dargestellt, deren Mitochondrien kein Cytochrom $c$ freigesetzt haben. Es konnten keine massiven Änderungen in sub-mitochondrialen Proteinverteilungen während der Apoptose nachgewiesen werden. Vielmehr finden subtile Änderungen hin zu größeren Proteinclustern und einer homogeneren Proteinverteilung statt. Zu beachten ist, dass die Angaben zu Clusterdurchmessern inklusive der Länge der verwendeten Antikörpern sind. 
Als Gesamteindruck kann festgehalten werden, dass für die verschiedenen Proteine bei allen drei Parametern eine generelle Tendenz zu erkennen ist:

In allen Fällen steigt der Clusterdurchmesser (zumindest leicht) von unbehandelten $\mathrm{zu}$ apoptotischen Zellen an. Es ist $\mathrm{zu}$ erkennen, dass die Clusterdurchmesser in unbehandelten Zellen bei ungefähr $100 \mathrm{~nm}$ liegen. Da $100 \mathrm{~nm}$ der Auflösung des Mikroskops entspricht, ist davon auszugehen, dass die realen Cluster kleiner als $100 \mathrm{~nm}$ sind. In der Tat konnte durch Aufnahmen mit einem anderen STED-Mikroskop (Auflösung $\sim 40 \quad \mathrm{~nm}$ ) $\quad$ z.B. für Tom20 Clusterdurchmesser von $\sim 60 \mathrm{~nm}$ bestimmt werden. Generell ist anzumerken, dass die Clusterdurchmesser durch mathematische Algorithmen bestimmt worden sind und nicht biologisch definierte Proteincluster voraussetzen. Speziell für dicht gepackte und recht homogen verteilte Proteine wie Cyclophilin D und die SiSoATP-Synthase sind absolute Werte für Clusterdurchmesser schwierig zu interpretieren. Nichtdestotrotz ist das Verhältnis von zwei Werten ein robustes Maß um Unterschiede zu quantifizeren.

Als zweiter Parameter wurde die Varianz der Fluoreszenzintenstität zur Beurteilung von Proteinverteilungen bestimmt (Abbildung 4.25). Für alle Proteine wurde eine Abnahme (für Tom20 und Cyclophilin D nicht signifikant) in der Varianz der Fluoreszenzintensität von unbehandelten zu apoptotischen Zellen beobachtet, was bedeutet, dass die Proteinverteilungen homogener werden.

Diese Beobachtung wird durch den dritten Parameter, das Verhältnis der Clusterzur Hintergrundintensität, bestätigt (Abbildung 4.25). Auch hier wurde für alle Proteine eine Abnahme (für Tom22 und Cyclophilin D nicht signifikant) von unbehandelten zu apoptotischen Zellen beobachtet.

Beim Vergleich der Werte für Drp1-herunterregulierte Zellen (ohne Cytochrom $c$-Freisetzung, Abbildung 4.25) mit denen für Wildtyp-Zellen (mit Cytochrom $c^{-}$ Freisetzung, Abbildung 4.26) sind Übereinstimmungen auffällig: Für fast alle Proteine in Wildtyp-Zellen wurde ebenfalls eine Zunahme des Clusterdurchmessers, eine Abnahme in der Varianz der Fluoreszenzintensität und 
A

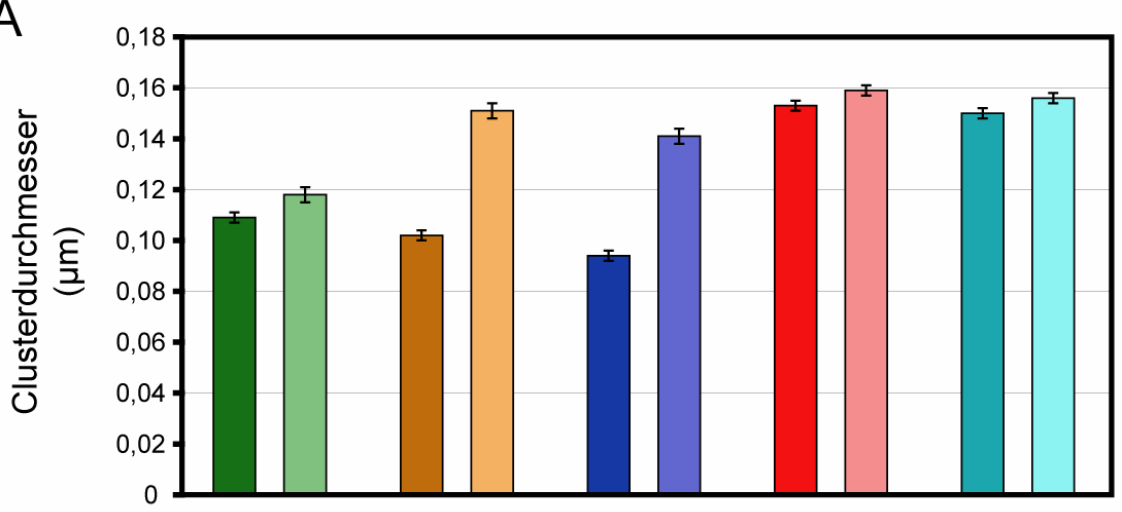

$B$

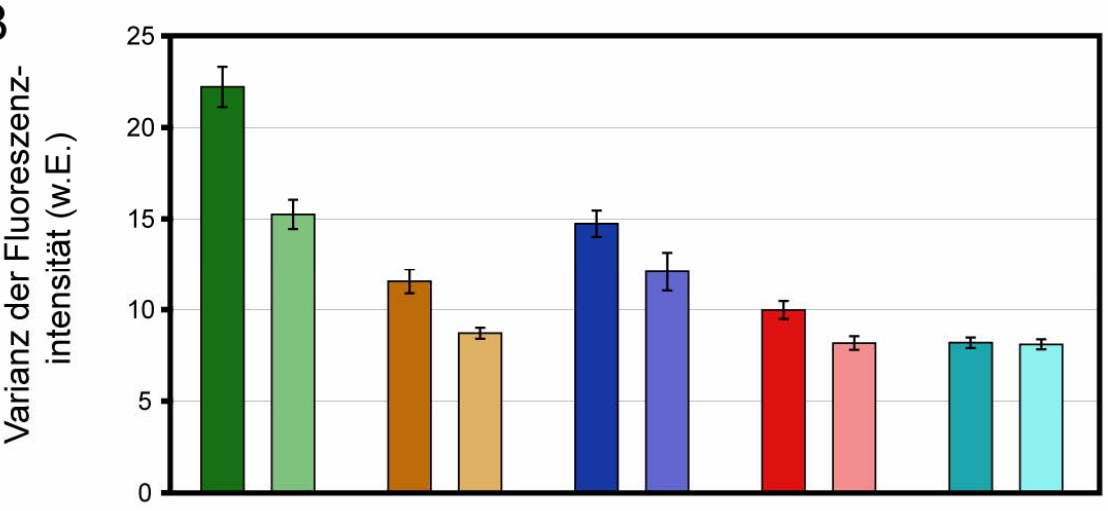

C

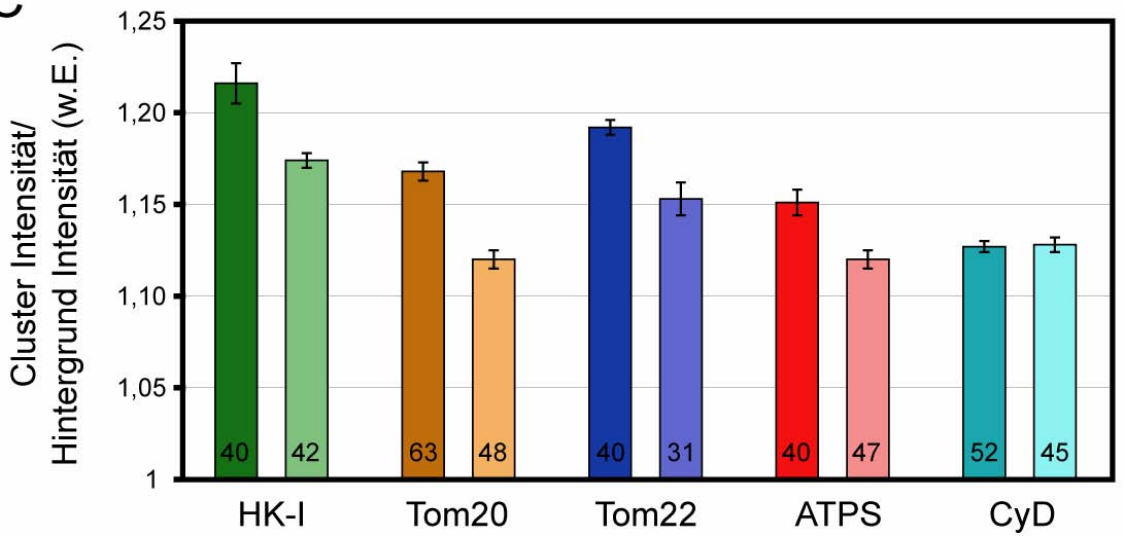

Abbildung 4.26: Ergebnisse der quantitativen Analyse sub-mitochondrialer Proteinverteilungen in unbehandelten und apoptotischen Wildtyp Zellen

Für die Proteine Hexokinase-I (HK-I), Tom20, Tom22, F1FoATP-Synthase (ATPS) und Cyclophilin D (CyD) wurden der Clusterdurchmesser (A), die Varianz der Fluoreszenzintensität (B) und das Verhältnis von Cluster- zu Hintergrundintensität (C) (in den Mitochondrien) bestimmt. Die Fehlerbalken entsprechen dem Standardfehler. Die Zahlen am unteren Ende der Balken in (C) geben die Anzahl der analysierten Zellen wieder. In der jeweils dunkleren Farbe (links) sind die unbehandelten Zellen, in der helleren Farbe (rechts) die Bax aktivierten, Cytochrom $c$-freigesetzten Zellen dargestellt. Es konnten keine massiven Änderungen in sub-mitochondrialen Proteinverteilungen während der Apoptose nachgewiesen werden. Vielmehr finden subtile Änderungen hin zu größeren Proteinclustern und einer homogeneren Proteinverteilung statt. Dieser Eindruck stimmt mit den Ergebnissen für Drp1herunterregulierte Zellen überein. Zu beachten ist, dass die Angaben zu Clusterdurchmessern inklusive der Länge der verwendeten Antikörpern sind. 
eine Abnahme des Verhältnisses von Cluster- zu Hintergrundintensität festgestellt.

Bei einer genaueren Betrachtung können einzelne Unterschiede in den Parametern zwischen Drp1-herunterregulierten Zellen und Wildtyp-Zellen beobachtet werden. Zum Beispiel nimmt der Clusterdurchmesser für Tom20 und Tom22 in apoptotischen Zellen stärker zu als das in Drp1-herunterregulierten Zellen der Fall ist. Ein anderes Beispiel ist Cyclophilin D, bei dem die Varianz der Fluoreszenzintensität in apoptotischen Drp1-herunterregulierten Zellen abnimmt (nicht signifikant), wohingegen sie bei apoptotischen Wildtyp-Zellen gleich bleibt.

Trotz einzelner Abweichungen ist die generelle Tendenz für Drp1herunterregulierte Zellen wie auch für die als Vergleich zur Kontrolle verwendeten Wildtyp-Zellen dieselbe: Während der Apoptose finden subtile Änderungen in sub-mitochondrialen Proteinverteilungen statt, mit einer Tendenz zu größeren Proteinclustern und zu einer homogeneren Proteinverteilung.

Wichtig ist an dieser Stelle zu betonen, dass die Daten zur Drp1Herunterregulierung auf apoptotischen Zellen basieren, deren Mitochondrien kein Cytochrom $c$ freigesetzt hatten, wohingegen die Daten von Wildtyp-Zellen auf Mitochondrien basieren, die Cytochrom $c$ freigesetzt hatten. Da festgestellt wurde, dass keine wesentlichen Unterschiede zwischen den beiden Datensätzen bestehen, sind zwei denkbare Schlussfolgerungen möglich. Entweder führt die Fragmentierung der Mitochondrien in apoptotischen Wildtyp-Zellen dazu, dass weitere Unterschiede verdeckt werden oder es finden zwar vor der Cytochrom $c^{-}$ Freisetzung Änderungen in sub-mitochondrialen Proteinverteilungen statt, nicht aber nach der Cytochrom $c$-Freisetzung.

Um dies zu klären, wurde ein fünfter Datensatz, basierend auf Drp1herunterregulierten Zellen, ausgewertet. Diese Zellen wiesen tubuläre, Baxaktivierte und Cytochrom $c$-freigesetzte Mitochondrien auf. Hierzu wurden pro Protein mindestens zehn Bilder in mindestens zwei unabhängigen Experimenten 
aufgenommen und mit den zuvor gewonnen Daten von Drp1-herunterregulierten Zellen, die zwar eine Bax-Aktivierung, aber keine Cytochrom $c$-Freisetzung aufwiesen, verglichen.

Für diese fünfte Bedingung wurden die Verteilung von vier verschiedenen Proteinen (Hexokinase-I, Tom20, Tom22, F1FoATP-Synthase) analysiert. Cytochrom $c$ konnte nicht untersucht werden, da es per Definition bei dieser Bedingung aus den Mitochondrien freigesetzt ist. Cyclophilin D wurde ebenfalls nicht untersucht, da dieses Protein in Drp1-herunterregulierten Zellen im gleichen Zeitrahmen wie Cytochrom $c$ freigesetzt worden ist (Abbildung 4.27).

Diese Beobachtung steht im Gegensatz zu der Situation in Wildtyp-Zellen, in denen keine Freisetzung von Cyclophilin D in einem vergleichbaren Zeitrahmen beobachtet wurde (Abbildung 4.27).

Die Ergebnisse der quantiativen Analyse von Drp1-herunterregulierten, Baxaktivierten, Cytochrom $c$ freigesetzten, tubulären Mitochondrien sind der Abbildung $4.28 \mathrm{zu}$ entnehmen. In fast allen Fällen sind keine signifikanten Unterschiede in den Proteinverteilungen von Mitochondrien mit Cytochrom $c^{-}$ Freisetzung im Vergleich zu Mitochondrien ohne Cytochrom $c$-Freisetzung zu erkennen. Ausnahmen sind eine geringe Abnahme des Clusterdurchmessers von Tom22 in Cytochrom $c$-freigesetzten Mitochondrien und eine leichte Zunahme in dem Verhältnis von Cluster- zur Hintergrundintensität für Hexokinase-I in Cytochrom $c$-freigesetzten Mitochondrien.

Abgesehen von den beiden Ausnahmen kann festgehalten werden, dass in Drp1herunterregulierten Zellen nach Cytochrom $c$-Freisetzung keine weiteren Änderungen in den Verteilungen der analysierten Proteine stattfinden. Somit finden die unter den experimentellen Bedingungen nachweisbaren subtilen Änderungen in sub-mitochondrialen Proteinverteilungen ausschließlich vor der Cytochrom $c$-Freisetzung statt. Da vergleichbare Änderungen auch für die als Kontrolle verwendeten Wildtyp-Zellen beobachtet worden sind, kann geschlussfolgert werden, dass die mitochondriale Fragmentierung während der 
Apoptose die quantitative Analyse sub-mitochondrialer Proteinverteilungen nicht erkennbar beeinflusst.

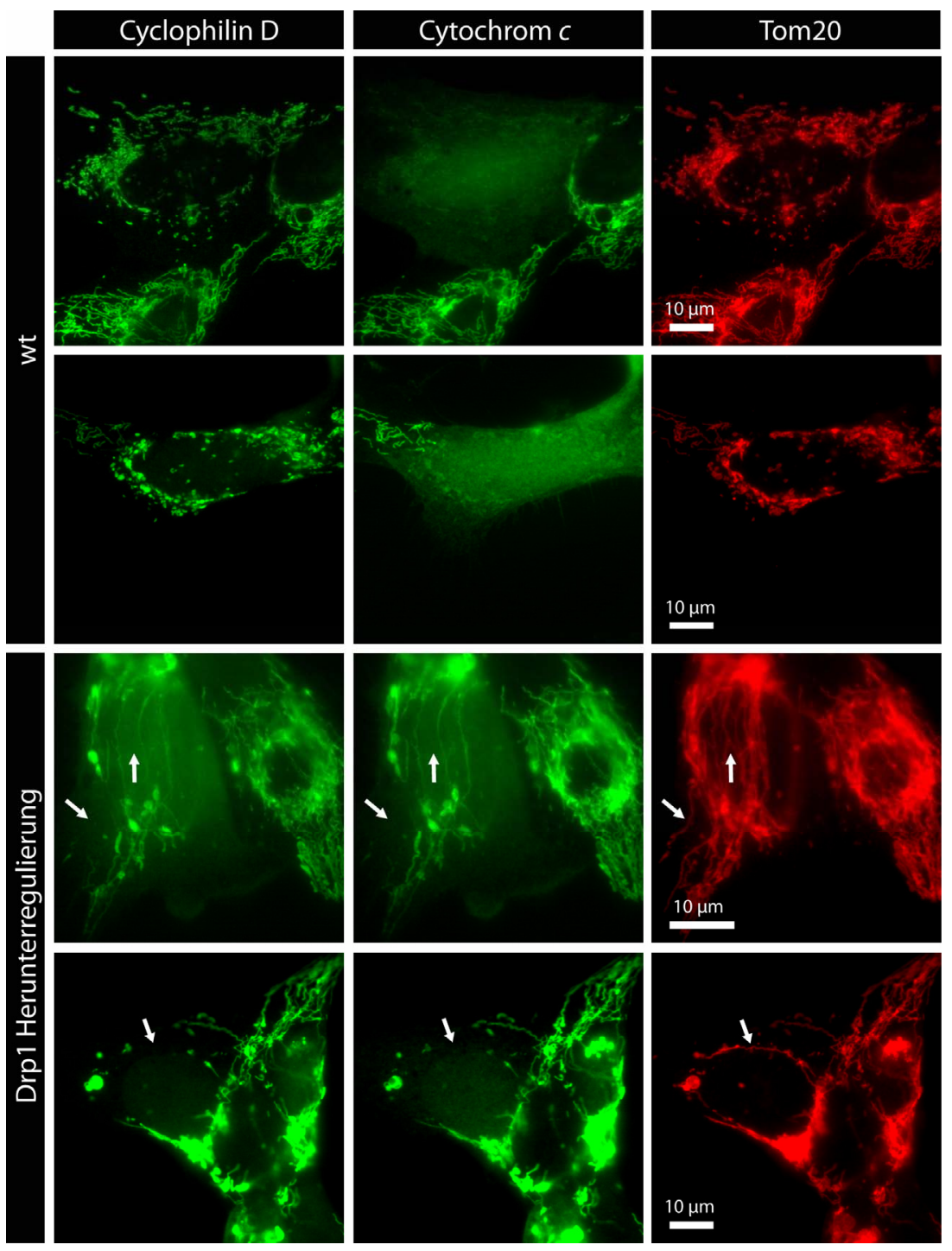

Abbildung 4.27: Cyclophilin D-Lokalisation in Cytochrom $c$-freigesetzten Wildtyp- und Drp1-herunterregulierten Zellen

In Wildtyp- und Drp1-herunterregulierte U2OS-Zellen wurde Apoptose durch Actinomycin DZugabe induziert und 14 Stunden später wurden die Zellen nach Fixierung mit Cyclophilin D, Cytochrom $c$ und Tom20 spezifischen Antikörpern inkubiert. Die Visualisierung und Dokumentation erfolgte mit einem Epifluoreszenzmikroskop. In ausgestreckten Wildtyp-Zellen konnte zwar eine Cytochrom $c$-Freisetzung, aber keine Cyclophilin D-Freisetzung beobachtet werden. In Drp1-herunterregulierten Zellen hatte die große Mehrzahl alle Mitochondrien mit einer Cytochrom $c$-Freisetzung ebenfalls Cyclophilin D freigesetzt. 
A

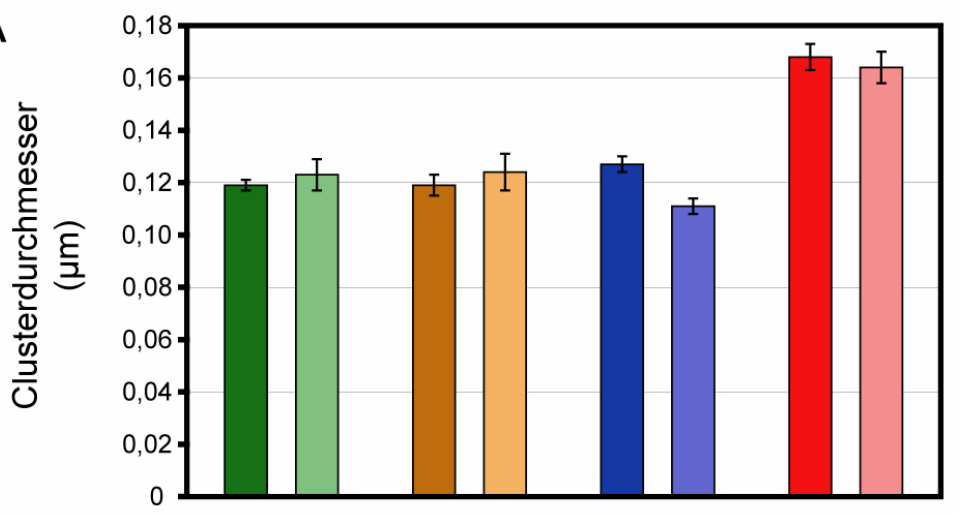

B

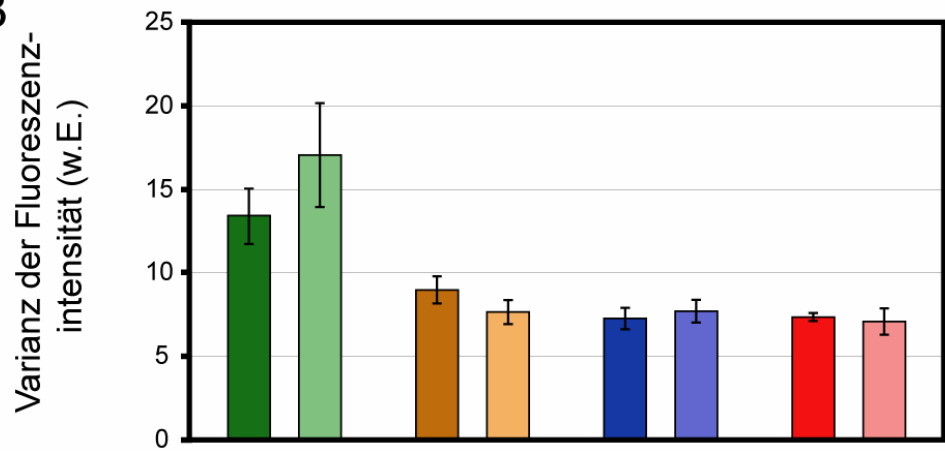

C

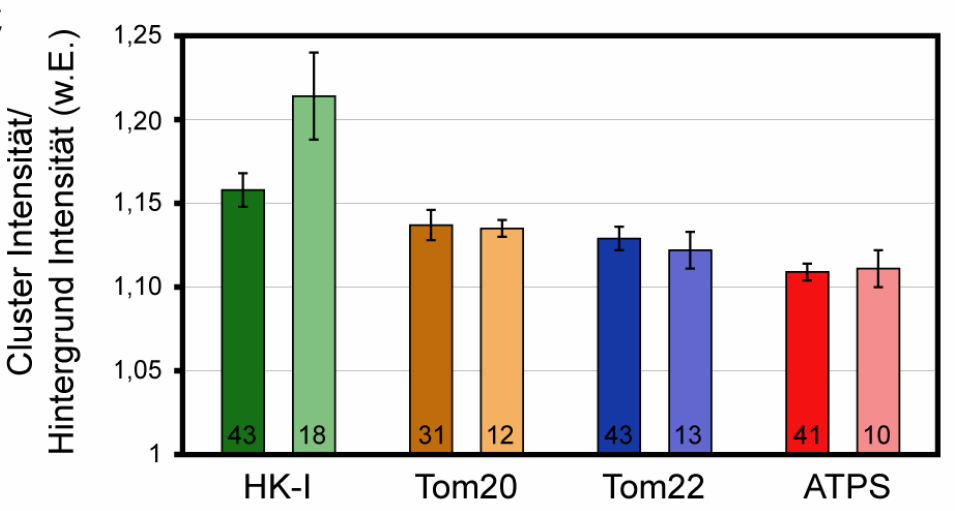

\section{Abbildung 4.28: Ergebnisse der quantitativen Analyse sub-mitochondrialer Proteinverteilungen in Prä- und Post-Cytochrom $c$ freigesetzten, Drp1 herunterregulierten Zellen}

Für die Proteine Hexokinase-I (HK-I), Tom20, Tom22 und F1FoATP-Synthase (ATPS) wurde der Clusterdurchmesser (A), die Varianz der Fluoreszenzintensität (B) und das Verhältnis von Cluster- zu Hintergrundintensität (C) (in den Mitochondrien) bestimmt. Die Fehlerbalken entsprechen dem Standardfehler. Die Zahlen am unteren Ende der Balken in (C) geben die Anzahl der analysierten Zellen wieder. In der jeweils dunkleren Farbe (links) sind die Baxaktivierten Zellen ohne Cytochrom $c$ Freisetzung dargestellt (entspricht den rechten Balken in Abbildung 4.25), in der helleren Farbe (rechts) sind die Bax-aktivierten Zellen dargestellt, die Cytochrom $c$ freigesetzt haben. Bis auf eine leichte Zunahme für die Varianz der Fluoreszenzintensität bei Hexokinase-I und eine leichte Abnahme in dem Clusterdurchmesser von Tom22, konnten keine signifkanten Unterschiede zwischen Prä- und Post-Cytochrom $c^{-}$ freigesetzten Zellen festgestellt werden. $\mathrm{Zu}$ beachten ist, dass die Angaben zu Clusterdurchmessern inklusive der Länge der verwendeten Antikörpern sind. 


\section{Diskussion}

\subsection{Sub-mitochondriale (Ko)Lokalisationsstudien zu den hVDAC- Isoformen}

VDACs (voltage dependent anion-selective channels) sind die häufigsten Proteine der äußeren, mitochondrialen Membran (Colombini, 1979; Mayer et al., 1993). Sie sind für den Transport von Metaboliten wie ATP verantwortlich und werden deshalb auch als globaler Regulator der mitochondrialen Funktion bezeichnet (Lemasters und Holmuhamedov, 2006).

Im Menschen sind drei verschiedene Isoformen beschrieben. Vor dieser Arbeit gab es wenige Daten zur sub-mitochondrialen Lokalisation der verschiedenen hVDAC-Isoformen ( $\mathrm{Yu}$ et al., 1995). Es waren entweder keine oder widersprüchliche Daten über mögliche Interaktionen zwischen den hVDACIsoformen untereinander als auch mit der Hexokinase-I bekannt (Blachly-Dyson et al., 1993; Azoulay-Zohar und Aflalo, 1999).

In dieser Arbeit konnte eine unterschiedliche sub-mitochondriale Lokalisation der verschiedenen Isoformen nachgewiesen werden (Abschnitt 4.1.1). Weiterhin konnte eine Aminosäure identifiziert werden (Abschnitt 4.1.2), die Einfluss auf die sub-mitochondriale Lokalisation von hVDAC hat. Ergebnisse von Kolokalisationsstudien (Abschnitt 4.1.3) geben Hinweise auf mögliche Interaktionen der hVDAC-Isoformen untereinander. Schließlich wurde mittels quantitativer Zwei-Farben-STED-Mikroskopie (Abschnitt 4.1.4) gezeigt, dass die verschiedenen hVDAC-Isoformen zu einem unterschiedlichen Grad mit Hexokinase-I kolokalisieren.

\subsubsection{Unterschiedliche sub-mitochondriale Lokalisation der hVDAC-Isoformen}

Die drei hVDAC-Isoformen weisen auf Aminosäureebene eine Sequenzähnlichkeit von mehr als $90 \quad \%$ auf. Trotz dieser hohen 
Sequenzähnlichkeit konnte in dieser Arbeit gezeigt werden, dass sich die submitochondriale Lokalisation der verschiedenen Isoformen beträchtlich unterscheidet (Abschnitt 4.1). hVDAC1 und hVDAC2 sind in einzelnen, klar erkennbaren Domänen lokalisiert, wohingegen hVDAC3 weitgehend homogen über das gesamte Mitochondrium verteilt vorliegt.

Diese Ergebnisse basieren auf Daten, die durch die Expression von hVDACFlag/V5 Fusionsproteinen gewonnen wurden. Der Vorteil in der Verwendung von Protein-Tags im Gegensatz zu fluoreszierenden Proteinen besteht in der Tatsache, dass der Protein-Tag aus nur wenigen Aminosäuren besteht und damit die Wahrscheinlichkeit reduziert, dass die nativen Eigenschaften des zu untersuchenden Proteins gestört werden. Darüber hinaus konnte durch die Verwendung von zwei verschiedenen Protein-Tags nachgewiesen werden, dass die sub-mitochondriale Lokalisation nicht durch einen speziellen Tag beeinflusst wird. Trotzdem kann nicht generell ausgeschlossen werden, dass das nicht native Expressionsniveau, durch Expression über ein in die Zelle eingebrachtes Plasmid, zu Änderungen in der Lokalisation der zu untersuchenden Proteine führt. Ein Argument dagegen ist die Tatsache, dass alle drei hVDAC-Isoformen über ein Plasmid mit einem CMV-Promotor exprimiert worden sind und eine unterschiedliche sub-mitochondriale Lokalisation aufweisen. Aufgrund dieser vergleichbaren Bedingungen kann davon ausgegangen werden, dass zumindest die Unterschiede zwischen den verschiedenen Isoformen nicht expressionsbedingt zustande kommen.

Des Weiteren existieren Daten von isolierten Hefe-Mitochondrien, die ebenfalls eine unterschiedliche sub-mitochondriale Lokalisation von VDAC nahelegen. Durch Rasterkraft-Mikroskopie (AFM) konnten kanal-ähnliche Strukturen in der äußeren mitochondrialen Membran identifiziert werden, die in unterschiedlicher Dichte vorkommen (Abbildung 5.1) (Goncalves et al., 2007). Regionen mit einer geringen Oberflächendichte (20\%) wechseln sich mit Regionen von hoher Oberflächendichte (80 \%) ab. Da VDAC das mit Abstand häufigste Protein der 


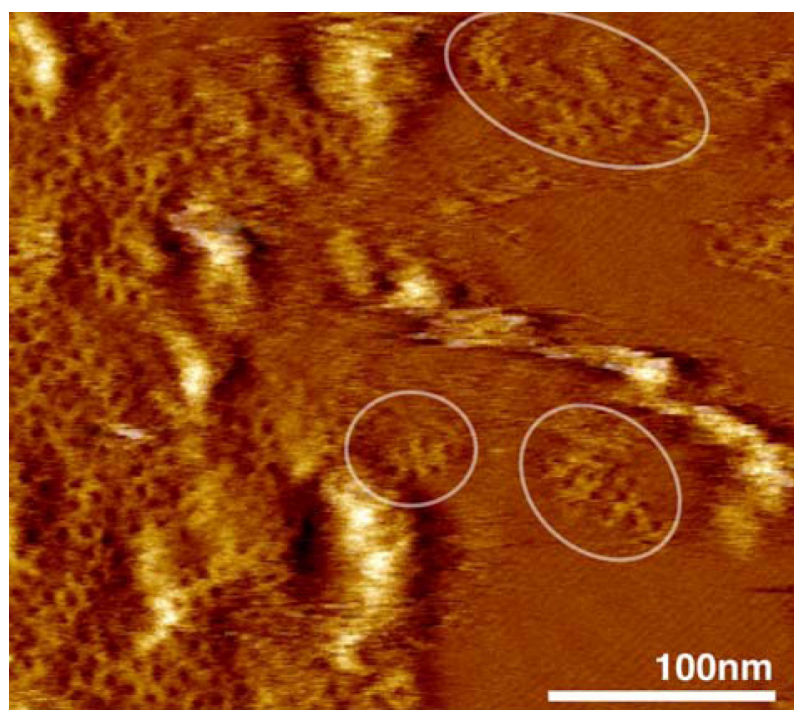

\section{Abbildung 5.1: Rasterkraft-mikroskopische Aufnahmen von der äußeren Membran isolierter Hefe-Mitochondrien}

Auf den rasterkraft-mikroskopischen Aufnahmen wurden kanal-ähnliche Strukturen identifiziert, wobei Regionen mit hoher Oberflächendichte (80\%, linke Seite) von Regionen mit geringer Oberflächendichte (20\%, rechte Seite) unterschieden werden konnten. In den Regionen mit geringer Oberflächendichte wurden oligomere Strukturen unterschiedlicher Größe gefunden (Kreise). Da es sich bei VDAC um das mit Abstand häufigste Protein in der äußeren mitochondrialen Membran handelt, wurde geschlussfolgert, dass es sich bei den im Rasterkraft-Mikroskop beobachteten kanal-ähnlichen Strukturen um VDAC handeln muss (aus Goncalves et al., 2008)

äußeren mitochondrialen Membran ist (Colombini, 1979; Mayer et al., 1993), wurde geschlussfolgert, dass es sich bei den beobachteten Strukturen um VDAC handeln muss. In der Hefe kommen zwei verschiedene VDAC-Isoformen vor (Young et al., 2007), die mittels Rasterkraft-Mikroskopie nicht unterschieden werden können. Es wäre somit durchaus denkbar, dass eine der beiden Hefe VDAC-Isoformen, so wie in dieser Arbeit für hVDAC1 und hVDAC2 beschrieben, vorwiegend in Domänen lokalisiert. Diese Domänenlokalisation würde den im Rasterkraft-Mikroskop beobachteten Regionen mit hoher Oberflächendichte entsprechen. Die andere Hefe VDAC-Isoform wäre demnach gleichmäßiger mit einer geringeren Dichte über die mitochondriale Membran verteilt sein. Diese Verteilung würde der Lokalisation von hVDAC3 entsprechen. Zur Bestätigung dieser Vermutungen, sind isoform-spezifische Studien in der Hefe nötig. 
Ein möglicher Grund für die unterschiedliche sub-mitochondriale Lokalisation der verschiedenen hVDAC-Isoformen könnten unterschiedliche Funktionen sein. Genduplikationsereignisse sind häufig die molekulare Basis für die Entwicklung verschiedener Isoformen eines Proteins, die in der Zelle hoch spezialisierte Funktionen erfüllen (Taylor und Raes, 2004). Phylogenetische Analysen ergaben, dass VDAC3 das ursprünglichste der drei Vertebraten-Gene ist und das die beiden näher miteinander verwandten VDAC1- und VDAC2-Gene erst später in der Vertebratenevolution entstanden sind (Saccone et al., 2003; Young et al., 2007).

Über Unterschiede in den Funktionen der einzelnen hVDAC-Isoformen ist bislang wenig bekannt. Daten bezügl. der Gewebeexpression zeigen, dass alle drei Isoformen in den meisten Geweben exprimiert werden, wenn auch in unterschiedlicher Menge (Shinohara et al., 2000; Cesar Mde und Wilson, 2004). Weitere Daten deuten darauf hin, dass hVDAC1 die mit Abstand am stärksten exprimierte Isoform ist (Yamamoto et al., 2006; De Pinto et al., 2010). In einer funktionellen Studie ist gezeigt worden, dass VDAC3, im Gegensatz zu den anderen beiden Isoformen, eine reduzierte Fähigkeit zur Membraninsertion zeigt und von den anderen beiden Isoformen abweichende Kanaleigenschaften besitzt (Xu et al., 1999). Komplementationsstudien an Hefe-Zellen mit einer VDACDeletion (4por1) haben nachgewiesen, dass VDAC3 zwar Wachstumsdefekte kompensieren kann, aber zu einem geringeren Maß als die anderen beiden VDAC-Isoformen (De Pinto et al., 2010). VDAC wird auch eine wichtige Funktion während der Apoptose zugesprochen, wobei ausschließlich hVDAC1 und hVDAC2 in diesem Prozess eine Rolle zu spielen scheinen (Shimizu et al., 2001; Cheng et al., 2003; Chandra et al., 2005; Zaid et al., 2005; Roy et al., 2009).

Somit zeigen einerseits phylogenetische und funktionale Studien und andererseits lichtmikroskopische Daten dieser Arbeit, dass sich VDAC3 von den anderen beiden Isoformen unterscheidet. Ob es allerdings einen direkten Zusammenhang zwischen der Funktion und der sub-mitochondrialen Lokalisation gibt, kann bis jetzt nicht beantwortet werden. 


\subsubsection{Einfluss der Aminosäuresequenz auf die sub-mitochondriale Lokalisation von} hVDAC

Um spezifische Aminosäuren oder Aminosäureregionen zu identifizieren, die für die Domänen-Lokalisation von hVDAC1 und hVDAC2 im Vergleich zu der homogenen Verteilung von hVDAC3 verantwortlich sind, wurden sowohl einzelne Aminosäuren ausgetauscht als auch die Deletion des N-Terminus von hVDAC1 durchgeführt (Abschnitt 4.1.2).

Für den Aminosäureaustausch L29A in hVDAC1 konnte, im Gegensatz zu allen anderen Austauschen, eine teilweise veränderte sub-mitochondriale Lokalisation beobachtet werden (Abbildung 4.4). Diese variierte aber von Zelle zu Zelle wie auch von Experiment zu Experiment zwischen einer homogenen Verteilung und einer Lokalisation in klar erkennbaren Domänen.

Dass eine einzelne Aminosäure $\mathrm{zu}$ einer veränderten sub-mitochondrialen Lokalisation führt, ist nicht überraschend. Erst kürzlich konnte für das mitochondriale Protein Oxa1 eine Verschiebung in der sub-mitochondrialen Lokalisation durch den Aminosäureaustausch (W128F) nachgewiesen werden (Stoldt, 2010). Das Wildtyp-Protein ist in der inneren Grenzflächenmembran angereichert (79 \%) wohingegen Oxa1-W128F bevorzugt in der Cristaemembran lokalisiert (69 \%). Im Gegensatz zu den Oxa1 Daten sind die Daten dieser Arbeit weit weniger klar. Hier wurde für den Aminosäureaustausch L29A bei hVDAC1 ein Verhältnis von homogener Verteilung zu Domänenlokalisation von ungefähr 1:1 beobachtet. Möglicherweise sind neben einer einzelnen Aminosäure noch andere Faktoren für die sub-mitochondriale Lokalisation von hVDAC verantwortlich, die nicht in dieser Arbeit idenifiziert werden konnten. Falls nun diese Faktoren innerhalb der U2OS-Zelllinie variieren, es also Sub-Populationen von Zellen innerhalb dieser Zelllinie gibt, könnten diese Variationen die Unterschiede in der hVDAC1-L29A Lokalisation erklären. Zum Beispiel wäre es denkbar, dass mit hVDAC1-L29A transfizierte Zellen, die ein bestimmtes Gen stärker exprimieren, eine Domänenlokalisation aufweisen wohingegen andere 
Zellen, die dieses Gen weniger stark exprimieren, eine homogene Lokalisation von hVDAC1-L29A zeigen. Weitere Studien sind nötig, um Aminosäuren bzw. weitere Faktoren zu identifizieren, die eindeutig für die sub-mitochondriale Lokalisation von hVDAC verantwortlich sind.

Neben den sechs einzelnen Aminosäureaustauschen gegen Alanin wurde für hVDAC1 auch der Aminosäureaustausch E73Q sowie der analoge Austausch Q73E in hVDAC3 mit dem Ziel durchgeführt, eine Aminosäure zu identifizieren die für die Domänenlokalisation von hVDAC1/2 verantwortlich ist. Für beide Austausche konnte mittels konventioneller Mikroskopie keine Änderung in der submitochondrialen Lokalisation beobachtet werden. In der Literatur ist für den Aminosäureaustausch an Position 73 beschrieben, dass er für die Interaktion mit Hexokinase-I entscheidend ist (Abu-Hamad et al., 2008; Shoshan-Barmatz et al., 2009). Nun ist es denkbar, dass leichte Änderungen, gerade in der hVDAC3 Lokalisation, aufgrund einer unterbrochenen Interaktion mit Hexokinase-I mittels konventioneller Mikroskopie nicht aufgelöst werden können. Deshalb wurde basierend auf Zwei-Farben-STED-Aufnahmen von hVDAC3-Q73E/Hexokinase-I eine quantitative Kolokalisationsanalyse durchgeführt (Abschnitt 3.4.5) und die Daten mit den zuvor beschriebenen Daten (Abbildung 4.11) für hVDAC3/Hexokinase-I verglichen (Abbildung 5.2). Es konnten keine signifikanten Unterschiede zwischen hVDAC3 und hVDAC3-Q73E in ihrer Kolokalisation mit der Hexokinase-I nachgewiesen werden. Dies deutet darauf hin, dass in hVDAC3 der Austausch von Glutamin zu Glutaminsäure an der Position 73 keinen Einfluss auf die Interaktion mit Hexokinase-I hat.

\subsection{3 hVDAC-Homo- und Heterooligomere}

Mittels STED-Mikroskopie wurden für hVDAC1 und hVDAC2 Domänendurchmesser (inklusive verwendeter Antikörper) von 70-340 nm und für hVDAC3 Clusterdurchmesser (inklusive verwendeter Antikörper) von 40-100 nm bestimmt (Abschnitt 4.1.4, Abbildung 8.3). Zunächst ist festzuhalten, dass es sich 


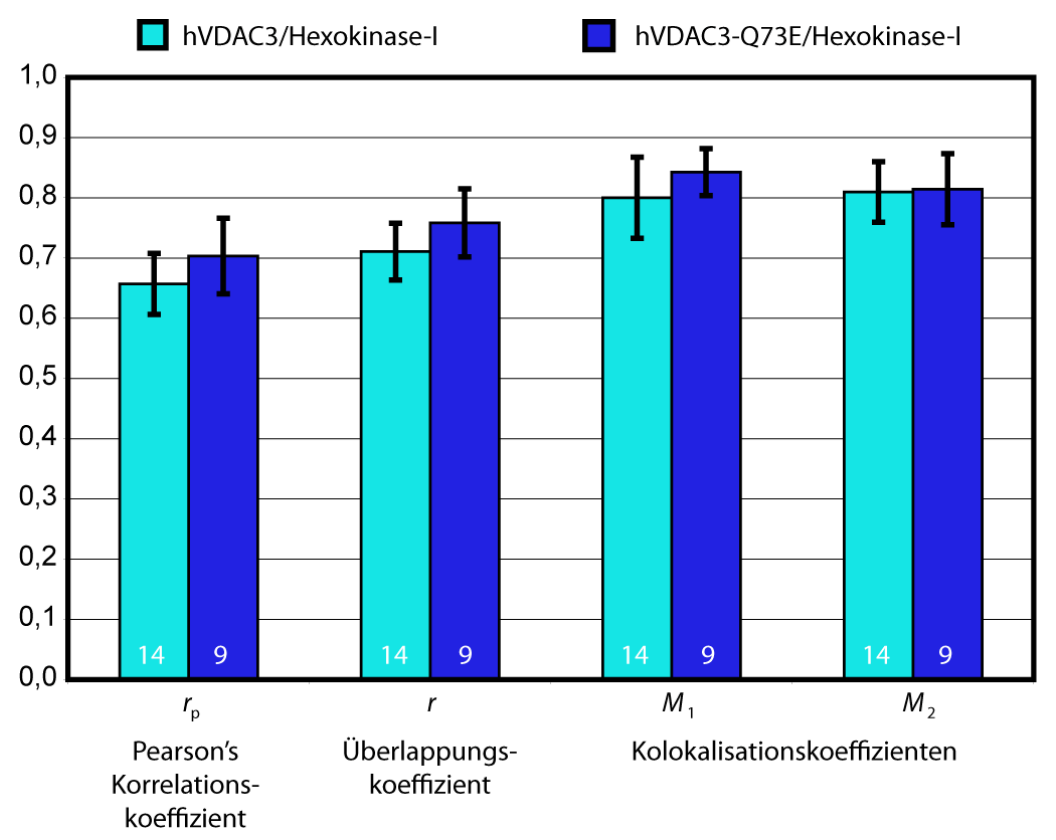

\section{Abbildung 5.2: Kolokalisationsanalyse zwischen der Hexokinase-I und hVDAC3 im Vergleich zu hVDAC3-Q73E}

Dargestellt sind der Pearson's Korrelationskoeffizient $r_{\mathrm{p}}$, der Überlappungskoeffizient $r$ und die Kolokalisationskoeffizienten $M_{1}$ (hVDAC3/Hexokinase-I) und $M_{2}$ (Hexokinase-I/hVDAC3). Die Kolokalisation zwischen hVDAC3 und der Hexokinase-I wird durch den Aminosäureaustausch Q73E nicht beeinflusst. Die Fehlerbalken stellen die Standardabweichung dar. Die Zahlen an den einzelnen Säulen geben die Anzahl der analysierten Zellen wieder. Die Daten für Hexokinase-I/hVDAC3 entstammen der Abbildung 4.11.

hierbei nur um ungefähre Angaben handeln kann. Der Clusterdurchmesser von $40 \mathrm{~nm}$ für hVDA3 entspricht z.B. der Auflösung des verwendeten Mikroskops. Somit liegt der reale Clusterdurchmesser noch unter $40 \mathrm{~nm}$. Genauso ist es denkbar, dass ein Cluster von $100 \mathrm{~nm}$ aus zwei kleineren Clustern besteht, die nur so nah beieinander liegen, dass sich nicht getrennt aufgelöst werden können. Aus diesem Grund ist es möglich, dass die wirklichen Cluster- und Domänendurchmesser kleiner sind, als die in dieser Arbeit bestimmten. Des Weiteren ist zu bedenken, dass endogenes VDAC nicht detektiert und somit auch nicht berücksichtigt werden kann. Unberücksichtigt bleiben auch die hVDACFlag/V5 Proteine, die nicht über die Antikörpermarkierung nachgewiesen wurden. Vermutlich handelt es sich hierbei um einen geringen Prozentsatz, da Antikörper eine sehr hohe Affinität zu ihrem Antigen besitzen. Für die Kontrolle 
hVDAC1-V5/hVDA1-Flag wurde bei den Kolokalisationsstudien Werte um 0,9 bzw. 0,83 für den Pearson's Korrelationskoeffizienten bestimmt. Diese Werte stellen einen Anhaltspunkt für die Markierungseffizienz dar, wobei diese vermutlich höher liegt. Bei der hVDAC1-V5/hVDAC1-Flag Kontrolle bleibt nämlich unberücksichtigt, dass sich an exakt der Stelle, an der sich ein hVDACFlag Molekül befindet, kein hVDAC-V5 Molekül befinden kann.

Trotz dieser Einschränkungen bietet sich die Möglichkeit, die ermittelten Durchmesser für Abschätzungen zu verwenden. Von der hVDAC1-Struktur ist bekannt, dass der Durchmesser eines hVDAC-Moleküls bei 3,5 nm x 3,1 nm liegt (Bayrhuber et al., 2008), wobei in den folgenden Überlegungen von 3,5 nm ausgegangen wird.

$\mathrm{Da}$ bei der indirekten Immunofluoreszenz-Markierung zwei Antikörper verwendet werden, wobei diese von verschiedenen Seiten an das zu untersuchende Protein binden können, ergibt sich, bei einer Antikörperlänge von $\sim 9 \mathrm{~nm}$ eine Strukturvergrößerung um $\sim 36 \mathrm{~nm}$ (exklusive des zu untersuchenden Proteins) (Weber et al., 1978; Dyba et al., 2003). Die Addition dieses Wertes mit dem für den VDAC Durchmesser von 3,5 nm ergibt 39,5 nm, was sehr nahe bei dem unteren, im STED-Mikroskop bestimmten, Clusterdurchmesser von hVDAC3 liegt. 1-18 VDAC-Moleküle würden hiernach Clusterdurchmesser von 40-100 nm entsprechen und 9-87 Moleküle den Domänendurchmessern von 70-340 nm. Einschränkend ist festzuhalten, dass es sich hierbei nur um Abschätzungen handelt und gerade die Werte um $40 \mathrm{~nm}$ mit Vorsicht zu behandeln sind, da diese der Auflösung des verwendeten Mikroskops entsprechen.

Die Angaben von 1-18 Molekülen für hVDAC3 und 9-87 Molekülen für hVDAC1 und hVDAC2 würden bedeuten, dass sich der Oligomerisierungsgrad der verschiedenen Isoformen unterscheidet und das hVDAC sowohl als Monomer (hVDAC3) wie auch als Oligomer verschiedener Größe vorliegt.

In der Tat sind für VDAC verschiedene Oligomerisierungsstufen beschrieben. Diese reichen von Monomeren, Dimeren, Trimeren, Tetrameren, Hexameren bis 
hin zu höheren Oligomeren (Mannella, 1982; Zalk et al., 2005; Hoogenboom et al., 2007; Malia und Wagner, 2007). Kristallographische Daten von humanem VDAC1 gehen von der Bildung eines parallelen Dimers aus (Bayrhuber et al., 2008), wohingegen die Analyse der Kristallpackung von VDAC1 aus der Maus einen antiparallelen Dimer mit einer Tendenz zur Hexamerbildung ergeben hat (Ujwal et al., 2009). Die Untersuchung von VDAC in isolierten Hefemitochondrien mittels Rasterkraft-Mikroskopie (AFM) hat gezeigt, dass sich Regionen mit hoher VDAC-Oberflächendichte mit Regionen geringer VDAC-Oberflächendichte abwechseln (Abbildung 5.1) (Goncalves et al., 2007). In Regionen mit geringer Oberflächendichte wurden Monomere, Dimere, Trimere, Hexamere und Anordnungen bis hin zu 20 Molekülen gefunden. Dies stimmt sehr gut mit den Daten dieser Arbeit für hVDAC3 überein.

Da Goncalves und Kollegen in ihrer Studie nicht zwischen verschiedenen VDACIsoformen unterscheiden konnten, wäre es denkbar, dass eine VDAC-Isoform gleichmäßig über die mitochondriale Membran in Hefe-Zellen verteilt ist, was eben den Regionen mit geringer Oberflächendichte entsprechen würde. In Regionen mit hoher Oberflächendichte würde diese Isoform noch mit einer anderen kolokalisieren. Da in dieser Arbeit für hVDAC3 eine recht gleichmäßige Lokalisation in vielen kleinen Clustern nachgewiesen werde konnte, ist der Vergleich mit Daten für die Regionen mit geringer Oberflächendichte nahe liegend.

Darüberhinaus wurde in der Studie von Goncalves festgestellt, dass VDAC keinen bevorzugten Oligomerisierungsgrad besitzt. Auch die Beobachtung stimmt mit Daten dieser Arbeit überein. Cluster- bzw. Domänendurchmesser variieren sehr stark, was als ein Hinweis für verschiedene Oligomerisierungszustände gewertet werden kann. Somit ist anscheinend entweder der Oligomierisierungszustand für die Funktion von VDAC nicht entscheidend oder VDAC erfüllt in Abhängigkeit von dem Oligomerisierungszustand verschiedene Funktionen. 
Bis jetzt gibt es meines Wissens nach keinerlei Daten über das Vorhandensein von VDAC-Hetero-Oligomeren. Diese Arbeit liefert zumindest erste Hinweise darauf. Es konnte gezeigt werden, dass hVDAC1 und hVDAC2 fast vollständig in denselben Domänen lokalisieren (Abschnitt 4.1.3). Diese klare Kolokalisation legt eine mögliche Interaktion der Proteine nahe. Des Weiteren ist beobachtet worden, dass in der Verteilung von hVDAC3 bei Koexpression mit einer anderen VDAC-Isoform eine gewisse Heterogenität induziert wird (Abschnitt 4.1.3). Diese Beobachtung deutet darauf hin, dass nicht nur Interaktionen zwischen hVDAC1 und hVDAC2 stattfinden, sondern möglicherweise auch zwischen hVDAC1 und hVDAC3 bzw. hVDAC2 und hVDAC3.

\subsubsection{Kolokalisationsstudien zwischen den hVDAC-Isoformen und der}

\section{Hexokinase-I}

Mittels quantitativer Zwei-Farben-STED-Experimente konnte der Grad an Kolokalisation zwischen Hexokinase-I und den drei hVDAC-Isoformen bestimmt werden (Abschnitt 4.1.4). Hierbei wurde festgestellt, dass hVDAC3 einen signifikant höheren Kolokalisationsgrad mit Hexokinase-I aufweist, als die beiden anderen Isoformen. Somit ist der Grad der Kolokalisation zwischen hVDAC und der Hexokinase-I isoform-spezifisch.

Bei Betrachtung der einzelnen Korrelationskoeffizienten sind Übereinstimmungen und Unterschiede aufgefallen (Abbildung 4.11). Die Werte für den Pearson's Korrelationskoeffizienten $r_{\mathrm{p}}$ waren fast vollständig identisch mit dem Überlappungskoeffizienten $r$. Unterschiede ergaben sich hingegen beim Vergleich mit den Kolokalisationskoeffizienten $M_{1}$ und $M_{2}$. Gerade die im Bereich der Positivkontrollen liegenden $M_{1}$ Werte (Abbildung 4.11) für hVDAC1/HexokinaseI, hVDAC2/Hexokinase-I und hVDAC3/Hexokinase-I sind auffällig und stimmen nicht mit dem visuellen Eindruck überein (Abbildung 4.10, Abbildung 5.3). Bei visueller Inspektion entsteht der Eindruck, dass VDAC-Cluster/Domänen häufig neben Hexokinase-I-Clustern liegen und keine komplette Kolokalisation 

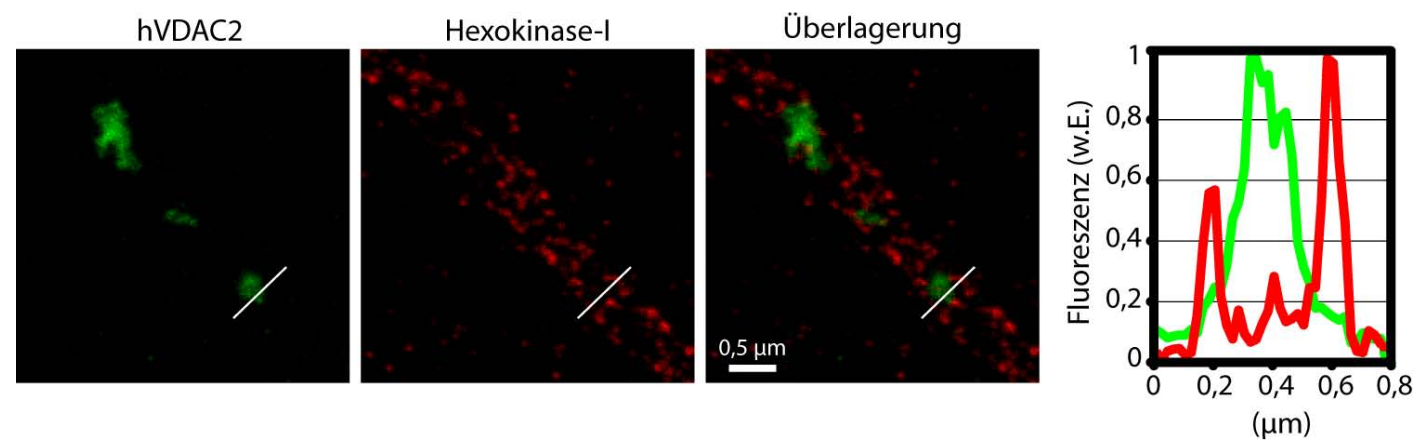

Abbildung 5.3: Aufnahmen und Intensitätsprofile zur Verdeutlichung des Kolokalisationsgrades zwischen hVDAC2 und der Hexokinase-I

Die Kolokalisationskoeffizienten $M_{1}$ und $M_{2}$ für die Kolokalisation von hVDAC1 und hVDAC2 sind sehr hoch und unterscheiden sich nicht signifikant von den Positivkontrollen (Abbildung 4.11). Zudem widersprechen sie dem visuellen Eindruck. $\mathrm{Da}$ für die Kolokalisationskoeffizienten eine binäre Entscheidung zwischen Signal und Hintergrund getroffen wird, kommt es bei der asymmetrischen Verteilung zwischen hVDAC1/2 und der Hexokinase-I zu einer Überbewertung der Kolokalisation, exemplarisch verdeutlicht durch die Intesitätsprofile. Im Bereich von 0,3-0,5 $\mu \mathrm{m}$ ist das Hexokinase-I Signal, zwar sehr schwach, liegt aber über dem Hintergrund und geht somit in die Kolokalisationsanalyse ein.

aufweisen. Ein exemplarisches Intensitätsprofil (Abbildung 5.3) zeigt ein zwar schwaches, aber über dem Hintergrund liegendes, Hexokinase-I-Signal in dem Bereich, in dem sich eine hVDAC2 Domäne befindet. Da bei der Berechnung der Kolokalisationskoeffizienten nur eine binäre Entscheidung zwischen Objekt und Hintergrund getroffen und Intensitäts-Unterschiede nicht berücksichtigt werden, kommt es bei Objekten mit vielen verschiedenen Intensitätsniveaus $\mathrm{zu}$ einer Überbewertung der Kolokalisation. Aus diesem Grund sind die Kolokalisationskoeffizienten $M_{1}$ und $M_{2}$, trotz deren Berücksichtigung von asymmetrischen Verteilungen, für die Kolokalisationsanalyse von hVDACIsoformen mit Hexokinase-I nur begrenzt geeignet. Somit kolokalisieren zwar die verschiedenen hVDAC-Isoformen mit der Hexokinase-I, wie durch den Pearson's Korrelationskoeffizienten $r_{\mathrm{p}}$ und den Überlappungskoeffizienten $r$ nachgewiesen, aber zu einem geringem Grad als die Kolokalisationskoeffizienten $M_{1}$ und $M_{2}$ nahelegen.

Zur Interaktion zwischen Hexokinase-I und den hVDAC-Isoformen sind verschiedene Daten veröffentlicht. Die Interaktion mit hVDAC1 ist klar 
beschrieben (Blachly-Dyson et al., 1993; Azoulay-Zohar und Aflalo, 1999), wohingegen es widersprüchliche Daten bezüglich der Interaktion mit hVDAC2 gibt (Blachly-Dyson et al., 1993; Azoulay-Zohar und Aflalo, 1999). Meines Wissens nach ist nichts über eine mögliche Interaktion zwischen Hexokinase-I und hVDAC3 bekannt.

In dieser Arbeit konnte eine Kolokalisation von Hexokinase-I mit allen drei hVDAC-Isoformen nachgewiesen werden. Der Grad diese Kolokalisation ist von Hexokinase-I/hVDAC3 signifikant höher als der von Hexokinase-I/hVDAC1 und Hexokinase-I/hVDAC2. Somit legen diese Daten nahe, dass alle drei Isoformen mit Hexokinase-I interagieren, sich der Interaktionsgrad aber möglicherweise unterscheidet.

Da Hexokinase-I und hVDAC3 den höchsten Kolokalisationsgrad aufweisen, ist zu vermuten, dass hVDAC3 vorwiegend für den Transport von ATP verantwortlich ist, da dieses von der Hexokinase benötigt wird. Die anderen beiden hVDACIsoformen erfüllen vielleicht andere Funktionen, möglicherweise in Zusammenhang mit der Apopotse (Shimizu et al., 2001; Cheng et al., 2003; Chandra et al., 2005; Zaid et al., 2005; Roy et al., 2009). Diese Überlegung steht im Widerspruch zu einer anderen Studie, in der für hVDAC3 eine reduzierte Fähigkeit zur Membraninsertion nachgewiesen wurde (Xu et al., 1999). Xu und Kollegen vermuten daher, dass hVDAC3 eher regulatorische Funktionen erfüllt, als Metabolite über die Membran zu transportieren. Dies wird durch Komplementationsstudien an Hefezellen gestützt, wobei gezeigt wurde, dass VDAC3 Wachstumsdeffekte zu einem geringen Maß kompensieren konnte, als die anderen beiden Isoformen (De Pinto et al., 2010).

Zusammenfassend ist festzuhalten, dass die quantitativen Kolokalisationsstudien dieser Arbeit zwar eine isoform-spezifische Interaktion von hVDAC mit der Hexokinase-I nahelegen, ob diese aber z.B. von einem isoform-spezifischen Metabolit-Transport (ATP) abhängt, kann nicht abschließend beantwortet werden. 


\subsubsection{Ausblick: Studien zur Lokalisation und Funktion von VDAC}

Ein zentrales Ergebnis dieser Arbeit besteht in der unterschiedlichen submitochondrialen Lokalisation von hVDAC1 und hVDAC2 im Gegensatz zu der von hVDAC3. Es wäre aufschlussreich festzustellen, inwieweit diese unterschiedliche Lokalisation über verschiedene Organismen hinweg konserviert ist. Wie zuvor beschrieben (Abschnitt 5.1.1) lassen die rasterkraftmikroskopischen Aufnahmen von Membranen isolierter Hefe-Mitochondrien (Goncalves et al., 2007) den Schluss zu, dass VDAC dort ebenfalls auf unterschiedlicher Weise in der äußeren Membran verteilt ist, wobei VDAC hier nicht direkt markiert worden ist. Um die sub-mitochondriale Lokalisation der beiden in Hefe vorhandenen Isoformen zu überprüfen, könnten diese genetisch mit einem fluoreszierenden Protein fusioniert und im Anschluss deren submitochondriale Lokalisation untersucht werden. Vergleichbare Experimente könnten außerdem mit VDAC Genen aus anderen Organismen durchgeführt werden, einschließlich Organismen, die nur eine Isoform besitzen. Hierzu gehören z.B. Invertebraten mit der Ausnahme der Arthropoden (Young et al., 2007). So könnte ein genaueres Bild von der sub-mitochondrialen Lokalisation von VDAC in verschiedenen Organismen gewonnen werden.

In dieser Arbeit konnte basierend auf konfokal-mikroskopischen Daten eine fast vollständige Kolokalisation von hVDAC1 mit hVDAC2 nachgewiesen werden. Darüberhinaus ist beobachtet worden, dass in der Verteilung von hVDAC3 bei Koexpression mit einer anderen VDAC-Isoform eine gewisse Heterogenität induziert wird. Somit liefern die Daten dieser Arbeit erste Hinweise auf VDACHeterooligomere. Da diese Ergebnisse aber auf konfokal-mikroskopischen Daten basieren, würden sich weiterführende Kolokalisationsstudien mittels ZweiFarben-STED-Mikroskopie anbieten. Durch die höhere Auflösung könnte sich ein von den bisherigen Werten abweichender Kolokalisationsgrad zwischen den einzelnen Isoformen ergeben. Des Weiteren könnten biochemische Studien zur Ergänzung der mikroskopischen Daten durchgeführt werden. Interaktionsstudien 
könnten Informationen über die Affinität der verschiedenen hVDAC-Isoformen untereinander liefern.

Um spezifische Aminosäuren oder Aminosäureregionen zu identifizieren, die für die Domänen-Lokalisation von hVDAC1 und hVDAC2 im Vergleich zu hVDAC3 verantwortlich sind, wurden verschiedene Aminosäureaustausche durchgeführt. Hierbei wurde für den Aminosäureaustausch L29A für hVDAC1 eine teilweise veränderte sub-mitochondriale Lokalisation beobachtet. Da diese Lokalisation aber nicht eindeutig war, würden sich zur Klärung des Einflusses der Aminosäure Leucin an der Position 29 weitere Aminosäureaustausche anbieten. Beim Vergleich der Aminosäuresequenzen (Abbildung 8.9) fällt auf, dass hVDAC3 an der Position 29 ein Isoleucin aufweist, wohingegen hVDAC1 und hVDAC2 dort ein Leucin besitzen. Da in dieser Arbeit aber die Aminosäure Leucin (29) gegen Alanin ausgetauscht worden ist, würde sich ein zusätzlicher Austausch gegen die Aminosäure Isoleucin anbieten (L29I). Drei Aminosäuren zuvor weisen hVDAC1 und hVDAC2 in ihrer Sequenz nochmals ein Leucin (L26) auf. An dieser Position befindet sich in der hVDAC3 Sequenz ein Methionin. Aus diesem Grund bietet sich der Austausch L26M alleine als auch in Kombination mit L29I für hVDAC1 an. Möglicherweise führen diese Mutationen zu einer eindeutig veränderten submitochondrialen Lokalisation von hVDAC1.

Die Funktionen der verschiedenen VDAC-Isoformen sind bis jetzt nicht geklärt. Hinweise könnten Interaktionen mit anderen Proteinen liefern. Zwar sind für VDAC eine Reihe von verschiedenen Interaktionen beschrieben (Felgner et al., 1979; Linden und Karlsson, 1996; Schlattner et al., 2001; Roman et al., 2006), ob diese aber isoform-spezifisch sind, ist weitgehend unklar. Somit würden sich systematische Interaktionsstudien mit den drei hVDAC-Isoformen und putativen Interaktionspartnern anbieten. Hierüber könnten isoform-spezifische Interaktionspartner identifziert werden. $\mathrm{Ob}$ diese isoform-spzefischen Interaktionen möglicherweise auch für die sub-mitochondriale Lokalisation verantwortlich sind, könnte durch die Kombination mit den Aminosäure- 
Austausch-Experimenten herausgefunden werden. Falls hierbei einzelne Aminosäuren identifiziert werden können, die für die sub-mitochondriale Lokalisation einer hVDAC-Isoform entscheidend sind, könnte überprüft werden, ob deren Austausch gleichzeitig zum Abbruch der Interaktion mit dem identifizierten isoform-spezifischen Interaktionspartner führt. Somit könnte ein Zusammenhang zwischen sub-mitochondrialer Lokalisation und Funktion der hVDAC-Isoformen hergestellt werden.

In dieser Arbeit wurde gezeigt, dass zwar alle hVDAC-Isoformen mit HexokinaseI kolokalisieren, dass der Grad der Kolokalisation aber isoform-spezifisch ist. Einige Daten deuten daraufhin, dass die Hexokinase in fast allen Tumoren überexprimiert ist und es $\mathrm{zu}$ einer verstärkten Interaktion mit VDAC in Tumorzellen kommt (Pedersen, 2007; Galluzzi et al., 2008; Gogvadze et al., 2010). Aus diesem Grund wäre es wichtig die Kolokalisation von Hexokinase-I und den drei hVDAC-Isoformen in primären Zellen ebenfalls zu quantifizieren und die Ergebnisse mit den Resultaten dieser Arbeit zu vergleichen. Es wird angenommen, dass vorwiegend die Hexokinase-II in Tumoren überexprimiert ist (Pedersen, 2007). Somit würde sich ein qualitativer und quantitativer Vergleich der beiden Hexokinase Isoformen in primären und auch Krebs-Zellen anbieten.

Zusammenfassend könnten die vorgeschlagenen Experimente dazu beitragen, weitere Unterschiede zwischen den verschiedenen hVDAC-Isoformen zu identifizieren, um diese möglicherweise mit der Funktion und der submitochondrialen Lokalisation zu korrelieren. 


\subsection{Sub-mitochondrialen Proteinverteilungen in unbehandelten und apoptotischen Zellen}

Der Zelltod ist ein fundamentaler Bestandteil des Lebens aller multizellulären Organismen (Spierings et al., 2005). Die häufigste Form des programmierten Zelltods, die Apoptose, ist von zentraler Bedeutung für die Organisation von Zellen und Geweben im Organismus. Ein wichtiges Ereignis im apoptotischen Signalweg ist die Permeabilisierung der äußeren mitochondrialen Membran (MOMP) (Chipuk et al., 2006; Jourdain und Martinou, 2009). Trotz intensiver Forschung ist wenig über die genauen Vorgänge bekannt, die zu MOMP führen, noch ist viel über sub-mitochondriale Proteinverteilungen und mögliche Änderungen während der Apoptose bekannt.

In dieser Arbeit wurde die sub-mitochondriale Verteilung verschiedener Proteine in unbehandelten und apoptotischen Zellen quantitativ mittels STED-Mikroskopie untersucht. Es konnte gezeigt werden, dass keine dramatischen Änderungen in den sub-mitochondrialen Proteinverteilungen stattfinden. Vielmehr wurden subtile Änderungen hin zu einer homogeneren Proteinverteilung nachgewiesen, die zeitlich gesehen vor der Cytochrom $c$-Freisetzung stattfinden.

\subsubsection{Sub-mitochondriale Proteinverteilungen in unbehandelten Zellen}

In dieser Arbeit konnten Unterschiede in den sub-mitochondrialen Proteinverteilungen zwischen der Hexokinase-I, Tom20, Tom22, Cytochrom $c$, F1FoATP-Synthase und Cyclophilin $\mathrm{D}$ in unbehandelten Wildtyp-Zellen nachgewiesen werden (Abschnitt 4.2.5).

Die Art und Dichte der Verteilung hängt möglicherweise von dem SubKompartiment $\mathrm{ab}$, in der das entsprechende Protein lokalisiert. Proteine der äußeren Membran (Hexokinase-I, Tom20, Tom22) scheinen nicht so dicht gepackt zu sein wie Proteine der inneren Membran (z.B. F1FoATP-Synthase). Bei diesen Überlegungen ist aber zu beachten, dass die Fläche der inneren Membran durch 
ihre starke Auffaltung deutlich größer ist als die der äußeren Membran. Da bei den in dieser Arbeit verwendeten Mikroskopen die Auflösung entlang der optischen Achse nicht verbessert ist, ergeben sich bei Aufnahmen in einer Ebene automatisch Maximalprojektionen der 200-400 nm großen Mitochondrien, wobei die innere Membran aufgrund ihrer Faltung überproportional stark im Vergleich zu äußeren Membran vertreten ist. Hierdurch kann der Eindruck entstehen, dass Proteine der äußeren Membran generell weniger dicht gepackt sind als Proteine der inneren Membran. Somit hängt die Verteilung der verschiedenen Proteine wahrscheinlich nicht oder zumindest nicht ausschließlich vom mitochondrialen Sub-Kompartiment ab.

Vielmehr kann die Funktion der Proteine Einfluss auf deren sub-mitochondriale Lokalisation haben. Es wird z.B. vermutet, dass der Tom-Komplex (mit dessen Rezeptoren Tom20 und Tom22) an Kontaktstellen lokalisiert ist (Reichert und Neupert, 2002; Chacinska et al., 2003). In der Tat konnte eine Korrelation zwischen der Anzahl der Tom20-Protein-Cluster und mitochondrialer Kontaktstellen (bestimmt über Elektronenmikroskopie) nachgewiesen werden (Wurm, 2008). Somit lokalisieren die Tom20 und Tom22 Proteincluster möglicherweise an mitochondrialen Kontaktstellen.

Für die $\mathrm{F}_{1} \mathrm{~F}_{\mathrm{O}} \mathrm{ATP}-\mathrm{Syn}$ thase ist gezeigt worden, dass sie innerhalb der inneren Membran bevorzugt in der Cristae-Membran lokalisiert (Vogel et al., 2006; Wurm und Jakobs, 2006). Diese Lokalisation hat ebenfalls einen funktionalen Hintergrund: Die anderen Komponenten der Atmungskette sind in der CristaeMembran lokalisiert, die somit den Ort der oxidativen Phosphorylierung darstellt (Gilkerson et al., 2003).

Die Visualisierung von einzelnen Cristae ist ohne verbesserte Auflösung entlang der optischen Achse nicht möglich (Schmidt et al., 2009). In dieser Arbeit wurden bei der Färbung der F1FoATP-Synthase zahlreiche Aussparungen beobachtet. Hierbei handelt es sich möglicherweise um Cristae-freie Regionen der Mitochondrien. Hingegen könnten die Aussparungen bei der Färbung des 
Matrixproteins Cyclophilin D Bereiche mit dicht gepackten Cristae-Regionen darstellen.

\subsubsection{Drp1-Herunterregulierung und deren Einfluss auf die Apoptose}

Die Ergebnisse dieser Arbeit zeigen, dass die Herunterregulierung von Drp1 die mitochondriale Fragmentierung inhibiert und eine Verzögerung der Cytochrom $c^{-}$ Freisetzung während der Apoptose bewirkt (Abschnitt 4.2.3 und 4.2.4).

Dies stimmt mit den Studien von Youle und Kollegen überein, die als Erste den Einfluss von Drp1 auf die mitochondriale Fragmentierung und Apoptose untersucht haben (Frank et al., 2001; Lee et al., 2004). Sie konnten für Drp1 zeigen, dass bei dessen Verlust nicht die Bax-Translokation, wohl aber die Cytochrom $c$-Freisetzung inhibiert wird. Im Folgenden haben weitere Studien ebenfalls die Hemmung der Cytochrom $c$-Freisetzung während der Apoptose als Konsequenz der Drp1-Herunterregulierung beschrieben (Parone et al., 2006; Estaquier und Arnoult, 2007). Zusätzlich wurde in diesen Arbeiten nachgewiesen, dass die Verzögerung in der Freisetzung selektiv auf das Protein Cytochrom $c$ zutrifft und nicht auf andere Proteine des Intermembranraums wie Omi/HtrA2 und Smac/DIABLO, die in Wildtyp-Zellen zeitgleich mit Cytochrom $c$ freigesetzt werden (Parone et al., 2006; Estaquier und Arnoult, 2007). Kürzlich wurde zudem ein chemischer Inhibitor für Drp1, genannt mdivi-1, beschrieben, der ebenfalls zu einer Hemmung der mitochondrialen Teilung führt und die Cytochrom $c^{-}$ Freisetzung während der Apoptose verzögert (Cassidy-Stone et al., 2008).

Im Gegensatz zu den zuvor beschriebenen Studien und den Ergebnissen dieser Arbeit sehen Martin und Kollegen keine bzw. eine vernachlässigbare Hemmung der Cytochrom $c$-Freisetzung bei der Überexpression einer dominant negativen Mutante von Drp1 (Drp1 ${ }^{\mathrm{K} 38 \mathrm{~A}}$ ) (Sheridan et al., 2008). Des Weiteren gehen sie davon aus, dass die mitochondriale Fragmentierung keine Rolle bei der Cytochrom $c$-Freisetzung spielt und beide Prozesse voneinander getrennt werden können. In der Tat ist für Mitglieder der Bcl-2 Proteinfamilie nachgewiesen worden, dass sie 
eine Rolle bei der mitochondrialen Morphologie unabhängig von der Regulierung des Zelltods spielen (Karbowski et al., 2006; Autret und Martin, 2009; Autret und Martin, 2010). Somit ist die mitochondriale Fragmentierung für sich genommen während der Apoptose möglicherweise nur ein Nebenprodukt ohne direkte Bedeutung für die Cytochrom $c$-Freisetzung.

Dies schließt aber nicht aus, dass einzelne Proteine der Teilungsmaschinerie, wie z.B. Drp1 sehr wohl eine funktionelle Relevanz für die Cytochrom $c$-Freisetzung haben, die unabhängig von ihrer Funktion bei der mitochondrialen Teilung ist (Ow et al., 2008; Suen et al., 2008; Jourdain und Martinou, 2009). Da aber Martin und Kollegen (Sheridan et al., 2008), keine bzw. eine vernachlässigbare Hemmung der Cytochrom $c$-Freisetzung bei der Überexpression einer dominant negativen Mutante von Drp1 (Drp1 ${ }^{\mathrm{K} 38 \mathrm{~A}}$ ) beobachtet haben, stehen diese Resultate im klaren Widerspruch zu den Ergebnissen dieser Arbeit und anderer (Frank et al., 2001; Lee et al., 2004; Parone et al., 2006; Estaquier und Arnoult, 2007; Cassidy-Stone et al., 2008). Dieser Widerspruch ist schwer zu erklären. Zwar wurde in dieser Arbeit nicht die dominant negative Mutante von Drp1 (Drp1 $\left.{ }^{\mathrm{K} 38 \mathrm{~A}}\right)$ verwendet, sondern Drp1 durch RNAi herunterreguliert, aber in anderen Studien wurde bei der Verwendung der dominant negativen Mutante von Drp1 ebenfalls eine Verzögerung der Cytochrom $c$-Freisetzung beobachtet (Frank et al., 2001; Brooks et al., 2007). Sowohl in dieser Arbeit, als auch in anderen (Lee et al., 2004; Parone et al., 2006) wurde mit Actinomycin D derselbe Apoptosestimulus verwendet wie bei Martin und Kollegen. Da in verschiedenen Studien dieselbe Zelllinie (HeLa) verwendet worden ist (Frank et al., 2001; Lee et al., 2004; Parone et al., 2006; Estaquier und Arnoult, 2007; Sheridan et al., 2008), kann ein zelltyp-spezifischer Effekt ebenfalls ausgeschlossen werden. Somit gibt es aus meiner Sicht, auf Grundlage der veröffentlichten Daten, keine Erklärung für die Tatsache, dass Martin und Kollegen keine bzw. eine vernachlässigbar geringe Verzögerung der Cytochrom c-Freisetzung durch Hemmung von Drp1 nachweisen konnten. Möglicherweise gibt es weitere Faktoren, welche aus den Veröffentlichungen 
nicht ersichtlich sind, die zu den unterschiedlichen Ergebnissen von Martin und Kollegen geführt haben.

Die Bedeutung von Drp1 für die Cytochrom $c$-Freisetzung wird durch weitere lichtmikroskopische Studien gestützt, in denen gezeigt worden ist, dass Drp1 während der Apoptose mit Bax und Bak in großen Komplexen an der äußeren mitochondrialen Membran kolokalisiert (Nechushtan et al., 2001; Karbowski et al., 2002).

Es wird darüber spekuliert, dass die konkrete Funktion von Drp1 möglicherweise in der Freisetzung von Cytochrom- $c$ aus den Cristae der Mitochondrien besteht (Abbildung 5.4). Es wird vermutet, dass zwei verschiedene Cytochrom cFraktionen existieren. Eine große Fraktion innerhalb der Cristae und eine kleinere Fraktion im restlichen Intermembranraum (James und Martinou, 2008; Suen et al., 2008; Scorrano, 2009). Die größere Fraktion kann in gesunden Zellen nicht aus den Cristae entweichen, da die Cristae Junctions durch das Protein Opa1 blockiert werden (Abbildung 5.4). Nun ist es denkbar, dass Drp1 während der Apoptose direkt oder indirekt die Blockade durch Opa1 löst, so dass die größere Cytochrom c-Fraktion aus den Cristae gelangt (Germain et al., 2005; James und Martinou, 2008; Wang und Youle, 2009) um dann durch putative Poren ins Cytosol freigesetzt $\mathrm{zu}$ werden. Dies würde den selektiven Einfluss der Drp1Herunterregulierung auf die Cytochrom $c$-Freisetzung erklären, wohingegen die Bax-Aktivierung unbeeinflusst bleibt. Darüberhinaus würde der selektive Einfluss von Drp1 die Beobachtung erklären, dass zwar die Cytochrom $c$-Freisetzung in Drp1-herunterregulierten Zellen verzögert wird, nicht aber die Freisetzung von Omi/HtrA2 und Smac/DIABLO. Diese befinden sich nämlich nicht in den Cristae (Parone et al., 2006; Estaquier und Arnoult, 2007) und können somit direkt durch MOMP freigesetzt werden.

Bei diesen Überlegungen handelt es sich aber weitgehend um Spekulationen, da bis jetzt weder eine direkte oder indirekte Interaktion von Opa1 mit Drp1 nachgewiesen worden ist, noch eindeutige Daten über das Vorhandensein von 

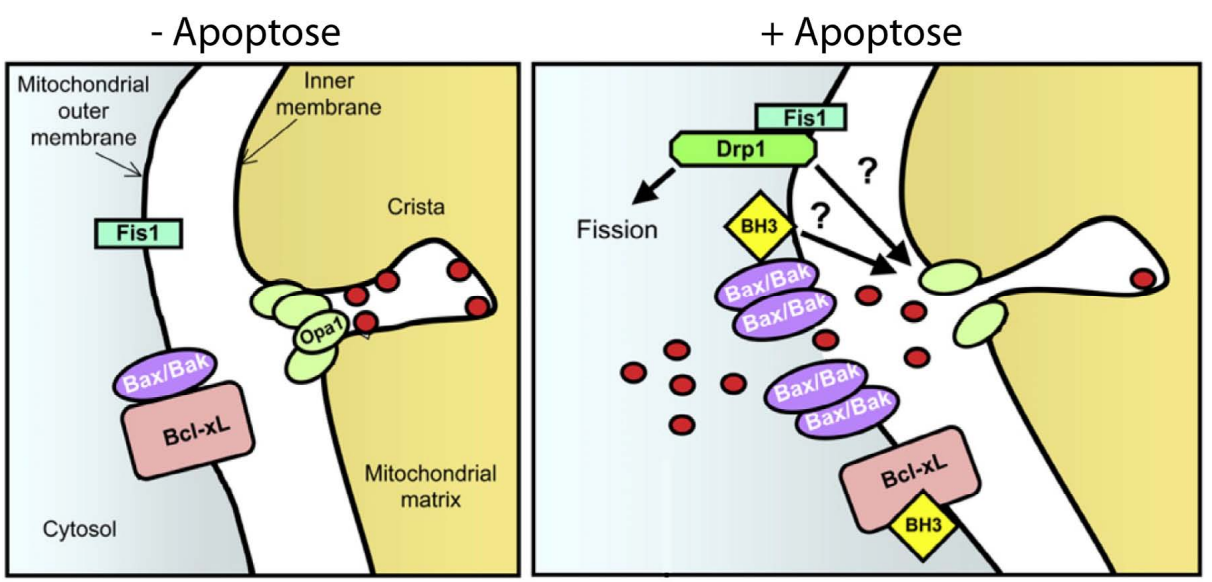

\section{Abbildung 5.4: postulierter Mechanismus zur Freisetzung von Cytochrom $c$ aus den Cristae der Mitochondrien}

Es wird vermutet, dass sich in unbehandelten Zellen das meiste Cytochrom $c$ (rot), eingeschlossen durch Opa1-Komplexe, in den Cristae der Mitochondrien befindet. Während der Apoptose findet, reguliert durch Proteine der Bcl-2 Familie, MOMP statt. Es wird nun angenommen, dass noch ein zweiter Prozess stattfinden muss, damit Cytochrom $c$ aus den Cristae und somit letztlich ins Cytosol gelangen kann. Ausgelöst bzw. reguliert durch Proteine der Teilungsmaschinerie wie Drp1 und Fis1 und/oder Proteine der Bcl-2 Familie werden möglicherweise die Opa1-Komplexe zerstört und Cytochrom $c$ kann als Folge aus den Cristae und somit ins Cytosol diffundieren (verändert nach James und Martinou, 2005).

zwei verschiedenen Cytochrom $c$-Fraktionen existieren. In einer Studie wurde nämlich gezeigt, dass Cytochrom $c$ in zwei aufeinander folgenden Schritten freigesetzt wird (Ott et al., 2002), wohingegen in einer anderen Studie nachgewiesen wurde, dass Cytochrom $c$ in nur einem Schritt vollständig freigesetzt wird (Goldstein et al., 2005).

In dieser Arbeit wurde gezeigt, dass in einer einzelnen Zelle mit Drp1Herunterregulierung sowohl Mitochondrien existieren, die Cytochrom $c$ freigesetzt haben als auch Mitochondrien die keine Cytochrom $c$-Freisetzung zeigen (Abschnitt 4.18). Diese mitochondrialen Sub-Populationen deuten ebenfalls auf eine funktionale Relevanz von Drp1 für die Cytochrom $c$-Freisetzung hin. Diese wird durch die Herunterregulierung von Drp1 verzögert, findet aber dann zeitlich verzögert und nicht synchron in verschiedenen Mitochondrien statt. Da es sich um einen knockdown und nicht um einen knockout von Drp1 handelt, ist es denkbar, dass einige Drp1-Moleküle ausreichen, um bei bestimmten 
Mitochondrien, im Zusammenwirken mit anderen Proteinen, die Cytochrom $c^{-}$ Freisetzung zu bewirken. Dieser Prozess findet aber im Gegensatz zu WildtypZellen nicht mehr synchron statt, da die Drp1 Proteinkonzentration zu gering ist. Andererseits wäre es auch denkbar, dass andere Proteine die Funktion von Drp1 teilweise kompensieren können und so zu einer verzögerten und asynchronen Cytochrom $c$-Freisetzung führen.

Außerdem wurde in Drp1-herunterregulierten Zellen dieser Arbeit beobachtet, dass Mitochondrien die Cytochrom $c$ freigesetzt haben, ebenfalls kein Cyclophilin D mehr besaßen (Abbildung 4.27). Für ausgestreckte Wildtyp-Zellen konnte hingegen in einem vergleichbaren Zeitrahmen keine Cyclophilin D-Freisetzung beobachtet werden. Möglicherweise findet hier durch die Drp1Herunterregulierung eine zeitliche Änderung im Ablauf des apoptotischen Signalweges statt. Zu einem späten apoptotischen Zeitpunkt konnten nämlich zusammengeschrumpfte Wildtyp-Zellen identifiziert werden, die sowohl Cytochrom $c$ als auch Cyclophilin D freigesetzt hatten (Abbildung 8.22). In der Tat ist die Freisetzung von Matrixproteinen wie HSP60 während der Apoptose beschrieben worden (Chandra et al., 2002; Chandra et al., 2007). Dies würde aber die Permeabilisierung der inneren mitochondrialen Membran voraussetzen. Diese findet aber vermutlich in Wildtyp-Zellen zeitlich gesehen deutlich nach der Cytochrom $c$-Freisetzung statt, da erst zu einem sehr späten Zeitpunkt die Cyclophilin D-Freisetzung beobachtet worden ist.

Zusammenfassend kann festgehalten werden, dass die Herunterregulierung von Drp1, zumindest in dem hier verwendeten Modellsystem, zu einer Verzögerung der Cytochrom $c$-Freisetzung und zur Hemmung der mitochondrialen Fragmentierung führt. Die Daten dieser Arbeit und andere deuten an, dass Drp1 eine Funktion bei der Apoptose zukommt, die unabängig von der mitochondrialen Fragmentierung ist. Um die genaue Funktion von Drp1 zu identifizieren, sind weitere Studien nötig. 


\subsubsection{Sub-mitochondriale Proteinverteilungen in apoptotischen Zellen}

Im Rahmen dieser Arbeit wurden sub-mitochondriale Verteilungen von den Proteinen Hexokinase-I, Tom20, Tom22, Cytochrom $c$, F1FoATP-Synthase und Cyclophilin D in unbehandelten Zellen quantitativ mittels STED-Mikroskopie untersucht und mit den entsprechenden Verteilungen in apoptotischen Zellen verglichen (Abschnitt 4.2.8).

Als Ergebnis der Untersuchung kann festgehalten werden, dass keine dramatischen Änderungen in den sub-mitochondrialen Verteilungen der untersuchten Proteine während der Apoptose stattfinden. Durch die Quantifizierung der STED-Daten konnten vielmehr für alle Proteine (Cyclophilin D mit Einschränkungen) subtile Änderungen, hin zu größeren Durchmessern von Proteinclustern und zu homogeneren Verteilungen nachgewiesen werden. Diese finden während der Apoptose zeitlich gesehen vor der Cytochrom $c$-Freisetzung statt.

Diese Ergebnisse können mit einem Modell erklärt werden, welches eine Tendenz zur Auflösung von Proteinclustern postuliert (Abbildung 5.5). Es basiert auf der Annahme, dass die Gesamtzahl der Proteine innerhalb der Mitochondrien während der Apoptose konstant bleibt.

In dieser Arbeit wurde gezeigt, dass die Clusterdurchmesser aller untersuchten Proteine in apoptotischen Zellen zunehmen (Abbildung $5.5 \mathrm{I} \rightarrow \mathrm{II}$ ). Dies kann entweder dadurch erklärt werden, dass zusätzliche Proteine das bestehende Cluster erweitern oder aber, dass die bereits im Cluster vorhandenen Proteine etwas auseinanderweichen. Im ersten Fall wäre eine zunehmende Zahl von Proteinen im Cluster zu erwarten. Im zweiten Fall würde die Zahl der Proteine, die den Cluster bilden, gleichbleiben.

Der erste Fall kann ausgeschlossen werden, wenn die Ergebnisse bezüglich des Verhältnisses von Cluster- zu Hintergrundintensität (in den Mitochondrien) hinzugezogen werden. Von unbehandelten zu apoptotischen Zellen nimmt das Verhältnis von Cluster- zu Hintergrundintensität ab. Würden sich hingegen 
A

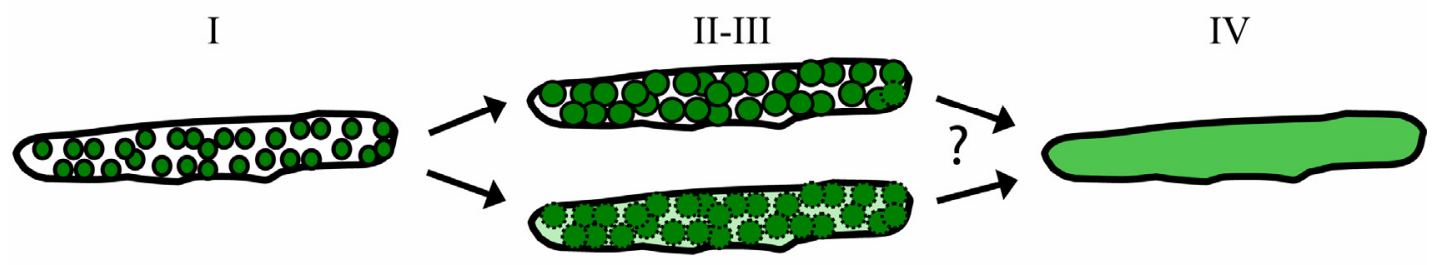

B

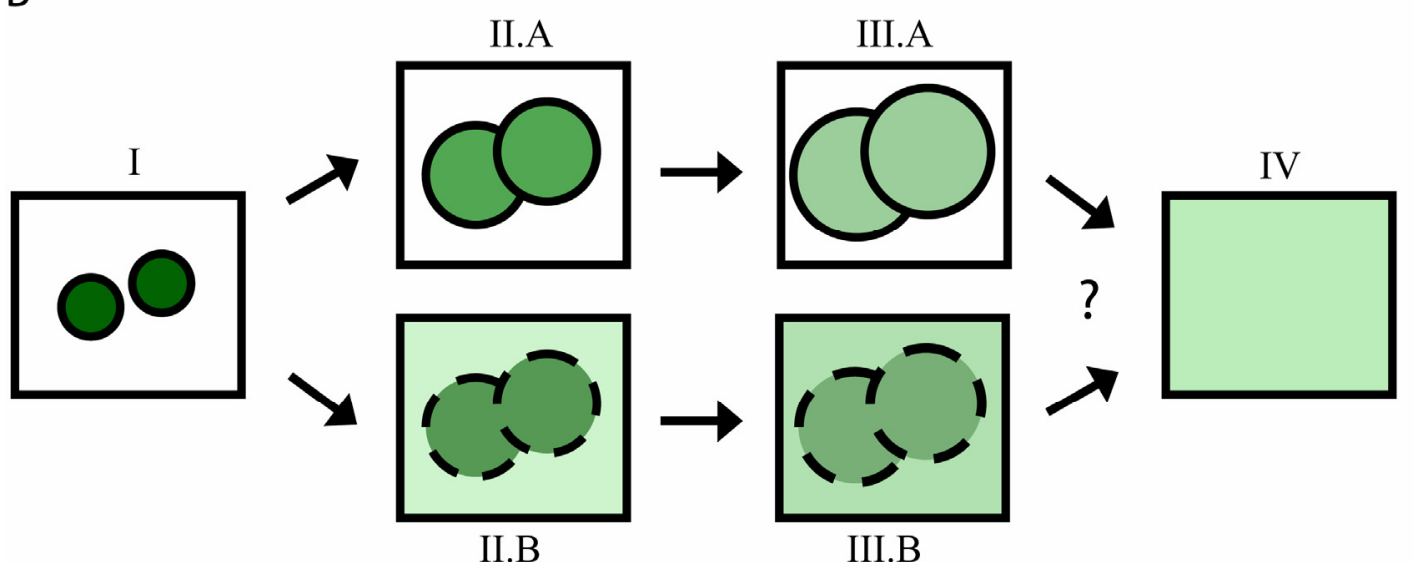

Abbildung 5.5: Modell zur Erklärung der subtilen Änderungen in den submitochondrialen Proteinverteilungen während der Apoptose

In (A) ist ein kompletter mitochondrialer Tubulus dargestellt, in (B) zwei einzelne Proteincluster. Die Proteincluster sind zur Vereinfachung als Kreise dargestellt. Die Zunahme des Clusterdurchmessers $(\mathrm{I} \rightarrow \mathrm{II})$ und eine homogenere Proteinverteilung während der Apoptose kann durch eine Tendenz zur Auflösung von Proteinclustern erklärt werden. Da das Verhältnis der Cluster- zur Hintergrundintensität ebenfalls während der Apoptose abnimmt, kann ausgeschlossen werden, dass sich zusätzliche Proteine an die Cluster anlagern. Vielmehr muss zur Erklärung der Beobachtungen die Proteinzahl in den Clustern gleich bleiben (II.A, III.A) oder abnehmen (II.B, III.B). Im ersten Fall bleibt die Zahl der nicht cluster-bildenden Proteine ("mitochondrialer Hintergrund") konstant, im zweiten Fall nicht sie zu. Ob diese subtilen Änderungen schließlich zu einer Gleichverteilung (IV) durch vollständige Auflösung der Proteincluster führen, kann aufgrund der experimentellen Daten nicht beantwortet werden.

weitere Proteine aus dem "mitochondrialen Hintergrund" an ein bestehendes Cluster anlagern, so müsste aber das Verhältnis von Cluster- zu Hintergrundintensität zunehmen. Da das Verhältnis aber abnimmt ist davon auszugehen, dass die bereits im Cluster vorhandenen Proteine etwas auseinanderweichen. 
Wenn sich keine zusätzlichen Proteine an ein bestehendes Cluster anlagern, besteht die Möglichkeit, dass die Zahl der Proteine pro Cluster gleich bleibt. Dies würde bedeuten, dass die Proteine eines Clusters auseinanderweichen, die Gesamtzahl pro Cluster aber gleich bleibt (Abbildung 5.5 I $\rightarrow$ II.A $\rightarrow$ III.A). Alternativ besteht die Möglichkeit, dass die Zahl der Proteine pro Cluster während der Apoptose abnimmt, was bedeuten würde, dass sich zusätzlich zum Auseinanderweichen einzelne Proteine vom Cluster lösen (Abbildung 5.5 $\mathrm{I} \rightarrow$ II.B $\rightarrow$ III.B). Im ersten Fall würde die Zahl der Proteine, die keine Cluster bilden ("mitochondrialer Hintergrund") konstant bleiben (Abbildung 5.5 $\mathrm{I} \rightarrow$ II.A $\rightarrow$ III.A), wohingegen sie im zweiten Fall zunehmen würde (Abbildung 5.5 $\mathrm{I} \rightarrow$ II.B $\rightarrow$ III.B). Für den ersten Fall wäre einer Abnahme der Clusterintensität bei gleichbleibender Hintergrundintensität zu erwarten, für den zweite Fall wäre eine eine Abnahme der Clusterintensität und eine Zunahme der Hintergrundintensität zu erwarten. Aufgrund der experimentellen Daten kann keine der beiden Varianten ausgeschlossen werden, da hierzu absolute Werte für die Cluster- und insbesondere für die Hintergrundintensität bestimmt werden müssten. Absolute Fluoreszenzintensitäten sind aber schwer zu ermitteln, da sie von verschiedenen Aufnahme-Parametern abhängen, die zudem noch zwischen den einzelnen Aufnahmen variieren können.

Fest steht aber, dass die Cluster größer werden und die Zahl der am Cluster beteiligten Proteine entweder gleichbleibt oder leicht abnimmt. Nun ist es aber selbst bei einer zunächst gleich bleibenden Zahl an Proteinen pro Cluster vorstellbar, dass die Cluster-bildenen Proteine immer weiter auseinanderweichen, so dass irgendwann überhaupt kein Cluster mehr existiert und die Proteine selbst zu einem Teil des Hintergrundes werden. Somit würde auch ein bloßes Auseinanderweichen der Proteine eines Clusters, ohne dass sich zusätzliche Proteine aus dem Cluster lösen, letztendlich zur Auflösung des Clusters führen (Abbildung 5.5 IV). Zudem ist es durchaus denkbar, dass die Übergänge zwischen den beiden Modellen (II-III A bzw. B) fließend sind. Möglicherweise verlieren 
einzelne Cluster beim Auseinanderweichen zusätzlich Proteine, wohingegen dies für andere Proteincluster nicht zutrifft.

Das Modell von größer werdenen Proteinclustern, die eine Tendenz zu Auflösung zeigen, wird durch den dritten experimentell ermittelten Parameter, die Varianz der Fluoreszenzintensität, gestützt. Für diese Varianz wurde nachgewiesen, dass sie während der Apoptose abnimmt, was bedeutet, dass die Gesamtverteilung der Proteine homogener wird.

Zusammenfassend führen diese Überlegungen zu der Vorstellung, dass während der Apoptose subtile Änderungen in sub-mitochondrialen Proteinverteilungen stattfinden, mit einer Tendenz hin zur Auflösung von Proteinclustern. Eine Konsequenz davon sind homogenere Proteinverteilungen.

Einige, wenige experimentelle Daten dieser Arbeit entsprechen nicht ganz dem Modell. Für Cyclophilin D z.B. wurde keine (Wildtyp) oder eine nicht signifikante (Drp1-Herunterregulierung) Abnahme in der Varianz der Fluoreszenzintensität und des Verhältnisses von Cluster- zu Hintergrundintensität beobachtet (Abbildung 4.25 und 4.26). Eine mögliche Erklärung besteht darin, dass das Matrixprotein an sich schon eine sehr homogene Verteilung aufweist. In der Tat ist es in unbehandelten Zellen das Protein mit der niedrigsten Varianz (Abbildung 4.25 und 4.26). Vielleicht ist somit eine homogenere Verteilung nicht mehr möglich oder kann aufgrund der Auflösung des Mikroskops nicht mehr nachgewiesen werden.

Des Weiteren wurde für Drp1-herunterregulierte Zellen eine geringe, aber signifikante Abnahme in dem Clusterdurchmesser von Tom22 in Cytochrom cfreigesetzten Mitochondrien beobachtet sowie eine leichte Zunahme in dem Verhältnis von Cluster- zur Hintergrundintensität für die Hexokinase-I in Cytochrom $c$-freigesetzten Drp1-herunterregulierten Zellen (Abbildung 4.28). Diese beiden Ergebnisse stimmen nicht mit den anderen Daten dieser Arbeit überein und können möglicherweise durch die geringe Datenmenge der Cytochrom $c$-freigesetzten, Drp1-herunterregulierten Zellen erklärt werden 
(Abschnitt 4.2.8). Darüberhinaus beziehen sich die Abweichungen von Tom22 und Hexokinase-I nicht auf alle drei ausgewerteten Parameter, sondern nur auf einen Teil davon und relativieren somit die Abweichungen.

Generell ist anzumerken, dass bei der Beurteilung von Proteinverteilungen die Auflösung des verwendeten Mikroskops mit berücksichtigt werden muss. Sie sollte zwar keinen Einfluss auf die beobachteten Unterschiede zwischen den Verteilungen verschiedener Proteine haben, wohl aber auf das absolute Erscheinungsbild. Bei einer hinreichend hohen Auflösung erscheint die Verteilung von Cyclophilin D möglicherweise nicht mehr homogen, da nun sehr dicht benachbarte Proteine auch noch getrennt aufgelöst werden können. Besonders die absoluten Werte für die Clusterdurchmesser sind mit Vorsicht zu behandeln. Speziell für dicht gepackte oder homogen verteilte Proteine wie Cyclophilin D und die $\mathrm{F}_{1} \mathrm{~F}_{\mathrm{O}} \mathrm{DTP}-\mathrm{Syn}$ thase sind absolute Werte für Clusterdurchmesser schwierig zu interpretieren. Des Weiteren ist zu beachten, dass die Angaben von Clusterdurchmessern in dieser Arbeit auf Daten basieren, die durch Immunofluoreszenz-Markierungen gewonnen wurden. Somit gehen in den Clusterdurchmesser nicht alleine die zu untersuchenden Proteine mit ein, sondern vielmehr zusätzlich die Länge der zur Detektion verwendeten Antikörper. Dies führt zu einer Strukturvergrößerung um ungefähr 36 nm (Weber et al., 1978; Dyba et al., 2003). Nichtsdestotrotz ist das Verhältnis von zwei Werten (unbehandelt, apoptotisch) eine robustes Maß um mögliche Änderungen zu quantifizieren.

Lange Zeit wurde angenommen, dass die massive Umgestaltung der Mitochondrien ein notwendiger Schritt für die komplette Freisetzung von Cytochrom $c$ während der Apoptose ist (Yamaguchi und Perkins, 2009). Hiernach kommt es zu deutlichen Umstrukturierungen der Cristae inklusive des Weitens von Cristae junctions (Scorrano et al., 2002; Germain et al., 2005). Dieses Weiten der Cristae junctions soll Voraussetzung für die komplette Freisetzung von 
Cytochrom $c$ sein. Aktuellere Publikationen hingegen stellen das in Frage (Suen et al., 2008; Yamaguchi et al., 2008).

Yamaguchi und Kollegen haben publiziert, das ausschließlich leichte Änderungen der Cristae Junctions für die komplette Cytochrom $c$-Freisetzung notwendig sind, wohingegen die mitochondriale Ultrastruktur vor der Cytochrom $c$-Freisetzung unverändert bleibt. Im Gegensatz zu den Daten von Scorrano hat Yamaguchi eine Verringerung im Durchmesser der Cristae Junctions nachgewiesen, die aber mit der Deassemblierung von Opa1-Komplexen einhergeht. Dadurch wird die Passage von Cytochrom $c$ auch durch schmalere, aber nun geöffnete Cristae Junctions möglich (Yamaguchi et al., 2008).

Sun und andere haben mittels korrelativer Licht- und Elektronenmikroskopie herausgefunden, dass Cytochrom $c$ aus den Cristae ohne Umstrukturierungen der inneren mitochondrialen Membran freigesetzt werden kann. Die Umstrukturierungen der inneren mitochondrialen Membran in viele, separate Matrixkompartimente findet später statt und ist eher eine Konsequenz als der Grund für die Cytochrom c-Freisetzung (Suen et al., 2008).

Zusammengenommen deuten die Daten an, dass sehr viel feinere Änderungen der mitochondrialen Struktur nötig sind als zuvor angenommen, um das komplette Cytochrom $c$ aus den Mitochondrien freizusetzen.

Die Beobachtungen von subtilen Änderungen in der mitochondrialen Struktur während der Apoptose stimmen sehr gut mit den in dieser Arbeit beschriebenen subtilen Änderungen mitochondrialer Proteinverteilungen während der Apoptose überein. Eine denkbare Erklärung für die subtilen Änderungen mitochondrialer Proteinverteilungen könnte energetischer Natur sein. Bei der Apoptose handelt es sich um ein Selbstmordprogramm der Zelle. Funktionsfähige Mitochondrien sind hiernach für eine sterbende Zelle nicht mehr nötig (zumindest nach der Cytochrom $c$-Freisetzung). Somit gibt es keine Notwendigkeit mehr funktionale Einheiten, wie z.B. Multiproteinkomplexe, aufrechtzuerhalten. Als Konsequenz setzt die Diffusion und somit die Gleichverteilung von Proteinen ein. Diese 
Überlegungen werden durch Daten gestützt, die zeigen, dass zeitlich kurz nach der Cytochrom $c$-Freisetzung das mitochondriale Membranpotential (MMP) zusammenbricht (Bouchier-Hayes et al., 2008; Knudson und Brown, 2008). Das Vorhandensein eines MMP ist die Voraussetzung für die oxidative Phosphorylierung und somit ein Indikator für die Funktionsfähigkeit von Mitochondrien. Hieraus lässt sich schließen, dass Mitochondrien zumindest kurz nach der Cytochrom $c$-Freisetzung nicht mehr funktionsfähig sind. Der Zusammenbruch des MMP während der Apoptose ist aber anscheinend reversibel (Waterhouse et al., 2001). Es ist gezeigt worden, dass 30-60 min nach dem Zusammenbruch des MMP dieses wiederhergestellt werden kann. Vor Zusammenbruch des MMP ist Cytochrom $c$ freigesetzt worden. Voraussetzung für die Wiederherstellung des MMP ist die Hemmung der Caspaseaktivität. Dies steht nicht im Widerspruch zu den Daten dieser Arbeit. Die Tendenz zur Auflösung von Proteinclustern impliziert keineswegs deren Abbau bzw. die irreversible Schädigung des gesamten Organells. Vielmehr können die Daten dieser Arbeit dahingehend interpretiert werden, dass während der Apoptose keine zusätzliche Energie investiert wird um funktionale Einheiten wie Proteincluster aufrecht zu erhalten.

Die Ergebnisse dieser Arbeit und das damit postulierte Modell, welches eine Auflösungstendenz von Proteinclustern während der Apoptose annimmt, werfen aber auch Fragen auf: Da MOMP in den meisten Zellen der Punkt im apoptotischen Signalweg ist, von dem an es kein zurück mehr gibt (Kroemer et al., 1995; Perfettini et al., 2005; Jourdain und Martinou, 2009) und das MMP kurz nach MOMP zusammenbricht, stellt sich die Frage, warum die Änderungen in sub-mitochondrialen Proteinverteilungen schon vor der Cytochrom $c$-Freisetzung stattfinden. Denkbar wäre, dass schon zu diesem Zeitpunkt keine Energie mehr investiert wird, um funktionale Einheiten aufrecht zu erhalten. Dies würde aber auch bedeuten, dass schon vor der Cytochrom $c$-Freisetzung weitestgehend feststeht, dass die Zelle sterben wird. Fraglich ist auch, wodurch genau die 
Änderungen in sub-mitochondrialen Proteinverteilungen ausgelöst werden. Es ist naheliegend zu vermuten, dass Bax direkt oder aber indirekt daran beteiligt ist. Hierzu gibt es bis jetzt aber keinerlei Daten. Genauso ist es denkbar, dass weitere Änderungen in den sub-mitochondrialen Proteinverteilungen nach der Cytochrom $c$-Freisetzung stattfinden. Möglicherweise können weitere Änderungen aber aufgrund einer recht homogenen Verteilung der Proteine schon vor der der Cytochrom $c$-Freisetzung trotz der hohen Auflösung des STEDMikroskops nicht mehr nachgewiesen werden. Weitere Experimente sind nötig um festzustellen, wodurch die Änderungen in den sub-mitochondrialen Proteinverteilungen hervorgerufen werden, bis $\mathrm{zu}$ welchem Zeitpunkt sie stattfinden und ob sie wirklich energetisch begründet sind.

Bis jetzt konnte trotz intensiver Forschung nicht abschließend geklärt werden, wie der exakte Mechanismus funktioniert, der zur Cytochrom $c$-Freisetzung führt (Jourdain und Martinou, 2009; Wang und Youle, 2009). Es wurden viele verschiedene Proteine genannt, die bei der Cytochrom $c$-Freisetzung eine Rolle spielen sollen, unter anderem auch Proteine dieser Arbeit: Der TOM-Komplex (also auch Tom20 und Tom22) soll für die Insertion von Bax in die äußere mitochondriale Membran während der Apoptose verantwortlich sein (Bellot et al., 2007; Ott et al., 2007; Cartron et al., 2008) und die Hexokinase sowie Cyclophilin D werden als Komponenten der PTP diskutiert (Desagher und Martinou, 2000; Kroemer et al., 2007; Galluzzi et al., 2009). Falls deutliche Umverteilungen von mitochondrialen Proteinen nötig sind, um eine mögliche Pore zur Cytochrom $c^{-}$ Freisetzung zu bilden, kann die Beteiligung von Proteinen, die in dieser Arbeit untersucht worden sind, ausgeschlossen werden. Zudem steht die eher einheitliche Änderung aller sechs Proteine im Gegensatz zu der möglichen spezifischen Funktion eines (oder eines Teils) dieser Proteine für MOMP. Es erscheint unwahrscheinlich, dass alle sechs Proteine an der Bildung einer Pore zur Cytochrom $c$-Freisetzung beteiligt sind. Somit stellen die subtilen Änderungen in den Proteinverteilungen vermutlich nicht die Bildung einer für die Cytochrom $c^{-}$ 
Freisetzung relevanten Pore dar. Hingegen ist es weiterhin denkbar, dass eine aus Bax/Bak bestehende Pore für die Cytochrom $c$-Freisetzung verantwortlich ist.

Bei all den Überlegungen ist zu bedenken, dass Apoptose ein sehr komplexer Prozess ist, der auf verschiedene Weise ausgelöst und auf verschiedene Weise ablaufen kann, natürlich in Abhängigkeit von dem Gesamtsystem (Gogvadze et al., 2006). Dies führt auch immer wieder zu widersprüchlichen Daten in der Literatur. Zum Beispiel wurde gezeigt, dass der Grad der Umstrukturierung der inneren mitochondrialen Membran von dem verwendeten apoptotischen Stimulus abhängt (Frey und Sun, 2008). Da auch die Ergebnisse dieser Arbeit von einem bestimmten Zelltyp (U2OS-Zellen) behandelt mit einem bestimmten Stimulus (Actinomycin D) stammen, ist es wichtig in weiteren Experimenten die sub-mitochondrialen Proteinverteilungen in anderen Zellen und unter Verwendung anderer apoptotischer Stimuli zu untersuchen.

In den letzten Jahren haben immer mehr Daten angedeutet, dass viel subtilere Änderungen in der mitochondrialen Architektur für die Cytochrom $c$-Freisetzung nötig sind als zunächst angenommen. Diese Sichtweise kann durch Ergebnisse dieser Arbeit erweitert werden: Es finden nicht nur subtile strukturelle Änderungen während der Apoptose statt, sondern vielmehr auch subtile Änderungen in den Verteilungen mitochondrialer Proteine. Wodurch diese Änderungen ausgelöst werden und inwieweit sie funktionale Relevanz für die Cytochrom $c$-Freisetzung haben, bleibt abzuwarten.

\subsubsection{Ausblick: Untersuchung von Bax-Komplexen}

Da MOMP in den meisten Zellen der Punkt im apoptotischen Signalweg ist, von dem an es kein Zurück mehr gibt, ist das genaue Verständnis des molekularen Mechanismus von zentraler Bedeutung für die Apoptoseforschung (Kroemer et al., 1995; Perfettini et al., 2005; Jourdain und Martinou, 2009).

Trotz widersprüchlicher Daten über viele Proteine, die an MOMP beteiligt sein sollen, steht zumindest fest, dass Bax und Bak für diesen Prozess notwendig sind 
und MOMP ohne diese Proteine nicht stattfindet (Ow et al., 2008; Dewson und Kluck, 2009). Somit kann die Untersuchung von Bax und Bak ein Schlüssel für das Verständnis von MOMP sein.

Während der Apoptose kolokalisieren Bax und Bak in großen, oligomeren Komplexen an der äußeren mitochondrialen Membran (Nechushtan et al., 2001). Über die Größe, Anzahl, Zusammensetzung und Regulation dieser Komplexe ist bisher aber wenig bekannt (Dewson und Kluck, 2009). In einer der wenigen Studien dazu wurde eine mittlerer Durchmesser von $250 \mathrm{~nm}$ für diese Komplexe bestimmt. Ausgehend von dem Durchmesser wurde eine Molekülzahl von mindestens 150 Bax Proteinen berechnet (Zhou und Chang, 2008). Zu beachten ist hierbei allerdings, dass der mittlere Durchmesser der Komplexe von 250 nm sehr nah an der Auflösungsgrenze des verwendeten Epifluoreszenzmikroskops liegt. Somit ist es durchaus denkbar, dass die Komplexe aus kleineren SubKomplexen bestehen, da aber nicht getrennt aufgelöst werden können. In der Tat konnte dies durch erste STED-Aufnahmen von Bax-Komplexen nachgewiesen werden (Abbildung 5.6). Die als einzelne Komplexe im konventionellen Mikroskop identifzierten Strukturen bestehen aus mehreren Sub-Strukturen, wie durch die STED-Aufnahme deutlich wird. Basierend auf ersten STED-Aufnahmen konnten für Bax mittlere Komplexdurchmesser von $145 \pm 119$ nm bestimmt werden (Tabelle 8.5). Unter der Anahme, dass ein Bax-Molekül einen ungefähren Durchmesser von $4 \mathrm{~nm}$ hat (Suzuki et al., 2000) und es aufgrund der indirekten Immunofluoreszenzmarkierung zu eine Strukturvergrößerung von ungefähr $36 \mathrm{~nm}$ kommt (Abschnitt 5.1.3), ergibt sich ein mittlere Bax-Molekül-Zahl von 27 pro Bax-Komplex, wobei die Durchmesser der einzelnen Bax-Komplexe eine hohe Varianz aufweisen (Tabelle 8.5).

Auch wenn, wie erste Experimente dieser Arbeit andeuten, die Gesamtanzahl mit 150 Bax-Molekülen pro Komplex (Zhou und Chang, 2008) zu hoch geschätzt ist, sind definitiv viele Bax-Moleküle in einem Bax-Komplex lokalisiert. Für die Bildung einer einzelnen Bax-Pore in Liposomen waren hingegen vier Moleküle 


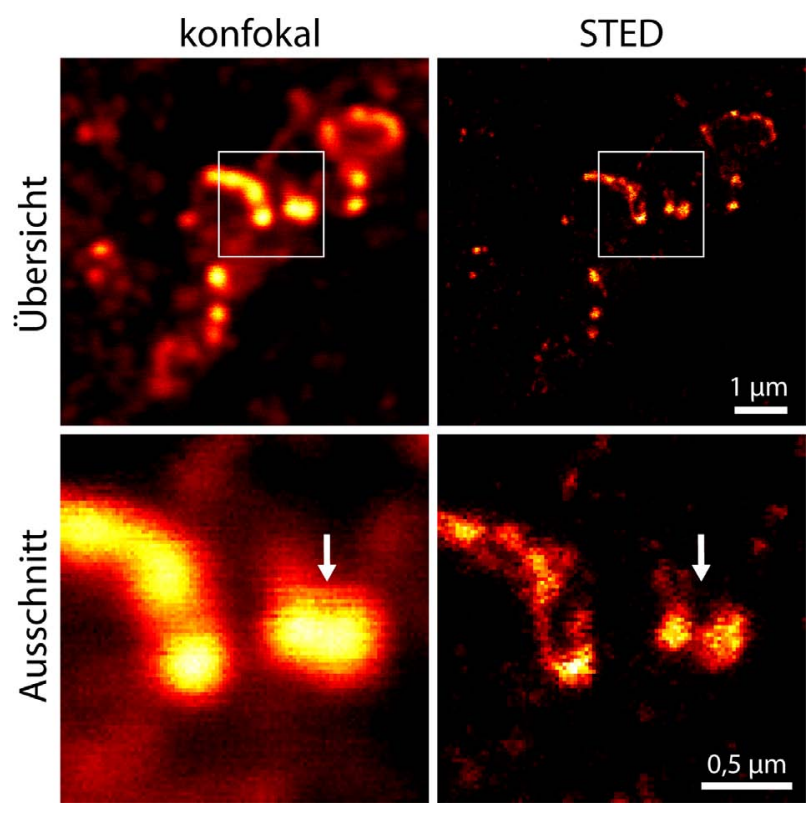

\section{Abbildung 5.6: Konfokale und STED Aufnahme von Bax-Komplexen}

U2OS-Zellen wurden mit $10 \mu \mathrm{m}$ Actinomycin für $14 \mathrm{~h}$ behandelt und im Anschluss mit Antikörpern inkubiert, die aktiviertes Bax erkennen. Die Analyse erfolgte mit einem nicht kommerziellen STED Mikroskop. Im STED-Mikroskop ist zu erkennen, dass einzelne BaxKomplexe Bild häufig aus mehreren Sub-Komplexen bestehen (Pfeile). Durch ihre räumliche Nähe, können sie aber im konfokalen Mikroskop nicht aufgelöst werden.

ausreichend (Saito et al., 2000). Somit erscheint es fraglich, dass die im Mikroskop beobachteten Bax-Komplexe einzelne Bax-Poren repräsentieren.

Es wird darüber spekuliert, dass Bax überhaupt keine spezifische Pore zur Freisetzung von Cytochrom $c$ bildet, sondern das vielmehr eine große Anzahl von Bax-Molekülen an der äußeren mitochondrialen Membran aggregiert, diese durch Bildung von Lipid-Protein-Komplexen destabilisiert und schließlich einen lokalen Bruch in der Membran bewirkt. In der Tat gibt es viele Studien, die eine Beteiligung von Lipiden an MOMP nahe legen (Kuwana et al., 2002; Terrones et al., 2004; Lucken-Ardjomande et al., 2008; Schafer et al., 2009). Denkbar ist ebenfalls, dass dieser Prozess durch andere Proteine wie z.B. VDAC und Drp1 reguliert wird. Hinweise auf eine mögliche, lokale Zerstörung der äußeren mitochondrialen Membran geben erste STED-Aufnahmen (Abbildung 5.7). Hier erscheint es so, dass an bestimmten Stellen, an denen sich Bax-Komplexe befinden, die Membran aufgerissen ist (siehe Pfeile). 
Zusammenfassend kann festgehalten werden, dass diese initalen Experimente einen Ausgangspunkt zur genaueren Untersuchung der Bax-Komplexe darstellen. Mittels quantitativer STED-Mikroskopie könnten der Durchmesser der BaxKomplexe und die exakte Lokalisation genauer bestimmt werden. Korrelationsanalysen können Aufschluss darüber geben, inwieweit es einen statistisch relevanten Zusammenhang zwischen den Bax-Komplexen und zerstörten Membranabschitten gibt. Somit könnten diese weiteren Studien an BaxKomplexen einen wichtigen Beitrag zum Verständnis des genauen Mechanismus von MOMP leisten.
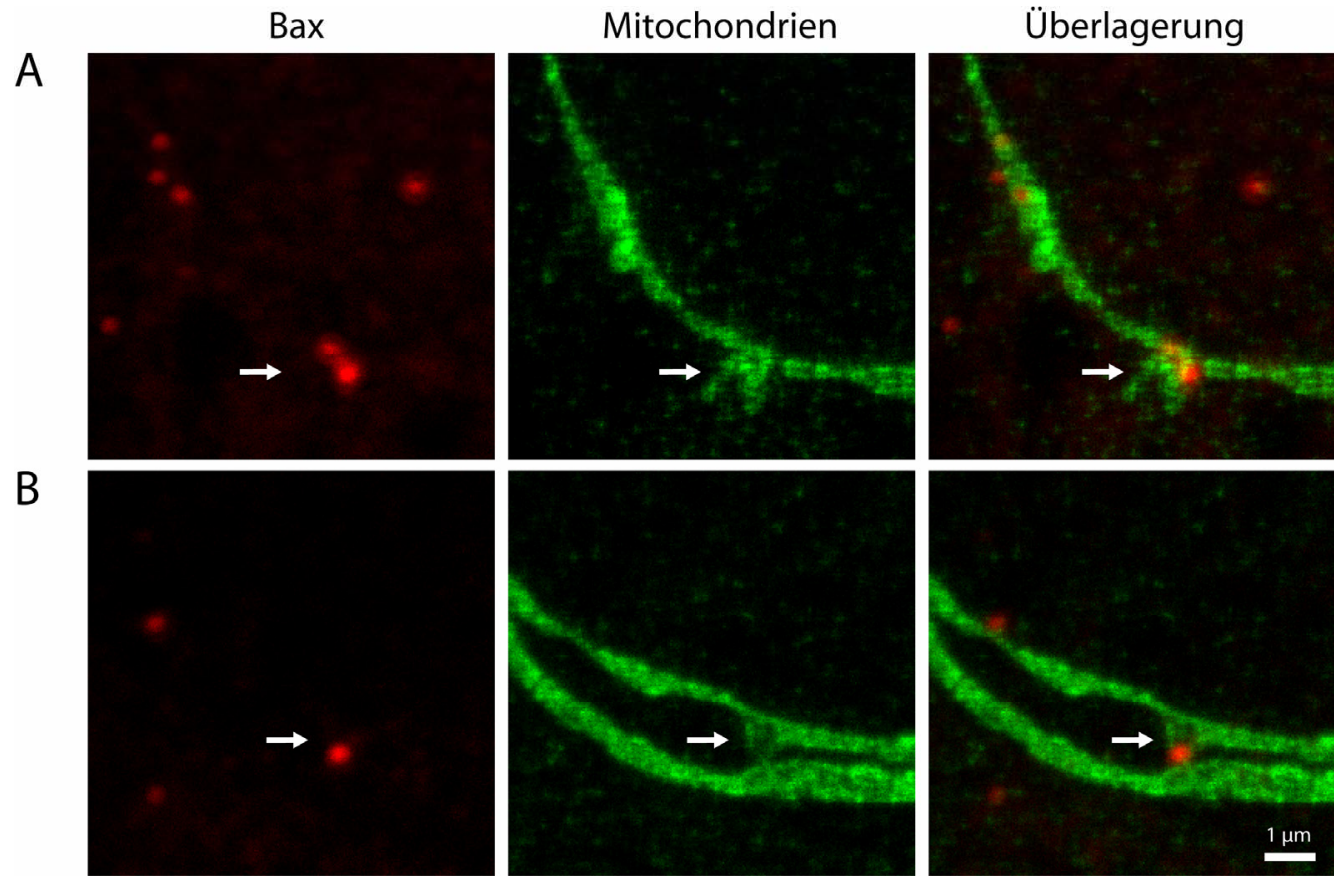

Abbildung 5.7: Kolokalisation von Bax-Komplexen mit mitochondrialen Membranregionen, die zerstört erscheinen

Bei Drp1-herunterregulierten U2OS-Zellen wurde Apoptose induziert und im Anschluss eine Immuno-Markierung mit Antikörpern gegen aktiviertes Bax und Hexokinase-I (A) bzw. Tom22 (B) durchgeführt. Im Anschluss wurde Bax im konfokalen-Modus und Hexokinsae-I/Tom22 in STED-Modus eines kommerziellen Mikroskops analysiert. Die Pfeile weisen auf Membranregionen hin, die aufgebrochen und zerstört erscheinen. Diese kolokalisieren mit BaxKomplexen. Zur Relativierung dieser Aufnahmen ist festgehalten, dass ebenfalls genügend BaxKomplexe beobachtet wurden, die sich an einer zumindest visuell intakten mitochondrialen Membran befanden. 


\section{Abkürzungsverzeichnis}

Die verwendeten ein- und dreibuchstabigen Abkürzungen für Aminosäuren, sowie alle verwendeten physikalischen Größen entsprechen der Konvention der International Union for Biochemistry (Liebecq, 1997).

\begin{tabular}{|c|c|}
\hline $\mathrm{ADP}$ & Adenosindiphosphat \\
\hline ANT & Adenin-Nukleotid-Translokase \\
\hline ATP & Adenosintriphosphat \\
\hline BSA & bovine serum albumin (Rinderserumalbum) \\
\hline \multirow[t]{2}{*}{ Caspase } & cysteine-dependent aspartate-specific proteases \\
\hline & (cystein-abhängige aspartat-spezifische Proteasen) \\
\hline CJ & Cristae Junction \\
\hline C-terminal & carboxylterminal \\
\hline $\mathrm{Da}$ & Dalton \\
\hline DAPI & Diamidino-2-Phenylindol \\
\hline \multirow[t]{2}{*}{ DISC } & death inducing signaling complex \\
\hline & (Tod-induzierender Signalkomplex) \\
\hline DMEM & dulbecco's modified eagle medium \\
\hline DMSO & Dimethylsulfoxid \\
\hline DNA & desoxyribonucleinacid (Desoxyribonukleinsäure) \\
\hline dNTPs & Desoxyribonucleotidtriphospat \\
\hline Drp1 & dynamin related protein 1 \\
\hline DTT & Dithiothreitol \\
\hline E. coli & Escherichia coli \\
\hline EDTA & Ethylendiamintetraessigsäure \\
\hline EM & Elektronenmikroskopie \\
\hline FAD & Flavinadenindinukleotid \\
\hline FBS & Fetal bovine serum (fötales Rinderserum) \\
\hline $\mathrm{xg}$ & multipliziert mit der Erdbeschleunigung \\
\hline GFP & grün fluoreszierendes Protein \\
\hline $\mathrm{h}$ & hour (Stunde) \\
\hline
\end{tabular}


IBM

IM

IMS

$\mathrm{kb}$

MDM

MIA

$\min$

MMP

MOMP

NAD

$\mathrm{N}$-terminal

OD

$\mathrm{OM}$

PAM

PBS

PCD

PCR

PEG

PTP

RNA

RNAi

RT

S. cerevisiae

SAM

STED

TAE inner boundary membrane (innere Grenzflächenmembran)

innere Membran

intermembrane space (Intermembranraum)

Kilobasen

mitochondrial distribution and morphology

(mitochondriale Verteilung und Morphologie)

mitochondrial intermembrane space assembly machinery

(mitochondriale Intermembranraum Aufbau-Maschinerie)

Minute

mitochondriales Membranpotential

mitochondrial outer membrane permeabilisation

(äußere mitochondriale Membran-Permeabilisierung)

Nikotinamidadenindinukleotid

aminoterminal

optische Dichte

äußere Membran

presequence translocase-associated motor

(Präsequenz Translokase-assoziierter Motor)

phosphate buffered saline (phosphatgepufferte Salzlösung)

programmed cell death (programmierter Zelltod)

polymerase chain reaction (Polymerasekettenreaktion)

Polyethylenglykol

permeability transition pore

(Permeabilisierungs-Transitions-Pore)

ribonucleinacid (Ribonukleinsäure)

ribonucleinacid-interference (Ribonukleinsäure-Interferenz)

Raumtemperatur

Saccharomyces cerevisiae

sorting and assembly machinery

(Sotierungs- und Assemblierungsmaschinerie)

stimulated emission depletion

(stimulierte Emssions-Entvölkerung)

Tris-Acetat-EDTA 
TIM

TOM

Tris

ÜK

VDAC

w.E. translocase of the inner mitochondrial membrane

(Translokase der inneren mitochondrialen Membran)

translocase of the outer mitochondrial membrane

(Translokase der äußeren mitochondrialen Membran)

Tris-Hydroxymethyl-Aminomethan

Übernachtkultur

voltage-dependent anion-selective channel

(spannungs-abhängiger Anion-selektiver Kanal)

willkürliche Einheiten 


\section{Literatur}

Abbe, E. (1873). Beiträge zur Theorie des Mikroskops und der mikroskopischen Wahrnehmung. Arch Mikr Anat 9, 413-468.

Abu-Hamad, S., Arbel, N., Calo, D., Arzoine, L., Israelson, A., Keinan, N., Ben-Romano, R., Friedman, O. und Shoshan-Barmatz, V. (2009). The VDAC1 N-terminus is essential both for apoptosis and the protective effect of anti-apoptotic proteins. J Cell Sci 122, 1906-1916.

Abu-Hamad, S., Zaid, H., Israelson, A., Nahon, E. und Shoshan-Barmatz, V. (2008). Hexokinase-I protection against apoptotic cell death is mediated via interaction with the voltage-dependent anion channel-1: mapping the site of binding. J Biol Chem 283, 13482-13490.

Alberts, B. (2004). Molekularbiologie der Zelle (Weinheim, Wiley-VCH).

Allan, V. (2000). Basic immunofluorescence. In Protein localization by fluorescence microscopy: a practical approach (Oxford, Oxford University Press), pp. 1-26.

Ardail, D., Privat, J. P., Egret-Charlier, M., Levrat, C., Lerme, F. und Louisot, P. (1990). Mitochondrial contact sites. Lipid composition and dynamics. J Biol Chem 265, 18797-18802.

Arnoult, D., Parone, P., Martinou, J. C., Antonsson, B., Estaquier, J. und Ameisen, J. C. (2002). Mitochondrial release of apoptosis-inducing factor occurs downstream of cytochrome $c$ release in response to several proapoptotic stimuli. J Cell Biol 159, 923-929.

Autret, A. und Martin, S. J. (2009). Emerging role for members of the Bcl-2 family in mitochondrial morphogenesis. Mol Cell 36, 355-363.

Autret, A. und Martin, S. J. (2010). Bcl-2 family proteins and mitochondrial fission/fusion dynamics. Cell Mol Life Sci 67, 1599-1606.

Azoulay-Zohar, H. und Aflalo, C. (1999). Binding of rat brain hexokinase to recombinant yeast mitochondria: identification of necessary molecular determinants. J Bioenerg Biomembr 31, 569579 .

Baines, C. P., Kaiser, R. A., Purcell, N. H., Blair, N. S., Osinska, H., Hambleton, M. A., Brunskill, E. W., Sayen, M. R., Gottlieb, R. A., Dorn, G. W., Robbins, J. und Molkentin, J. D. (2005). Loss of cyclophilin D reveals a critical role for mitochondrial permeability transition in cell death. Nature 434, 658-662.

Baines, C. P., Kaiser, R. A., Sheiko, T., Craigen, W. J. und Molkentin, J. D. (2007). Voltagedependent anion channels are dispensable for mitochondrial-dependent cell death. Nat Cell Biol 9, 550-555.

Baker, M. J., Frazier, A. E., Gulbis, J. M. und Ryan, M. T. (2007). Mitochondrial protein-import machinery: correlating structure with function. Trends Cell Biol 17, 456-464.

Bartlett, K. und Eaton, S. (2004). Mitochondrial beta-oxidation. Eur J Biochem 271, 462-469. 
Bayrhuber, M., Meins, T., Habeck, M., Becker, S., Giller, K., Villinger, S., Vonrhein, C., Griesinger, C., Zweckstetter, M. und Zeth, K. (2008). Structure of the human voltage-dependent anion channel. Proc Natl Acad Sci US A 105, 15370-15375.

Bellot, G., Cartron, P. F., Er, E., Oliver, L., Juin, P., Armstrong, L. C., Bornstein, P., Mihara, K., Manon, S. und Vallette, F. M. (2007). TOM22, a core component of the mitochondria outer membrane protein translocation pore, is a mitochondrial receptor for the proapoptotic protein Bax. Cell Death Differ 14, 785-794.

Blachly-Dyson, E. und Forte, M. (2001). VDAC channels. IUBMB Life 52, 113-118.

Blachly-Dyson, E., Zambronicz, E. B., Yu, W. H., Adams, V., McCabe, E. R., Adelman, J., Colombini, M. und Forte, M. (1993). Cloning and functional expression in yeast of two human isoforms of the outer mitochondrial membrane channel, the voltage-dependent anion channel. $J$ Biol Chem 268, 1835-1841.

Bleackley, R. C. und Heibein, J. A. (2001). Enzymatic control of apoptosis. Nat Prod Rep 18, 431440 .

Bolender, N., Sickmann, A., Wagner, R., Meisinger, C. und Pfanner, N. (2008). Multiple pathways for sorting mitochondrial precursor proteins. EMBO Rep $9,42-49$.

Born, M. und Wolf, E. (2002). Principles of Optics (Cambridge, New York, Melbourne, Madrid, Cape Town, Cambridge University Press).

Bouchier-Hayes, L., Munoz-Pinedo, C., Connell, S. und Green, D. R. (2008). Measuring apoptosis at the single cell level. Methods 44, 222-228.

Bratthauer, G. L. (1999). Processing of tissue-culture cells. Methods Mol Biol 115, 71-76.

Broker, L. E., Kruyt, F. A. und Giaccone, G. (2005). Cell death independent of caspases: a review. Clin Cancer Res 11, 3155-3162.

Brooks, C., Wei, Q., Feng, L., Dong, G., Tao, Y., Mei, L., Xie, Z. J. und Dong, Z. (2007). Bak regulates mitochondrial morphology and pathology during apoptosis by interacting with mitofusins. Proc Natl Acad Sci US A 104, 11649-11654.

Cartron, P. F., Bellot, G., Oliver, L., Grandier-Vazeille, X., Manon, S. und Vallette, F. M. (2008). Bax inserts into the mitochondrial outer membrane by different mechanisms. FEBS Lett 582, 30453051 .

Cassidy-Stone, A., Chipuk, J. E., Ingerman, E., Song, C., Yoo, C., Kuwana, T., Kurth, M. J., Shaw, J. T., Hinshaw, J. E., Green, D. R. und Nunnari, J. (2008). Chemical inhibition of the mitochondrial division dynamin reveals its role in Bax/Bak-dependent mitochondrial outer membrane permeabilization. Dev Cell 14, 193-204.

Cereghetti, G. M. und Scorrano, L. (2006). The many shapes of mitochondrial death. Oncogene 25, 4717-4724.

Cerveny, K. L., Tamura, Y., Zhang, Z., Jensen, R. E. und Sesaki, H. (2007). Regulation of mitochondrial fusion and division. Trends Cell Biol 17, 563-569. 
Cesar Mde, C. und Wilson, J. E. (2004). All three isoforms of the voltage-dependent anion channel (VDAC1, VDAC2, and VDAC3) are present in mitochondria from bovine, rabbit, and rat brain. Arch Biochem Biophys 422, 191-196.

Chacinska, A., Pfannschmidt, S., Wiedemann, N., Kozjak, V., Sanjuan Szklarz, L. K., SchulzeSpecking, A., Truscott, K. N., Guiard, B., Meisinger, C. und Pfanner, N. (2004). Essential role of Mia40 in import and assembly of mitochondrial intermembrane space proteins. EMBO J 23, 37353746.

Chacinska, A., Rehling, P., Guiard, B., Frazier, A. E., Schulze-Specking, A., Pfanner, N., Voos, W. und Meisinger, C. (2003). Mitochondrial translocation contact sites: separation of dynamic and stabilizing elements in formation of a TOM-TIM-preprotein supercomplex. EMBO J22, 5370-5381.

Chalberg, T., Philips JE, Calos P (2005). Transfection of DNA into Mammalian Cells in Culture. In Encyclopedia of Life Science (Hoboken, John Wiley \& Sons)

Chandra, D., Choy, G., Daniel, P. T. und Tang, D. G. (2005). Bax-dependent regulation of Bak by voltage-dependent anion channel 2.J Biol Chem 280, 19051-19061.

Chandra, D., Choy, G. und Tang, D. G. (2007). Cytosolic accumulation of HSP60 during apoptosis with or without apparent mitochondrial release: evidence that its pro-apoptotic or pro-survival functions involve differential interactions with caspase-3. J Biol Chem 282, 31289-31301.

Chandra, D., Liu, J. W. und Tang, D. G. (2002). Early mitochondrial activation and cytochrome $c$ up-regulation during apoptosis. J Biol Chem 277, 50842-50854.

Cheng, E. H., Sheiko, T. V., Fisher, J. K., Craigen, W. J. und Korsmeyer, S. J. (2003). VDAC2 inhibits BAK activation and mitochondrial apoptosis. Science 301, 513-517.

Chipuk, J. E., Bouchier-Hayes, L. und Green, D. R. (2006). Mitochondrial outer membrane permeabilization during apoptosis: the innocent bystander scenario. Cell Death Differ 13, 13961402.

Chipuk, J. E., Moldoveanu, T., Llambi, F., Parsons, M. J. und Green, D. R. (2010). The BCL-2 family reunion. Mol Cell 37, 299-310.

Colombini, M. (1979). A candidate for the permeability pathway of the outer mitochondrial membrane. Nature 279, 643-645.

Craddock, V. M. und Simpson, M. V. (1961). Amino acid-activating enzymes in rat-liver mitochondria. Biochem J80, 348-352.

De Pinto, V., Guarino, F., Guarnera, A., Messina, A., Reina, S., Tomasello, F. M., Palermo, V. und Mazzoni, C. (2010). Characterization of human VDAC isoforms: A peculiar function for VDAC3? Biochim Biophys Acta, doi:10.1016/j.bbabio.2010.01.031

Desagher, S. und Martinou, J. C. (2000). Mitochondria as the central control point of apoptosis. Trends Cell Biol 10, 369-377.

Dewson, G. und Kluck, R. M. (2009). Mechanisms by which Bak and Bax permeabilise mitochondria during apoptosis. J Cell Sci 122, 2801-2808. 
Dietmeier, K., Honlinger, A., Bomer, U., Dekker, P. J., Eckerskorn, C., Lottspeich, F., Kubrich, M. und Pfanner, N. (1997). Tom5 functionally links mitochondrial preprotein receptors to the general import pore. Nature 388, 195-200.

Dimmer, K. S. und Scorrano, L. (2006). (De)constructing mitochondria: what for? Physiology (Bethesda) 21, 233-241.

Donnert, G., Keller, J., Wurm, C. A., Rizzoli, S. O., Westphal, V., Schonle, A., Jahn, R., Jakobs, S., Eggeling, C. und Hell, S. W. (2007). Two-color far-field fluorescence nanoscopy. Biophys J92, L6769.

Dyall, S. D., Brown, M. T. und Johnson, P. J. (2004). Ancient invasions: from endosymbionts to organelles. Science 304, 253-257.

Dyba, M., Jakobs, S. und Hell, S. W. (2003). Immunofluorescence stimulated emission depletion microscopy. Nat Biotechnol 21, 1303-1304.

Eggeling, C., Ringemann, C., Medda, R., Schwarzmann, G., Sandhoff, K., Polyakova, S., Belov, V. N., Hein, B., von Middendorff, C., Schonle, A. und Hell, S. W. (2009). Direct observation of the nanoscale dynamics of membrane lipids in a living cell. Nature 457, 1159-1162.

Egner, A., Jakobs, S. und Hell, S. W. (2002). Fast 100-nm resolution three-dimensional microscope reveals structural plasticity of mitochondria in live yeast. Proc Natl Acad Sci US A 99, 3370-3375.

Eskes, R., Antonsson, B., Osen-Sand, A., Montessuit, S., Richter, C., Sadoul, R., Mazzei, G., Nichols, A. und Martinou, J. C. (1998). Bax-induced cytochrome $c$ release from mitochondria is independent of the permeability transition pore but highly dependent on $\mathrm{Mg} 2+$ ions. $J$ Cell Biol $143,217-224$.

Eskes, R., Desagher, S., Antonsson, B. und Martinou, J. C. (2000). Bid induces the oligomerization and insertion of Bax into the outer mitochondrial membrane. Mol Cell Biol 20, 929-935.

Estaquier, J. und Arnoult, D. (2007). Inhibiting Drp1-mediated mitochondrial fission selectively prevents the release of cytochrome $c$ during apoptosis. Cell Death Differ 14, 1086-1094.

Felgner, P. L., Messer, J. L. und Wilson, J. E. (1979). Purification of a hexokinase-binding protein from the outer mitochondrial membrane. J Biol Chem 254, 4946-4949.

Ferri, K. F. und Kroemer, G. (2001). Organelle-specific initiation of cell death pathways. Nat Cell Biol3, E255-263.

Frank, S., Gaume, B., Bergmann-Leitner, E. S., Leitner, W. W., Robert, E. G., Catez, F., Smith, C. L. und Youle, R. J. (2001). The role of dynamin-related protein 1, a mediator of mitochondrial fission, in apoptosis. Dev Cell 1, 515-525.

Frazier, A. E., Kiu, C., Stojanovski, D., Hoogenraad, N. J. und Ryan, M. T. (2006). Mitochondrial morphology and distribution in mammalian cells. Biol Chem 387, 1551-1558.

Frederick, R. L. und Shaw, J. M. (2007). Moving mitochondria: establishing distribution of an essential organelle. Traffic 8, 1668-1675. 
Frey, T. G. und Sun, M. G. (2008). Correlated light and electron microscopy illuminates the role of mitochondrial inner membrane remodeling during apoptosis. Biochim Biophys Acta 1777, 847-852.

Galluzzi, L., Blomgren, K. und Kroemer, G. (2009). Mitochondrial membrane permeabilization in neuronal injury. Nat Rev Neurosci 10, 481-494.

Galluzzi, L., Kepp, O., Tajeddine, N. und Kroemer, G. (2008). Disruption of the hexokinase-VDAC complex for tumor therapy. Oncogene 27, 4633-4635.

Galluzzi, L. und Kroemer, G. (2007). Mitochondrial apoptosis without VDAC. Nat Cell Biol 9, 487489.

Galluzzi, L., Larochette, N., Zamzami, N. und Kroemer, G. (2006). Mitochondria as therapeutic targets for cancer chemotherapy. Oncogene 25, 4812-4830.

Galluzzi, L., Maiuri, M. C., Vitale, I., Zischka, H., Castedo, M., Zitvogel, L. und Kroemer, G. (2007). Cell death modalities: classification and pathophysiological implications. Cell Death Differ 14, 1237-1243.

Gelb, B. D., Adams, V., Jones, S. N., Griffin, L. D., MacGregor, G. R. und McCabe, E. R. (1992). Targeting of hexokinase 1 to liver and hepatoma mitochondria. Proc Natl Acad Sci US A 89, 202206.

Germain, M., Mathai, J. P., McBride, H. M. und Shore, G. C. (2005). Endoplasmic reticulum BIK initiates DRP1-regulated remodelling of mitochondrial cristae during apoptosis. EMBO J 24, 1546 1556.

Gilkerson, R. W., Selker, J. M. und Capaldi, R. A. (2003). The cristal membrane of mitochondria is the principal site of oxidative phosphorylation. FEBS Lett 546, 355-358.

Gogvadze, V., Orrenius, S. und Zhivotovsky, B. (2006). Multiple pathways of cytochrome $c$ release from mitochondria in apoptosis. Biochim Biophys Acta 1757, 639-647.

Gogvadze, V., Orrenius, S. und Zhivotovsky, B. (2009). Mitochondria as targets for chemotherapy. Apoptosis 14, 624-640.

Gogvadze, V., Zhivotovsky, B. und Orrenius, S. (2010). The Warburg effect and mitochondrial stability in cancer cells. Mol Aspects Med 31, 60-74.

Goldstein, J. C., Munoz-Pinedo, C., Ricci, J. E., Adams, S. R., Kelekar, A., Schuler, M., Tsien, R. Y. und Green, D. R. (2005). Cytochrome $c$ is released in a single step during apoptosis. Cell Death Differ 12, 453-462.

Goncalves, R. P., Buzhynskyy, N., Prima, V., Sturgis, J. N. und Scheuring, S. (2007). Supramolecular assembly of VDAC in native mitochondrial outer membranes. J Mol Biol 369, 413418.

Gopalakrishnan, B., Wolff, J. (2009). siRNA and DANN transfer to cultured cells. Methods Mol Biol $480,31-52$

Gray, M. W., Burger, G. und Lang, B. F. (1999). Mitochondrial evolution. Science 283, 1476-1481. 
Green, D. R. und Kroemer, G. (2004). The pathophysiology of mitochondrial cell death. Science 305, 626-629.

Griparic, L. und van der Bliek, A. M. (2001). The many shapes of mitochondrial membranes. Traffic 2, 235-244.

Harke, B., Keller, J., Ullal, C. K., Westphal, V., Schonle, A. und Hell, S. W. (2008a). Resolution scaling in STED microscopy. Opt Express 16, 4154-4162.

Harke, B., Ullal, C. K., Keller, J. und Hell, S. W. (2008b). Three-dimensional nanoscopy of colloidal crystals. Nano Lett 8, 1309-1313.

Hell, S. W. (2009a). Far-Field Optical Nanoscopy. In Single Molecule Spectroscopy in Chemistry, Physics and Biology (Berlin, Springer), pp. 298-365.

Hell, S. W. (2009b). Microscopy and its focal switch. Nat Methods 6, 24-32.

Hell, S. W. und Wichmann, J. (1994). Breaking the diffraction resolution limit by stimulated emission: stimulated-emission-depletion fluorescence microscopy. Opt Lett 19, 780-782.

Hengartner, M. O. (2000). The biochemistry of apoptosis. Nature 407, 770-776.

Herrmann, J. M. und Neupert, W. (2000). Protein transport into mitochondria. Curr Opin Microbiol3, 210-214.

Hiller, S., Garces, R. G., Malia, T. J., Orekhov, V. Y., Colombini, M. und Wagner, G. (2008). Solution structure of the integral human membrane protein VDAC-1 in detergent micelles. Science 321, 1206-1210.

Hoogenboom, B. W., Suda, K., Engel, A. und Fotiadis, D. (2007). The supramolecular assemblies of voltage-dependent anion channels in the native membrane. JMol Biol370, 246-255.

Hoogenraad, N. J., Ward, L. A. und Ryan, M. T. (2002). Import and assembly of proteins into mitochondria of mammalian cells. Biochim Biophys Acta 1592, 97-105.

Huizing, M., Ruitenbeek, W., van den Heuvel, L. P., Dolce, V., Iacobazzi, V., Smeitink, J. A., Palmieri, F. und Trijbels, J. M. (1998). Human mitochondrial transmembrane metabolite carriers: tissue distribution and its implication for mitochondrial disorders. J Bioenerg Biomembr 30, 277284.

James, D. I. und Martinou, J. C. (2008). Mitochondrial dynamics and apoptosis: a painful separation. Dev Cell 15, 341-343.

Jourdain, A. und Martinou, J. C. (2009). Mitochondrial outer-membrane permeabilization and remodelling in apoptosis. Int J Biochem Cell Biol 41, 1884-1889.

Jurgensmeier, J. M., Xie, Z., Deveraux, Q., Ellerby, L., Bredesen, D. und Reed, J. C. (1998). Bax directly induces release of cytochrome $c$ from isolated mitochondria. Proc Natl Acad Sci US A 95, 4997-5002. 
Karbowski, M., Arnoult, D., Chen, H., Chan, D. C., Smith, C. L. und Youle, R. J. (2004). Quantitation of mitochondrial dynamics by photolabeling of individual organelles shows that mitochondrial fusion is blocked during the Bax activation phase of apoptosis. J Cell Biol 164, 493499.

Karbowski, M., Lee, Y. J., Gaume, B., Jeong, S. Y., Frank, S., Nechushtan, A., Santel, A., Fuller, M., Smith, C. L. und Youle, R. J. (2002). Spatial and temporal association of Bax with mitochondrial fission sites, Drp1, and Mfn2 during apoptosis. J Cell Biol 159, 931-938.

Karbowski, M., Norris, K. L., Cleland, M. M., Jeong, S. Y. und Youle, R. J. (2006). Role of Bax and Bak in mitochondrial morphogenesis. Nature 443, 658-662.

Kawanishi, S. und Hiraku, Y. (2004). Amplification of anticancer drug-induced DNA damage and apoptosis by DNA-binding compounds. Curr Med Chem Anticancer Agents 4, 415-419.

Kennedy, E. P. und Lehninger, A. L. (1949). Oxidation of fatty acids and tricarboxylic acid cycle intermediates by isolated rat liver mitochondria. J Biol Chem 179, 957-972.

Kerr, J. F., Wyllie, A. H. und Currie, A. R. (1972). Apoptosis: a basic biological phenomenon with wide-ranging implications in tissue kinetics. Br J Cancer 26, 239-257.

Kiess, W. und Gallaher, B. (1998). Hormonal control of programmed cell death/apoptosis. Eur J Endocrinol 138, 482-491.

Kim, H., Rafiuddin-Shah, M., Tu, H. C., Jeffers, J. R., Zambetti, G. P., Hsieh, J. J. und Cheng, E. H. (2006). Hierarchical regulation of mitochondrion-dependent apoptosis by BCL-2 subfamilies. Nat Cell Biol 8, 1348-1358.

Knudson, C. M. und Brown, N. M. (2008). Mitochondria potential, bax "activation," and programmed cell death. Methods Mol Biol 414, 95-108.

Kokoszka, J. E., Waymire, K. G., Levy, S. E., Sligh, J. E., Cai, J., Jones, D. P., MacGregor, G. R. und Wallace, D. C. (2004). The ADP/ATP translocator is not essential for the mitochondrial permeability transition pore. Nature 427, 461-465.

Kroemer, G., Galluzzi, L. und Brenner, C. (2007). Mitochondrial membrane permeabilization in cell death. Physiol Rev 87, 99-163.

Kroemer, G., Galluzzi, L., Vandenabeele, P., Abrams, J., Alnemri, E. S., Baehrecke, E. H., Blagosklonny, M. V., El-Deiry, W. S., Golstein, P., Green, D. R., Hengartner, M., Knight, R. A., Kumar, S., Lipton, S. A., Malorni, W., Nunez, G., Peter, M. E., Tschopp, J., Yuan, J., Piacentini, M., Zhivotovsky, B. und Melino, G. (2009). Classification of cell death: recommendations of the Nomenclature Committee on Cell Death 2009. Cell Death Differ 16, 3-11.

Kroemer, G., Petit, P., Zamzami, N., Vayssiere, J. L. und Mignotte, B. (1995). The biochemistry of programmed cell death. Faseb J9, 1277-1287.

Kunsch, K. (2006). Der Mensch in Zahlen, 3 edn (Heidelberg, Spektrum Akademischer Verlag).

Kutik, S., Guiard, B., Meyer, H. E., Wiedemann, N. und Pfanner, N. (2007). Cooperation of translocase complexes in mitochondrial protein import. J Cell Biol 179, 585-591. 
Kuwana, T., Mackey, M. R., Perkins, G., Ellisman, M. H., Latterich, M., Schneiter, R., Green, D. R. und Newmeyer, D. D. (2002). Bid, Bax, and lipids cooperate to form supramolecular openings in the outer mitochondrial membrane. Cell 111, 331-342.

Lamesch, P., Li, N., Milstein, S., Fan, C., Hao, T., Szabo, G., Hu, Z., Venkatesan, K., Bethel, G., Martin, P., Rogers, J., Lawlor, S. McLaren, S., Dricot, A., Borick, H., Cusick, M. E., Vandenhaute, J., Dunham, I., Hill, D. E. und Vidal, M. (2007). hORFeome v3.1: a resource of human open reading frames representing over 10,000 human genes. Genomics 89, 307-315.

Landy, A. (1989). Dynamic, structural, and regulatory aspects of lambda site-specific recombination. Annu Rev Biochem 58, 913-949.

Lang, B. F., Gray, M. W. und Burger, G. (1999). Mitochondrial genome evolution and the origin of eukaryotes. Annu Rev Genet 33, 351-397.

Lang, K. (1985). Mycoplasmen und Zellkulturen. Biologie in unserer Zeit 2, 52-61.

Lee, Y. J., Jeong, S. Y., Karbowski, M., Smith, C. L. und Youle, R. J. (2004). Roles of the mammalian mitochondrial fission and fusion mediators Fis1, Drp1, and Opa1 in apoptosis. Mol Biol Cell 15, 5001-5011.

Lehman, I. R. (1974). DNA ligase: structure, mechanism, and function. Science 186, 790-797.

Lemasters, J. J. und Holmuhamedov, E. (2006). Voltage-dependent anion channel (VDAC) as mitochondrial governator-thinking outside the box. Biochim Biophys Acta 1762, 181-190.

Levi, S. und Rovida, E. (2009). The role of iron in mitochondrial function. Biochim Biophys Acta 1790, 629-636.

Li, H., Zhu, H., Xu, C. J. und Yuan, J. (1998). Cleavage of BID by caspase 8 mediates the mitochondrial damage in the Fas pathway of apoptosis. Cell 94, 491-501.

Liebecq, C. (1997). IUPAC-IUBMB Joint Commission on Biochemical Nomenclature (JCBN) and Nomenclature Committee of IUBMB (NC-IUBMB). Newsletter 1996. Eur J Biochem 247, 733-739.

Liesa, M., Palacin, M. und Zorzano, A. (2009). Mitochondrial dynamics in mammalian health and disease. Physiol Rev 89, 799-845.

Lill, R. (2009). Function and biogenesis of iron-sulphur proteins. Nature 460, 831-838.

Linden, M., Gellerfors, P. und Nelson, B. D. (1982). Pore protein and the hexokinase-binding protein from the outer membrane of rat liver mitochondria are identical. FEBS Lett 141, 189-192.

Linden, M. und Karlsson, G. (1996). Identification of porin as a binding site for MAP2. Biochem Biophys Res Commun 218, 833-836.

Lindsten, T., Ross, A. J., King, A., Zong, W. X., Rathmell, J. C., Shiels, H. A., Ulrich, E., Waymire, K. G., Mahar, P., Frauwirth, K., Chen, Y., Wei, M., Eng, V. M., Adelman, D. M., Simon, M.C., Ma, A., Golden, J. A., Evan, G., Korsmeyer, S. J., MacGregor, G. R. und Thompson, C. B. (2000). The combined functions of proapoptotic Bcl-2 family members bak and bax are essential for normal development of multiple tissues. Mol Cell 6, 1389-1399. 
Logan, D. C. (2006). The mitochondrial compartment. J Exp Bot 57, 1225-1243.

Lucken-Ardjomande, S. und Martinou, J. C. (2005). Newcomers in the process of mitochondrial permeabilization. J Cell Sci 118, 473-483.

Lucken-Ardjomande, S., Montessuit, S. und Martinou, J. C. (2008). Contributions to Bax insertion and oligomerization of lipids of the mitochondrial outer membrane. Cell Death Differ 15, 929-937.

Luo, X., Budihardjo, I., Zou, H., Slaughter, C. und Wang, X. (1998). Bid, a Bcl2 interacting protein, mediates cytochrome $c$ release from mitochondria in response to activation of cell surface death receptors. Cell 94, 481-490.

Maier, K. P., Helbig, C., Hoppe-Seyler, G., Frohlich, J., Schollmeyer, P., Gerok, W. und Talke, H. (1974). Extractability and intracellular localisation of urea cycle enzymes from rat liver. Z Klin Chem Klin Biochem 12, 524-529.

Malia, T. J. und Wagner, G. (2007). NMR structural investigation of the mitochondrial outer membrane protein VDAC and its interaction with antiapoptotic Bcl-xL. Biochemistry 46, 514-525.

Malka, F., Aure, K., Goffart, S., Spelbrink, J. N. und Rojo, M. (2007). The mitochondria of cultured mammalian cells: I. Analysis by immunofluorescence microscopy, histochemistry, subcellular fractionation, and cell fusion. Methods Mol Biol372, 3-16.

Manders, E., Verbeek, FJ, Aten, JA (1993). Measurement of co-localization of objects in dual-colour confocal images. Journal of Microscopy 169, 375-382.

Mannella, C. A. (1982). Structure of the outer mitochondrial membrane: ordered arrays of porelike subunits in outer-membrane fractions from Neurospora crassa mitochondria. J Cell Biol 94, 680687.

Mannella, C. A. (2006). Structure and dynamics of the mitochondrial inner membrane cristae. Biochim Biophys Acta 1763, 542-548.

Margulis, L. (1970). Origin of Eukaryotic Cells (New Haven, Yale University Press).

Martinou, J. C. und Youle, R. J. (2006). Which came first, the cytochrome $c$ release or the mitochondrial fission? Cell Death Differ 13, 1291-1295.

Mayer, A., Lill, R. und Neupert, W. (1993). Translocation and insertion of precursor proteins into isolated outer membranes of mitochondria. J Cell Biol 121, 1233-1243.

McBride, H. M., Neuspiel, M. und Wasiak, S. (2006). Mitochondria: more than just a powerhouse. Curr Biol 16, R551-560.

Meienhofer, J. und Atherton, E. (1973). Structure-activity relationships in the actinomycins. Adv Appl Microbiol 16, 203-300.

Meier, P., Finch, A. und Evan, G. (2000). Apoptosis in development. Nature 407, 796-801.

Meisinger, C., Sickmann, A. und Pfanner, N. (2008). The mitochondrial proteome: from inventory to function. Cell 134, 22-24. 
Meselson, M., Yuan, R. und Heywood, J. (1972). Restriction and modification of DNA. Annu Rev Biochem 41, 447-466.

Model, K., Meisinger, C., Prinz, T., Wiedemann, N., Truscott, K. N., Pfanner, N. und Ryan, M. T. (2001). Multistep assembly of the protein import channel of the mitochondrial outer membrane. Nat Struct Biol 8, 361-370.

Mullis, K. B. und Faloona, F. A. (1987). Specific synthesis of DNA in vitro via a polymerasecatalyzed chain reaction. Methods Enzymol 155, 335-350.

Nakagawa, T., Shimizu, S., Watanabe, T., Yamaguchi, O., Otsu, K., Yamagata, H., Inohara, H., Kubo, T. und Tsujimoto, Y. (2005). Cyclophilin D-dependent mitochondrial permeability transition regulates some necrotic but not apoptotic cell death. Nature 434, 652-658.

Nechushtan, A., Smith, C. L., Lamensdorf, I., Yoon, S. H. und Youle, R. J. (2001). Bax and Bak coalesce into novel mitochondria-associated clusters during apoptosis. J Cell Biol 153, 1265-1276.

Neumann, D., Bückers, J., Kastrup, L., Hell, S. W. und Jakobs, S. (2010). Two-color STED microscopy reveals different degrees of colocalization between hexokinase-I and the three human VDAC isoforms. PMC Biophys 3, 4.

Osborn, M. (2006). Immunofluorescence Microscopy of Cultured Cells. In Cell biology: A laboratory handbook (San Diego, Academic Press).

Ott, M., Norberg, E., Walter, K. M., Schreiner, P., Kemper, C., Rapaport, D., Zhivotovsky, B. und Orrenius, S. (2007). The mitochondrial TOM complex is required for $\mathrm{tBid} / \mathrm{Bax}$-induced cytochrome c release. J Biol Chem 282, 27633-27639.

Ott, M., Robertson, J. D., Gogvadze, V., Zhivotovsky, B. und Orrenius, S. (2002). Cytochrome $c$ release from mitochondria proceeds by a two-step process. Proc Natl Acad Sci U S A 99, 1259-1263.

Ow, Y. P., Green, D. R., Hao, Z. und Mak, T. W. (2008). Cytochrome $c$ : functions beyond respiration. Nat Rev Mol Cell Biol9, 532-542.

Parone, P. A., James, D. I., Da Cruz, S., Mattenberger, Y., Donze, O., Barja, F. und Martinou, J. C. (2006). Inhibiting the mitochondrial fission machinery does not prevent Bax/Bak-dependent apoptosis. Mol Cell Biol 26, 7397-7408.

Pastorino, J. G., Chen, S. T., Tafani, M., Snyder, J. W. und Farber, J. L. (1998). The overexpression of Bax produces cell death upon induction of the mitochondrial permeability transition. J Biol Chem 273, 7770-7775.

Pastorino, J. G. und Hoek, J. B. (2003). Hexokinase II: the integration of energy metabolism and control of apoptosis. Curr Med Chem 10, 1535-1551.

Pastorino, J. G. und Hoek, J. B. (2008). Regulation of hexokinase binding to VDAC. J Bioenerg Biomembr 40, 171-182.

Pedersen, P. L. (2007). Warburg, me and Hexokinase 2: Multiple discoveries of key molecular events underlying one of cancers' most common phenotypes, the "Warburg Effect", i.e., elevated glycolysis in the presence of oxygen. J Bioenerg Biomembr 39, 211-222. 
Perez, H. D., Vilander, L., Andrews, W. H. und Holmes, R. (1994). Human formyl peptide receptor ligand binding domain(s). Studies using an improved mutagenesis/expression vector reveal a novel mechanism for the regulation of receptor occupancy. J Biol Chem 269, 22485-22487.

Perfettini, J. L., Roumier, T. und Kroemer, G. (2005). Mitochondrial fusion and fission in the control of apoptosis. Trends Cell Biol 15, 179-183.

Perkins, G., Renken, C., Martone, M. E., Young, S. J., Ellisman, M. und Frey, T. (1997). Electron tomography of neuronal mitochondria: three-dimensional structure and organization of cristae and membrane contacts. J Struct Biol 119, 260-272.

Pfanner, N., Wiedemann, N., Meisinger, C. und Lithgow, T. (2004). Assembling the mitochondrial outer membrane. Nat Struct Mol Biol 11, 1044-1048.

Rabl, R., Soubannier, V., Scholz, R., Vogel, F., Mendl, N., Vasiljev-Neumeyer, A., Korner, C., Jagasia, R., Keil, T., Baumeister, W., Cyrklaff, M., Neupert, W. und Reichert, A. S. (2009). Formation of cristae and crista junctions in mitochondria depends on antagonism between Fcj1 and Su e/g. J Cell Biol 185, 1047-1063.

Rehling, P., Brandner, K. und Pfanner, N. (2004). Mitochondrial import and the twin-pore translocase. Nat Rev Mol Cell Biol 5, 519-530.

Rehling, P., Model, K., Brandner, K., Kovermann, P., Sickmann, A., Meyer, H. E., Kuhlbrandt, W., Wagner, R., Truscott, K. N. und Pfanner, N. (2003). Protein insertion into the mitochondrial inner membrane by a twin-pore translocase. Science 299, 1747-1751.

Reichert, A. S. und Neupert, W. (2002). Contact sites between the outer and inner membrane of mitochondria-role in protein transport. Biochim Biophys Acta 1592, 41-49.

Rich, T., Allen, R. L. und Wyllie, A. H. (2000). Defying death after DNA damage. Nature 407, 777783.

Riedl, S. J. und Salvesen, G. S. (2007). The apoptosome: signalling platform of cell death. Nat Rev Mol Cell Biol 8, 405-413.

Roman, I., Figys, J., Steurs, G. und Zizi, M. (2006). Direct measurement of VDAC-actin interaction by surface plasmon resonance. Biochim Biophys Acta 1758, 479-486.

Ross, W. E. und Bradley, M. O. (1981). DNA double-stranded breaks in mammalian cells after exposure to intercalating agents. Biochim Biophys Acta 654, 129-134.

Rostovtseva, T. K., Antonsson, B., Suzuki, M., Youle, R. J., Colombini, M. und Bezrukov, S. M. (2004). Bid, but not Bax, regulates VDAC channels. J Biol Chem 279, 13575-13583.

Rostovtseva, T. K., Tan, W. und Colombini, M. (2005). On the role of VDAC in apoptosis: fact and fiction. J Bioenerg Biomembr 37, 129-142.

Roy, S. S., Ehrlich, A. M., Craigen, W. J. und Hajnoczky, G. (2009). VDAC2 is required for truncated BID-induced mitochondrial apoptosis by recruiting BAK to the mitochondria. $E M B O$ $\operatorname{Rep~10,1341-1347.~}$ 
Saccone, C., Caggese, C., D'Erchia, A. M., Lanave, C., Oliva, M. und Pesole, G. (2003). Molecular clock and gene function. JMol Evol57 Suppl 1, S277-285.

Sagan, L. (1967). On the origin of mitosing cells. J Theor Biol 14, 255-274.

Saito, M., Korsmeyer, S. J. und Schlesinger, P. H. (2000). BAX-dependent transport of cytochrome $c$ reconstituted in pure liposomes. Nat Cell Biol 2, 553-555.

Sambrook, J. R., DW (2001). Molecular Cloning: A Laboratory Manual (Cold Spring Harbor, New York, Cold Spring Harbour Laboratory Press).

Sampson, M. J., Lovell, R. S. und Craigen, W. J. (1996). Isolation, characterization, and mapping of two mouse mitochondrial voltage-dependent anion channel isoforms. Genomics 33, 283-288.

Saraste, M. (1999). Oxidative phosphorylation at the fin de siecle. Science 283, 1488-1493.

Schafer, B., Quispe, J., Choudhary, V., Chipuk, J. E., Ajero, T. G., Du, H., Schneiter, R. und Kuwana, T. (2009). Mitochondrial outer membrane proteins assist Bid in Bax-mediated lipidic pore formation. Mol Biol Cell 20, 2276-2285.

Scheffler, I. E. (1999). Mitochondria (New Jersey, John Wiley and Sons).

Scheffler, I. E. (2001). A century of mitochondrial research: achievements and perspectives. Mitochondrion 1, 3-31.

Schlattner, U., Dolder, M., Wallimann, T. und Tokarska-Schlattner, M. (2001). Mitochondrial creatine kinase and mitochondrial outer membrane porin show a direct interaction that is modulated by calcium. J Biol Chem 276, 48027-48030.

Schmidt, R., Wurm, C. A., Jakobs, S., Engelhardt, J., Egner, A. und Hell, S. W. (2008). Spherical nanosized focal spot unravels the interior of cells. Nat Methods 5, 539-544.

Schmidt, R., Wurm, C. A., Punge, A., Egner, A., Jakobs, S. und Hell, S. W. (2009). Mitochondrial cristae revealed with focused light. Nano Lett 9, 2508-2510.

Scorrano, L. (2009). Opening the doors to cytochrome $c$. changes in mitochondrial shape and apoptosis. Int J Biochem Cell Biol 41, 1875-1883.

Scorrano, L., Ashiya, M., Buttle, K., Weiler, S., Oakes, S. A., Mannella, C. A. und Korsmeyer, S. J. (2002). A distinct pathway remodels mitochondrial cristae and mobilizes cytochrome $c$ during apoptosis. Dev Cell 2, 55-67.

Semenza, G. L. (2007). Life with oxygen. Science 318, 62-64.

Sheridan, C., Delivani, P., Cullen, S. P. und Martin, S. J. (2008). Bax- or Bak-induced mitochondrial fission can be uncoupled from cytochrome $c$ release. $\mathrm{Mol} \mathrm{Cell} \mathrm{31,} \mathrm{570-585.}$

Shimizu, S., Matsuoka, Y., Shinohara, Y., Yoneda, Y. und Tsujimoto, Y. (2001). Essential role of voltage-dependent anion channel in various forms of apoptosis in mammalian cells. J Cell Biol 152, 237-250. 
Shimizu, S., Narita, M. und Tsujimoto, Y. (1999). Bcl-2 family proteins regulate the release of apoptogenic cytochrome $c$ by the mitochondrial channel VDAC. Nature 399, 483-487.

Shinohara, Y., Ishida, T., Hino, M., Yamazaki, N., Baba, Y. und Terada, H. (2000). Characterization of porin isoforms expressed in tumor cells. Eur J Biochem 267, 6067-6073.

Shoshan-Barmatz, V., Zakar, M., Rosenthal, K. und Abu-Hamad, S. (2009). Key regions of VDAC1 functioning in apoptosis induction and regulation by hexokinase. Biochim Biophys Acta 1787, 421430.

Spierings, D., McStay, G., Saleh, M., Bender, C., Chipuk, J., Maurer, U. und Green, D. R. (2005). Connected to death: the (unexpurgated) mitochondrial pathway of apoptosis. Science 310, 66-67.

Stoldt, S. (2010) Dynamische sub-mitochondriale Lokalisation von Oxa1, Georg-AugustUniversität, Göttingen.

Suen, D. F., Norris, K. L. und Youle, R. J. (2008). Mitochondrial dynamics and apoptosis. Genes Dev 22, 1577-1590.

Suzuki, M., Youle, R. J. und Tjandra, N. (2000). Structure of Bax: coregulation of dimer formation and intracellular localization. Cell 103, 645-654.

Tait, S. W. und Green, D. R. (2008). Caspase-independent cell death: leaving the set without the final cut. Oncogene 27, 6452-6461.

Taylor, F. (1974). Implications and extensions of the serial endosymbiosis theory of the origin of eukaryotes. Taxon 23, 229-258.

Taylor, J. S. und Raes, J. (2004). Duplication and divergence: the evolution of new genes and old ideas. Annu Rev Genet 38, 615-643.

Taylor, R. C., Cullen, S. P. und Martin, S. J. (2008). Apoptosis: controlled demolition at the cellular level. Nat Rev Mol Cell Biol 9, 231-241.

Terrones, O., Antonsson, B., Yamaguchi, H., Wang, H. G., Liu, J., Lee, R. M., Herrmann, A. und Basanez, G. (2004). Lipidic pore formation by the concerted action of proapoptotic BAX and tBID. $J$ Biol Chem 279, 30081-30091.

Ujwal, R., Cascio, D., Chaptal, V., Ping, P. und Abramson, J. (2009). Crystal packing analysis of murine VDAC1 crystals in a lipidic environment reveals novel insights on oligomerization and orientation. Channels (Austin) 3, 167-170.

Ujwal, R., Cascio, D., Colletier, J. P., Faham, S., Zhang, J., Toro, L., Ping, P. und Abramson, J. (2008). The crystal structure of mouse VDAC1 at 2.3 A resolution reveals mechanistic insights into metabolite gating. Proc Natl Acad Sci US A 105, 17742-17747.

Vaux, D. L. und Korsmeyer, S. J. (1999). Cell death in development. Cell 96, 245-254.

Vial, S., Lu, H., Allen, S., Savory, P., Thornton, D., Sheehan, J. und Tokatlidis, K. (2002). Assembly of Tim9 and Tim10 into a functional chaperone. J Biol Chem 277, 36100-36108. 
Vogel, F., Bornhovd, C., Neupert, W. und Reichert, A. S. (2006). Dynamic subcompartmentalization of the mitochondrial inner membrane. J Cell Biol 175, 237-247.

Wang, C. und Youle, R. J. (2009). The role of mitochondria in apoptosis. Annu Rev Genet 43, 95118.

Warburg, O. (1926). Über den Stoffwechsel der Tumoren (Berlin, Springer).

Waterhouse, N. J., Goldstein, J. C., von Ahsen, O., Schuler, M., Newmeyer, D. D. und Green, D. R. (2001). Cytochrome $c$ maintains mitochondrial transmembrane potential and ATP generation after outer mitochondrial membrane permeabilization during the apoptotic process. J Cell Biol 153, 319328.

Weber, K., Rathke, P. C. und Osborn, M. (1978). Cytoplasmic microtubular images in glutaraldehyde-fixed tissue culture cells by electron microscopy and by immunofluorescence microscopy. Proc Natl Acad Sci US A 75, 1820-1824.

Wei, M. C., Zong, W. X., Cheng, E. H., Lindsten, T., Panoutsakopoulou, V., Ross, A. J., Roth, K. A., MacGregor, G. R., Thompson, C. B. und Korsmeyer, S. J. (2001). Proapoptotic BAX and BAK: a requisite gateway to mitochondrial dysfunction and death. Science 292, 727-730.

Westermann, B. (2007). Focus on mitochondria: introducing a new series in Trends in Cell Biology. Trends Cell Biol 17, 417-418.

Westermann, B. (2008). Molecular machinery of mitochondrial fusion and fission. J Biol Chem 283, 13501-13505.

Wiedemann, N., Truscott, K. N., Pfannschmidt, S., Guiard, B., Meisinger, C. und Pfanner, N. (2004). Biogenesis of the protein import channel Tom 40 of the mitochondrial outer membrane: intermembrane space components are involved in an early stage of the assembly pathway. J Biol Chem 279, 18188-18194.

Wildanger, D., Buckers, J., Westphal, V., Hell, S. W. und Kastrup, L. (2009). A STED microscope aligned by design. Opt Express 17, 16100-16110.

Willig, K. I., Rizzoli, S. O., Westphal, V., Jahn, R. und Hell, S. W. (2006). STED microscopy reveals that synaptotagmin remains clustered after synaptic vesicle exocytosis. Nature 440, 935-939.

Willis, S. N., Fletcher, J. I., Kaufmann, T., van Delft, M. F., Chen, L., Czabotar, P. E., Ierino, H., Lee, E. F., Fairlie, W. D., Bouillet, P., et al. (2007). Apoptosis initiated when BH3 ligands engage multiple Bcl-2 homologs, not Bax or Bak. Science 315, 856-859.

Wilson, J. E. (1995). Hexokinases. Rev Physiol Biochem Pharmacol 126, 65-198.

Wong, W. W. und Puthalakath, H. (2008). Bcl-2 family proteins: the sentinels of the mitochondrial apoptosis pathway. IUBMB Life 60, 390-397.

Wurm, C. A. (2008) Lichtmikroskopische Untersuchung submitochondrialer Proteinverteilungen, Ruprecht-Karls-Universität, Heidelberg.

Wurm, C. A. und Jakobs, S. (2006). Differential protein distributions define two sub-compartments of the mitochondrial inner membrane in yeast. FEBS Lett 580, 5628-5634. 
Wurm, C. A., Neumann, D., Schmidt, R., Egner, A. und Jakobs, S. (2010). Sample preparation for STED microscopy. Methods Mol Biol 591, 185-199.

Xu, X., Decker, W., Sampson, M. J., Craigen, W. J. und Colombini, M. (1999). Mouse VDAC isoforms expressed in yeast: channel properties and their roles in mitochondrial outer membrane permeability. JMembr Biol 170, 89-102.

Yamaguchi, R., Lartigue, L., Perkins, G., Scott, R. T., Dixit, A., Kushnareva, Y., Kuwana, T., Ellisman, M. H. und Newmeyer, D. D. (2008). Opa1-mediated cristae opening is Bax/Bak and BH3 dependent, required for apoptosis, and independent of Bak oligomerization. Mol Cell 31, 557-569.

Yamaguchi, R. und Perkins, G. (2009). Dynamics of mitochondrial structure during apoptosis and the enigma of Opa1. Biochim Biophys Acta 1787, 963-972.

Yamamoto, T., Yamada, A., Watanabe, M., Yoshimura, Y., Yamazaki, N., Yamauchi, T., Kataoka, M., Nagata, T., Terada, H. und Shinohara, Y. (2006). VDAC1, having a shorter N-terminus than VDAC2 but showing the same migration in an SDS-polyacrylamide gel, is the predominant form expressed in mitochondria of various tissues. J Proteome Res 5, 3336-3344.

Youle, R. J. und Karbowski, M. (2005). Mitochondrial fission in apoptosis. Nat Rev Mol Cell Biol 6, 657-663.

Youle, R. J. und Strasser, A. (2008). The BCL-2 protein family: opposing activities that mediate cell death. Nat Rev Mol Cell Biol 9, 47-59.

Young, M. J., Bay, D. C., Hausner, G. und Court, D. A. (2007). The evolutionary history of mitochondrial porins. BMC Evol Biol7, 31.

Yu, W. H., Wolfgang, W. und Forte, M. (1995). Subcellular localization of human voltagedependent anion channel isoforms. J Biol Chem 270, 13998-14006.

Yung, B. Y., Chang, F. J., Bor, A. M. und Lee, E. S. (1992). Schedule-dependent effects of two consecutive, divided, low doses of actinomycin D on translocation of protein B23, inhibition of cell growth and RNA synthesis in HeLa cells. Int J Cancer 52, 317-322.

Zaid, H., Abu-Hamad, S., Israelson, A., Nathan, I. und Shoshan-Barmatz, V. (2005). The voltagedependent anion channel-1 modulates apoptotic cell death. Cell Death Differ 12, 751-760.

Zalk, R., Israelson, A., Garty, E. S., Azoulay-Zohar, H. und Shoshan-Barmatz, V. (2005). Oligomeric states of the voltage-dependent anion channel and cytochrome $c$ release from mitochondria. Biochem J386, 73-83.

Zhou, B. B. und Bartek, J. (2004). Targeting the checkpoint kinases: chemosensitization versus chemoprotection. Nat Rev Cancer 4, 216-225.

Zhou, L. und Chang, D. C. (2008). Dynamics and structure of the Bax-Bak complex responsible for releasing mitochondrial proteins during apoptosis. J Cell Sci 121, 2186-2196.

Zimmermann, K. C., Bonzon, C. und Green, D. R. (2001). The machinery of programmed cell death. Pharmacol Ther 92, 57-70. 
Zimmermann, T. (2005). Spectral Imaging and Linear Unmixing in Light Microscopy. In Advances in biochemical engineering/biotechnology (Berlin/Heidelberg, Springer), pp. 245-265.

Zinchuk, V. und Zinchuk, O. (2008). Quantitative colocalization analysis of confocal fluorescence microscopy images. Curr Protoc Cell Biol Chapter 4, Unit 419. 


\section{Anhang}

\subsection{STED-Mikroskopie und ihre Eignung zur Untersuchung sub-}

\section{mitochondrialer Proteinverteilungen}

Bei der STED (stimulated emission depletion)-Mikroskopie handelt es sich um eine lichtmikroskopische Technik, bei der die Auflösung im Vergleich zur konventionellen Lichtmikroskopie deutlich verbessert ist und somit mehr Details visualisiert werden können. Die STED-Mikroskopie eröffnet somit neue Möglichkeiten, Proteine innerhalb von Zellen zu analysieren. Das Prinzip der Methode wird im Folgenden vorgestellt.

Die Auflösung (d) eines Mikroskops ist definiert als der minimale Abstand, bei dem zwei Punkte gerade noch getrennt wahrgenommen werden können. Diese, durch Ernst Abbe Ende des 19. Jahrhunderts definierte Beugungsgrenze (Abbe, 1873) liegt für konventionelle Lichtmikroskope bei ungefähr $200 \mathrm{~nm}$ in lateraler (in der Bildebene) und bei ungefähr $500 \mathrm{~nm}$ in axialer Richtung (entlang des optischen Weges). Sie hängt von der Wellenlänge des verwendeten Lichtes und von der numerischen Appertur des Objektives ab und kann durch die Formel in Abbildung 8.1A beschrieben werden (Born und Wolf, 2002).

Grundlage dieser Beugungsgrenze ist, dass das Licht ausgehend von der Probe
(A) $\quad d=\frac{\lambda}{2 n \cdot \sin \alpha}$
(B) $\quad \mathrm{d}=\frac{\lambda}{2 \mathrm{n} \cdot \sin \alpha \sqrt{1+\mathrm{I} / \mathrm{I}_{\mathrm{s}}}}$

\section{Abbildung 8.1: Formeln zur Berechnung der Auflösungsgrenze eines konventionellen Lichtmikroskops (A) und eines STED-Mikroskops (B)}

Die von Ernst Abbe Ende des 19. Jahrunderts aufgestellte Beugungsgrenze ist durch die Wellenlänge des Lichtes und die numerische Appertur limitiert (A). Die durch Stefan Hell entwickelte STED-Mikroskopie ist beugungsunbegrenzt. Das heißt, dass die Auflösung nicht mehr von den Welleneigenschaften des Lichtes, sondern von den Eigenschaften der Fluorophore abhängt. Je höher die Intensität des STED-Strahles, desto besser die Auflösung (B). 
durch Interaktionen mit dem physikalischen Medium (Mikroskop) Änderungen unterliegt, die zu einem unscharfen Fleck am Ende des Strahlengangs führen. Diese durch das Mikroskop hervorgerufenen Änderungen des Lichtes führen zu einer Unschärfe und können durch eine sog. Punkt-Bild-Funktion (PSF) beschrieben werden (Born und Wolf, 2002). Als Konsequenz dieser Änderungen können zwei dicht nebeneinander liegende Punkte in einem konventionellen Lichtmikroskop nicht mehr getrennt aufgelöst werden. Die prinzipelle Idee der STED-Mikroskopie besteht darin, die Punkte nacheinander einzeln an- und auszuschalten. Somit können beide Punkte getrennt und nacheinander visualisiert und zu einem hochauflösenden Bild zusammengefügt werden (Hell und Wichmann, 1994).

Praktisch wird die zu untersuchende Probe mit fluoreszierenden Farbstoffen markiert und zunächst angeregt ( $\mathrm{S}_{1}$ Zustand, Abbildung 8.2A). Bevor aber die angeregten Fluorophore ihre Energie in Form von langwelligerem Licht abgeben können und zurück in den So Zustand übergehen, wird ein zweiter, ausgehend vom Anregungslaser rot verschobener Laserpuls (STED-Laser) auf die Probe gestrahlt, der zur stimulierten Emission führt. Hierdurch wird die spontane Fluoreszenz unterbunden und die Energie wird in Form von Photonen längerer Wellenlänge, nämlich der des STED-Lasers, abgegeben. Der Trick bei diesem Verfahren besteht darin, dass die Fluoreszenz nicht in der kompletten Probe unterbunden wird, sondern vielmehr auf das Zentrum der Probe beschränkt wird (Abbildung 8.2B, 8.2C). Dies wird erreicht, indem man den Fokus des STEDStrahls in der Form eines Rings (doughnut) mit einem Intensitätsminium in der Mitte erzeugt. Nur Fluorophore in dessen Zentrum fluoreszieren, werden detektiert und besitzen dadurch gleichzeitig eine definierte Position. Alle anderen Fluorophore in der direkten Umgebung sind hingegen ausgeschaltet. Durch das Abrastern der gesamten Probe mit dem beschriebenen Verfahren (genauso wie mit einem konfokalen Mikroskop), wird stückweise, ein beugungsunbegrenztes Bild generiert (Hell, 2009b; Hell, 2009a). 
A

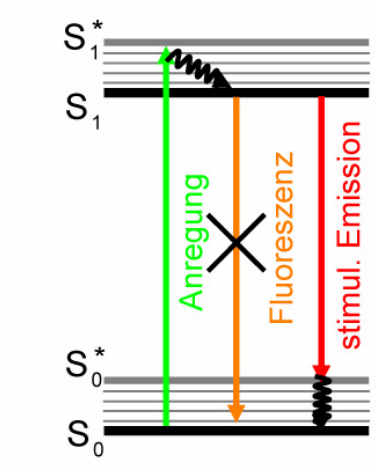

B

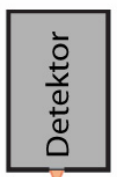

$\lambda / 2$

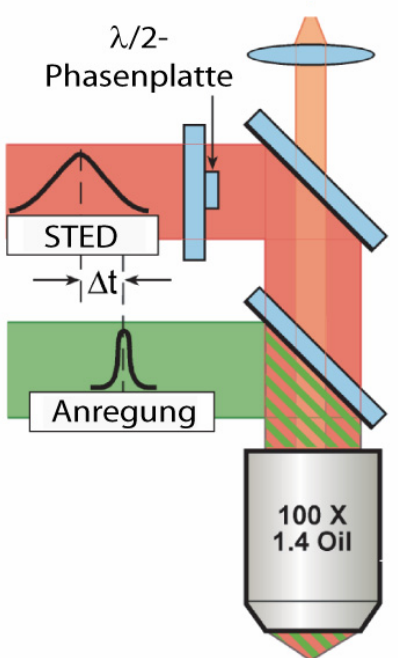

effektive PSF
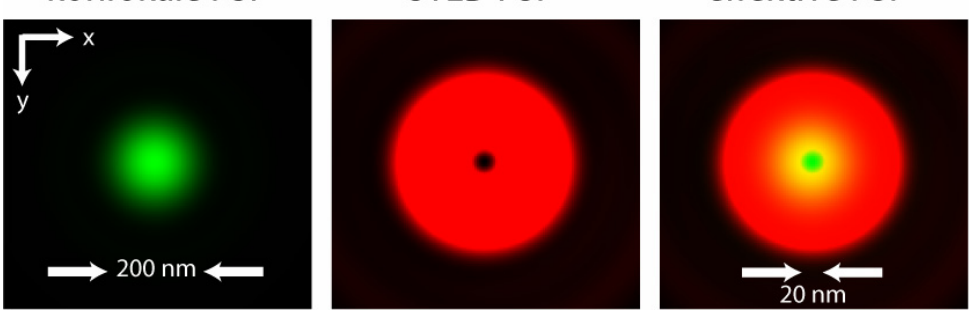

Abbildung 8.2: Jablonski-Diagramm (A), schematischer Aufbau eines STEDMikroskops (B) und die dazugehörigen Punkt-Bild-Funktionen (C)

Das Prinzip der STED-Mikroskopie beruht auf dem Schalten zwischen zwei Zuständen ( $\mathrm{S}_{0}, \mathrm{~S}_{1}$, A). Das Schalten wird durch durch einen zweiten, sog. STED-Laser erreicht (B), dessen PunktBild-Funktion eine Ring-Form (doughnut) aufweist (C). Aufgrund dieser Ring-Form wird ein Großteil der gerade angeregten Moleküle direkt wieder durch stimulierte Emission in den AusZustand überführt (A). Nur Fluorophore im Zentrum des Fokus fluoreszieren. Diese können von benachbarteten, ausgeschalteten Fluorophoren getrennt werden. Durch das Scannen der Probe wird somit Stück für Stück ein hochauflösendes Bild generiert.

Die durch den zweiten Laserpuls hervorgerufene stimulierte Emission ermöglicht das Schalten zwischen zwei Zuständen (fluoreszierend, nicht fluoreszierend). Entsprechend wird diese Technik als stimulated emission depletion (STED) Mikroskopie bezeichnet (Hell und Wichmann, 1994). Die von Ernst Abbe aufgestellte Formel (Abbildung 8.1A) kann durch einen zusätzlichen Term erweitert werden (Abbildung 8.1B), der einen wichtigen Zusammenhang verdeutlicht: Je höher die Intensität I des STED Strahles gewählt wird (wobei Is 
eine für die Umwandlung der beiden Zustände charakteristische

Sättigungsintensität ist), desto mehr Moleküle unterliegen dem Übergang von $\mathrm{S}_{1}$ zu So und eine desto bessere Auflösung kann erzielt werden. In biologischen Proben wird typischerweise eine laterale Auflösung zwischen 30-50 nm erreicht.

Die STED-Mikroskopie wurde bis jetzt für verschiedene biologische Anwendungen eingesetzt. Hierzu gehören die Visualisierung von Proteinen an der Synapse von Nervenzellen (Willig et al., 2006), Proteine des Cytoskeletts (Dyba et al., 2003) sowie die Analyse von lipid rafts (Eggeling et al., 2009).

Da der Durchmesser von Mitochondrien mit 200-400 nm im Bereich der Auflösungsgrenze konventioneller Lichtmikroskope liegt, sind diese zur Analyse sub-mitochondrialer Proteinverteilungen ungeeignet. Hingegen bietet sich die STED-Mikroskopie mit ihrer deutlich verbesserten Auflösung zur Untersuchung sub-mitochondrialer Proteinverteilungen an. Dies wird beim Vergleich einer STED- und der korrespondierenden konfokal-mikroskopischen Aufnahme von der Verteilung des TOM-Komplexes deutlich (Abbildung 8.3). Im konfokalen Bild erscheint die Proteinverteilung vollkommen homogen. Es lassen sich keine
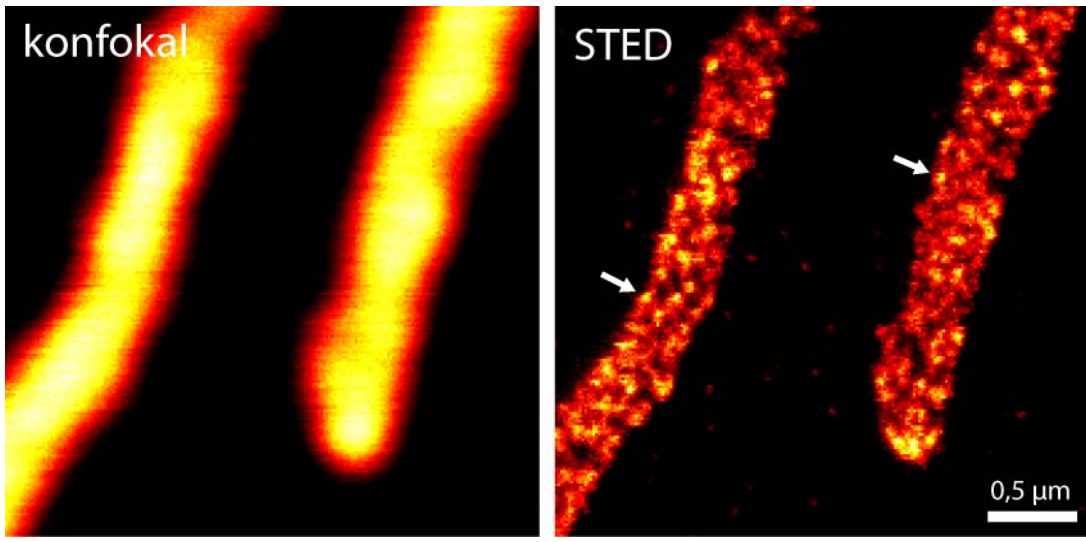

Abbildung 8.3: STED-Mikroskopie als Methode zur Untersuchung submitochondrialer Proteinverteilungen

Auf fixierten U2OS-Zellen wurden Immunofluoreszenz-Markierungen mit Antikörpern gegen die Tom20 Untereinheit des TOM-Komplexes durchgeführt. Im Anschluss wurden die Zellen im konfokalen und STED-Modus eines nicht kommerziellen Mikroskops untersucht. Im STEDModus ist zu erkennen, dass Tom20 in unterscheidbaren Clustern lokalisiert (siehe Pfeile) und nicht komplett homogen über die Mitochondrien verteilt ist, wie die konfokale Aufnahme nahelegt. 
Sub-Strukturen erkennen. Im Gegensatz dazu ist auf den STED-Aufnahmen deutlich zu erkennen, dass das Protein Tom20 nicht homogen über das gesamte Mitochondrium verteilt ist, sondern vielmehr in unterscheidbaren, aber dich angeordneten Clustern lokalisiert (Pfeile). Somit ist die STED-Mikroskopie, im Gegensatz zur konventionellen Lichtmikroskopie, geeignet, um submitochondriale Proteinverteilungen zu untersuchen.

\subsection{Wahl des STED-Mikroskops zur quantitativen Datenanalyse sub- mitochondrialer Proteinverteilungen}

Zur Untersuchung sub-mitochondrialer Proteinverteilungen in unbehandelten und apoptotischen Zellen wurden qualitative STED-Daten (Abschnitt 4.2.6) an einem nicht kommerziellen Mikroskop aufgenommen. Hingegen wurden die für die quantitative Analyse verwendeten STED-Daten an einem kommerziellen STED-Mikroskop generiert (Abschnitt 4.2.7).

Hierfür gibt es zwei Gründe: An dem nicht kommerziellen Mikroskop bestand nur die Möglichkeit, insgesamt zwei verschieden gefärbte Strukturen aufzunehmen. Somit wäre die Differenzierung zwischen Bax-Aktivierung und Cytochrom $c$ Freisetzung, neben der Untersuchung des eigentlichen Proteins, nicht möglich gewesen. Zum anderen ist es mit dem kommerziellen Mikroskop möglich, die Proben direkt mit einem großen Gesichtsfeld zu betrachten und die gefärbten Strukturen schnell zu beurteilen. Für die Generierung von vielen Aufnahmen für statistische Zwecke erweist sich diese Tatsache als großer Vorteil. Ein Nachteil besteht hingegen in der schlechteren Auflösung des kommerziellen im Vergleich zum nicht kommerziellen STED-Mikroskops. Am Beispiel der Hexokinase-I sind die STED Aufnahmen und die korrespondierenden konfokalen Bilder von beiden STED-Mikroskopen im Vergleich gezeigt (Abbildung 8.4). Hier ist zu erkennen, dass Hexokinase-I-Cluster mit dem nicht kommerziellen STED-Mikroskop besser aufgelöst werden können. Trotzdem unterscheidet sich auch beim kommerziellen 
STED-Mikroksop die STED-Aufnahme deutlich vom korrespondieren konfokalmikroskopischen Bild. Auch in der STED-Aufnahme vom kommerziellen Mikroskop können einzelne Proteincluster erkannt werden. Somit eignet sich auch dieses Mikroskop zur Analyse von sub-mitochondrialen Proteinverteilungen.

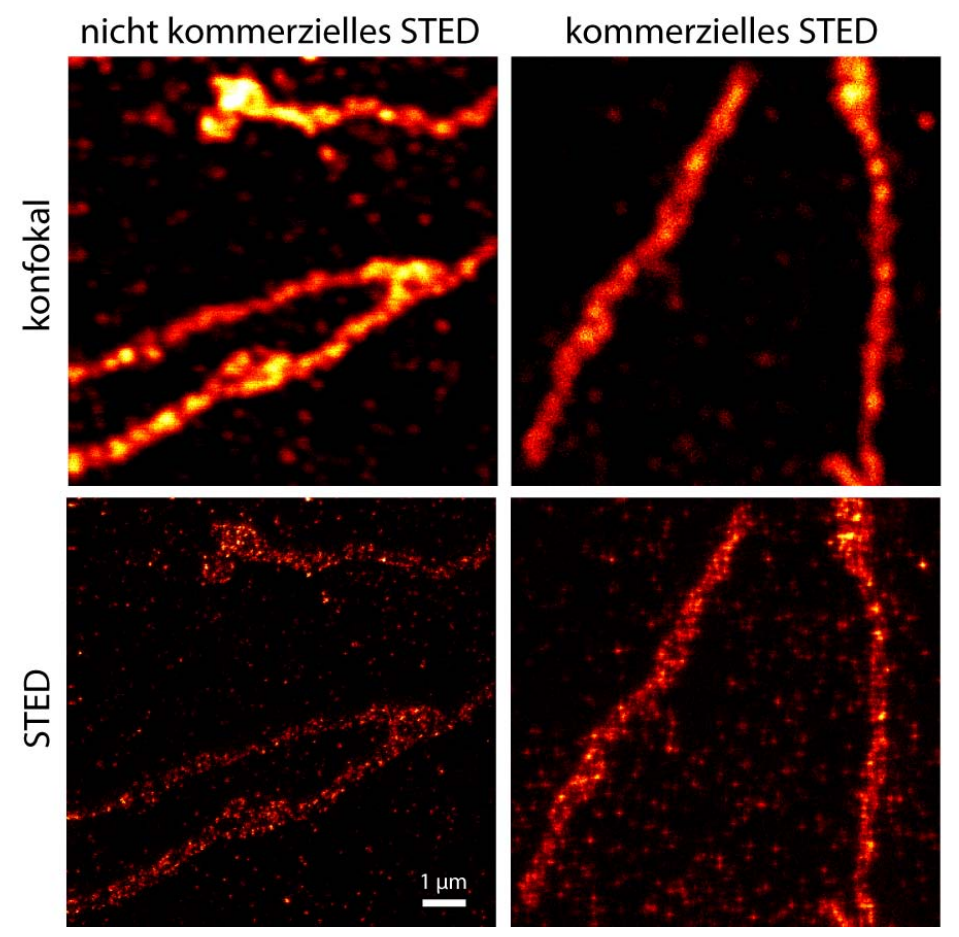

Abbildung 8.4: Vergleich des nicht kommerziellen mit dem kommerziellen STED Mikroskop anhand einer Hexokinase-I Markierung

U2OS-Zellen wurden mit Antikörpern gegen das Protein Hexokinase-I immuno-markiert und im Folgenden in beiden STED-Mikroskopen visualisiert. Einzelne Proteincluster sind deutlicher auf nicht kommerziellen STED-Aufnahmen zu erkennen, was mit der besseren Auflösung des Mikroskops zusammenhängt. Nichts desto trotz unterscheidet sich das STEDBild des kommerziellen STED-Mikroskops deutlich von der korrespondierenden, konfokalen Aufnahme. Hier ist ebenfalls zu erkennen, dass die Hexokinase-I in einzelnen Proteinclustern lokalisiert ist. 


\subsection{Ergänzende Abbildungen und Tabellen}

A

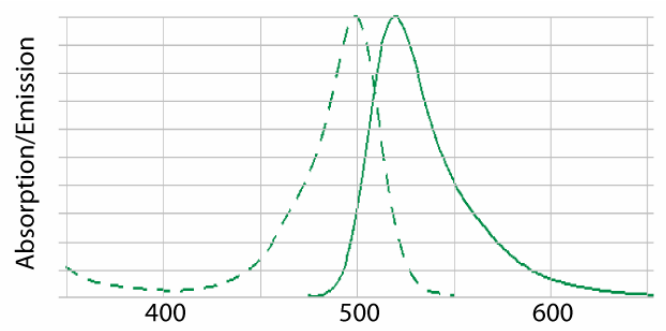

B

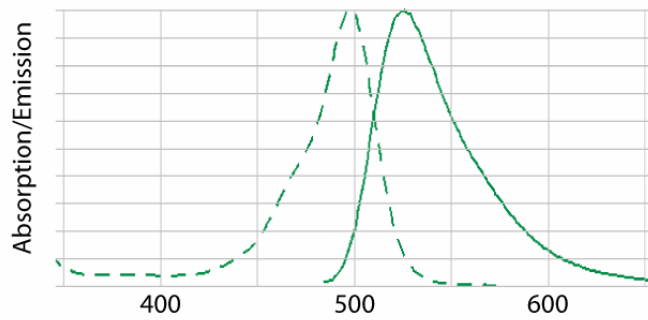

$\mathrm{C}$

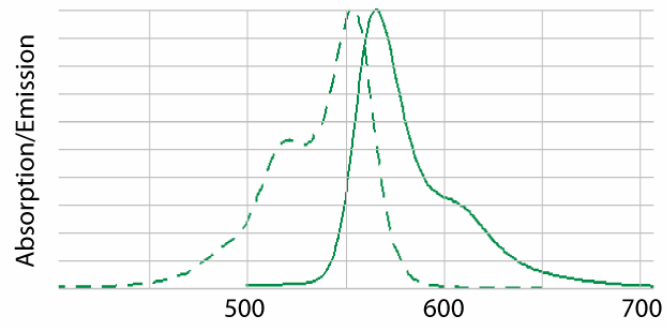

D

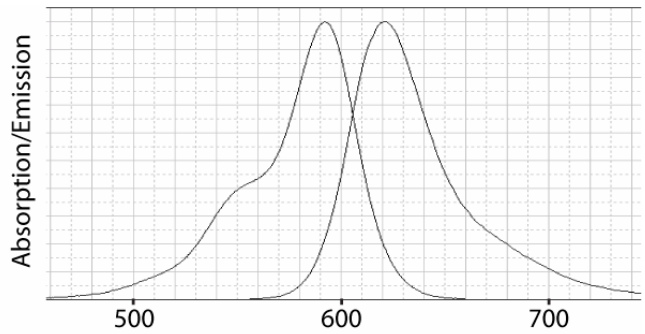

$\mathrm{E}$

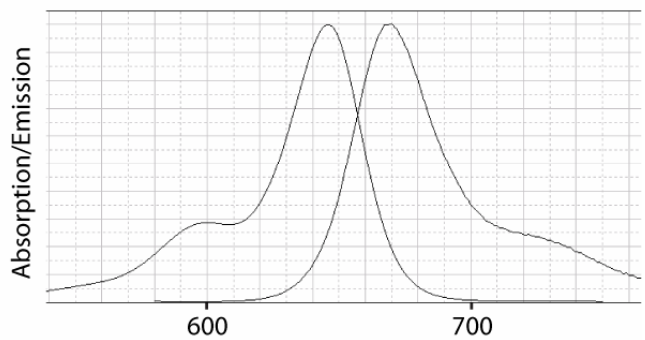

$\mathrm{F}$

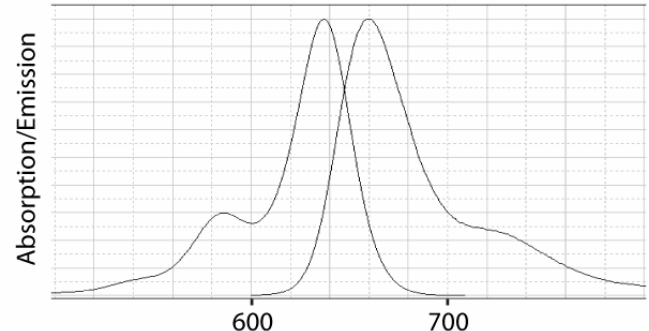

Abbildung 8.5: Absorptions- und Emissionsspektren der verwendeten Fluorophore

Die Absorptions- (linke Kurve) und Emissionsspektren (rechte Kurve) der in dieser Arbeit verwendeten Fluorophore sind dargestellt. Auf den $\mathrm{x}$-Achsen ist die Wellenlänge in $\mathrm{nm}$ angegeben. (A) Alexa488, (B) Oregon Green488, (C) Cy3, (D) Atto590, (E) Atto647N, (F) KK114 
A

B

C

D

\section{Abbildung 8.6: Verwendete Farbtabellen}

In dieser Arbeit wurden vier verschiedene Farbtabellen verwendet, wobei es sich bei der blauen (A), grünen (B) und roten (C) um lineare Farbtabellen und bei der fire (D) Farbtabelle um eine nicht lineare Farbtabelle handelt.

\section{Tabelle 8.1: hVDAC1 und hVDAC2 Domänendurchmesser (konfokale Aufnahmen)}

Um den Durchmesser von hVDAC1 und hVDAC2 Domänen zu bestimmen, wurde für jeweils 4 konfokal-mikroskopische Aufnahmen der Durchmesser von sechs Domänen manuell bestimt. Der jeweils kleinste und größte Wert sowie der Mittelwert und die Standardabweichung (Stdev) wurden bestimmt. Alle Angaben sind in $\mu \mathrm{m}$. Die kleinste gemessene VDAC-Domäne hat einen Durchmesser von $276 \mu \mathrm{m}$ und die größe einen Durchmesser von $887 \mu \mathrm{m}$. Der mittlere Domänendurchmesser für hVDAC1 liegt bei 452,2 \pm 132,1 $\mu \mathrm{m}$ und für hVDAC2 bei $459,4 \pm 161,7 \mu \mathrm{m}$. Zu beachten ist, dass die Angaben zu Domänendurchmessern inklusive der Länge der verwendeten Antikörpern sind.

\begin{tabular}{|c|c|c|c|c|c|c|c|c|c|c|c|c|c|c|c|}
\hline & & & $\begin{array}{l}\text { einzz } \\
\text { durc }\end{array}$ & $\begin{array}{l}\text { elne } \\
\text { Chmes }\end{array}$ & $\begin{array}{l}\text { Domän } \\
\text { sser ( }\end{array}$ & $\begin{array}{l}\text { inen- } \\
(\mu \mathrm{m})\end{array}$ & & kl. Wert & gr. Wert & $\begin{array}{c}\text { Mittel- } \\
\text { wert }\end{array}$ & Stdev & kl. Wert & gr. Wert & $\begin{array}{c}\text { Mittel- } \\
\text { wert }\end{array}$ & Stdev \\
\hline \multirow{4}{*}{ hVDAC1 } & 1. Aufnahme & 643 & 499 & 574 & 378 & \begin{tabular}{|l|}
482 \\
\end{tabular} & 648 & 378 & 648 & 531,3 & 104,6 & \multirow{4}{*}{319} & \multirow{4}{*}{741} & \multirow{4}{*}{452,2} & \multirow{4}{*}{132,1} \\
\hline & 2. Aufnahme & 335 & 444 & 345 & 399 & 740 & 406 & 335 & 740 & 468,0 & 150,2 & & & & \\
\hline & 3. Aufnahme & \begin{tabular}{|l|}
361 \\
\end{tabular} & 328 & 573 & 335 & 741 & 319 & 319 & 741 & 464,6 & 174,8 & & & & \\
\hline & 4. Aufnahme & \begin{tabular}{|l|}
443 \\
\end{tabular} & 362 & 367 & 356 & 432 & 343 & 343 & 443 & 386,1 & 42,5 & & & & \\
\hline \multirow{4}{*}{ hVDAC2 } & 1. Aufnahme & 309 & 527 & 551 & \begin{tabular}{|l|}
372 \\
\end{tabular} & 344 & 505 & 309 & 551 & 433,5 & 104,8 & \multirow{4}{*}{276} & \multirow{4}{*}{887} & \multirow{4}{*}{459,4} & \multirow{4}{*}{161,7} \\
\hline & 2. Aufnahme & \begin{tabular}{|l|}
371 \\
\end{tabular} & \begin{tabular}{|l|l|}
553 \\
\end{tabular} & 389 & \begin{tabular}{|l|}
381 \\
\end{tabular} & 314 & 301 & 301 & 553 & 395,4 & 90,1 & & & & \\
\hline & 3. Aufnahme & \begin{tabular}{|l|}
704 \\
\end{tabular} & 855 & 401 & \begin{tabular}{|l|}
367 \\
\end{tabular} & 452 & 276 & 276 & 855 & 523,3 & 222,3 & & & & \\
\hline & 4. Aufnahme & \begin{tabular}{|l|l|}
552 \\
\end{tabular} & 887 & 444 & \begin{tabular}{|l|}
374 \\
\end{tabular} & 381 & 415 & 374 & 887 & 539,3 & 196,2 & & & & \\
\hline
\end{tabular}



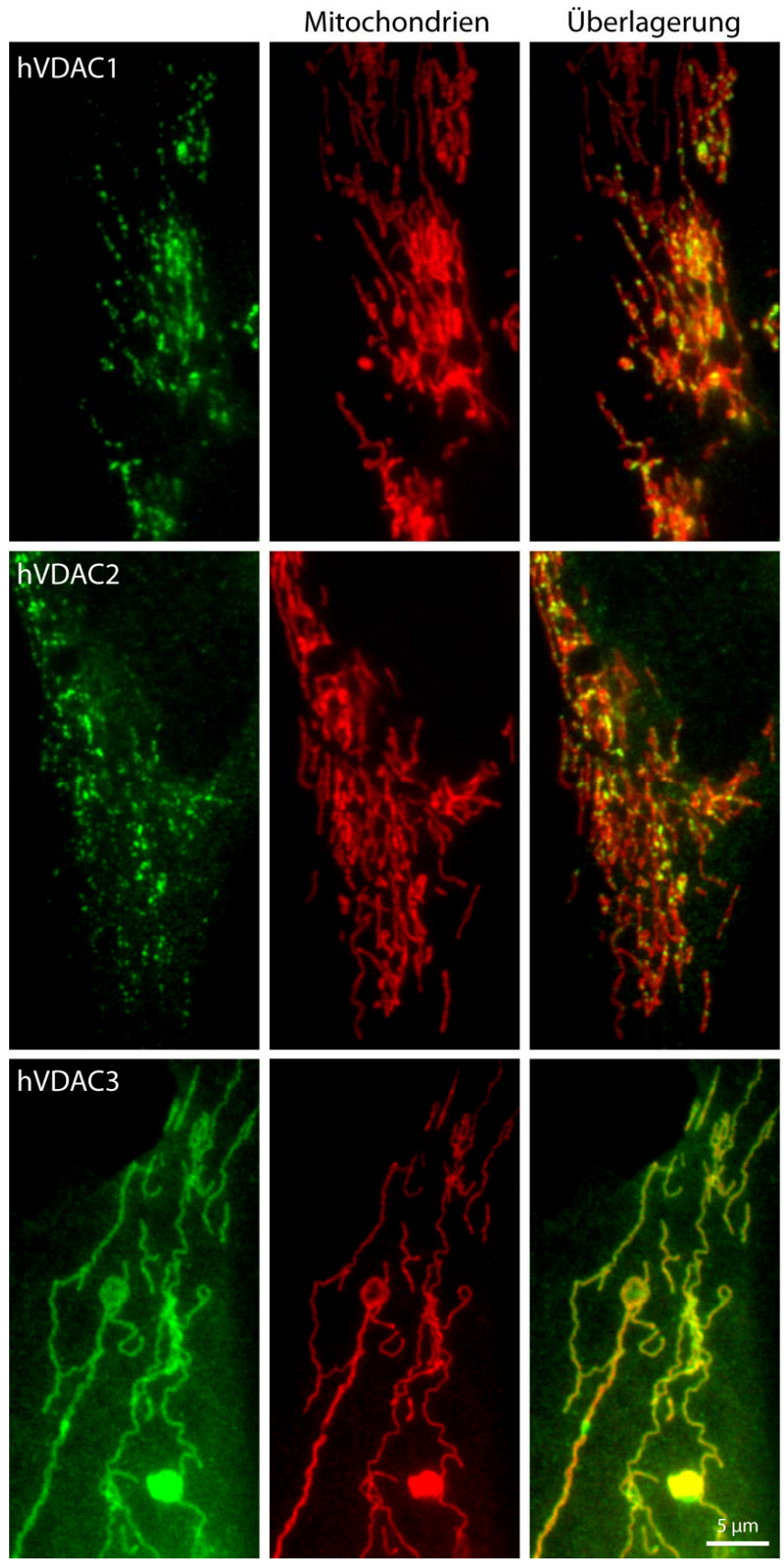

\section{Abbildung 8.7: Sub-mitochondriale Lokalisation der drei hVDAC Isoformen}

Epifluoreszenz-mikroskopische-Aufnahmen von immuno-fluoreszenz markierten U2OS-Zellen. Zur Visualisierung der hVDAC-Isoformen wurden die entsprechenden V5-Fusionsproteine mit Antikörpern gegen das V5-Tag detektiert (grün). Als mitochondrialer Marker wurde Tom20 verwendet (rot). hVDAC1 und hVDAC2 sind in distinkten Domänen in der mitochondrialen Membran lokalisiert, wohingegen hVDAC3 gleichförmig verteilt erscheint. Die hier beobachtete Lokalisation der hVDAC-Isoformen stimmt mit der Lokalisation überein, die bei Verwendung von VDAC-Flag Plasmiden (Abbildung 4.2) beschrieben worden ist. 
A

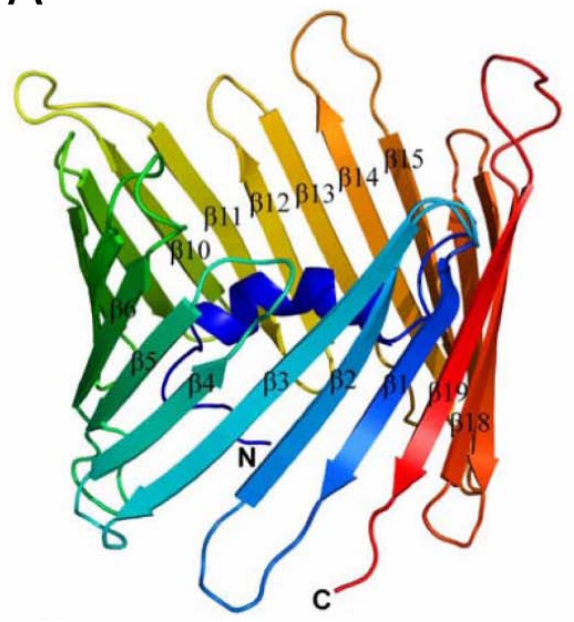

B

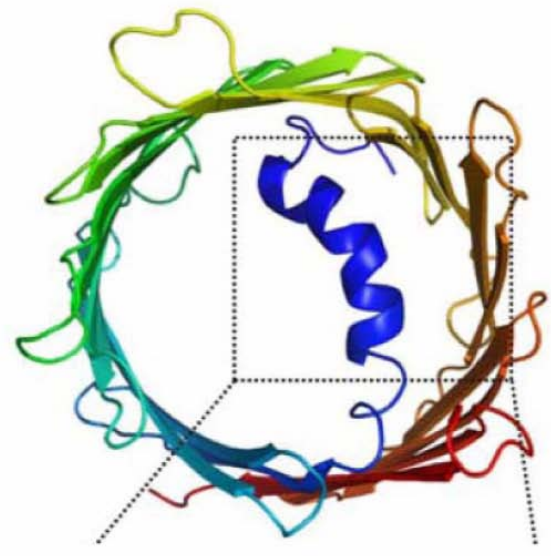

\section{Abbildung 8.8: 3D-Struktur von hVDAC1}

Die hVDAC1 Struktur ist in der ribbon Darstellung abgebildet, farbkodiert vom N- zum C-Terminus. Die Zahlen einiger B-Faltblätter sind eingetragen. In (A) ist eine Seitenansicht in (B) eine Aufsicht gewählt. hVDAC1 besteht aus $19 \AA$-Faltblättern und einer $\mathrm{N}$-terminalen $\alpha$-Helix.

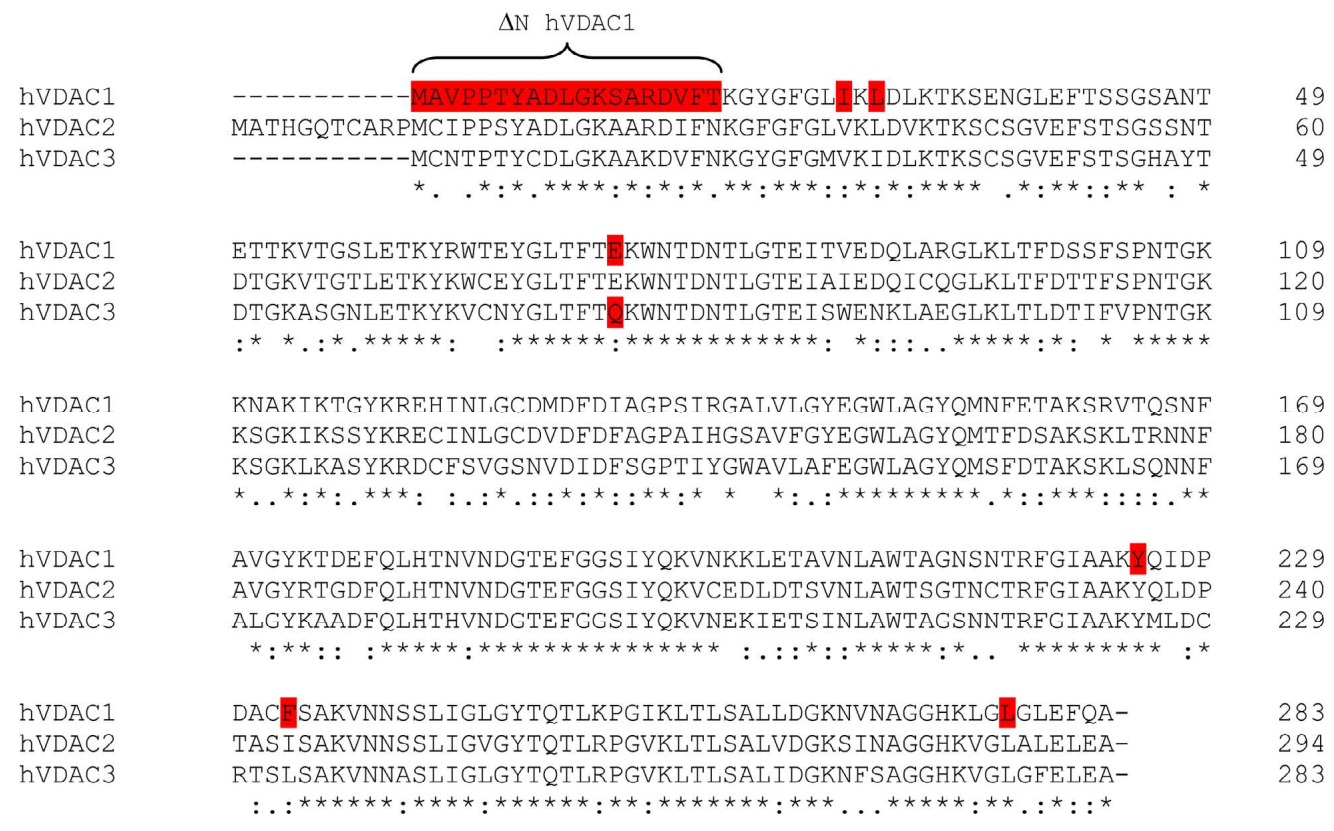

\section{Abbildung 8.9: Aminosäure-Sequenz-Vergleich der drei hVDAC-Isoformen}

In rot hervorgehoben sind die in dieser Arbeit durchgeführten Aminosäureaustausche bzw. Deletionen. Hierzu gehören für hVDAC1 die Deletion des N-Terminus sowie die folgenden Aminosäureaustausche: I27A, L29A, Y225A, Y247A, L277A, F233A und E73Q. Bei hVDAC3 wurde der Aminosäureaustausch Q73E durchgeführt. ${ }^{*}=$ identische Aminosäuren, $:=$ konservierter Austausch,.$=$ semi-konservierter Austausch 


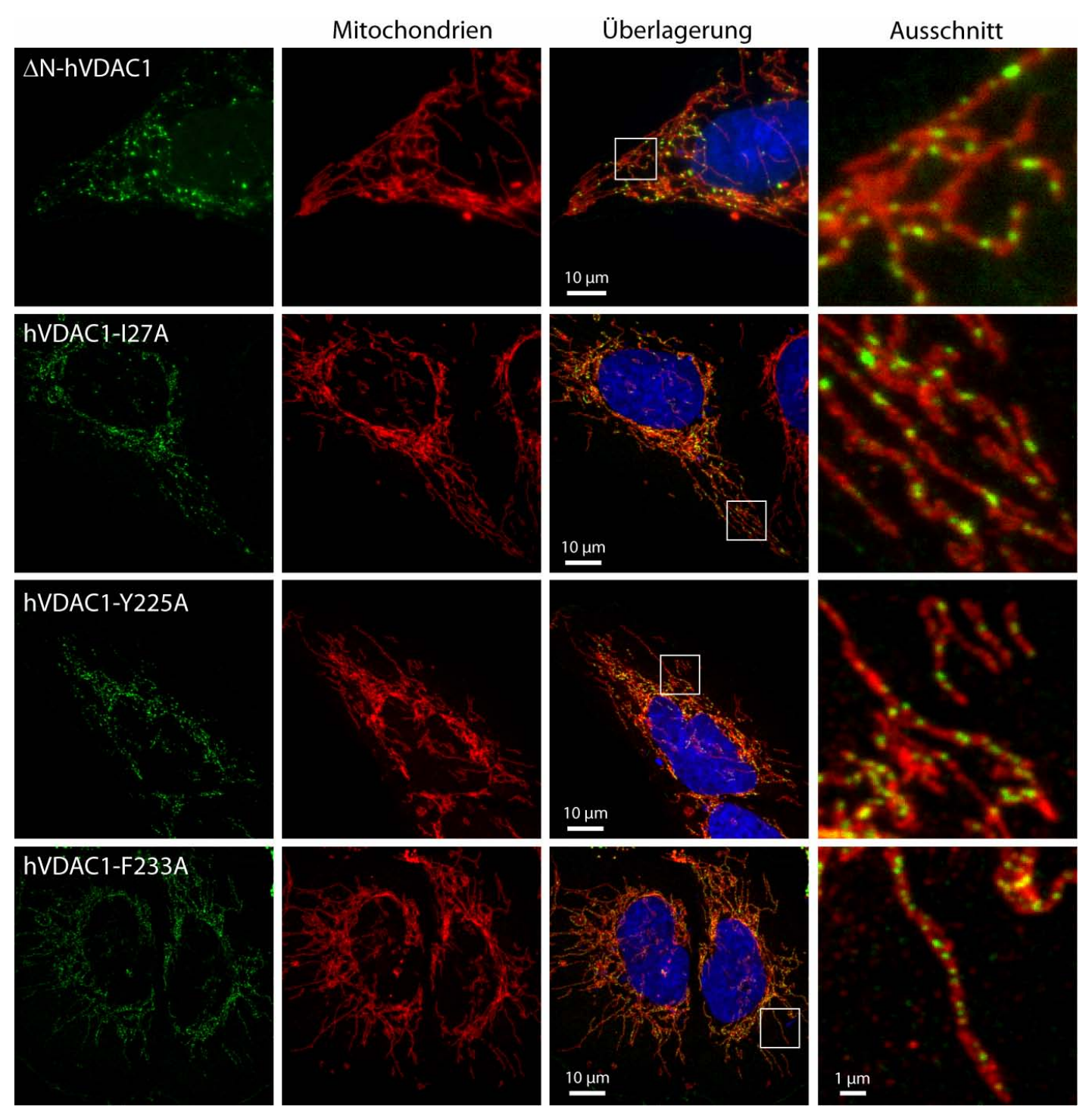

Abbildung 8.10A: Lokalisationsstudien zu den Aminosäureaustauschen von hVDAC1

Es wurden verschiedene Aminosäureaustausche bei hVDAC1 durchgeführt und deren Lokalisation wurde unter Verwendung eines Flag-Antikörpers (grün) im EpifluoreszenzMikroskop analysiert. Als mitochondrialer Marker wurde Hexokinase-I (rot) verwendet. Die Zellkerne (blau) wurden mit DAPI gefärbt. Sowohl für die Deletion des N-Terminus, als auch für die Aminosäureaustausche I27A, Y225A und F233A konnte keine veränderte submitochondriale Lokalisation beobachtet werden. 

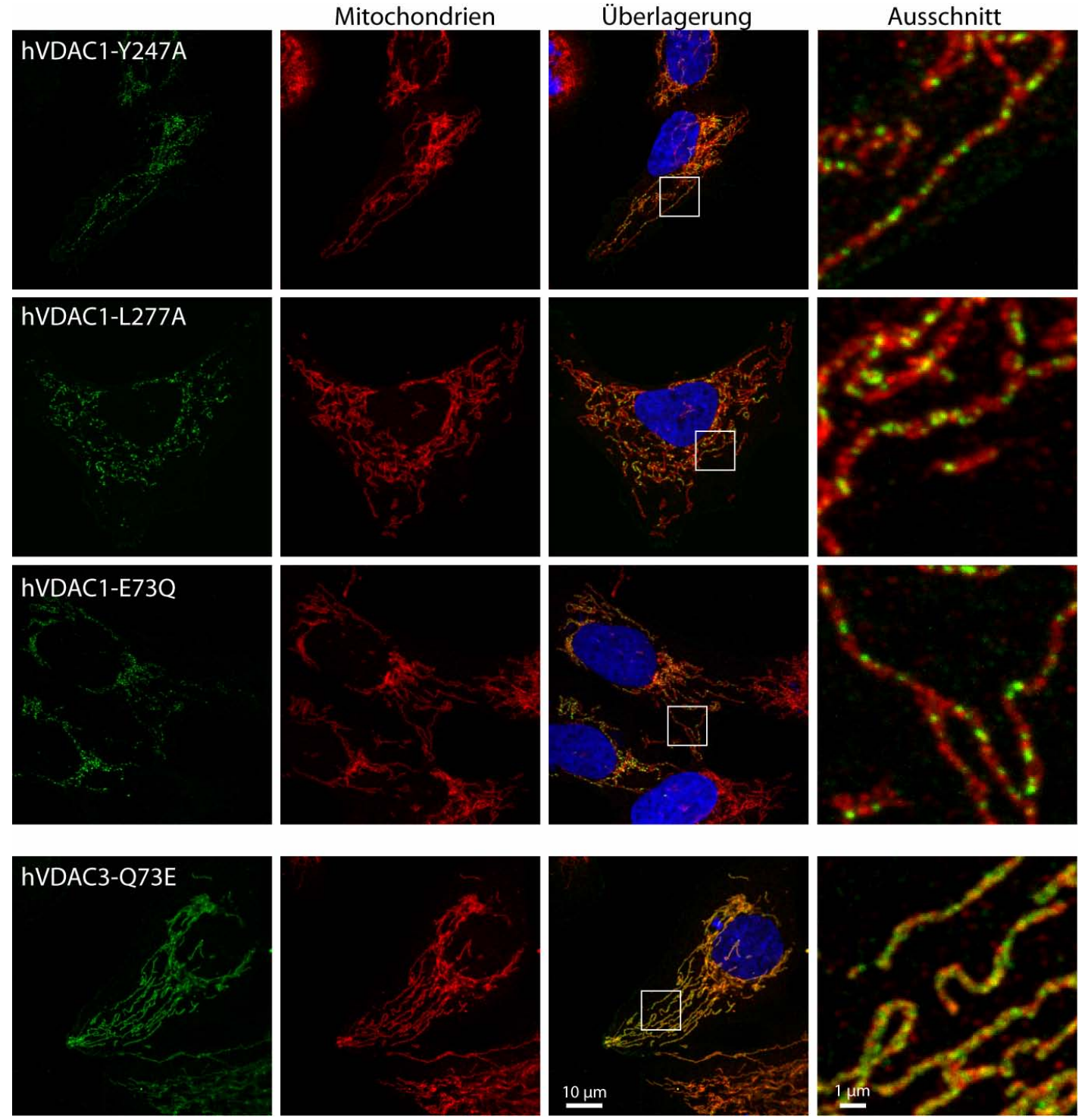

Abbildung 8.10B: Lokalisationsstudien zu den Aminosäureaustauschen von hVDAC1 und hVDAC3

Es wurden verschiedene Aminosäureaustausche bei hVDAC1 bzw. hVDAC3 durchgeführt und deren Lokalisation wurde unter Verwendung eines Flag-Antikörpers (grün) im EpifluoreszenzMikroskop analysiert. Als mitochondrialer Marker wurde Hexokinase-I (rot) verwendet. Die Zellkerne (blau) wurden mit DAPI gefärbt. Für die Aminosäureaustausche Y247A, L277A, E73Q bei hVDAC1 als auch für den Aminosäureaustausch Q73E bei hVDAC3 konnte keine Änderung in der sub-mitochondrialen Lokalisation beobachtet werden. 

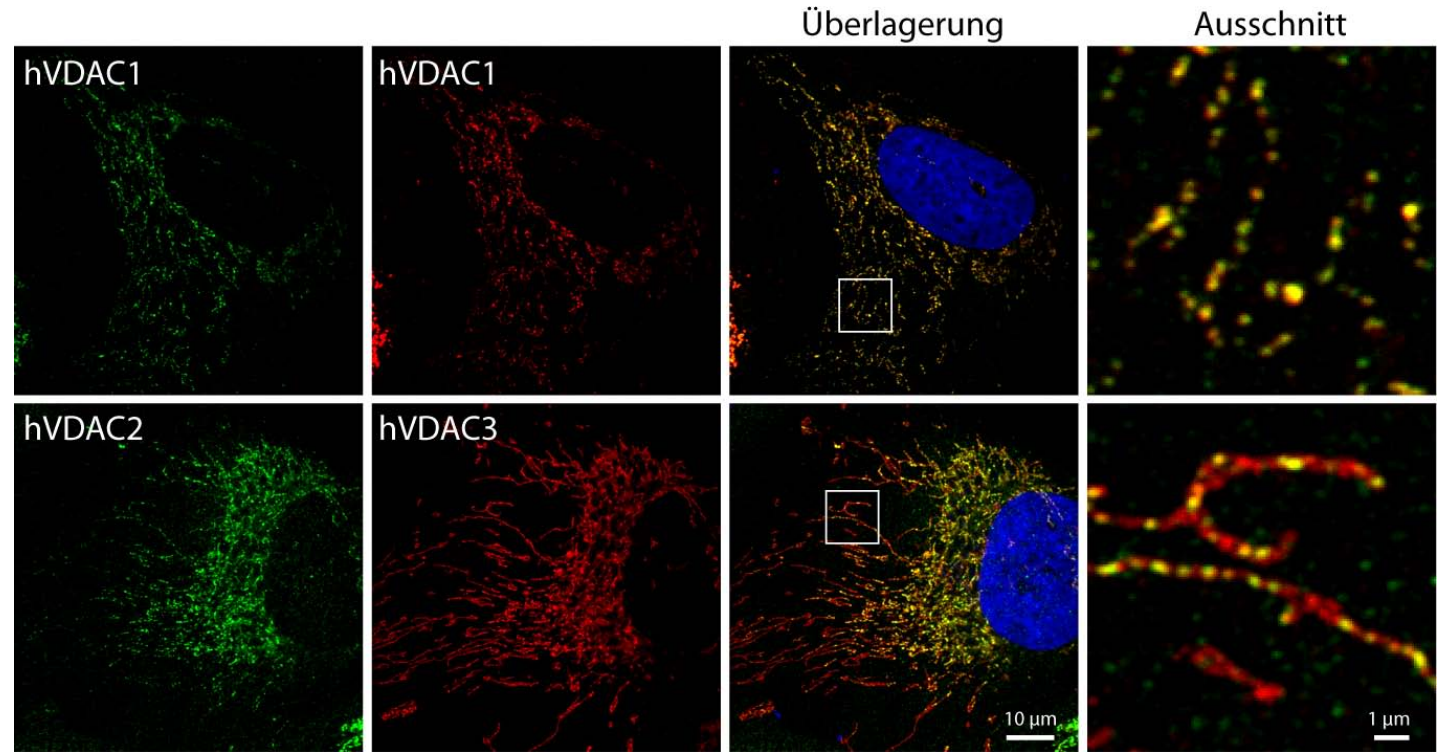

\section{Abbildung 8.11: Kolokalisationsstudien zu den hVDAC-Isoformen}

U2OS-Zellen, die zwei hVDAC-Isoformen exprimierten, wurden mit Antikörpern gegen den Flag-Tag und den V5-Tag inkubiert und im Anschluss konfokal-mikroskopisch analysiert. Die Fluoreszenzsignale von hVDAC1-V5 und hVDAC1-Flag überlappen fast vollständig, wohingegen hVDAC2-V5 und hVDAC3-Flag eine deutliche geringe Kolokalisation aufweisen. Die Zellkerne wurden mit DAPI (blau) gefärbt.
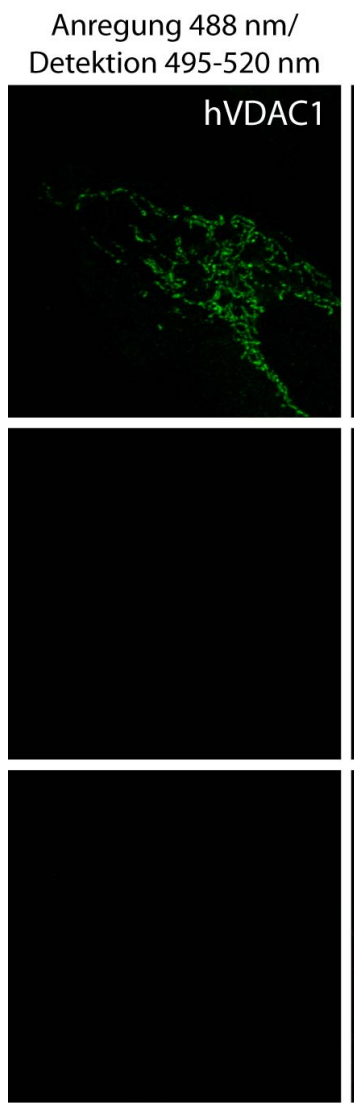

Anregung $561 \mathrm{~nm} /$ Detektion $570-650 \mathrm{~nm}$

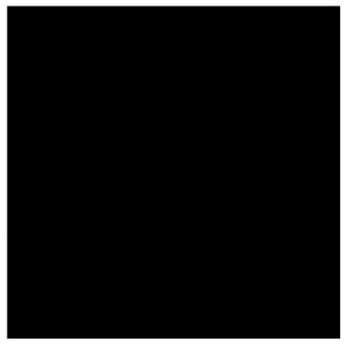

hVDAC2
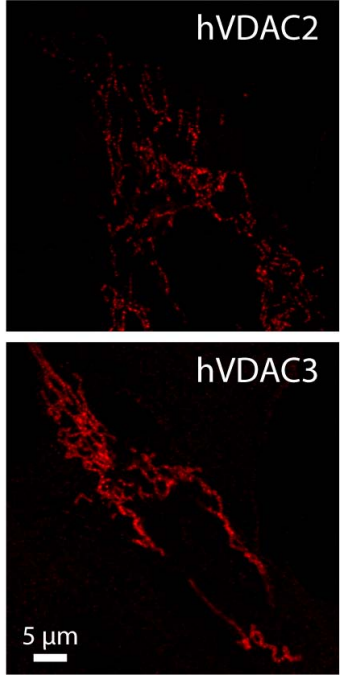

Abbildung 8.12: Crosstalk-Analyse zwischen dem "grünen" und dem "roten" Kanal des konfokalen Mikroskops

Um das Ausmaß an crosstalk zwischen den beiden Detektionskanälen zu bestimmen, wurden U2OS-Zellen wie für eine doppelte Immuno-Markierung behandelt, mit der Ausnahme, dass nur ein primärer und der dazugehörige sekundäre Antikörper verwendet wurden. Es wurden die gleichen Aufnahmeparameter wie für die Aufnahmen mit doppelter Immuno-Markierung verwendet. Dabei konnte kein crosstalk nachgewiesen werden. 
Tabelle 8.2: Kolokalisationsanalyse zwischen den hVDAC-Isoformen basierend auf konfokalen Daten

Analysiert worden ist die Kolokalisation von hVDAC1 mit hVDAC2 bzw. mit hVDAC3. Als Positivkontrolle diente die Kolokalisation von hVDAC1-V5 mit hVDAC1-Flag. Bestimmt wurden der Pearson's Korrelationskoeffizient $r_{\mathrm{p}}$, der Überlappungskoeffizient $r$ und die Kolokalisationskoeffizienten $M_{1}$ und $M_{2}$. Die Fehlerbalken stellen die Standardabweichungen von zehn Aufnahmen dar. Die Daten sind in der Abbildung 4.7 graphisch dargestellt.

\begin{tabular}{|c|c|c|cc|}
\hline Proteine & $\begin{array}{c}\text { Pearson's Korrelations- } \\
\text { koeffizient } \\
r_{p}\end{array}$ & $\begin{array}{c}\text { Überlappungs- } \\
\text { koeffizient } \\
r\end{array}$ & \multicolumn{2}{|c|}{$\begin{array}{c}\text { Kolokalisationskoeffizienten } \\
M_{1}\end{array}$} \\
\hline hVDAC1/hVDAC1 & $0,899 \pm 0,021$ & $0,905 \pm 0,019$ & $0,818 \pm 0,068$ & $0,903 \pm 0,032$ \\
hVDAC1/hVDAC2 & $0,889 \pm 0,035$ & $0,893 \pm 0,034$ & $0,864 \pm 0,070$ & $0,829 \pm 0,068$ \\
hVDAC1/hVDAC3 & $0,770 \pm 0,044$ & $0,784 \pm 0,041$ & $0,924 \pm 0,055$ & $0,662 \pm 0,086$ \\
\hline
\end{tabular}

\section{Tabelle 8.3: Domänen- und Clusterdurchmesser der hVDAC-Isoformen und der Hexokinase-I (STED-Aufnahmen)}

Um den Durchmesser von hVDAC1 und hVDAC2 Domänen zu bestimmen, wurde für jeweils vier STED-Aufnahmen der Durchmesser von sechs Domänen manuell bestimt. Der jeweils kleinste und größte Wert sowie der Mittelwert und die Standardabweichung (Stdev) wurden bestimmt. Alle Angaben sind in $\mu \mathrm{m}$. Die kleinste gemessene VDAC-Domäne hatte einen Durchmesser von $67 \mu \mathrm{m}$ und die größe einen Durchmesser von $336 \mu \mathrm{m}$. Der mittlere Domänendurchmesser lag für hVDAC1 bei 151,3 $\pm 54,1 \mu \mathrm{m}$ und für hVDAC2 bei $151,5 \pm 61,9 \mu \mathrm{m}$. Für hVDAC3 variierte der Clusterdurchmesser von 44-98 $\mu \mathrm{m}$ mit einem mittleren Durchmesser von 67,7 $\mu \mathrm{m} \pm 13,8 \mu \mathrm{m}$. Für Hexokinase-I wurde Clusterdurchmesser von 43-90 $\mu \mathrm{m}$ bestimmt, wobei sich ein mittlerer Durchmesser von $67,8 \mu \mathrm{m} \pm 11,8 \mu \mathrm{m}$ ergab. $\mathrm{Zu}$ beachten ist, dass die Angaben zu Clusterdurchmessern inklusive der Länge der verwendeten Antikörpern sind.

\begin{tabular}{|c|c|c|c|c|c|c|c|c|c|c|c|c|c|c|c|}
\hline & & & $\begin{array}{l}\text { einz } \\
\text { durc }\end{array}$ & $\begin{array}{l}\text { elne } \\
\text { chme }\end{array}$ & omä & $\begin{array}{l}\text { nen- } \\
\mu \mathrm{m})\end{array}$ & & kl. Wert & gr. Wert & $\begin{array}{c}\text { Mittel- } \\
\text { wert }\end{array}$ & Stdev & kl. Wert & gr. Wert & $\begin{array}{c}\text { Mittel- } \\
\text { wert }\end{array}$ & Stdev \\
\hline \multirow{4}{*}{ hVDAC1 } & 1. Aufnahme & 97 & 107 & 203 & 165 & 112 & 199 & 97 & 203 & 147,2 & 47,9 & \multirow{4}{*}{71} & \multirow{4}{*}{274} & \multirow{4}{*}{151,3} & \multirow{4}{*}{54,1} \\
\hline & 2. Aufnahme & 141 & 167 & 186 & 71 & 274 & 133 & 71 & 274 & 162,0 & 67,4 & & & & \\
\hline & 3. Aufnahme & 119 & 89 & 250 & 152 & 113 & 139 & 89 & 250 & 143,7 & 56,5 & & & & \\
\hline & 4. Aufnahme & 101 & 180 & 255 & 120 & 135 & 123 & 101 & 255 & 152,3 & 56,8 & & & & \\
\hline \multirow{4}{*}{ hVDAC2 } & 1. Aufnahme & 124 & 67 & 79 & 172 & 129 & 117 & 67 & 172 & 114,7 & 37,8 & \multirow{4}{*}{67} & \multirow{4}{*}{336} & \multirow{4}{*}{151,5} & \multirow{4}{*}{61,9} \\
\hline & 2. Aufnahme & 118 & 213 & 127 & 189 & 157 & 86 & 86 & 213 & 148,3 & 47,3 & & & & \\
\hline & 3. Aufnahme & 336 & 248 & 215 & 180 & 115 & 185 & 115 & 336 & 213,2 & 74,6 & & & & \\
\hline & 4. Aufnahme & 116 & 107 & 137 & 119 & 207 & 93 & 93 & 207 & 129,8 & 40,5 & & & & \\
\hline \multirow{4}{*}{ hVDAC3 } & 1. Aufnahme & 89 & 48 & 73 & 80 & 44 & 61 & 44 & 89 & 65,8 & 17,9 & \multirow{4}{*}{44} & \multirow{4}{*}{98} & \multirow{4}{*}{67,7} & \multirow{4}{*}{13,8} \\
\hline & 2. Aufnahme & 51 & 98 & 56 & 71 & 58 & 91 & 51 & 98 & 70,8 & 19,6 & & & & \\
\hline & 3. Aufnahme & 75 & 65 & 73 & 72 & 72 & 56 & 56 & 75 & 68,8 & 7,1 & & & & \\
\hline & 4. Aufnahme & 59 & 52 & 69 & 81 & 67 & 63 & 52 & 81 & 65,2 & 9,8 & & & & \\
\hline \multirow{4}{*}{ Hexokinase-I } & 1. Aufnahme & 70 & 77 & 59 & 43 & 53 & 89 & 43 & 89 & 65,2 & 16,8 & \multirow{4}{*}{43} & \multirow{4}{*}{90} & \multirow{4}{*}{67,8} & \multirow{4}{*}{11,3} \\
\hline & 2. Aufnahme & 69 & 74 & 71 & 72 & 68 & 85 & 68 & 85 & 73,2 & 6,2 & & & & \\
\hline & 3. Aufnahme & 54 & 71 & 61 & 71 & 56 & 56 & 54 & 71 & 61,5 & 7,7 & & & & \\
\hline & 4. Aufnahme & 74 & 61 & 72 & 64 & 66 & 90 & 61 & 90 & 71,2 & 10,4 & & & & \\
\hline
\end{tabular}


Tabelle 8.4: Kolokalisationsanalyse zwischen der Hexokinase-I und den hVDACIsoformen basierend auf STED Daten

Analysiert worden ist die Kolokalisation der Hexokinase-I mit hVDAC1, hVDAC2 und hVDAC3. Als Positivkontrollen wurden einerseits mit hVDAC1-V5 mit hVDAC1-Flag Plasmiden transfizierte Zellen verwendet. Andererseits wurde eine Hexokinase-I-Antikörper-Markierung durchgeführt, in der sekundäre und tertiäre Antikörper verwendet wurden, an die zwei unterschiedliche Flurophore (KK114, Atto590) gekoppelt waren. Dargestellt sind die Werte des Pearson's Korrelationskoeffizient $r_{\mathrm{p}}$, des Überlappungskoeffizienten $r$ und der Kolokalisationskoeffizienten $M_{1}$ und $M_{2}$. Die angegebenen Fehler entsprechen der Standardabweichung. Die einzelnen Werte sind der Abbildung 4.11 graphisch dargestellt.

\begin{tabular}{|c|c|c|cc|}
\hline Proteine & $\begin{array}{c}\text { Pearson's Korrelations- } \\
\text { koeffizient } \\
r_{p}\end{array}$ & $\begin{array}{c}\text { Überlappungs- } \\
\text { koeffizient } \\
r\end{array}$ & \multicolumn{2}{|c|}{ Kolokalisationskoeffizienten } \\
$M_{1}$ & $M_{2}$ \\
\hline hVDAC1/Hexokinase-I & $0,452 \pm 0,060$ & $0,497 \pm 0,058$ & $0,756 \pm 0,058$ & $0,521 \pm 0,076$ \\
hVDAC2/Hexokinase-I & $0,463 \pm 0,053$ & $0,490 \pm 0,056$ & $0,785 \pm 0,031$ & $0,517 \pm 0,067$ \\
hVDAC3/Hexokinase-I & $0,657 \pm 0,051$ & $0,711 \pm 0,047$ & $0,800 \pm 0,067$ & $0,810 \pm 0,050$ \\
Hexokinase-1/Hexokinase-I & $0,811 \pm 0,039$ & $0,842 \pm 0,033$ & $0,801 \pm 0,049$ & $0,916 \pm 0,016$ \\
hVDAC1/hVDAC1 & $0,834 \pm 0,038$ & $0,846 \pm 0,035$ & $0,838 \pm 0,042$ & $0,814 \pm 0,074$ \\
\hline
\end{tabular}




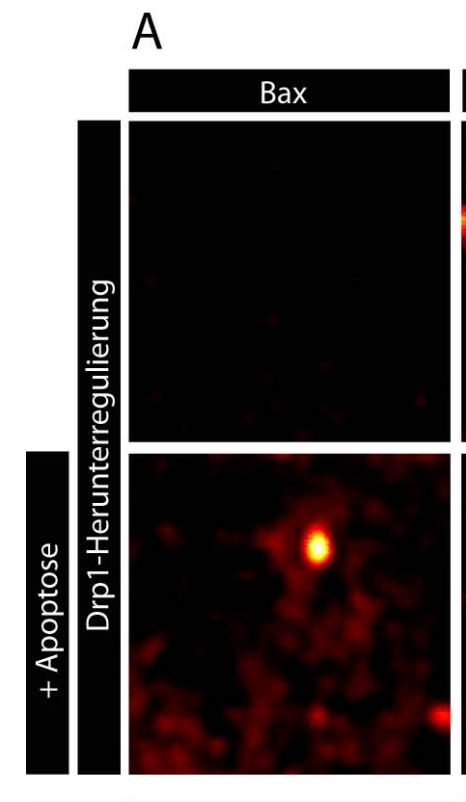

B
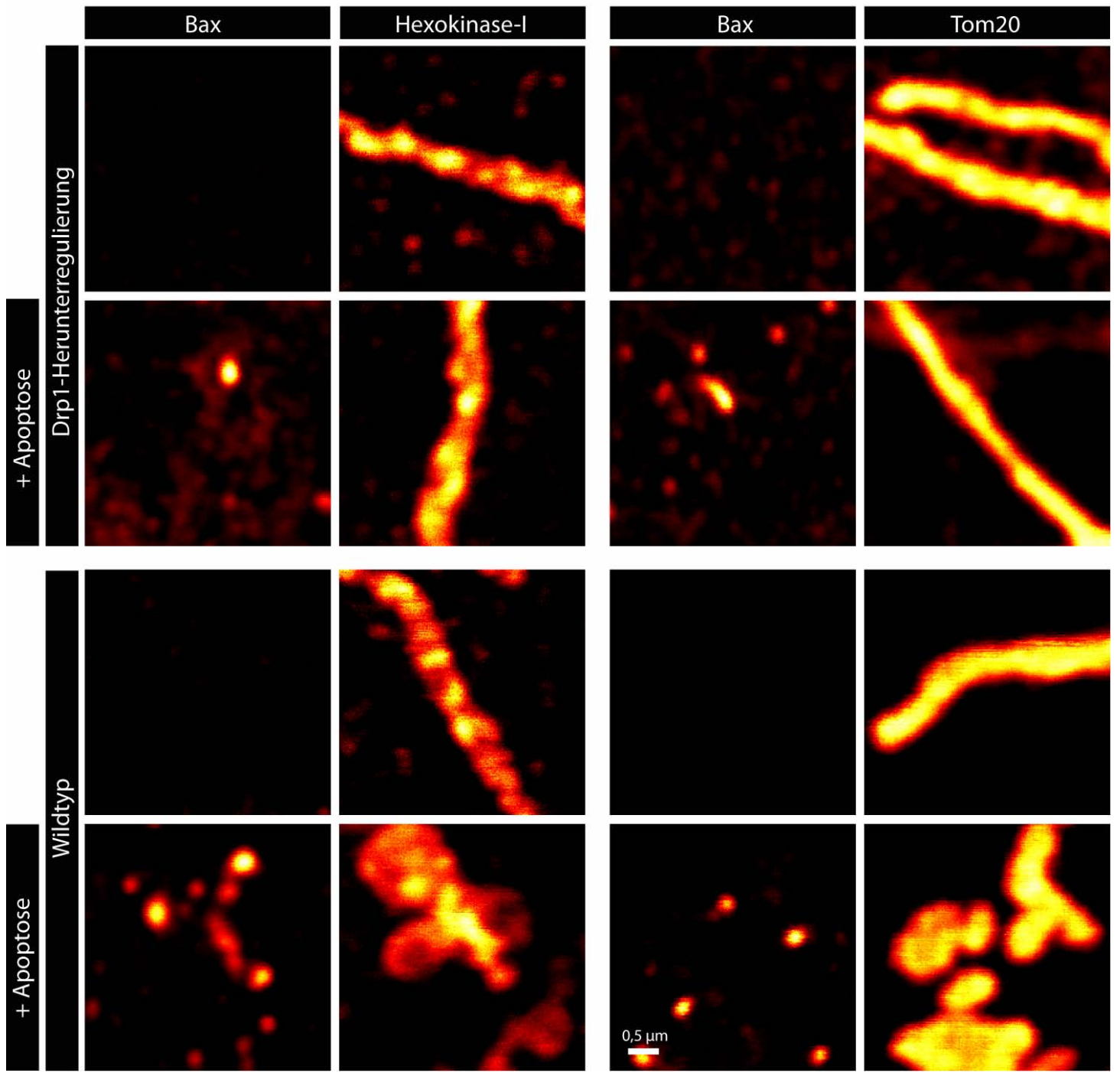

Abbildung 8.13: Konfokal-mikroskopische Aufnahmen von Hexokinase-I (A) und Tom20 (B), korrespondierend zu den STED-Aufnahmen in Abbildung 4.22

Dargestellt sind die, korrespondierend zu den STED-Aufnahmen in Abbildung 4.22, konfokalmikroskopischen Aufnahmen der Hexokinase-I (A) und Tom20 (B). Zur Charakterisierung des apoptotischen Status der Zellen ist eine Bax-Aktivierung durch Verwendung eines Baxspezifischen Antikörpers (erkennt nur aktiviertes Bax) gezeigt. In apoptotischen Wildtyp-Zellen sind fragmentierte Mitochondrien zu erkennen, wohingegen in apoptotischen Drp1herunterregulierten Zellen die Mitochondrien weiterhin eine tubuläre Morphologie aufweisen. 

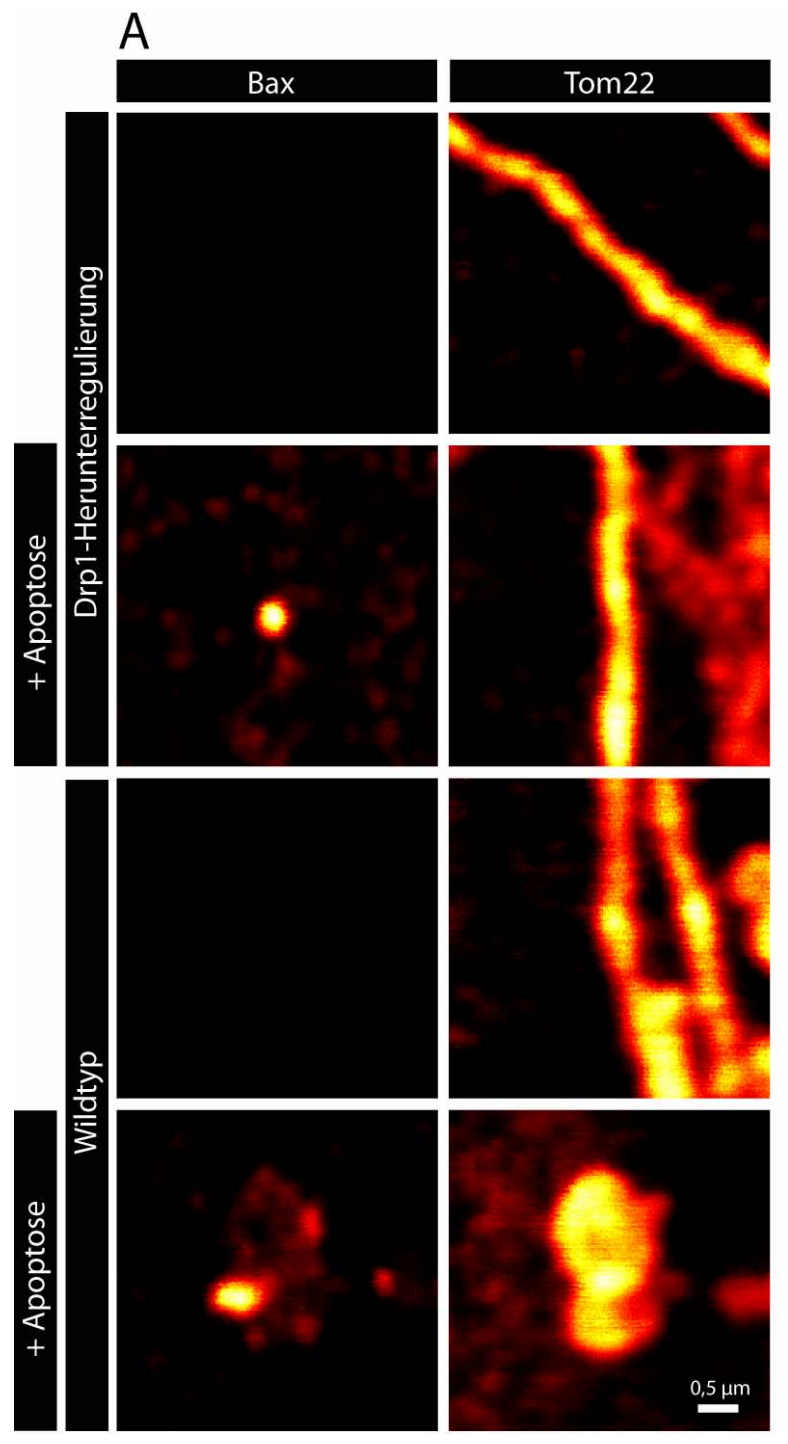

B
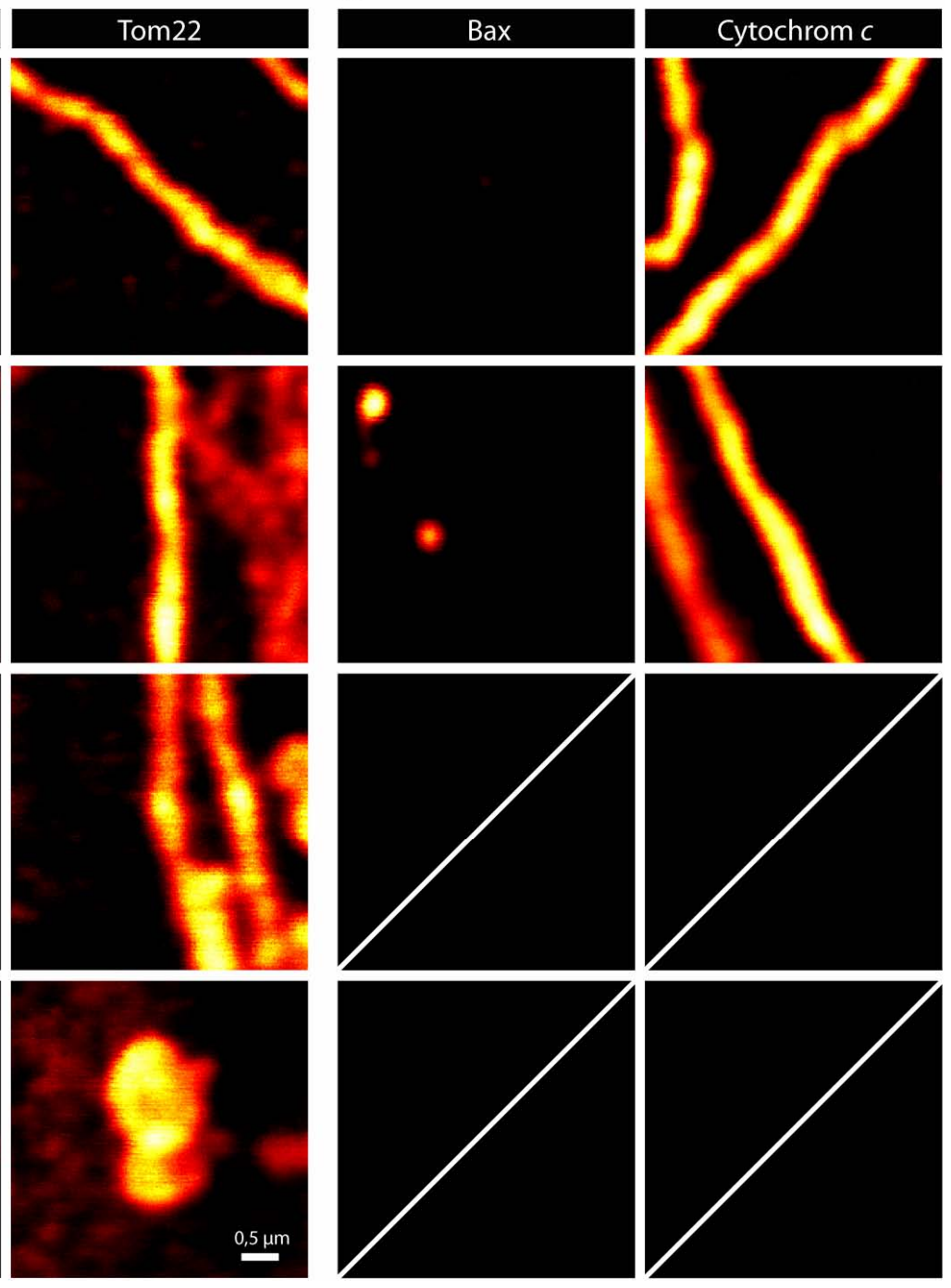

Abbildung 8.14: Konfokal-mikroskopische Aufnahmen von Tom22 (A) und Cytochrom $c$ (B), korrespondierend zu den STED-Aufnahmen in Abbildung 4.22

Dargestellt sind die, korrespondierend zu den STED-Aufnahmen in Abbildung 4.22, konfokalmikroskopischen Aufnahmen von Tom22 (A) und Cytochrom $c$ (B). Zur Charakterisierung des apoptotischen Status der Zellen ist eine Bax-Aktivierung durch Verwendung eines Baxspezifischen Antikörpers (erkennt nur aktiviertes Bax) gezeigt. In apoptotischen Wildtyp-Zellen sind fragmentierte Mitochondrien zu erkennen, wohingegen in apoptotischen Drp1herunterregulierten Zellen die Mitochondrien weiterhin eine tubuläre Morphologie aufweisen. Die Verteilung von Cytochrom $c$ wurde nur in Drp1-herunterregulierten Zellen untersucht, da es in Wildtyp-Zellen bei Bax-Aktivierung sehr häufig schon freigesetzt ist. 


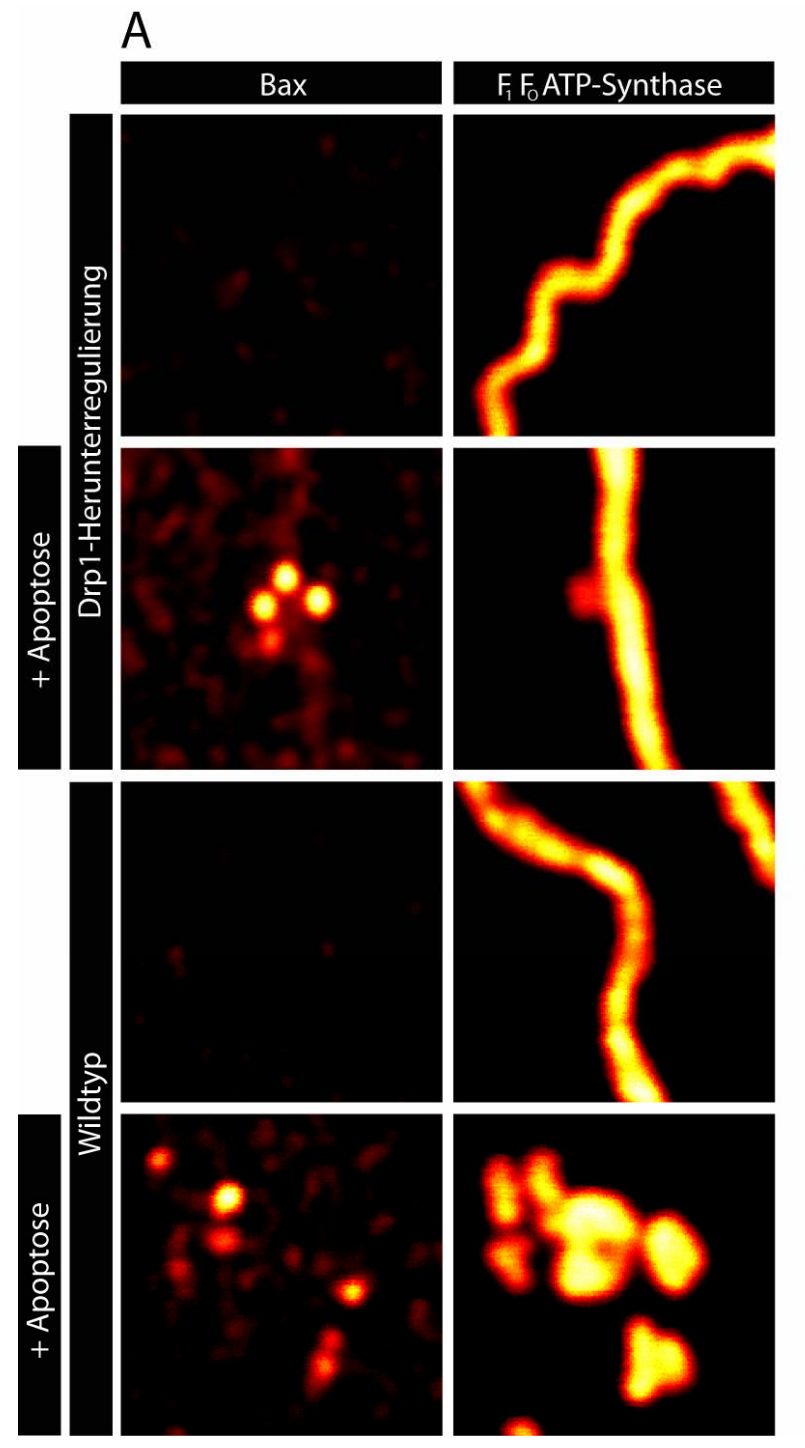

B

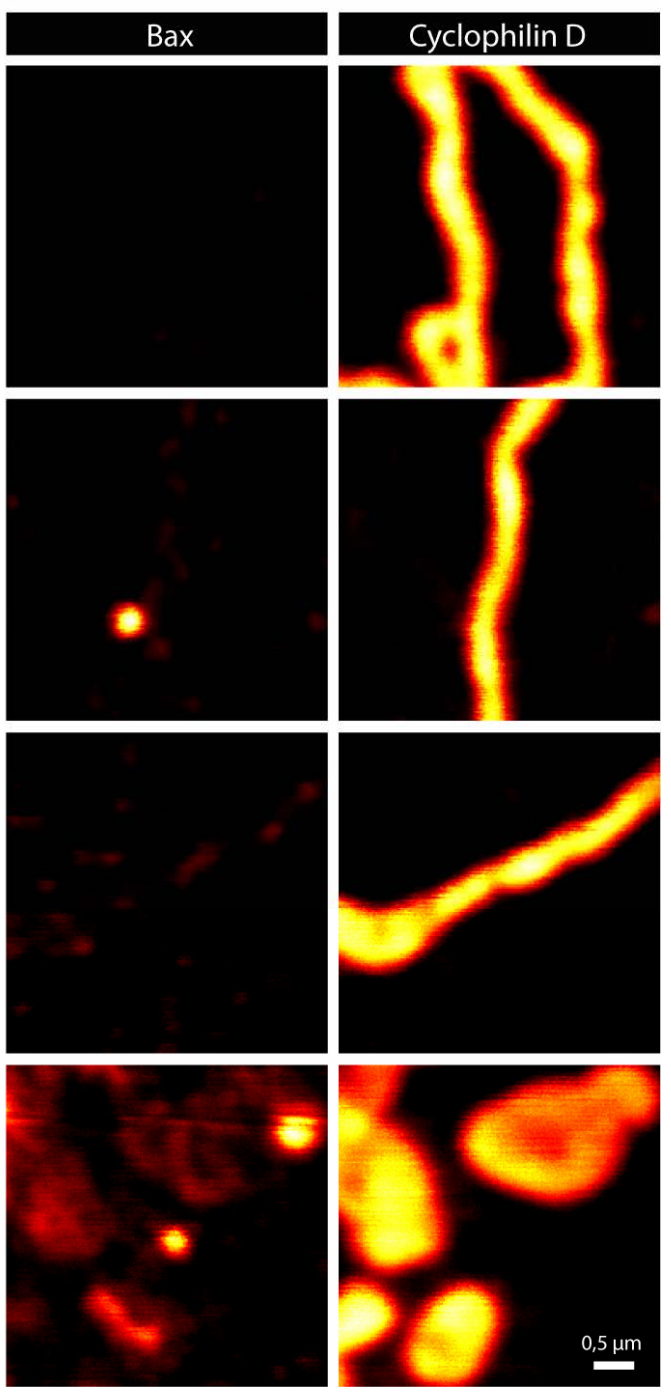

Abbildung 8.15: Konfokal-mikroskopische Aufnahmen von $F_{1} F_{0} A T P-S y n t h a s e$ (A) und Cyclophilin D (B), korrespondierend zu den STED-Aufnahmen in Abbildung 4.22

Dargestellt sind die, korrespondierend zu den STED-Aufnahmen in Abbildung 4.22, konfokalmikroskopischen Aufnahmen der F1FoATP-Synthase (A) und Cyclophilin D (B). Zur Charakterisierung des apoptotischen Status der Zellen ist eine Bax-Aktivierung durch Verwendung eines Bax-spezifischen Antikörpers (erkennt nur aktiviertes Bax) gezeigt. In apoptotischen Wildtyp-Zellen sind fragmentierte Mitochondrien zu erkennen, wohingegen in apoptotischen Drp1-herunterregulierten Zellen die Mitochondrien weiterhin eine tubuläre Morphologie aufweisen. 

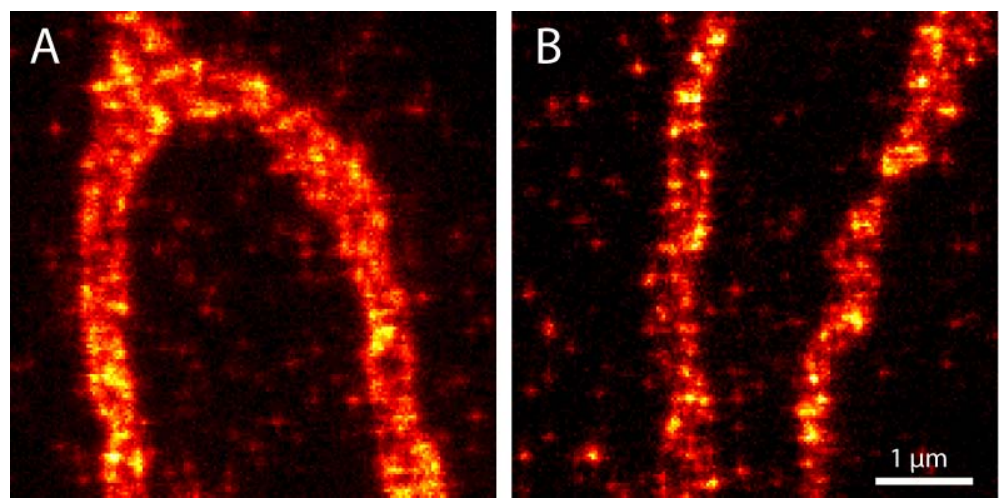

\section{Abbildung 8.16: Variabilität in der sub-mitochondrialen Proteinverteilung}

Fixierte U2OS-Zellen wurden mit Antikörpern gegen die Hexokinase-I inkubiert und im Anschluss mit einem kommerziellen STED-Mikroskop analysiert. Es ist deutlich zu erkennen, dass in Abhängigkeit von der aufgenommenen Region die Hexokinase-I dichter (A) oder dünner (B) verteilt ist. Aufgrund dieser Streuung zwischen den einzelnen Aufnahmen war die quantiative Analyse eines größeren Datensatzes nötig, um genaue Aussagen über submitochondriale Proteinverteilungen und mögliche Änderungen während der Apoptose treffen zu können. 


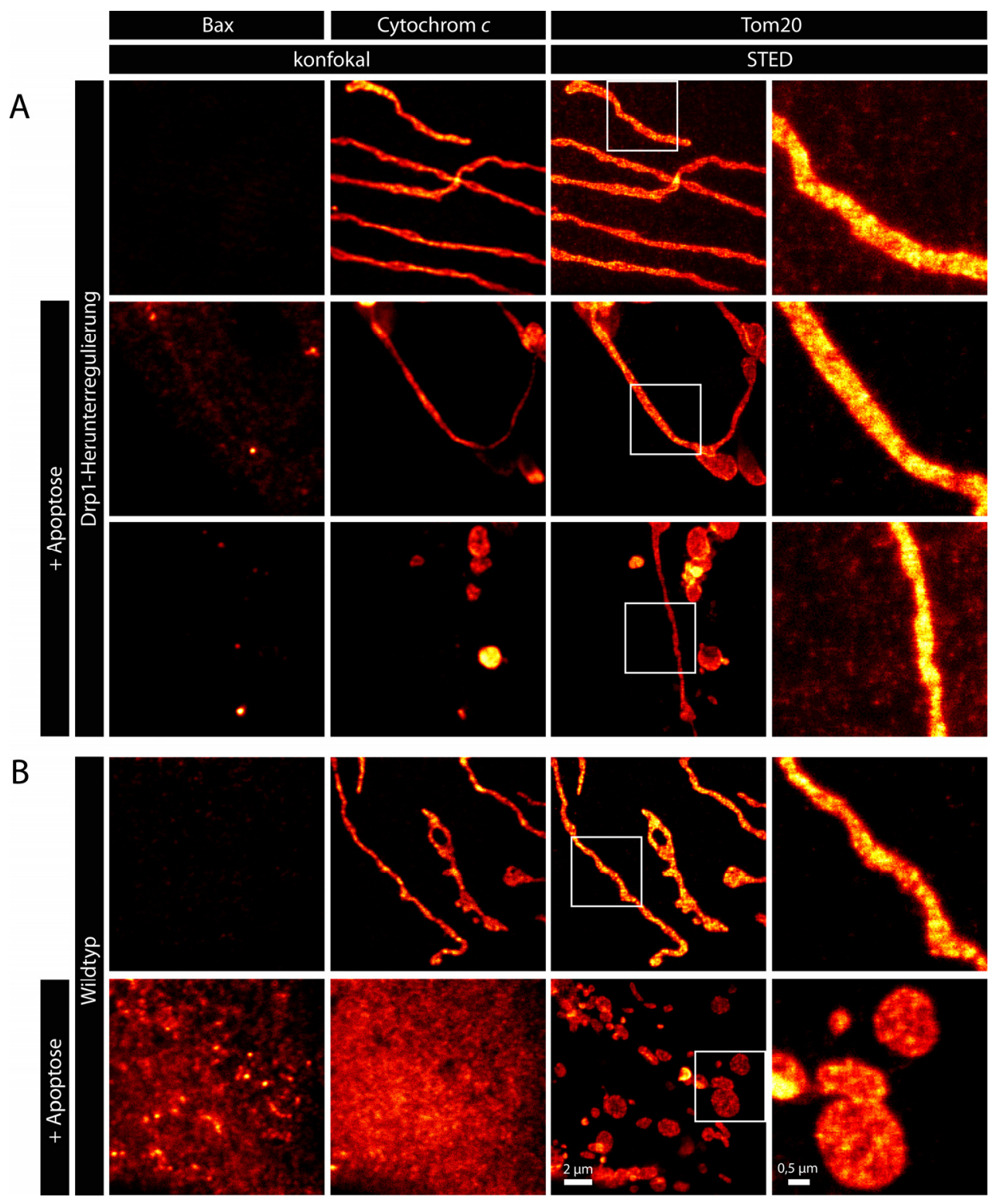

Abbildung 8.17: STED-Aufnahmen von der sub-mitochondrialen Verteilung von Tom20 in unbehandelten und apoptotischen Zellen

Unbehandelte oder mit Actinomycin D behandelte Drp1-herunterregulierte (A) und Wildtyp (B) -Zellen wurden mit Antikörpern gegen Bax, Cytochrom $c$ und Tom20 inkubiert. Die Bilder wurden an einem kommerziellen Aufbau aufgenommen und zusammen mit vielen Anderen für die quantitative Analyse sub-mitochondrialer Proteinverteilungen verwendet (Abschnitt 4.2.8). Zur Charakterisierung des apoptotischen Status der Zelle wurden die Bax-Aktivierung, Cytochrom $c$-Freisetzung und die mitochondriale Morphologie analysiert. In Bax-aktivierten Wildtyp-Zellen ist Cytochrom $c$ freigesetzt worden und die Mitochondrien sind fragmentiert. In Bax-aktivierten Drp1-herunterregulierten Zellen hingegen sind weiterhin tubuläre Mitochondrien zu erkennen, die entweder kein Cytochrom $c$ freigesetzt oder Cytochrom $c$ freigesetzt haben. 


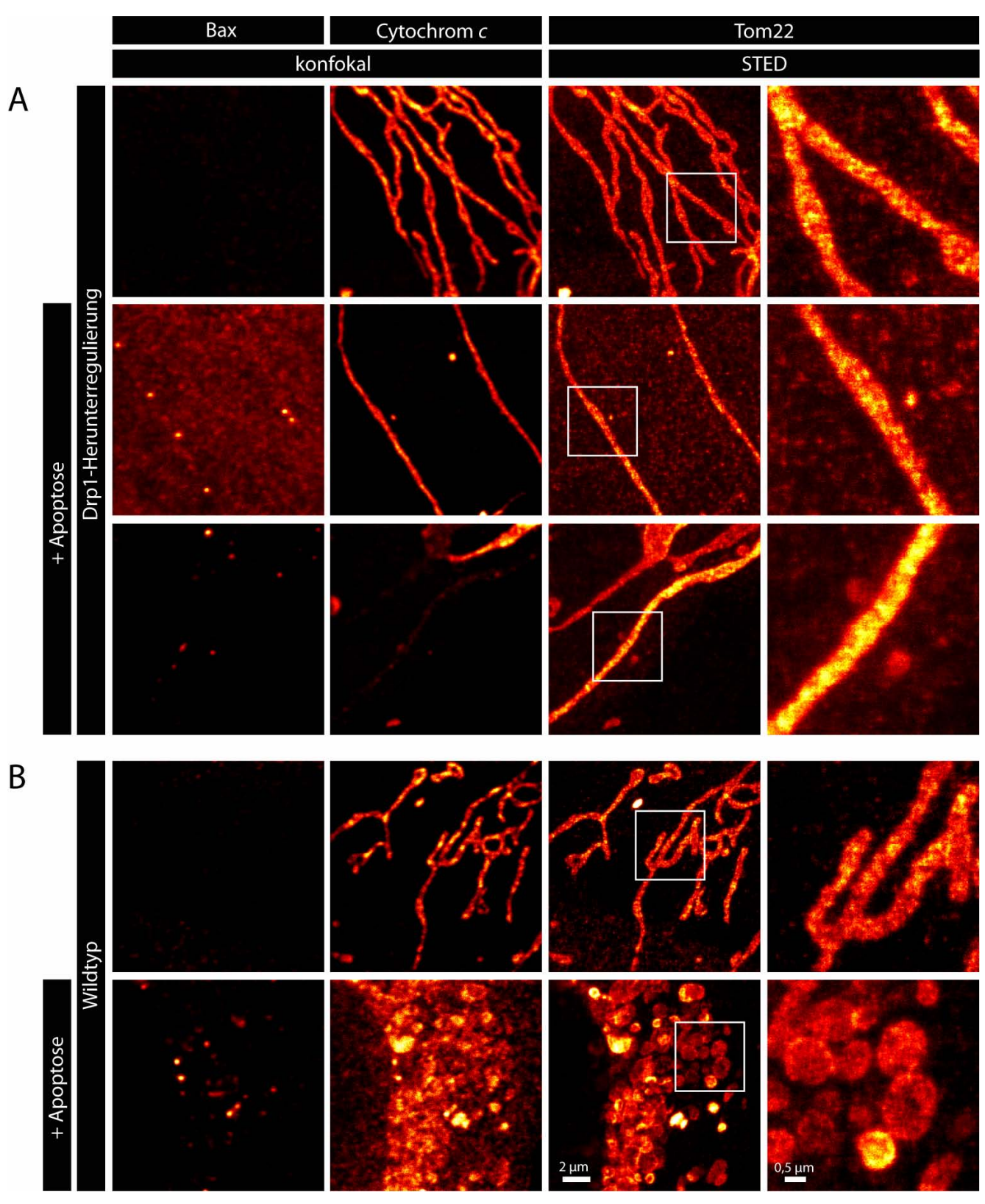

Abbildung 8.18: STED-Aufnahmen von der sub-mitochondrialen Verteilung von Tom22 in unbehandelten und apoptotischen Zellen

Unbehandelte oder mit Actinomycin D behandelte Drp1-herunterregulierte (A) und Wildtyp (B) -Zellen wurden mit Antikörpern gegen Bax, Cytochrom $c$ und Tom22 inkubiert. Die Bilder wurden an einem kommerziellen Aufbau aufgenommen und zusammen mit vielen Anderen für die quantitative Analyse sub-mitochondrialer Proteinverteilungen verwendet (Abschnitt 4.2.8). Zur Charakterisierung des apoptotischen Status der Zelle wurden die BaxAktivierung, Cytochrom $c$-Freisetzung und die mitochondriale Morphologie analysiert. In Bax-aktivierten Wildtyp-Zellen ist Cytochrom $c$ freigesetzt worden und die Mitochondrien sind fragmentiert. In Bax-aktivierten Drp1-herunterregulierten Zellen hingegen sind weiterhin tubuläre Mitochondrien zu erkennen, die entweder kein Cytochrom $c$ freigesetzt oder Cytochrom $c$ freigesetzt haben. 


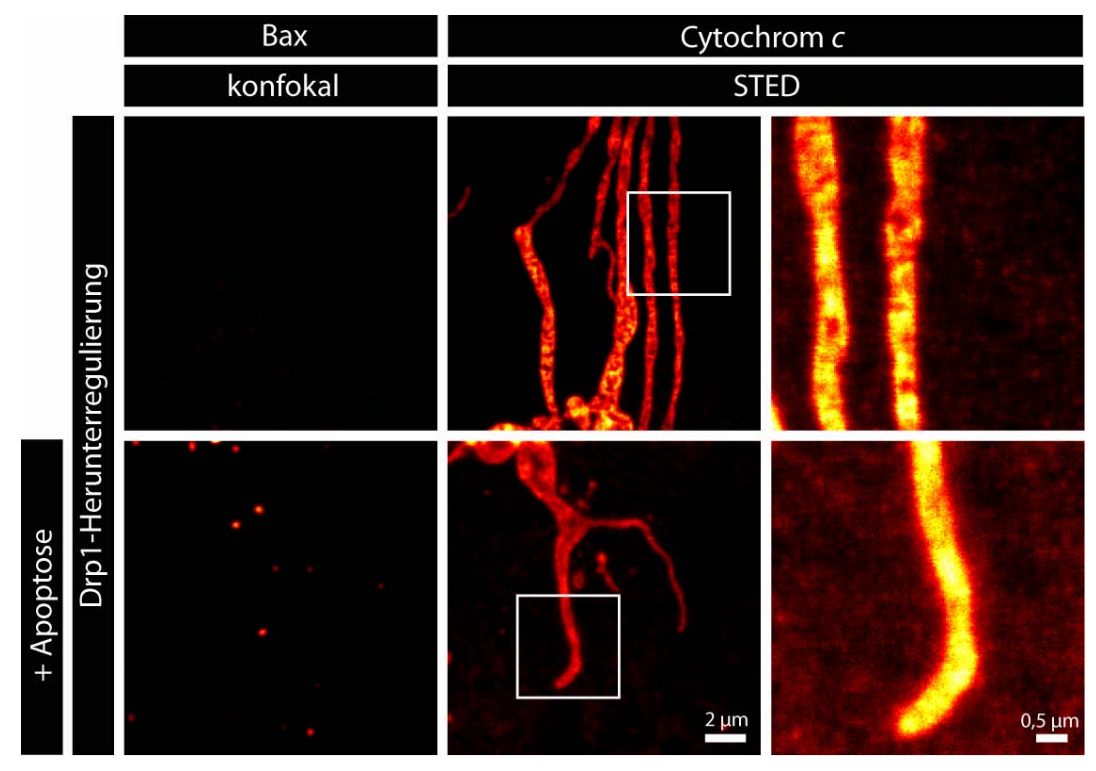

Abbildung 8.19: STED-Aufnahmen von der sub-mitochondrialen Verteilung von Cytochrom $c$ in unbehandelten und apoptotischen Zellen

Unbehandelte oder mit Actinomycin D behandelte Drp1-herunterregulierte U2OS-Zellen wurden mit Antikörpern gegen Bax und Cytochrom $c$ inkubiert. Die Bilder wurden an einem kommerziellen Aufbau aufgenommen und zusammen mit vielen Anderen für die quantitative Analyse sub-mitochondrialer Proteinverteilungen verwendet (Abschnitt 4.2.8). Zur Charakterisierung des apoptotischen Status der Zelle wurden die Bax-Aktivierung, Cytochrom $c^{-}$ Freisetzung und die mitochondriale Morphologie analysiert. In Bax-aktivierten Drp1herunterregulierten Zellen sind tubuläre Mitochondrien zu erkennen, die kein Cytochrom $c$ freigesetzt haben. Es konnten keine Aufnahmen von Cytochrom $c$ in apoptotischen WildtypZellen gemacht werden, da Cytochrom $c$ per Definition unter dieser Bedingung freigesetzt ist. 


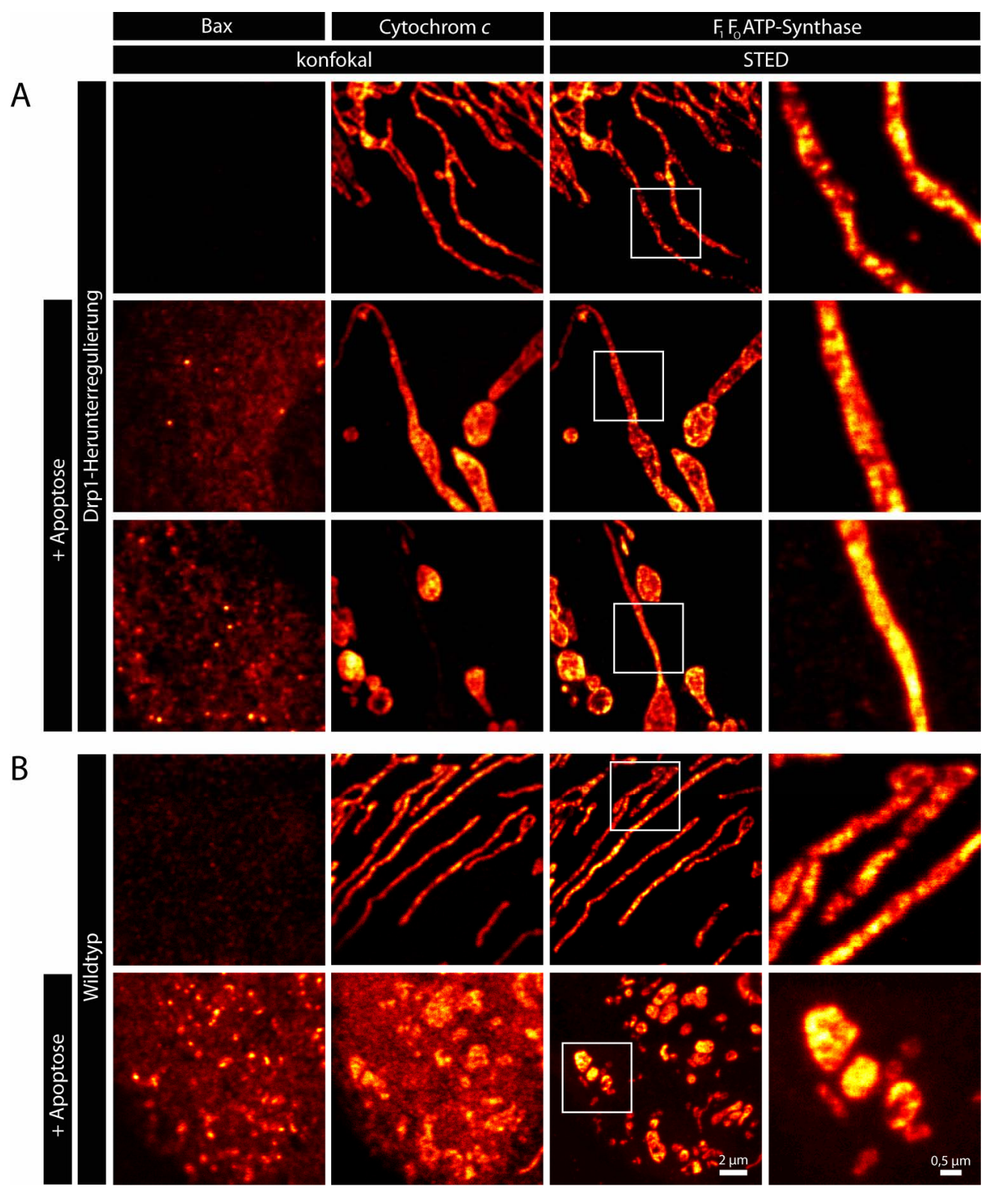

Abbildung 8.20: STED-Aufnahmen von der sub-mitochondrialen Verteilung von $\mathrm{F}_{1}$ FoATP-Synthase in unbehandelten und apoptotischen Zellen

Unbehandelte oder mit Actinomycin D behandelte Drp1-herunterregulierte (A) und Wildtyp (B) -Zellen wurden mit Antikörpern gegen Bax, Cytochrom $c$ und $\mathrm{F}_{1} \mathrm{Fo}_{\mathrm{F}}$-ATP-Synthase inkubiert. Die Bilder wurden an einem kommerziellen Aufbau aufgenommen und zusammen mit vielen Anderen für die quantitative Analyse sub-mitochondrialer Proteinverteilungen verwendet (Abschnitt 4.2.8). Zur Charakterisierung des apoptotischen Status der Zelle wurden die Bax-Aktivierung, Cytochrom $c$-Freisetzung und die mitochondriale Morphologie analysiert. In Bax-aktivierten Wildtyp-Zellen ist Cytochrom $c$ freigesetzt worden und die Mitochondrien sind fragmentiert. In Bax-aktivierten Drp1-herunterregulierten Zellen hingegen sind weiterhin tubuläre Mitochondrien zu erkennen, die entweder kein Cytochrom $c$ freigesetzt oder Cytochrom $c$ freigesetzt haben. 


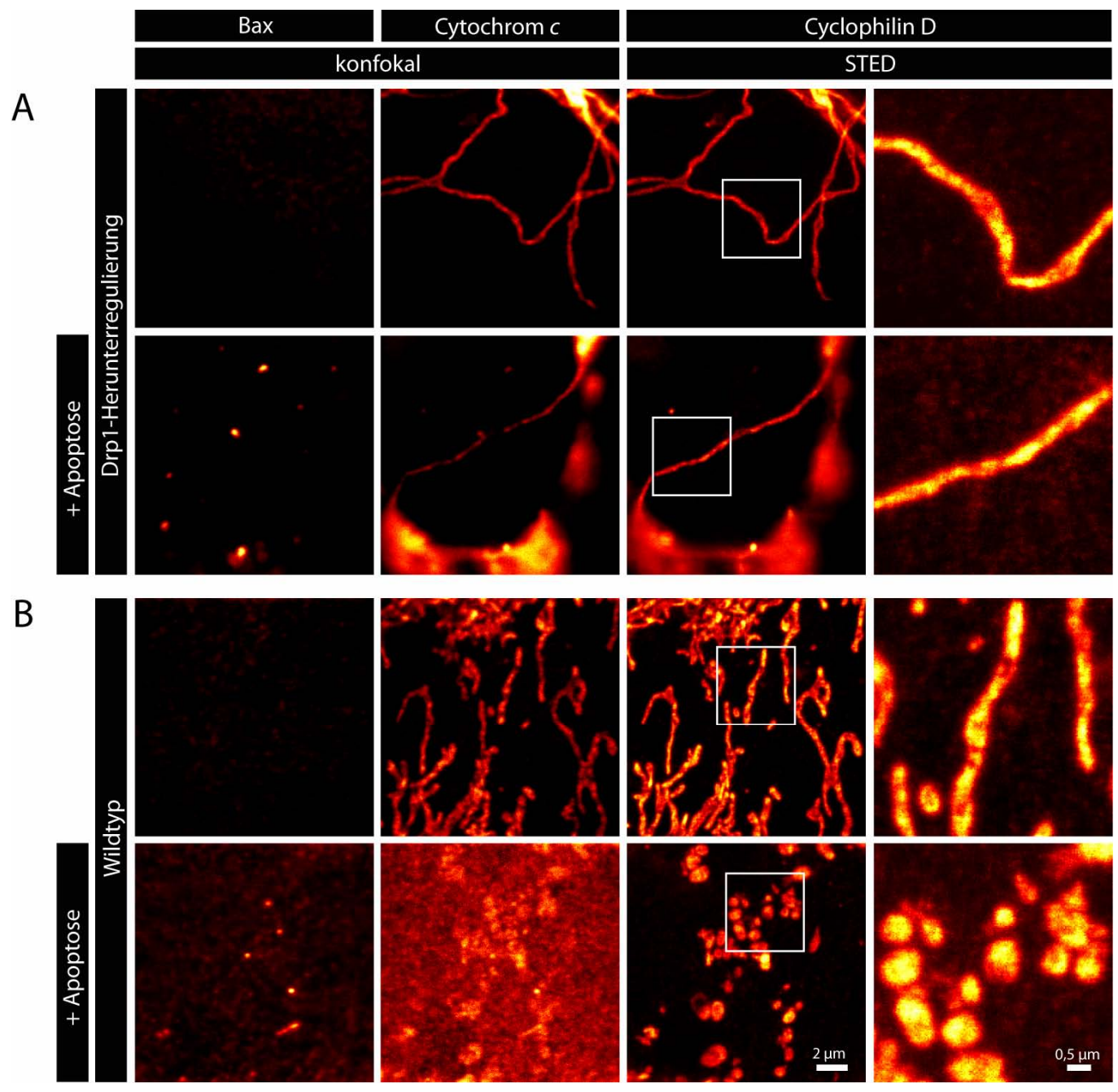

Abbildung 8.21: STED-Aufnahmen von der sub-mitochondrialen Verteilung von Cyclophilin D in unbehandelten und apoptotischen Zellen

Unbehandelte oder mit Actinomycin D behandelte Drp1-herunterregulierte (A) und Wildtyp (B) -Zellen wurden mit Antikörpern gegen Bax, Cytochrom $c$ und Cyclophilin D inkubiert. Die Bilder wurden an einem kommerziellen Aufbau aufgenommen und zusammen mit vielen Anderen für die quantitative Analyse sub-mitochondrialer Proteinverteilungen verwendet (Abschnitt 4.2.8). Zur Charakterisierung des apoptotischen Status der Zelle wurden die BaxAktivierung, Cytochrom $c$-Freisetzung und die mitochondriale Morphologie analysiert. In Baxaktivierten Wildtyp-Zellen ist Cytochrom $c$ freigesetzt worden und die Mitochondrien sind fragmentiert. In Bax-aktivierten Drp1-herunterregulierten Zellen hingegen sind weiterhin tubuläre Mitochondrien zu erkennen, die kein Cytochrom $c$ freigesetzt haben. 
Cyclophilin D

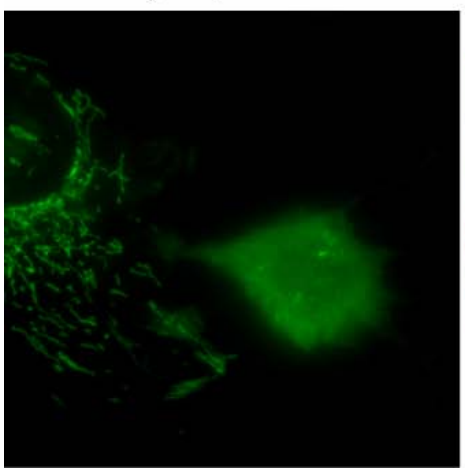

Cytochrom c

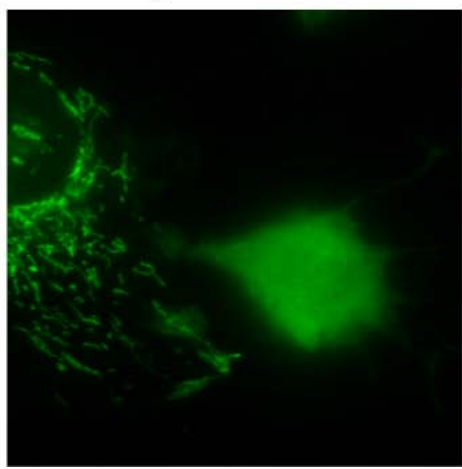

Bax

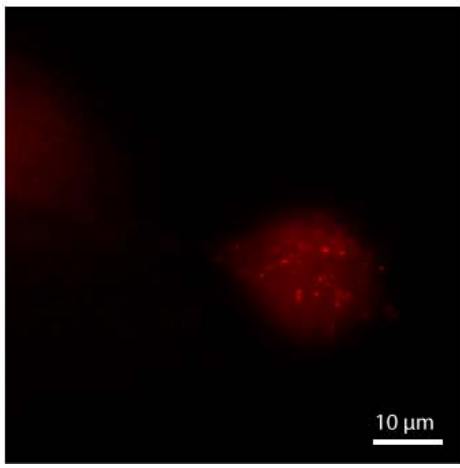

Abbildung 8.22: Freisetzung von Cytochrom $c$ und Cyclophilin D zu einem späten apoptotischen Zeitpunkt in Wildtyp-Zellen

Mit Actinomycin D behandelte U2OS-Zellen wurden mit Antikörpern gegen Cyclophilin D, Cytochrom $c$ und Bax inkubiert. Im Gegensatz zu ausgestreckten Wildtyp-Zellen, konnte bei zusammengeschrumpften Cytochrom $c$-freigesetzten Zellen teilweise auch eine Cyclophilin DFreisetzung beobachtet werden. Möglicherweise findet diese nach der Cytochrom $c$ Freisetzung spät im apoptotischen Signalweg statt.

\section{Tabelle 8.5: Bax-Komplex-Durchmesser basierend auf STED-Daten}

Mit Actinomycin D behandelte U2OS-Zellen wurden mit Antikörpern gegen Bax (erkennt aktiviertes Bax) und Tom20 inkubiert und im Anschluss mit einem nicht kommerziellen STEDMikroskop analysiert. Für jede Aufnahme wurden drei Bax-Komplex-Durchmesser bestimmt. Unter der Voraussetzung, dass ein einzelnes Bax-Molekül eine ungefähre Größe von $4 \mathrm{~nm}$ hat (wurde basierend auf der Struktur (PDB 1F16) von Suzuki et al. (2000) bestimmt) und bei einer zusätzlichen Strukturvergrößerung von ungefähr $36 \mathrm{~nm}$ (durch die indirekte Immunofluoreszenzmarkierung, Abschnitt 5.1.3), ergibt sich eine mittlere Anzahl von 27 BaxMolekülen pro Komplex. Die einzelnen Komplexdurchmesser variieren stark, was durch die hohe Standardabweichung reflektiert wird.

\begin{tabular}{|c|c|c|c|}
\hline Aufnahme & \multicolumn{3}{|c|}{ Durchmesser [nm] } \\
\hline 1 & 172 & 107 & 127 \\
\hline 2 & 114 & 129 & 107 \\
\hline 3 & 135 & 101 & 120 \\
\hline 4 & 157 & 104 & 193 \\
\hline 5 & 333 & 331 & 143 \\
\hline 6 & 347 & 328 & 137 \\
\hline 7 & 353 & 210 & 126 \\
\hline 8 & 372 & 209 & 176 \\
\hline 9 & 259 & 197 & 165 \\
\hline 10 & 219 & 183 & 187 \\
\hline 11 & 232 & 239 & 132 \\
\hline 12 & 179 & 186 & 218 \\
\hline 13 & 120 & 286 & 159 \\
\hline 14 & 164 & 172 & 151 \\
\hline 15 & 174 & 140 & 253 \\
\hline 16 & 248 & 327 & 304 \\
\hline kleinster Wert: & $101 \mathrm{~nm}$ & (entspricht $\sim 16$ Molekülen) \\
\hline größter Wert: & $372 \mathrm{~nm}$ & (entspricht 84 Molekülen) \\
\hline Mittelwert: & $145 \mathrm{~nm}$ & (entspricht $~ 27$ Molekülen) \\
\hline Standardab.: & $119 \mathrm{~nm}$ & (entspricht $~ 21$ Molekülen) \\
\hline
\end{tabular}




\section{Veröffentlichungen und Konferenzbeiträge}

\subsection{Veröffentlichungen}

Mueller J.W., Kessler D., Neumann D., Stratmann T., Papatheodorou P., Hartmann-Fatu C. und Bayer P. (2006): "Characterization of novel elongated Parvulin isoforms that are ubiquitously expressed in human tissues and originate from alternative transcription initiation". BMC Mol Biol $7: 1-9$

Altmann K., Frank M., Neumann D., Jakobs S. und Westermann B (2008): "The class V myosin motor protein, Myo2, plays a major role in mitochondrial motility in Saccharomyces cerevisiae". J Cell Biol 181:119-130

Wurm C.A., Neumann D., Schmidt R., Egner A. und Jakobs S. (2009): "Sample preparation for STED microscopy”. Methods in Molecular Biology, Humana Press, New York, USA, 185-199

Neumann D., Bückers J., Kastrup. L., Hell, S.W. und Jakobs, S. (2010): “Two-color STED microscopy reveals different degrees of colocalization between hexokinase-I and the three human VDAC isoforms". PMC Biophys 3(1):4

Grum D., van den Boom J., Neumann D., Matena A., Link N.M. und Mueller J.W. (2010): “A heterodimer of human 3'-phospho-adenosine-5'-phosphosulphate (PAPS) synthases is a new sulphate activating complex". Biochem Biophys Res Commun 395(3):420-5

Jakobs S., Stoldt S. und Neumann D. (eingereicht Mai 2010): "Light microscopic analysis of mitochondrial heterogeneity in cell populations and within single cells". Adv Biochem Eng Biotechnol, Springer Berlin/Heidelberg

Wurm C.A., Neumann D., Harke B., Lauterbach M., Schilde J., Egner A., Hell S.W. und Jakobs S. (in Vorbereitung): "The metabolic rate defines the number of mitochondrial protein translocation sites in mammalian cells"

Neumann D., Wurm C.A., Keller J., Harke B., Egner A., Hell S.W. und Jakobs S. (in Vorbereitung): "STED microscopy reveals subtle changes in protein distributions during apoptosis"

\subsection{Konferenzbeiträge}

Neumann D., Wurm C.A. und Jakobs S. (2007): Mitochondrial Dynamics during Apoptosis; Horizons in Molecular Biology; Göttingen; Posterpräsentation

Neumann D., Wurm C.A., Harke B., Hell S.W. und Jakobs S. (2008): STED-microscopy opens the door to investigate sub-mitochondrial protein distributions during apoptosis; The Sixth European Workshop on Cell Death (EWCD), Hauenstein, Posterpräsentation

Neumann D., Wurm C.A., Harke B., Bückers J., Kastrup L., Hell S.W. und Jakobs S. (2009): STEDmicroscopy opens the door to investigate sub-mitochondrial protein distributions during apoptosis; EMBO Workshop on Mitochondria, Apoptosis and Cancer (MAC), Prag, tschechische Republik, Posterpräsentation 


\section{Danksagung}

Allen, die zum Gelingen dieser Arbeit beigetragen haben, möchte ich danken.

PD Dr. Stefan Jakobs gilt ein besonderer Dank für die Betreuung meiner Arbeit sowie für die Übernahme des Korreferats. Durch seine ständige Diskussionsbereitschaft, seine vielen Erklärungen und Ratschläge ist meine Arbeit entscheidend geprägt worden.

PD Dr. Thomas Teichmann danke ich für die Bereitschaft zur Übernahme des Referats dieser Arbeit und für sein aufrichtiges Interesse an dessen Fortgang.

Prof. Dr. Dr. Stefan W. Hell danke ich für die Möglichkeit die Arbeit in seiner interdisziplinären Abteilung anfertigen zu dürfen.

Dr. Christian Wurm gilt ebenfalls ein besonderer Dank. Christian war ein permanenter Ansprechpartner für mich und hat durch seine Hilfsbereitschaft, durch Hinweise und Diskussionen den Verlauf meiner Arbeit immer wieder gefördert.

Dipl.-Phys. Johanna Bückers und Dr. Benjamin Harke danke ich für die gute Zusammenarbeit und insbesondere für die Möglichkeit die Verteilung mitochondrialer Proteine an ihren STED-Mikroskopen zu untersuchen.

Dr. Lars Kastrup, Dr. Alexander Egner und Dr. Jan Keller danke ich herzlich für ihre Diskussionsbereitschaft sowie für die Hilfe bei der Datenauswertung, ohne die die Quantifizierungen in dieser Arbeit nicht möglich gewesen wären.

Sylvia Löbermann und Rita Schmitz-Salue gilt ein besonderer Dank für die fortwährende technische Hilfe und Unterstützung während der gesamten Arbeit.

Dr. Frank Eßmann gilt ebenfalls ein besonderer Dank für die Bereitstellung der verschiedenen Zelllinien sowie für die vielen wertvollen Tipps und Hilfestellungen in dem komplexen apoptotischen Forschungsfeld.

Ich danke der gesamten Abteilung NanoBiophotonik und meinen Kollegen der Arbeitsgruppe mitochondriale Struktur und Dynamik, insbesondere Dr. Stefan Stoldt und Dipl.-Biol. Daniel Jans, für die Hilfsbereitschaft, die vielen Diskussionen und die gute Zusammenarbeit.

Ein besonderer Dank gilt meiner Familie, die mich immer unterstützt und für mich da ist. Ohne Sie würde es diese Arbeit nicht geben.

Abschließend danke ich Klarita für ihre Unterstützung und die wundervolle Zeit, die sie mir schenkt. 


\section{Lebenslauf}

\section{Persönliche Daten}

Name:

Anschrift:

Geburtsdatum/-ort:

Staatsangehörigkeit:

Familienstand:

\section{Schulbildung}

1988-1992

1992-1998

1998-2001

Schulabschluss

\section{Zivildienst}

08.2001-05.2002

Studium

10.2002-12.2006

09.2004

11.2005-02.2006

03.2006-12.2006

\section{Abschluss}

02.2007-06.2010

Göttingen, 08.06.2010

\section{Daniel Neumann}

Kellnerweg 24, App. 111-112, 37077 Göttingen

15.08.1981 in Essen

deutsch

ledig

Joachimschule, Essen

Franz-Dinnendahl-Realschule, Essen

Gymnasium an der Wolfskuhle, Essen

Abitur (Note 1,4)

Finanzbuchhaltung, Elisabeth-Krankenhaus, Essen

Studium der Biologie, Ruhr- Universität Bochum

Vordiplom (Note: sehr gut)

Diplomprüfungen in den Fächern: Botanik, molekulare

Genetik, Zellbiologie, Naturstoffchemie

Diplomarbeit

Zentrum für medizinische Biotechnologie, Abteilung strukturelle und medizinische Biochemie (Prof. Dr. Bayer),

Essen, Thema: "Strukturelle und biochemische

Charakterisierung der humanen PAPS-Synthetase 2“

Diplom-Biologe (Note: sehr gut)

Doktorarbeit

Georg-August-Universität Göttingen, angefertigt am MaxPlanck-Institut für biophysikalische Chemie, Abteilung Nanobiophotonik (Prof. Dr. Dr. S. Hell), Arbeitsgruppe Struktur und Dynamik von Mitochondrien (PD Dr. S. Jakobs), Thema: "Untersuchung sub-mitochondrialer Proteinverteilungen in unbehandelten und apoptotischen humanen Zellen mittels STED-Mikroskopie“ 